\title{
Under-serving the Over-represented: Indigenous People's Access to Specialized Courts
}

\author{
Jaclyn Tompalski
}

A thesis submitted to the Faculty of Graduate and Post Doctoral Affairs in partial fulfillment of the requirements for the degree of

\section{Master of Arts}

In

Sociology

\author{
Carleton University \\ Ottawa, Ontario
}

(C) 2021

Tompalski, Jaclyn 


\begin{abstract}
This thesis examines specialized courts (such as drug courts and mental health courts) across what is known as Canada and how they meet the needs of Indigenous persons. This thesis explores such courts' admission and participation policies and connects under an Indigenizing framework developed from four Indigenous scholars. Then, it explores the experiences of Indigenous persons with previous drug-related criminal convictions and the experiences of service providers whose roles support those clients. In general, Indigenous persons are disproportionately excluded from participation in specialized courts. I argue current specialized court policies fail to adequately account for colonial challenges and barriers faced by Indigenous peoples. I suggest recommendations that acknowledge the need for programs to return to Indigenous communities, allow for Indigenous autonomy and self-governance of such programs, Indigenous development in programs, and increased capacity to individualize approaches to the participant's needs.
\end{abstract}




\section{Acknowledgements}

From conceptualization to completion of this thesis, I have received tremendous love, support, assistance, encouragement, and inspiration. I could not have completed this project without the following people.

First, I must acknowledge the ongoing help of the healthcare workers, frontline workers, supportive or care workers, public health professionals, and researchers during the COVID-19 global pandemic throughout the time of this research. You have my gratitude for keeping life as normal as possible, for working tirelessly to help others, and for applying your collective knowledge to get us out of this situation. May those lost through this pandemic rest peacefully.

I would like to thank my excellent supervisor, Dr. Aaron Doyle. Thank you for believing in me as a graduate student when others did not, for valuing me and my works instead of tokenizing me, and for providing consistent and inspiring mentorship. Thank you so much for making such an effort to be a good ally, both academically and in general life, to members of Indigenous communities. Thank you so much for setting and example and embodying the praxis that academics can challenge norms and conventions, use our work for the good of our communities, and have balanced lives. Finally, thank you so much for being so supportive and helpful without your patience and kindness I never could have finished this. I am excited and grateful that we will continue working together.

I would next like to thank Dr. Natasha Stirrett. I am so grateful to have the influence of a strong, Indigenous academic. Thank you for your flexibility on this project and for prioritizing it while finishing your own work. You are already a trail blazer, and I know your future work will positively contribute to decolonization. 
I would like to thank my external committee member, Dr. Julie Tomiak, for contributing to this project. Though we have not yet had much contact, I value your unique and Indigenous perspectives.

I want to thank and honour Michelle Robinson, Red Thunder Woman, who entered our academic spaces with grace and wisdom. This study could have become too bureaucratic, arrogantly formal, or unapplicable to communities without her input. Additionally, I thank her for her commitment and contributions to educating non-Indigenous people about Indigenous issues, events, and accomplishments. Before I met you, I never personally knew someone with the same community origins as me. I feel lucky to have been accepted by you so warmly.

I want to thank and acknowledge my colleagues and friends from my cohort and those within the Sociology department and other graduate programs for their outstanding collaborative nature. I would particularly like to mention Christine Moreau, Stuart Warren, Wesley Partington, Seamus Hodgins, Shelby Deane, Sarah Fiander, Kelsey Sutton, Danika DeCarlo, and Shaylyn Hunter. Thank you for listening to my ideas, inspiring me constantly, and filling my downtime with laughter and creativity.

I would like to thank and acknowledge my other mentors in the field for giving me a chance and getting my career started. Dr. Jana Grekul, for her constant faith in me, detailed and kind feedback, and for creating countless opportunities for me. Dr. Jeffrey Brassard, for soothing my anxieties about graduate studies and for dedicating his free time to teaching me how to write. Dr. Kevin Haggerty for giving me my first research assistantship when I was utterly underqualified. Without this opportunity, I wouldn't have known academia was the career path I wanted to follow (nor would I have found my supervisor). Chris Hay, for creating fabulous opportunities for me to hone my research skills and for helping me out when I had no idea what I was doing. 
Dr. Chris Dixon for helping me discover my values as a scholar and the importance of process when enacting my projects.

I would like to thank the Social Sciences and Humanities Research Council for funding this research and providing me with the MINDS Master's Supplement for Indigenous Students. I would also like to thank Indspire for providing me with two generous bursaries. I would also like to thank my department and donors for awarding me the John Porter Graduate Scholarship (and Aaron again for submitting me for this award without telling me, and for clarifying that he had when I thought I had received a scam email).

I would like to thank Adriene Mishler for providing me with free daily yoga practices online. You significantly contributed to my physical health, mental health, and overall self-esteem.

I would like to thank Warpig for providing me with endless hype, laughter, and love. Never has anyone been so fortunate to have such intelligent, thoughtful, encouraging, hilarious, and genuine friends.

I would like to acknowledge, thank, and celebrate all Indigenous mentors who have guided me along the Red Road, particularly those Elders who took the time to educate me on even the basics, and Jeremy for getting me started in my journey.

I would like to thank my family. Thank you, Auntie Martha, for giving me the funds to buy my first computer for school and for reading everything I send you so thoroughly. Thank you, Auntie Verda, for filling my home with beautiful things that brought me such joy and for teaching me through your actions the power an individual has. May you rest in peace with our ancestors. Thank you to Hindley, Carl, Stella, Bannock, and Gunther for all the love. While it might seem silly that I am acknowledging my cats in the most significant project I have ever 
undertaken (so far), I know my life would have substantially less joy without you in it. Thank you, Jake, for understanding my mind in a way that only you can and for making me laugh harder than anyone ever has. Thank you, Kalea, for genuinely being so excited for every little bit of progress and every accomplishment - you lifted me up so much. Thank you, Mom, for so completely and enthusiastically supporting my work, educating yourself in your spare time so you could teach me things about this subject, and for continuously validating me. May the way you evolve, apply your knowledges, and unconditional love be an example to everyone. Thank you, Dad, for constantly being available to discuss sociological topics, to listen to me rant, and to talk whenever I call. May your reliability, level-headedness, hard work, and goofy sense of humour be an example to everyone. I love you all a very great deal.

Finally, thank you so much, Joe. You are funny, kind, patient, accepting, open-minded, gracious, fun, intelligent, creative, and supportive. Thank you for sharing all these beautiful qualities with me every day, for allowing herds of cats and foster cats to live in our home, for inspiring me to be better, and for believing in me. The amount of support you provided cannot be quantified, much like the amount of joy you have brought to my life. I love you so much! 


\section{Table of Contents}

Abstract

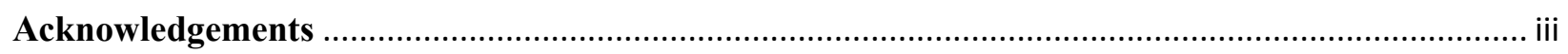

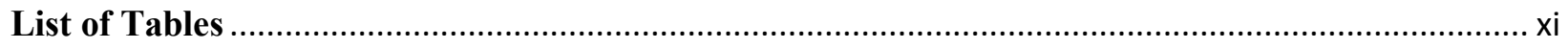

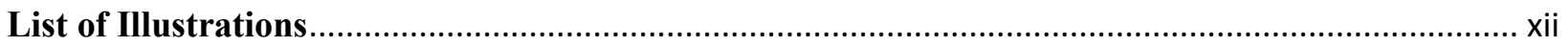

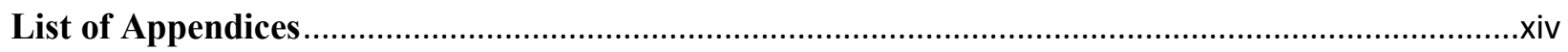

Dedicated in loving memory to Verda Dunphy .........................................................................

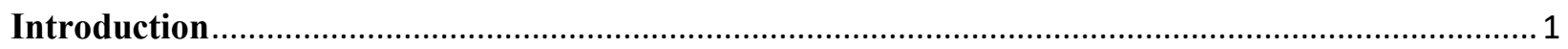

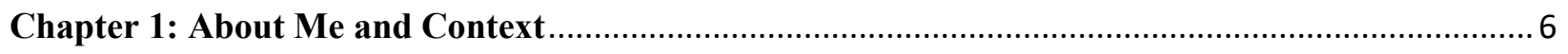

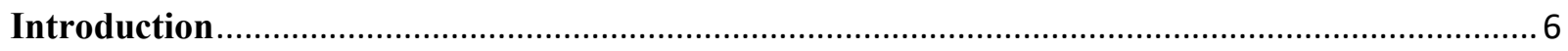

Acknowledgement of Indigenous Differences and Terminology ............................................. 7

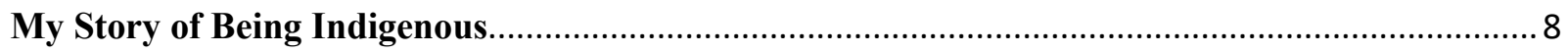

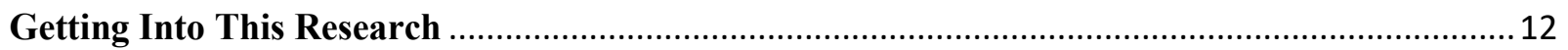

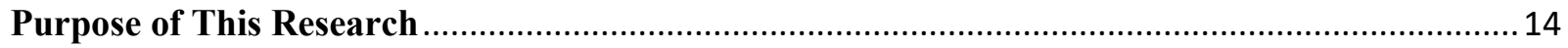

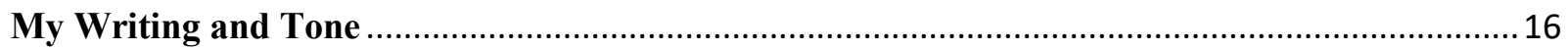

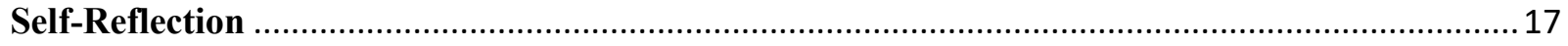

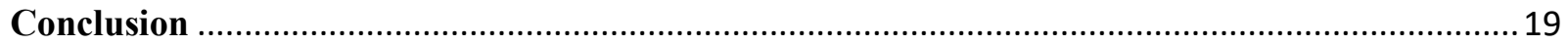

Chapter 2: Review of Literature on Colonialism and Indigenous Peoples in the Criminal Justice

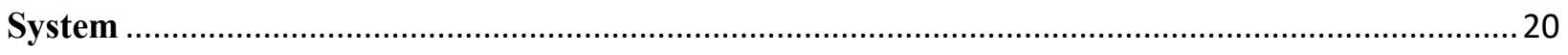

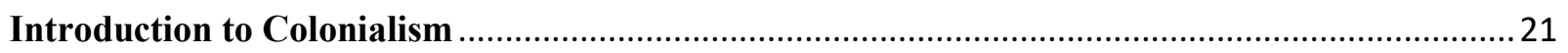


A Brief Historical Account of Colonialism in "Canada"

A Picture of Indigenous Persons and the Criminal Justice System.

Historical vs. Modern Colonialism

Conclusion 43

Chapter 3: Review of Literature on Specialized Courts and Programs 45

Introduction 46

Systemic Racism .47

Gladue Reports 50

Drug Courts 52

Mental Health Courts 55

Other Specialized Courts 55

Indigenous Admissions into Specialized Courts. 56

Policy Critiques and Limitations of Specialized Courts. 57

Organization-Specific Specialized Programs 60

Indigenous Courts and Gladue Courts 61

Indigenous-Centred Specialized Programs 62

Conclusion 64

Chapter 4: Theoretical Framework .66

Introduction. 67

Pillar 1 - Vanessa Watts 69 


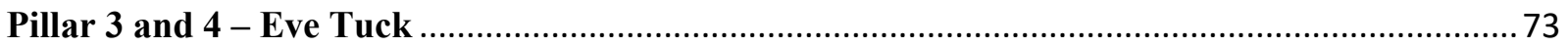

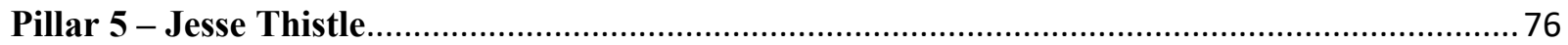

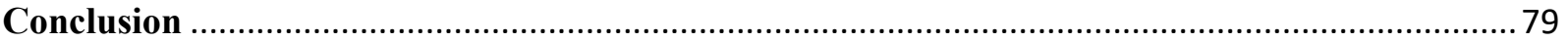

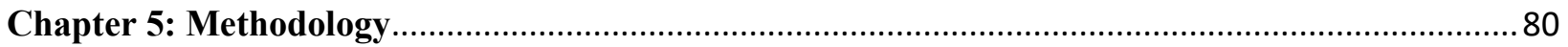

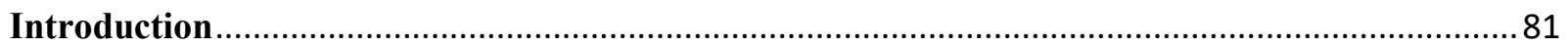

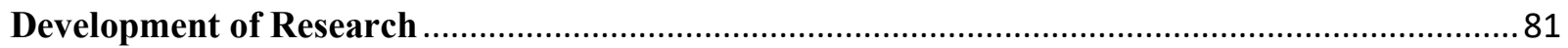

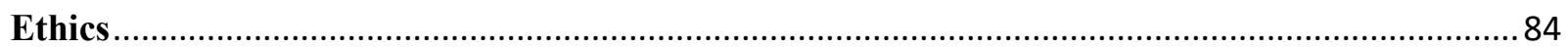

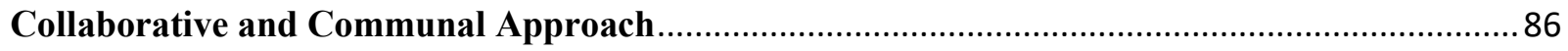

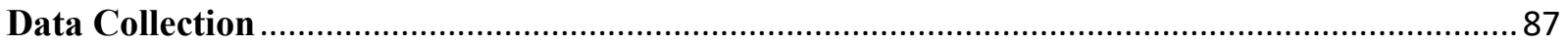

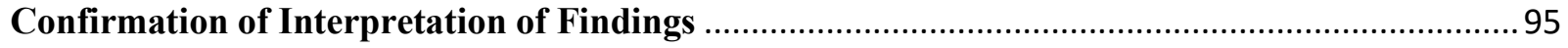

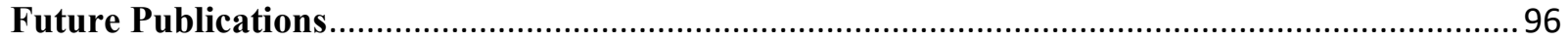

Acknowledgement of Thanks For Indigenous-Centered Research ..........................................96

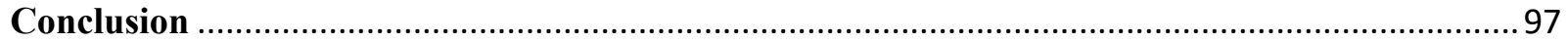

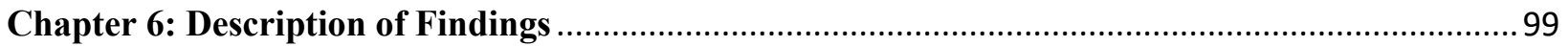

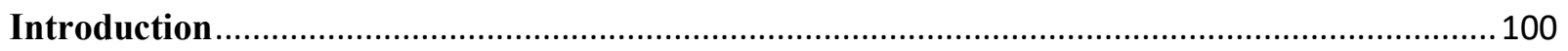

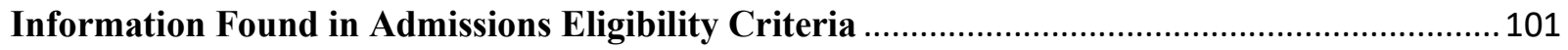

Information Found in Participant Handbooks (Program Rules for Enrolled Participants) ....... 105

Interview Data from Formerly Incarcerated Indigenous Persons .......................................... 106

Interview Data from Service Providers Working with Indigenous Persons............................... 111 
Introduction

A Reminder of Theoretical Framework

Analysis of Admissions Eligibility Criteria

Interview Data from Service Providers Working with Indigenous Persons. 128

Finding Embodying Theoretical Framework

Limitations 135

Conclusion 136

Chapter 8: Policy Recommendations and Areas for Future Research 138

Program and Policy Recommendations 139

Recommendations for Further Research.

Anti-Limitations 151

Conclusion and Goodbye 155

Appendix 1 - Information for Participants 187

Appendix 2 - Admission Eligibility Criteria for Specialized Courts 207

Appendix 3 - Program Rules for Participants Once Enrolled in Specialized Court Program........ 245 


\section{List of Tables}

Table 1 - Indigenous Population Percentages Across Provinces/Territories, Incarceration, and Community Corrections 


\section{List of Illustrations}

Illustration 1 - Chapter Linking Artwork: Turtle (Truth)

Digital illustration by Jaclyn Tompalski

Illustration 2 - Chapter Linking Artwork: Sasquatch (Honesty)

Digital illustration by Jaclyn Tompalski

Illustration 3 - Chapter Linking Artwork: Beaver (Wisdom)

Digital illustration by Jaclyn Tompalski

Illustration 4 - Chapter Linking Artwork: Buffalo (Respect)

Digital illustration by Jaclyn Tompalski

Illustration 5 - Chapter Linking Artwork: Bear (Courage)

Digital illustration by Jaclyn Tompalski

Illustration 6 - Chapter Linking Artwork: Wolf (Humility)

Digital illustration by Jaclyn Tompalski 
Illustration 7 - Chapter Linking Artwork: Eagle (Love)

Digital illustration by Jaclyn Tompalski 


\section{List of Appendices}

Appendix 1 - Information for Participants

Appendix 2 - Admission Eligibility Criteria for Specialized Courts

Appendix 3 - Program Rules for Participants Once Enrolled in Specialized Court Program 
Dedicated in loving memory to Verda Dunphy (Dec 16, 1958 - Apr 13, 2021)

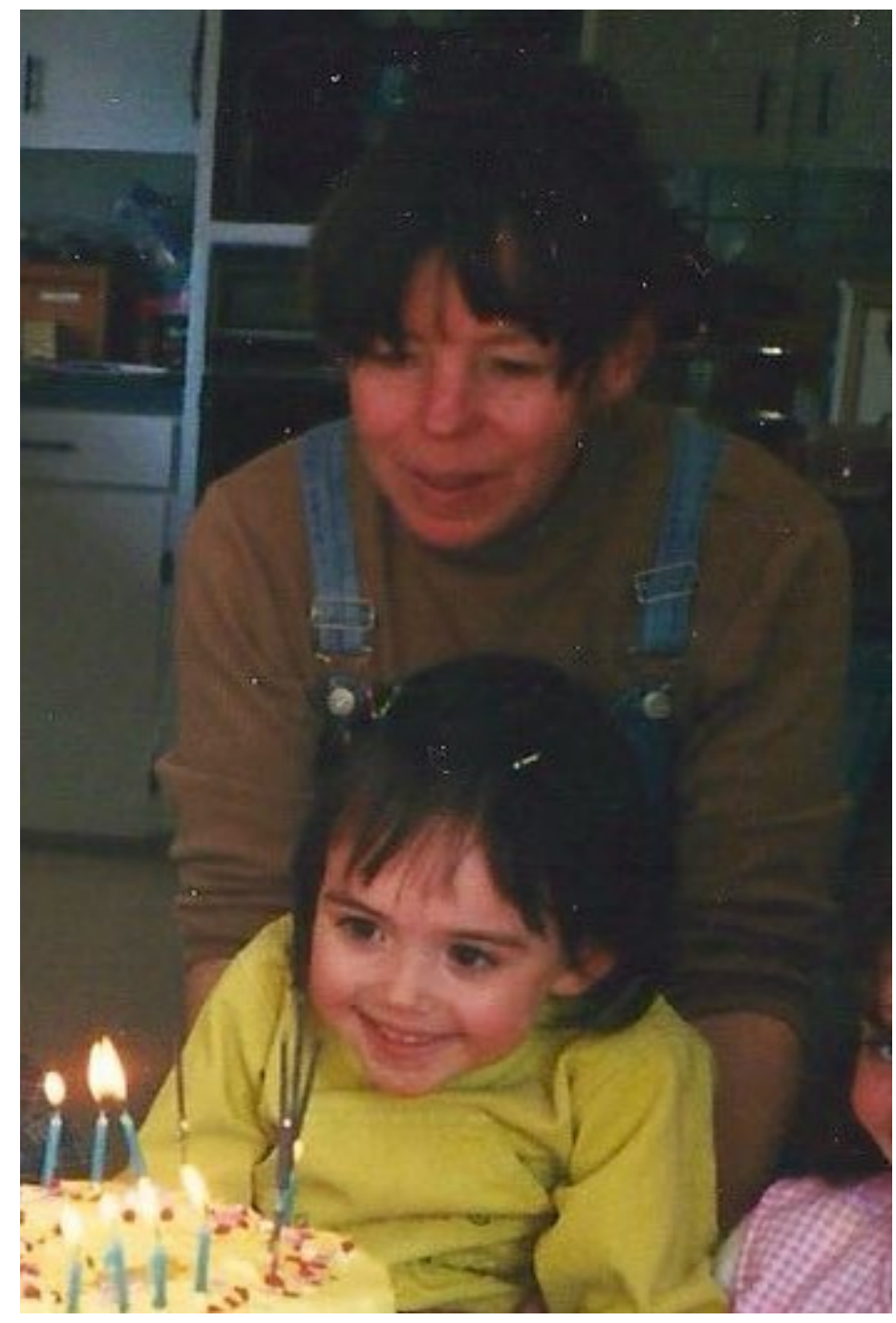

"Many heartbeats, one Dene drum." 


\section{Introduction}

My thesis contributes to the growing body of work surrounding the over-representation of Indigenous persons in Canadian jails and prisons. I examine specialized courts (e.g. drug treatment courts, mental health courts, etc.) as measures potentially diverting accused Indigenous people from incarceration, as well as the barriers and challenges for such Indigenous persons in obtaining access to specialized courts. Specifically, I examine admission criteria and policy, policy and rules for participants once enrolled, the relationship between specialized courts and other justice system areas, and the unique needs and experiences of Indigenous persons in the criminal justice system. By examining policy, interviewing Indigenous individuals who were previously incarcerated, interviewing actors within or adjacent to the criminal justice system (both Indigenous and non-Indigenous) who might help Indigenous people access specialized courts. I have concluded that Indigenous persons are systemically excluded from specialized courts by analyzing their information through an Indigenous theoretical lens.

Indigenous over-representation in jails and prisons is not something new - government agencies have been aware of the issue for decades (Jamil, 2020). Despite an extended awareness of the problem, Indigenous over-representation in corrections has become worse, not better. As noted by the Correctional Investigator of Canada, Ivan Zinger, "In the ten-year period between March 2009 and March 2018, the Indigenous inmate population increased by $42.8 \%$ compared to a less than $1 \%$ overall growth [in the total adult custodial population] during the same period (Zinger, 2019)." While the growth of Indigenous incarceration is very concerning, the problem is made even more severe given that overall incarceration rates in Canada have been falling since 2017. Indigenous persons account for around $30 \%$ of the incarcerated population (across both provincial/territorial corrections and federal corrections), but less than $5 \%$ of the Canadian 
population overall, and so are over-represented by more than six times. The Truth and Reconciliation Commission of Canada drew substantial attention to the over-representation of Indigenous persons in corrections (Truth and Reconciliation Commission of Canada, 2015a) and many other systemic challenges and inequalities faced by Indigenous peoples, yet the issue persists. In fact, in the 94 Calls to Action produced by the Truth and Reconciliation Commission of Canada (2015b), multiple calls spoke to the (in)justice issues and oppression facing Indigenous peoples. Call 30 states clearly, "We call upon federal, provincial, and territorial governments to commit to eliminating the overrepresentation of Aboriginal people in custody over the next decade, and to issue detailed annual reports that monitor and evaluate progress in doing so.” Despite commitments from the provincial, territorial, and federal governments to implement all 94 calls to action (Assembly of First Nations, 2018), Indigenous incarceration rates continue to rise.

This thesis cannot suggest one clear solution to reducing the over-representation of Indigenous persons in Canadian jails and prisons - it is too large and too systemic of a problem to address through specialized courts that combined serve only a few hundred clients every year. However, I believe the thesis contributes substantially to the relevant works concerning Call 31, which states, "We call upon the federal, provincial, and territorial governments to provide sufficient and stable funding to implement and evaluate community sanctions that will provide realistic alternatives to imprisonment for Aboriginal offenders and respond to the underlying causes of offending (Truth and Reconciliation Commission of Canada, 2015b).” Given that specialized court programs offer an alternative to incarceration that also addresses the root causes of crime, it stands to reason that this thesis contributes to the knowledge that could help achieve the realization of Call 31. It must also be acknowledged that I, an independent Indigenous graduate 
student, should not have been required to produce this work, and I am filling a gap in research and action that should not exist. Instead, as per their official commitment to the Calls to Action (Assembly of First Nations, 2018), governments should have examined this issue and responded to it long before 2021.

To produce this work with the intention of applying decolonizing principles and Indigenous methodologies, I developed a theoretical framework that focuses on 1) place and being 2) the processes of engagement surrounding Indigenous-focused works, 3) engagement of the studied Indigenous persons in the process, 4) desire-based research surrounding Indigenous peoples, and 5) Indigenous identity as a form of healing from colonial trauma. The policies and practices of both specialized courts and the experiences of those interviewed were observed through an approach based on these five pillars. Doing so demonstrated that many drug treatment courts and mental health courts do not have policies or practices that expressly acknowledge the colonially produced disadvantages of Indigenous applicants, nor do they consider the unique circumstances of Indigenous clients once they are enrolled in the programs. Further, such programs lack the resources and Indigenous involvement to produce culturally relevant and meaningful programming for Indigenous clients.

Based on my data, the criminal justice system as a whole does not provide adequate culturally meaningful programming or resources. Differing areas of the criminal justice system (e.g. courts, prisons, community correction, etc.) have challenges of limited communication between them and lacked knowledge of how different areas of the system functioned. However, even if different parts of the system were better aware of the different types of programming and processes, it would have been unlikely to have much impact given that many supportive programs were under-resourced and highly inaccessible to Indigenous persons (reasons 
including, for example, lack of legal resources, location, and lack suitability of available programming).

Through this thesis, I initially aimed to contribute knowledges that could produce reform in specialized courts. However, it became clear through interviews with Indigenous participants that reform of specialized courts should not be the objective. Instead, they emphasized the importance of Indigenous-led, -governed, -developed, -implemented, and -evaluated alternatives to the current Canadian "correctional" model. Programs that centre Indigenous knowledges and cultures, as well as colonial history and its impacts, stand the greatest chance of actually providing the support that criminalized Indigenous persons need. As such, this thesis evolved from prioritizing reform to prioritizing abolition.

Based on the key findings from my analysis, I have produced several recommendations. I should note that, while I may be the first (or one of the first) to make these recommendations specifically in these contexts, I am by no means the first to provide similar recommendations broadly. Indigenous peoples and organizations, activist groups, and the Truth and Reconciliation Commission of Canada are among some of those who have provided similar recommendations on how to support Indigenous persons on justice matters better. Generally, my recommendation is that Indigenous communities be permitted to govern their own justice matters and be supported with the resources required to do so. However, where that is not observed, the following specific recommendations are provided. The policy and procedures for specialized courts be re-developed in collaboration with Indigenous peoples. Further, that Indigenousspecific policy is produced by Indigenous peoples. Additionally, existing policy should be examined for instances where it may produce systemic racism. With regards to supportive programming, such programming should have its resources increased so that service providers 
have the time and tools necessary to actually serve the needs of their clients. In a similar vein, programs should not be required to provide a one-size-fits-all approach with their program delivery and should instead have the operational framework to individualize their approach to the needs of their clients. Finally, Indigenous clients should have access to relevant Indigenous service providers when enrolled in such programming and be able to access the necessary programming within their community. The recommendations fit with the theoretical framework by 1) place and being - allowing Indigenous clients to access supports in areas of cultural relevance and which are accessible; 2) the processes of engagement surrounding Indigenousfocused works - the experiences of Indigenous clients are valued as much as the potential outcome (which also contributed to the decolonization of the justice system); 3) engagement of Indigenous persons in the process - by including Indigenous persons in the development, implementation, and evaluation of such programs, 4) desire-based research surrounding Indigenous peoples - by focusing on the empowerment of Indigenous clients and the resilience and wisdom of their communities, and 5) Indigenous identity as a form of healing from colonial trauma - by ensuring that cultural access is at the forefront of the process to help Indigenous clients being healing from colonial harms. If the recommendations were to be followed, it is likely that Indigenous clients would have greater access to alternatives to incarceration, thereby contributing to lowering the over-representation of Indigenous peoples in jails and prisons. As an added benefit, Indigenous clients would have access to cultural supports, healing, and community - all of which could contribute to the long-term success of the criminalized Indigenous persons in question. Finally, steps in these directions would allow the governments to uphold their commitments to the Calls to Action and contribute to reconciliation efforts. 


\section{Chapter 1: About Me and Context}

"We go to the schools and they leach the dreams from where our ancestors hid them, in the honeycombs of slushy marrow buried in our bones. And us? Well, we join our ancestors, hoping we left enough dreams behind for the next generation to stumble across." - Cherie Dimaline, The Marrow Thieves

\section{Introduction}

This chapter is supplementary to the core of this work. Specifically, I wanted to highlight my own personal history. I believe this is important because it lends additional context to the work I have produced. Further, there is often little opportunity for the reader to get to know the scholar behind an academic work. I have regularly wanted to understand the contexts of writers following their texts. Through my journey with ADHD, I have found it is easier for me to maintain focus and interest on a text when I found a way to feel invested, often by learning more about the author. Finally, I find there are so few opportunities for academics to show themselves as whole people beyond their work. So much of what we do leaves us isolated, and in academia, we are placed in a situation where we can only learn about our colleagues through whatever can be gleaned from publications, conferences, or social media. I hope that you, as a reader, enjoy reading this thesis. If anyone (besides my committee) ever chooses to read this, please feel free to reach out. I would love to hear from you.

I have included this preface for the purpose of explaining my intentions with this work and the intentions behind some of the choices within this text. Specifically, I have included information on my writing style, on the development of this research, and on the language I have used. These 
are all important factors in contributing to decolonizing the research process ${ }^{1}$, and I want to be deliberate and draw attention to these intentions I bring to this work.

\section{Acknowledgement of Indigenous Differences and Terminology}

Historically, Indigenous groups are homogenized in academic writing. The Canadian government defines Indigenous persons as being a part of three distinct groups: First Nation, Metis, and Inuit (Statistics Canada, 2019). Documents that most Canadians have the greatest access to, such as government texts, legal documents, and press releases, tend to focus on one of these three groups or on Indigenous groups as a whole. While there is absolute validity in examining the Indigenous population of Canada as a whole, approaches that homogenize Indigenous communities fail to recognize the distinct cultures, traditions, and experiences of different Indigenous groups. Further, it should be noted that currently accepted best practices, most frequently observed by Indigenous authors, Indigenous organizations, and those within the field of Indigenous Studies, include the intentional naming of belonging to specific communities, nations, or kinship groups.

The Government of Canada recognizes more than 630 First Nation communities. Each of these nations is distinct. Further, academics and the governments in Canada have failed to acknowledge some of the Indigenous communities in Canada (The Dene Nation, 2018). While Indigenous communities and nations are all interconnected by virtue of being the Indigenous Peoples of Turtle Island, they still maintain their own communities. These communities are distinct in their language, cultural practices, traditions, and ways of life. It is not my intention to overly generalize or homogenize Indigenous peoples and communities of Canada, but, for lack

\footnotetext{
${ }^{1}$ I acknowledge that the research process I am engaging in is inherently colonial, particularly given that I am doing so at a state-funded institution. Though decolonization will never be truly possible through this format, I am keen to contribute to any possible decolonization I can.
} 
of better terminology, I am forced to refer to these groups using language that does not distinguish them sufficiently. I also utilize the term 'Canada' for want of a better term, in full acknowledgement of the unceded and surrendered territories within its borders (Wilson, 2018), as well as treaty lands whose contracts were implemented in bad faith or through inappropriate practices (Centennial College, 2020). I am studying courts that are part of the settler-colonial state known as Canada.

I assume responsibility for any mistakes observed in this chapter, including, but not limited to, terminology errors and inaccurate accounts of Indigenous persons or communities. Furthermore, I am merely one Indigenous voice, and my words do not speak for all Indigenous Peoples or communities. It is also possible (or even likely) that after this document is published, the terminology that I use and consider to be acceptable might evolved to the point where it is no longer the best choice of language. When such a time occurs, please do not utilize this chapter as a justification for out-of-date or unwanted terminology, and instead, call Indigenous Peoples or communities by what they themselves identify as appropriate.

\section{My Story of Being Indigenous}

I do not exactly remember when I first understood myself as being Indigenous - nor when I began identifying myself as Indigenous, but I have three significant memories related to my Indigenous identity and the lack of knowledge I had growing up about who I am, my identity, and culture. The first was around when I was in the sixth or seventh grade. I remember being in Mr. Godin's social studies class, and we were learning about the fur trade. He explained to us what Indigenous peoples are and then asked if anyone in the class was Indigenous (or back then, the terminology was likely "autochthones" as I attended a French immersion school). I knew 
enough to put my hand up, but when further questioned, I could not elaborate because I had shared all that I knew.

My second and third memories are embarrassing to me now, but I am opting to share them anyway as I know I am not alone in these experiences, and I wish I could have known at the time that others had gone through this. My second memory is from high school. I had walked into the building with a few friends, and we smelled what we thought was marijuana. Someone in my group of friends corrected us that it was white wage being smudged in ceremony for the Aboriginal Students Group. I learned the group had free food in their lounge, which is ultimately why I bothered to attend.

I share these embarrassing stories for two reasons. First, as I have previously mentioned, I want these accounts to exist somewhere so that if someone who identifies with my experiences ever reads, then they will know it is a common - or at very least shared - experience. Second, I think these specific stories highlight the disconnect I experienced to my Indigenous identity and culture until early adulthood.

My journey to reconnection to my Indigenous identity is not one I wish on others. While I am grateful and humbled beyond words for being given many opportunities to learn more about myself, family, ancestors, and community, I wish the process had taken place in a more uplifting setting. I say this because my Indigeneity is fundamentally woven within what is officially called corrections. I gained the greatest access and opportunity to reconnect with my heritage through corrections. In Edmonton, as much as half of the incarcerated population in an institution were Indigenous - meaning that there were often cultural opportunities through my work placement. I very much doubt that I would have begun the journey towards reconnection if I had not been 
working in corrections because events put on by corrections were my first circles, my first sweats, and my first access to speaking with Elders.

I am mixed-race, white and Sahtu Dene. I was raised white because my mother was raised as if she was white. The purpose of this was to protect her and her siblings from the violence faced by my Indigenous grandmother and her siblings. I do not want to tell stories here that are not mine to tell, but I will briefly mention that my grandmother, Mary, some of her siblings, and both of her parents (deceased before I was born) survived residential schools. We are not exactly sure which communities we belong to, but we know we are Sahtu Dene from the Fort Good Hope First Nation - this is where my grandma's mom was born and where she attended residential schools. I will never know exactly what happened to her - all I have ever known from my mother is that whatever happened to her grandma (my great-grandma). However, my grandma, Mary, attended the Fort Resolution Indian Residential School. Again, there is little that my mom and I know of her experience, though we know from her accounts that there was tremendous abuse experienced by some of the other children there. The one thing I know for sure is that is where she learned the French language, and that being a quick study lead her to being considered 'good' by the nuns there. We also have additional lineage from my great-grandfather - who was from a different Indigenous community still on Treaty 11 lands, which I learned from my grandmother and mother. Based on the location my grandmother was born, he may have been from the Deh Gáh Got'ie Dene First Nation. Alternatively, it is possible he was from Liidlii Kue First Nation. However, I will not claim to be a member or descendent from either of these First Nations as I do not yet know if I actually have links to these specific first nation communities. I include this speculation so that you, the reader, can understand just how fragmented our history is. I have spent countless hours trying to figure it out, and I regularly feel shame for not knowing 
yet. I have reached out to countless individuals from these First Nation communities for confirmation but have not yet received any definitive answers.

My Dene identity has been pieced together by my mother and me over the last two years. Every couple of weeks, we mustered up the energy to dig through everything (our lineage documents, family photos, histories known by relatives, and my mother's recollections) and try to figure it out. Fortunately, we now know much more than we did a few years ago.

However, many other things have been much more accessible to me. Elder teachings, ceremonies, and traditional art forms have been much more accessible to me. I regularly have the opportunity to engage with the broader urban Indigenous community through these means, and I always leave feeling so full and happy. My art, my participation in ceremony, and my commitment to learning about my history is an act of resistance. My grandmother and her family could not have done what I do now, and I feel so fortunate that I get to figure this out alongside my mother and her mother. Once I had established reconnecting and healing, it was like a whole new world opened to me. To this day, I am so blown away by the patience, love, and acceptance I have experienced from urban? Indigenous peoples from different communities of origin in helping me to reclaim what I have lost. Further, I am honoured by the friendship and welcoming attitudes that are constantly being offered to me.

I have learned about the true value of reciprocity in reconnecting with my heritage. Though my cultural knowledges are developing (something I believe will be a lifelong journey), I still know that I have something to offer. I can act as a bridge to connecting other Indigenous Peoples like me - who did not know their heritage - with the right people and resources to begin that healing journey. I can also actually step up and use the knowledges I do have to fight against racism, oppression, and colonialism. I can use my voice and privileges to amplify the voices of other 
Indigenous urban community members. Finally, I think I can contribute by highlighting and showcasing some of the amazing things about Indigenous Peoples, groups, and communities so that they might reach more non-Indigenous peoples.

\section{Getting Into This Research}

After less than a year working in corrections, I knew I could not work there alongside my incarcerated kin. I had the time to form connections with those incarcerated, learn our shared histories, and get to know them as people. First, I vowed to contribute to the change by being "one of the good ones." I figured I would be a member of staff who treated those prisoners or on conditional release well. I would listen to their stories, share my feelings and lives with them when they did the same with me, and I would never set out to punish them or police trivial matters. I think I did a good job of that for a while - I treated all persons I was working with (Indigenous or not) with the same respect I hoped to receive. Interestingly, in the nearly eight months I worked at a halfway house, I was never once working while an individual was suspended and had their conditional release revoked. Upon reflection, I believe this was mostly owing to my desire to discuss issues that would result in discipline as they arose and work towards a solution, validate the feelings of those I was working with, and that I did not start every shift with the intention of catching them doing something they were not permitted to do. I still did my job, but I did it without trying to make them into the bad guys.

There came a time when I could no longer even work in corrections. I was not permitted to treat those I was working with like humans while doing my job. I was unable to share myself with them as in the ways they were sharing themselves with me - I could not tell those in the halfway house about my life because it was deemed inappropriate by my superiors. I always come back to this one story. At the halfway house I worked at, the residents were not permitted alcohol or 
drugs. In addition to that rule, they were not permitted anything that bore an image or reference to alcohol or drugs. One day, at 20-years-old, I was told by a senior colleague to confiscate a toy race car from an Indigenous resident in his sixties. It "needed" to be confiscated because it was an authentic model of a real-life race car. For those unfamiliar, race cars often are covered with brand sponsorships - including alcohol brands. So, I was told to confiscate a toy race car from one of our best-behaved residents because it had a few centimetres wide sticker for a beer brand. That is what our tax dollars were going into. Confiscating that toy car did not make the facility safer, strengthen my relationship of trust with the resident, or really benefit anyone in any discernible way. But those were the rules. If I had not done as directed by my supervisor, I would have been disciplined for not doing my job. I regret the choice to participate in confiscating that car, as I contributed to the dehumanization of someone who really had not done anything wrong morally by having a model race car.

It was after I confiscated the toy, I started exploring the idea of pursuing research instead of working within the system. Firstly, I feared that many of those doing research did not have the practical knowledge and experience of what it is like in corrections. Further, I became highly disillusioned with the justice system because it appeared to me that all those working within the system were aware of the issues, but nothing was changing. Sure, there were people who apparently only got into that line of work to create an outlet for their hatred and punitive instincts, but the majority of those I worked with seemed to be highly compassionate individuals. It just seemed like we never had the resources we needed to make improvements, and the policy we worked under left no room for innovation (or even just doing things differently than how others were doing it). 
My decision to pursue this specific research project came after working at the Edmonton Drug Treatment Court. At the time I worked there, the court served about twenty clients at a time.

Given the average time to graduation was over a year, it meant that there were really only twenty spots a year at that specialized court. While I was working there, Indigenous clients filled two of those spots, though, by the time I left, there were no Indigenous participants at all. In sharp contrast, Indigenous peoples accounted for over $40 \%$ of the incarcerated population of Alberta (Jamil, 2019). It seemed like such an extreme failure on behalf of the justice system that I knew I needed to do something about it.

\section{Purpose of This Research}

The purpose of this research was ultimate to identify if the policy of specialized courts accounted for and supported Indigenous populations. Specifically, does policy account for the colonial trauma and barriers experienced by criminalized Indigenous persons, does it meet their unique needs, is it culturally relevant, and does it at very least ensure equal access and outcomes for Indigenous persons as with non-Indigenous persons. Originally, my intention was only to include drug treatment courts in the study. However, additional research and participant interviews indicated a broader need to explore specialized courts across what is known today as Canada.

Specifically, this project is intended to shed greater light on the admission policies and processes of specialized courts programs and to identify ways that the unique needs of Indigenous applicants are responded to (if at all). While the review of policies was highly illuminating on the failures to consider Indigenous needs, thereby excluding Indigenous clients from admission, it was also necessary to consult with Indigenous persons and their service providers to explore the impacts of those barriers. Additionally, as it was never my intention to produce a document that only ever harped on about the negatives, I wanted also to include information on processes and 
procedures that are meeting the needs of Indigenous clients in or adjacent to the criminal justice system.

In combination, the policy analysis and interviews I will discuss in the remainder of the thesis highlight the tremendous barriers to success Indigenous Peoples face within the criminal justice system, with decreased access to diversion programs because of their increased criminalization, by having the 'wrong kinds' of addictions, and by the racist perception of being higher risk. Despite relevant Calls to Action (Truth and Reconciliation Commission of Canada, 2015b), Indigenous Peoples are constantly found without access to specialized court programs as an alternative to incarceration.

My research will highlight the importance of Indigenous autonomy in the development of justice programs. In the case of specialized courts, Indigenous clients would have substantially improved opportunity to be admitted to such programs if the policy better accounted for colonial factors (e.g. systemic racism, higher risk for criminalization, higher risk for addictions, higher risk for mental health challenges, reduced access to supportive services). However, the absolute ideal would see the defunding of institutional corrections and the redirection of those funds to Indigenous developed and run community criminal justice alternatives.

My analysis is important to Indigenous communities across what is known as Canada as it provides an additional explanation for our over-representation in jails and prisons. Additionally, it is important because it identifies clear examples where institutional failings are negatively impacting Indigenous persons. Identifying areas of need is essential for the powers that be to correct them. By exploring the policy of specialized courts, I was able to identify areas that did not account for the different lived experiences of Indigenous persons, for systemic racism and racial bias in the criminal justice system, and which ignored their already substantial over- 
representation in the criminal justice system. My research growing body of academic and community work on systemic racism, particularly institutional racism, in the Canadian criminal justice system. If governments across Canada are committed to the Calls to Action identified by the Truth and Reconciliation Commission of Canada (Assembly of First Nations, 2018), my research is also highly relevant to those governments as it could serve as a tool to identify systemic failings contributing to the ongoing colonization and oppression of Indigenous Peoples.

In the short term, this work would be best mobilized in policy development for specialized courts to ensure they are more inclusive and accommodating of Indigenous persons. It also provides some potential explanatory factors to the problem of over-representation of Indigenous persons in Canadian jails and prisons, as previously mentioned. Finally, the recommendations found in this thesis could be of use to those involved in program delivery where criminalized Indigenous persons are included in the client base. In the long term, it serves as evidence for the need for greater study on government policy and its impacts on Indigenous peoples - with particular emphasis on the need for Indigenous methodology and analysis conducted by Indigenous researchers.

\section{My Writing and Tone}

I wanted to produce research that I felt could contribute to the academic literature that attends to the topic of reducing the over-representation of Indigenous Peoples in the criminal justice system. My ADHD is essential to the ways I read and write - I was only formally diagnosed and began treatment about four months ago ${ }^{2}$. Before knowing this was the source of many of my educational difficulties, I really struggled with reading for school. In fact - I never actually read

\footnotetext{
${ }^{2}$ At the time this was written (June 2021).
} 
more than a few lines of any of the assigned readings in my undergraduate degree. Upon beginning this degree, I learned that I could read an entire article if it were written differently than was the standard practice. Specifically, I had the easiest time reading articles that felt like it was a conversation between the scholar and myself. So often, the need to sound intelligent or the presumption the reader is familiar with all discipline-specific jargon made texts completely unreadable for me. When discussing it with non-academic peers, particularly those working in or adjacent to the justice system, I realized many others felt that way as well, even those without ADHD.

Following my discoveries, I opted to write this thesis with a more conversational, accessible tone. I want you to know who I am. I want you to hear my voice in how this is written. Most importantly, I want you, reader, to be able to read this and have it keep your attention. I am confident in my own intelligence, and I am confident in yours, reader. Because of that, I do not feel the need to create an elitist space with my writing or bog it down with flowery and dense language. So, when you read this, please understand it is written like this deliberately.

Additionally, there are instances where I could not find a "credible" source to explain knowledges I have from Elder teachings, ceremonies or just general cultural knowledge obtained through daily life. Many Indigenous knowledges are passed orally (Porter, 2008), and even those written down are sometimes not intended to be published without context or guidance. As such, I have opted to include these knowledges despite their lack of citable material so as to remain authentic to the ways I know. Where these instances occur, I will identify them accordingly.

\section{Self-Reflection}

I must acknowledge some of my personal insecurities as an often white presenting, neurodivergent, Indigenous woman, as these are sure to bias my writing. First and foremost, I am 
constantly worried about being "Indigenous enough.” As previously mentioned, I grew up without contact or connection to my community. I am often concerned about if I have the right to be doing this work. Wouldn't it be so much better if someone who was immersed in their Indigenous culture from an early age be the one to do this? These thoughts are often racing through my mind. However, I also know that it is the fault of colonialism that I was disconnected from my community. Further, I know that it was my "fault" that I became reconnected with my culture, as well as broader Indigenous urban communities, in adulthood. I also must acknowledge that my experience is a common one. In fact, many young Indigenous Peoples, particularly those of us who are mixed race, had to grow up with this disconnect.

My sessions with Elders and experiences with other Indigenous peoples have shown me that there is no way to be "Indigenous enough" beyond being yourself and demonstrating your good intentions with your actions. I know I am Indigenous enough. I also know that if there is anyone reading this who is unsure of their right to their own Indigeneity, you are also enough. Practicing our cultures and embracing our identities is an act of resistance.

With that said, I believe it would be disrespectful of me not to acknowledge the ways that I have benefited from the perception that I am white. Though many people can tell I am Indigenous by looking at me (or at least that I am mixed race), I am easily overlooked and presumed to be completely white. Further, I have the European last name of my father. I have endured nowhere near the degree of bias, discrimination, and racism that other Indigenous persons have endured simply because I am "not that Native looking." Not only that, but the same was true for my mother in many ways. As a result, I have not only lived a relatively privileged life, but I have experienced intergeneration benefits because of the perceived whiteness of my family. I am 
confident that without my privilege much of what I have "achieved" would not have been possible.

In acknowledgement of my privilege, I must commit myself to Indigenous communities. I am not only Indigenous when it is convenient to me (e.g. when it qualifies me for a scholarship or gets me a job interview). I am Indigenous all the time. With the privilege that comes with others' perception of me, with my access to education, and with the overall good quality of life that has been afforded to me, I must commit myself to supporting Indigenous communities. Being a part of a community includes being there for that community.

\section{Conclusion}

I hope that this section has painted a picture of who I am. In better knowing me, I hope you can better understand my work and are able to gain meaning from it. I also hope it is clear how much this work has meant to me over the course of my adulthood. For me, corrections and Indigeneity are fundamentally woven together in my personal story. I would not know who I am if it weren't for the cultural resources made available to me in working in corrections - but I never want that to be the case for anyone else. There should have been a better way. A way that didn't require thousands of Indigenous peoples again to be removed from their lands and communities. I made the best out of a bad situation. I want to make it clear that this is not my endorsement of corrections or even to be looked at as a silver lining. The same people and institutions that are responsible for me not knowing my heritage are those that over-incarcerate and over-criminalize Indigenous Peoples. I do not owe them a damn thing, but I believe I do owe Indigenous communities my time and dedication towards reducing our over-representation in corrections. This thesis is one of my first steps towards that goa 1. 


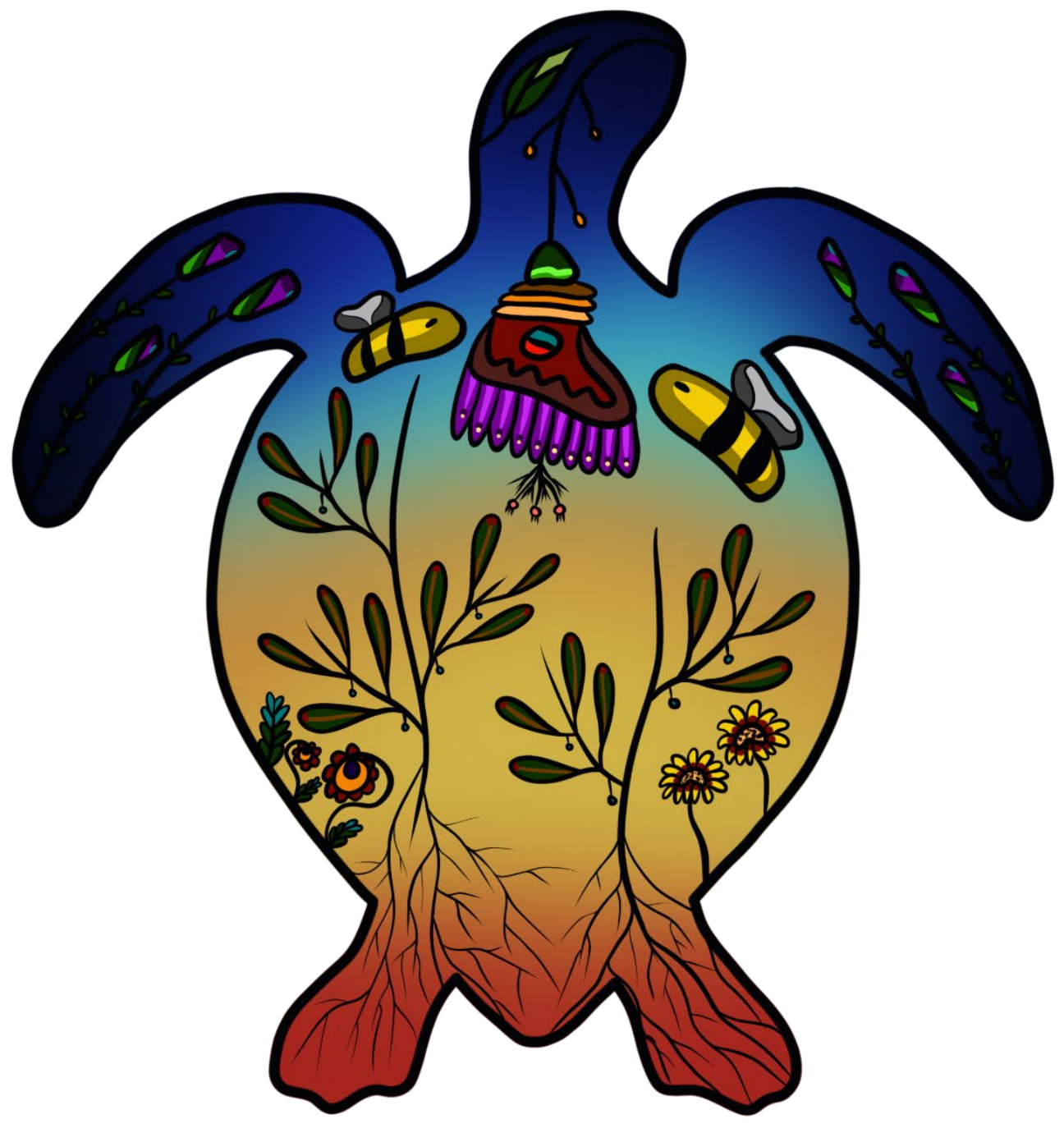




\section{Chapter 2: Review of Literature on Colonialism and Indigenous Peoples in the}

\section{Criminal Justice System}

\section{Introduction to Colonialism}

Before a productive effort can be made to understand the specific nuances I am exploring in this piece, a basic understanding of colonialism is required. When I say basic, I do not mean the general education all Canadians received that could be summed up on a single sheet of paper. Instead, I mean a fundamental understanding of the legal, cultural, social, psychological, and physical impacts of colonialism against Indigenous Peoples in what is now known as Canada. These fundamentals might seem like massive topics to cover. That is because they are. However, they are central to our basic understanding of Indigenous Peoples. Colonialism and the criminal justice system might as well be considered one and the same, as far as I am concerned. For example, what is now known as the Royal Canadian Mounted Police (RCMP) were originally the North West Mounted Police (NWMP) (Gerster, 2019). The NWMP was established with the express intent and priority to enact colonialism against Indigenous peoples using military-like practices.

In this introduction, I highlight relevant events in Canada's colonial history. I use the word highlight because it is impossible to do the topic justice without dedicating this entire thesis to it or (realistically) several books ${ }^{3}$. My accounts below are insufficient in exploring the individual or community experiences that impacted peoples' experiences. Even so, I try to provide meaningful context and nuance. Unfortunately, my own experience when working with non-

\footnotetext{
${ }^{3}$ I acknowledge that books alone are insufficient in sharing the colonial history. Many cultural and historic knowledges of Indigenous peoples are transmitted though other art forms, such as storytelling, or cultural practices, such as ceremony.
} 
Indigenous peoples is that the full breadth of colonialism is often not considered in conversations surrounding Indigenous Peoples, much less actual reconciliation. Following the brief historical accounts, I indicate specific ways that the justice system upholds and perpetuates colonialism. Lastly, I explore historical vs modern colonialism.

Also, though this chapter (and the next) is functioning as a literature review, it will not be limited to 'verifiable sources'. Specifically, I will draw on my own cultural knowledges and lived experiences, as well as teachings from other Indigenous persons (e.g., Elders, knowledge keepers, relatives, community connections, etc.) throughout this thesis. I have done this to commit my own act of decolonization in relation to academic spaces. While any academic can highlight the importance of citing and confirming sources, I also acknowledge the limited definition of a 'verifiable source.' I cannot cite a teaching from an Elder such that a reader could find it in my bibliography and use that to obtain access to these teachings. Not only would that be rude to the Elder as they might not want their knowledges shared, but also because such information is often conveyed orally (Indigenous Foundations, 2009). There is, of course, no public, easily accessible database of all Indigenous knowledges, and sometimes the information itself cannot be understood without the teacher. To consider these forms of knowledge as lesser is to engage in colonialism because these are some of the ways we share our information.

\section{A Brief Historical Account of Colonialism in "Canada"}

The section below focuses on highlighting some fundamental elements of colonialism. It is important to note that what is below is an incomplete account. Not only is it incomplete because of the need for brevity ${ }^{4}$, but also because historical accounts are incomplete. Much like during

\footnotetext{
${ }^{4}$ The need for brevity is something that I know many authors and scholars struggle with. Here, I particularly struggle with it because I feel that the consequence of leaving out something important could leave the reader
} 
the Holocaust, where information considered subversive was destroyed (Alon, 2012), written accounts of the atrocities committed against Indigenous peoples were destroyed or altered to show the Canadian state and the Church in a better light (Vowel, 2016a; Woolford \& Benvenuto, 2015). Even worse, entire nations of Indigenous peoples were wiped out, leaving their languages, ceremonies, histories, and peoples extinct (Thornton, 1987; Vowel, 2016c). It is estimated that as many as $40 \%$ to $80 \%$ of the Indigenous population died following contact with Europeans (Northcott \& Wilson, 2008). Those that survived experienced forced assimilation, forced relocation, and the destruction or corruption of their lands, leaving the survivors' customs, knowledges, and languages either disconnected or fractured to some degree (Valerie, 2016), particularly given the high prevalence of knowledges being shared orally or through ceremony instead of being written down (Gomashie, 2019; Hunt, 2016; Indigenous Foundations, 2009). In many instances, it is hard to identify exactly what occurred through colonization. In fact, in the prologue I identified my own examples of not knowing exactly happened to my grandmother and her parents beyond assimilation, relocation, and trauma. It would be inappropriate for me, or any author, to suggest we have a complete account of the full colonial history of Canada today.

Fortunately, the Indigenous peoples of Turtle Island resisted colonialism through the private practices of culture and language (Gomashie, 2019; Vowel, 2016c), storytelling (Wilkes, Corrigall-Brown, \& Ricard, 2010), record keeping (Luker, 2017), and other brave means (Hallinan, 2013). Indigenous peoples showed tremendous resiliency - as clearly indicated by the fact that their cultures and histories have not been completely erased. The ongoing resilience of Indigenous peoples has kept many communities, cultures, and languages in existence. Not only

with a fractured understanding of key concepts. Here, and every other place I am forced to be brief, leaves me concerned my works could be misunderstood by the reader and used in such a way that harms Indigenous peoples. I am aware and conscious of the consequence of these actions and I assume responsibility for them. 
have many shared their experiences of colonialism to heal and educate others (Chartrand, Logan, \& Daniels, 2006; Truth and Reconciliation Commission of Canada, 2015a), but some Indigenous peoples fought back against - and continue to fight for (Luker, 2017) - changing the colonial narrative of what has occurred across Turtle Island (Facing History and Ourselves, 2015b).

"When I started school in 1958 there were no books written by Aboriginals in the school system and everything about Native life was written by white people through their eyes. Now, Aboriginal writers can tell their stories. They have always been our narratives to tell, not others." - Rick

Revelle

\section{"Discovering" "Canada"}

As many of us were taught early on in school (Ireland, 2013), Christopher Columbus and his crew sailed across the Atlantic Ocean from Spain on his quest to find a faster route to India, thereby facilitating trade (Jeakle, 2020). Having miscalculated the circumference of the world, Columbus instead "discovered" Turtle Island, later to become America (Morison, 1942). The "discovery" of "America" began the rapid exploration, resource extraction, and ultimate colonization of the lands (Columbus, Corte-Real, \& Cabot, 1980). Columbus' "discovery" led to the rapid explorations of Turtle Island by many European countries. The British and the French were the dominant forces of colonialism in what is now known as Canada (Cartier, Biggar, \& Cook, 1993; Kelley \& Trebilcock, 2010; Rose, 2007), fighting for land claims (Nolan, 2008; Welton, 2012). While fighting to be the ultimate colonizers of what became Canada, the Europeans brought technology, knowledge, and development to the otherwise simple Indigenous peoples who occupied the land before its "discovery" (Columbus et al., 1980; Truth and Reconciliation Commission of Canada, 2015a). Eventually, after continued fighting between the 
British and French (Read, 2018), Canada became its own country in 1867 under the British Commonwealth (Dijkink \& Knippenberg, 2001).

While it seems redundant to provide the well-known colonization story of Canada as told by the settlers, it is also an opportunity to highlight the revisionist nature of the settlers' accounts of colonization and the history of "Canada"(McNeil, 2007). Often, settler accounts have left out the realities of horrific colonial practices, any acknowledgement of genocide, and have given oversimplified or incorrect representations of the Indigenous peoples whose lands they colonized. Turtle Island, the land otherwise occupied by millions of Indigenous peoples before colonization (Macklem, 2000), was not "discovered" by Christopher Columbus. In fact, Indigenous cultures were diverse, established, and highly socially sophisticated. Perhaps, one could argue that Christopher Columbus "discovered" America for Europeans, but even then, it is flawed because peoples of European descent from as early as the 9th century have been discovered (Cordell, Lightfoot, McManamon, \& Milner, 2008). The incorrectness of this telling highlights the pervasive dehumanization and devaluing of Indigenous peoples that was required from the onset to colonize Turtle Island.

The debunking of Canada's best-known colonial story is an essential first step in examining specific elements and events which occurred since European colonization began. It demonstrates the effective way settlers changed the narrative about colonization and why it is important to examine all aspects of colonization through a critical lens (Luker, 2017; Valerie, 2016). Understanding the perceived intentions of the colonizers and settlers provides valuable context to their actions. The same critical lens is applied in the following sections.

\section{$\underline{\text { Treaties and Unceded Land }}$}


The best-known historical land agreements are the treaties. Commonly, treaties are understood as the deals Indigenous peoples made with settlers exchanging goods or resources for land ownership (Vowel, 2016b). However, the realities of treaties are much less pleasant. During early periods of colonization - before there were many settlers with strong military capabilities Indigenous peoples and settlers shared generally positive, equal relationships (McNeil, 2007). As settlers' numbers grew - as well as competition from European militaries for colonization - the settlers developed Peace and Friendship Treaties (Dussault \& Erasmus, 1996). Essentially, their treaties were much simpler, providing the settlers with additional support from Indigenous peoples for military defence.

The Peace and Friendship Treaties were the first major treaties between Indigenous peoples and Europeans, but they were not the first treaties used by the Indigenous peoples of Turtle Island. Indigenous peoples have a long history of inter-nation treaties (Porter, 2008; Wallace, 1986). Such treaties were discussed and developed orally, were highly sophisticated, and are still in place today (Courtney \& Foxie, 2015). Notably, these treaties were also developed in good faith with the intention of being mutually beneficial to all parties and avoided inequitable terms that benefits one party more than others. Finally, such treaties are maintained, regularly readdressed as needed, and hold consequences for violation.

Then came the numbered treaties, which greatly benefited settlers through land "ownership" ${ }^{5 "}$ and access to the best resources (McNeil, 2007). Correspondingly, Indigenous peoples were moved to smaller pieces of land with relatively poor compensation. Given the previous understandings of how treaties functioned and were developed, the numbered treaties functioned much

\footnotetext{
${ }^{5}$ I put ownership in quotations as I contest the notion that it is possible for a person to own land.
} 
differently - disproportionately negatively impacting Indigenous peoples. Indeed, the conditions of these treaties so negatively impact Indigenous peoples (e.g., seeing Indigenous peoples "give away" large amounts of land for smaller, inferior pieces of land) that there is the belief that the terms of these treaties have been misrepresented (Vowel, 2016b). Lastly, the numbered treaties have not been properly implemented. There are not processes of accountability for the settlers when they do not meet the conditions of the treaties, nor are the agreements regularly revisited and altered to meet the needs of their subjects.

In contrast to the treaties, some Indigenous peoples did not come to legal agreements about their lands. Indeed, the land on which I have completed this entire thesis is the unceded and unsurrendered territory of the Algonquin Nation, though it is now mostly known as Ottawa (Taylor, 1986). In the interest of brevity, it is sufficient to say that unceded land "agreements" functioned much the way that treaties did, but without actually forming a treaty (Gurston, 2002). Indigenous peoples still experienced relocation, isolation, and many other acts of disrespect or violence; they just never gave up their lands. As far as I am concerned (and one of the interviewed subjects for this thesis states the same thing) the Indigenous peoples of Turtle Island are living under forcible occupation, seen particularly in situations where the lands are unceded.

I chose to include the section on treaties and unceded land because it powerfully demonstrates a historical example of colonial legal systems working against Indigenous Peoples. The practices and disrespect shown to Indigenous peoples surrounding their lands have impoverished Indigenous peoples, severed land connections, and sewed deep distrust between Indigenous peoples and settlers, particularly the official governments (Bolongaro, 2014).

\section{Forced Displacement}




\section{Residential Schools}

Residential schools appear to be one of the best-known examples of the horrors of colonialism, as indicated by recent heavy media coverage (CBC News, 2021) and changes to school curriculums (Johnson, 2021). A common misrepresentative understanding is that residential schools functioned similarly to a boarding school, where Indigenous children were sent away from their families and communities to learn the ways of the settlers. These schools were run by members of Christian faiths (Chrisjohn, Young, \& Maraun, 1997) - exact denominations varying dependent on location - and were supported and endorsed by the state (Dickason, 2002). At these schools, Indigenous children were forbidden from using their languages and were instead forced to use English or French (location dependent), lest they be punished (Truth and Reconciliation Commission of Canada, 2015a). Additionally, the Indigenous children were educated about the ways and histories of the settlers, taught skills that would make the students more productive under the colonialist regime, and taught Christian religious education to supplement their own spiritual beliefs (Truth and Reconciliation Commission of Canada, 2012). Some even indicated that residential schools' explicit purposes were to "kill the Indian in the child" so as to effectively assimilate them and eliminate Indigenous cultures (Facing History and Ourselves, 2015a).

The above description reflects the general knowledge surrounding residential schools and is generally correct. However, such an understanding fails to examine the most impactful and horrific elements of residential schools. First and foremost, residential schools were tools for the attempted total dissolution of Indigenous cultures, language, and knowledges (Truth and Reconciliation Commission of Canada, 2015a). Participation in activities from Indigenous communities was not permitted and was often met with severe discipline. Such discipline 
included, but is not limited to, physical abuse, starvation, group punishments, human experiments, sexual abuse, and psychological abuse (Blackburn, 2013; J. R. Miller, 1996; Truth and Reconciliation Commission of Canada, 2012). Officially, it is estimated that around 3000 Indigenous children were killed or died while attending residential schools (J. Miller, 2020), though this number has been contested by Indigenous groups who have suggested that the number is likely higher, with some suggesting thousands or more children were left out of the count. Further, there are many Indigenous children who simply did not return home and were considered missing but could not be proved dead (Chrisjohn et al., 1997).

Residential schools were effective tools in managing the Indigenous adults outside of the schools as well. The potential harms that could be inflicted onto the children or relatives of Indigenous adults deemed problematic by settlers were enough to produce submission (Dupuis, 2016; Truth and Reconciliation Commission of Canada, 2015a). Even those that did not yet have children taken to residential schools feared acting out against settlers lest their children be taken or fled from their lands and communities to prevent their children from being taken (J. Miller, 2020). By forcing Indigenous peoples to flee their lands, the settlers found another way to displace Indigenous peoples and disconnect them from their communities forcibly.

I want to note that I left the previous paragraph in this work despite it recently becoming out of date. Two weeks after I wrote the above paragraph, 215 bodies of Indigenous children were discovered at the former Kamloops residential school in unmarked and mass graves (The Canadian Press, 2021). The horrific discovery prompted a national call for the lands of residential schools to be surveyed to find more of the children who were murdered at these 
schools (Eneas, 2021; Talaga, 2021). At the time I am writing this ${ }^{6}$, more mass graves have been discovered. The largest number of children discovered was 751 bodies found at Cowessess First Nation (Eneas, 2021). However, it is expected that thousands more will be found, particularly now that the government is finally taking this seriously and pledging resources to finding these children.

I elected to leave the outdated information in, despite having the opportunity to change it before submission, for a very simple reason. As mentioned in that chapter, the number of children lost has been contested for decades, particularly by residential school survivors. I knew from the very first ceremony I ever attended that the estimates of lives lost were far too conservative. However, when it came time to finding written sources to credibly cite for this thesis, I was unable to do so. I called my mom, as well as some of my Indigenous colleagues, but eventually, I just moved past it. The discovery of these additional bodies has been horrifying, demoralizing, and exhausting. The one thing it was not to me was surprising.

I believe it is important that I include the journey surrounding writing this specific account of residential schools. The knowledges I had passed on to me by residential school survivors was not sufficient for decades. My plight pales in comparison to the dehumanization and delegitimization of those survivors who shared their stories. When we talk about (or, in this case, write about) residential schools, we must also acknowledge the mountain that survivors and Indigenous community members had to climb to have their claims taken seriously. Canada's complacency towards residential schools and those impacted by them an additional, powerful tool of colonialism.

${ }^{6}$ July 2021 
There are also prevalent myths, misunderstandings, and half-truths about residential schools popular in the general Canadian knowledge. First, there is the belief that the enrolment of Indigenous children in residential schools was voluntary. Perhaps some children were sent to these schools willingly by their families (Ostroff, 2015), but that is not representative of many other groups. As previously mentioned, many families feared having their children sent to residential schools and even had their children forcibly taken to the schools against the wills of their families or communities (Truth and Reconciliation Commission of Canada, 2015a). It is likely that the alleged support of Indigenous peoples of residential schools is an inflated argument created by settlers to legitimize residential schools (Blackburn, 2012). There is also the prevalent understanding that residential schools needed to be actual boarding schools. While many schools required students to live away from their families, other schools were situated in communities so as not to require the Indigenous children to be housed by the schools (Mason, Pind, \& Christou, 2020). Doing so was just a different method to provide Indigenous children with the same assimilating education. Such schools were more common in recent years and are now best known as day schools (Hanson, 2020).

Finally, I would be remiss to leave out a sometimes uncomfortable and very nuanced point: there are some rare cases where Indigenous peoples enjoyed attending residential schools or recount positive experiences there - I have met these survivors and heard their accounts firsthand. While one could certainly argue that such fond memories could be a manifestation of trauma or assimilation (Ostroff, 2015; Truth and Reconciliation Commission of Canada, 2012), it is also not my place to contradict the stories of Indigenous people who survived residential schools. Given that Indigenous peoples have so often had their perspectives left out of the telling of colonization (Luker, 2017), I believe if I am to represent Indigenous voices and experiences in 
my work, I should represent even the voices and experiences which are not representative of the general experience. However, I acknowledge that these limited positive experiences in no way delegitimize the traumatic experiences of many at the hand of residential schools. Additionally, I want to clarify my personal positionality that I condemn residential schools and associated practices.

I have included the section on residential schools for many reasons, but two reasons specifically stand out. First, I believe that it is important to remind readers of the realities of residential schools and to highlight the specific atrocities that provincial, territorial, and federal governments leave out when discussing residential schools. Second, and most importantly, residential schools highlight significant examples of colonial theory and praxis that will be relevant in future chapters. The removal of Indigenous peoples from their communities, the severing of their connections to the land, the inability to practice ceremony, the forced homogenization and assimilation, the isolation, and the stigmatization of Indigenous peoples are elements that occurred both in residential schools and that continue today in mainstream institutional corrections.

\section{Northern Relocation}

A lesser-known critical practice of colonization was the forced relocation of Indigenous peoples to the extreme north, often through specified settlements. Where groups could not be neatly controlled and assimilated through treaties, some were relocated. The best-known relocation was to what is now known as Nunavut (Porteous \& Smith, 2001). For those that were relocated like this, it appears that assimilation was not the priority, but instead, the goal was to keep Indigenous peoples away from the settler colonies and served Canada's interests of asserting sovereignty over the Arctic (Boldt, Long, \& Long, 2014; Gerster, 2019). The relocated peoples were often 
not forced to abide by many of the colonial rules but instead were isolated to areas with extremely harsh living conditions. The intention was likely to have Indigenous peoples sent north to ultimately die out (or at least preserve the colonial culture by preventing Indigenous peoples from corrupting it with their ideologies), though, fortunately, that ultimately did not occur.

Northern relocation, like residential schools, is an important colonial precedent for understanding so as to understand modern practices around "corrections" better. Even in the modern-day, many permitted Indigenous lands, such as reservations, are in extremely rural areas (Indian Act, 2009) and lack many of the resources, supports, and amenities available to the majority of Canadians. This also has the added 'benefit' of keeping Indigenous peoples, as well as the realities of their lives as a result of colonialism, away from the eyes of most Canadians. Problems they face in their daily lives cannot be seen - and therefore, there is less pressure to fix them - another theme in Canadian corrections that is discussed in the next chapter.

\section{Child Welfare, Sixties Scoop, Millennium Scoop}

As evidenced by the previous sections, Indigenous peoples are no strangers to forced displacement, assimilation, and the fracturing of families and communities. It is particularly notable that at the time residential schools saw their grip on Indigenous peoples lessening, the involvement of Indigenous peoples in the child welfare sector increased substantially (Hanson, 2009). A period that might have been looked at as one of progress merely saw a shift in the mechanisms and technologies of colonialism.

The term "Sixties Scoop" refers primarily to the period in the 1960s and 1970s where the proportion of Indigenous children taken into the custody of the state skyrocketed (AlstonO'Connor, 2019). Before the Sixties Scoop, Indigenous children accounted for around 1\% of 
children in the care of the state (Hanson, 2009). However, by 1964, Indigenous children accounted for $34 \%$. While certainly, the standard forces of colonialism were broadly active during the Sixties Scoop, there are three elements of note I wish to highlight. First, the social workers entering Indigenous communities lacked specialized training relating to Indigenous cultures, family structures, and child-rearing practices, in addition to limited training on the impacts of colonialism (Sinclair, 2007). The social workers, and the policy they were operating under, caused the mass removal of Indigenous children. Second, many family members were denied the opportunity to act as temporary or permanent guardians of the children removed from their parents, including those whose justifications were rooted in racism. For example, grandparents, aunts, or uncles who were acting as caregivers to the seized children before their removal were not offered the opportunity to act as their guardians (CBC News, 2016). Finally, and correspondingly, the majority of Indigenous children taken by child services were placed in non-Indigenous homes. In 1964, approximately $70 \%$ of the seized Indigenous children resided in non-Indigenous homes (Truth and Reconciliation Commission of Canada, 2015a). As such, Indigenous children became disconnected from their lands, cultures, traditions, languages, families, and communities. Much like residential schools, non-Indigenous foster families were ideal locations for the assimilation of Indigenous children, as well private spaces where Indigenous children could be abused and traumatized without much attention (McKenzie, Varcoe, Browne, \& Day, 2016). The Sixties Scoop gained national attention in 2017 when Parliament ruled that the Indigenous victims had their rights violated (Deer, 2021), offering compensation payments to the survivors (Ontario Sixties Scoop Steering Committee, 2017).

Unlike the Sixties Scoop, the Millennium Scoop is not as well known in the Canadian consciousness. In fact, some argue that it never occurred (CBC Radio, 2018). The impact of the 
Millennium Scoop is less well known, as the impacted children are just recently entering adulthood, recovering from their traumas, and sharing their stories (The Canadian Press, 2011). Even searching for a suitable source to draw upon to support this section was challenging as it is just not written about with comparable coverage to the Sixties Scoop or residential schools. However, in honour and respect of, and solidarity with, the survivors - particularly one of the research participants in this study - I acknowledge the validity and corresponding traumas of the Millennium Scoop. The Millennium Scoop was much the same as the Sixties Scoop, as there were a substantial number of Indigenous children taken into the care of the state beginning in the 2000s. Additionally, a practice known as "birth alerts" was in place, where child and family services could legally be notified when an Indigenous woman gave birth, even if the mother had not committed any offences to harm the child (Stueck, 2019).

As of the 2016 Census, Indigenous children account for $7.7 \%$ of all children in Canada ${ }^{7}$, but for $52.2 \%$ of children in foster care (Government of Canada, 2020). Contact with child and family services has been identified as a risk factor for traumatization and criminalization (Ryan \& Testa, 2005). A child in foster care is at risk for exposure to criminal behaviour, trauma, abuse, and loss of identity (Stevenson, 2019). When an Indigenous child is placed in the care of the state, they are also revictimized through the colonial traumas they - or their relatives - have endured. Displacement, assimilation, and traumatization place Indigenous youth at risk for future criminalization, meaning that it is essential context for understanding the over-representation of Indigenous peoples in the criminal justice system.

\footnotetext{
${ }^{7}$ Children between the ages of $0-14$
} 


\section{A Picture of Indigenous Persons and the Criminal Justice System}

\section{Over-representation of Indigenous Peoples in the Criminal Justice System}

Indigenous peoples are heavily represented in the Canadian criminal justice system (Jamil, 2020), meaning that they account for a much greater proportion of the prison population than they occupy of the general population of Canadian. However, saying Indigenous peoples are over-represented in the criminal justice system is insufficient in explaining the horrific reality of the incarceration of Indigenous peoples. Indigenous peoples account for approximately $5 \%$ of the population of Canada but represent around one-third of the prison population. That figure is particularly well known in movements surrounding Indigenous rights and among those who have worked in the criminal justice system, but the realities of that figure are not fully understood.

Indigenous adults account for over $30 \%$ of the federally incarcerated population and approximately $31 \%$ of the provincially/territorially incarcerated population across Canada (Jamil, $2020)^{8}$. However, when reflecting on the incarceration figures, one might hypothesize that the same would be reflected in the community corrections figures, particularly when considering that the overwhelming majority of criminal sentences are served entirely in the community (Jamil, 2018). Unfortunately, this is far from true. Indigenous peoples are actually under-represented in community corrections ${ }^{9}$ relative to their representation in institutional corrections.

\footnotetext{
${ }^{8}$ Indigenous youths account for $8.8 \%$ of the youth population of Canada, but $47 \%$ of custody admissions and $40 \%$ of community admissions (Jamil, 2020). As this thesis does not specifically focus on Indigenous youths, it was not included above. However, these percentages are still notable in the conversation surrounding Indigenous overrepresentation in the criminal justice system. ${ }^{9}$ Community corrections include, but are not limited to, probation (provincial), parole (federal), statutory release (federal), bail (provincial), conditional sentences, etc. (Public Safety Canada, 2010)
} 


\section{Table 1}

\begin{tabular}{|c|c|c|c|c|c|}
\hline $\begin{array}{l}\text { Province or } \\
\text { Territory }\end{array}$ & Population & $\begin{array}{c}\text { Indigenous } \\
\text { (\% of } \\
\text { pop.) }\end{array}$ & $\begin{array}{c}\text { Indigenous } \\
\text { Admissions } \\
\text { in } \\
\text { Correctional } \\
\text { Centres (\% } \\
\text { of pop.) }\end{array}$ & $\begin{array}{l}\text { Indigenous } \\
\text { Under } \\
\text { Community } \\
\text { Supervision } \\
\text { (\% of pop.) }\end{array}$ & $\begin{array}{c}\text { Difference } \\
\text { Correctional } \\
\text { Centres vs } \\
\text { Community } \\
\text { Supervision }\end{array}$ \\
\hline British Columbia & $4,560,240$ & $5.9 \%$ & $32.0 \%$ & $27.0 \%$ & $-5.0 \%$ \\
\hline Alberta & $3,978,145$ & $6.5 \%$ & $42.0 \%$ & $27.0 \%$ & $-13.0 \%$ \\
\hline Saskatchewan & $1,070,560$ & $16.3 \%$ & $76.0 \%$ & $73.0 \%$ & $-3.0 \%$ \\
\hline Manitoba & $1,240,695$ & $18.0 \%$ & $74.0 \%$ & $58.0 \%$ & $-16.0 \%$ \\
\hline Ontario & $13,242,160$ & $2.8 \%$ & $12.0 \%$ & $10.0 \%$ & $-2.0 \%$ \\
\hline Quebec & $7,965,450$ & $2.3 \%$ & $5.0 \%$ & $7.0 \%$ & $+2.0 \%$ \\
\hline $\begin{array}{l}\text { Newfoundland and } \\
\text { Labrador }\end{array}$ & 512,250 & $8.9 \%$ & $25.0 \%$ & $23.0 \%$ & $-2.0 \%$ \\
\hline New Brunswick & 730,705 & $4.0 \%$ & $10.0 \%$ & $10.0 \%$ & - \\
\hline Nova Scotia & 908,340 & $5.7 \%$ & $10.0 \%$ & $7.0 \%$ & $-3.0 \%$ \\
\hline Prince Edward & 139,685 & $2.0 \%$ & $3.0 \%$ & $5.0 \%$ & $+2.0 \%$ \\
\hline Yukon & 35,110 & $23.3 \%$ & $64.0 \%$ & $51.0 \%$ & $-13.0 \%$ \\
\hline Northwest Territories & 41,135 & $50.7 \%$ & $88.0 \%$ & $86.0 \%$ & $-2.0 \%$ \\
\hline Nunavut & 35,580 & $85.9 \%$ & $100.0 \%$ & $100.0 \%$ & - \\
\hline
\end{tabular}

(Statistics Canada, 2019) (Jamil, 2018) ${ }^{10}$

The above table demonstrates the percentage of Indigenous peoples of the provincial or territorial population, Indigenous admissions into institutional corrections, and the percentage of Indigenous peoples under community supervision. Notably, only two provinces, Quebec and Prince Edward Island, have more Indigenous people in community corrections instead of incarceration. Also, Prince Edward Island is the only province even remotely close to having a representative percentage of Indigenous peoples incarcerated relative to their percentage of the provincial population.

\footnotetext{
${ }^{10}$ Note that these numbers are reflective of the 2016 Canadian Census; correspondingly, the admissions figures are reflective of the 2016/2017 year. Since the time that those figures were produced, Indigenous peoples went from being over-represented in institutional corrections at $27 \%$ of the population to $30 \%$ (Office of the Correctional Investigator, 2020).
} 
Despite that crime and incarceration are trending downwards in Canada (Jamil, 2018), Indigenous peoples see their numbers rise in custody (Jamil, 2020). In 2010, Indigenous peoples accounted for around $20 \%$ of the incarcerated population, but in 2020 Indigenous peoples account for around $30 \%$ of the incarcerated population. Indigenous women are the fastestgrowing incarcerated demographic group, with $47 \%$ of incarcerated women in Canada being Indigenous women (Jamil, 2020). These figures highlight systemic failings, particularly since 2015 after the provincial, territorial, and federal governments committed to the 91 Calls to Action, of which several calls highlighted the need for justice reform and the substantial reduction of Indigenous persons in the system (Truth and Reconciliation Commission of Canada, 2015b). Indigenous peoples are facing an incarceration crisis for which corrections must be awarded much of the blame. Current practices have not supported Indigenous peoples and have indeed allowed the problem to worsen. The time has long passed when alternatives should have been implemented.

"Every intelligent man saw the poverty that would follow the destruction of the beaver, but there were no chiefs to control it; all was perfect liberty and equality." - David Thompson

\section{Indigenous-Specific Corrections and "Indigenizing" Corrections}

Currently, in custodial corrections, Indigenous peoples seldom have access to meaningful, culturally relevant programming. Federal corrections have two correctional streams: the standard stream and the "Traditional" Indigenous healing stream (Zinger, 2020). The Indigenous-specific stream provides its participants programming entwined with cultural healing practices ${ }^{11}$. Most

\footnotetext{
${ }^{11}$ It should be noted that these cultural elements are very generalized, not individualized to the participant. It is not inclusive of all Indigenous nations. Instead, this program homogenizes Indigenous needs, or provides only the teachings from the cultures of the Indigenous staff.
} 
unfortunately, the Indigenous-specific stream is substantially under-resourced. The wait times to begin Indigenous-specific programming are much longer. Indigenous peoples might choose the standard stream, even if it is not what they want or would be helpful to them ${ }^{12}$, because it fulfills their case plan more quickly so that they might be granted parole. These wait times are made worse by the fact that non-Indigenous persons are also permitted to enroll in the Indigenousspecific stream, furthering wait times. Non-Indigenous participants are permitted to enrol for purposes of fairness, but there is also another incredibly important reason. If participants had to prove they were Indigenous to attend this stream, it could cause substantial problems for individuals who lost their status through enfranchisement ${ }^{13}$. Another "resource" that Indigenousspecific programming lacks is Indigenous staff. Though certain roles, like Elders, are filled by Indigenous persons, the majority of the roles are not, meaning that incarcerated Indigenous peoples are receiving "traditional" Indigenous programming from many staff who are nonIndigenous (Zinger, 2020).

There also exist two specific areas of corrections for incarcerated Indigenous persons: Section 81 and Section 84. Section 81 refers to Indigenous healing lodges, where the entire correctional facility is dedicated to Indigenous programming and cultural practices (Correctional Service Canada, 2019). Section 84 refers to conditional release facilities, such as a community-based residential facility ${ }^{14}$, for Indigenous clients on parole or statutory release. While both of these avenues are better than nothing, they are not without their faults in conception or implementation. In addition to the lack of available Indigenous staff in these facilities, these

\footnotetext{
${ }^{12}$ This might contribute to the over-representation of Indigenous peoples in custodial corrections, as they might not receive relevant programming that actually rehabilitates or heals them.

13 “Enfranchisement is a legal process for terminating a person's Indian status and conferring full Canadian citizenship. Enfranchisement was a key feature of the Canadian federal government's assimilation policies regarding Aboriginal peoples." (Crey, 2009)

${ }^{14}$ Colloquially known as a halfway house.
} 
avenues leave much to be desired by way of policy. Incarcerated Indigenous persons only qualify for Section 81 if they are classified at minimum security, which is written into the policy (Correctional Service Canada, 2019). Most frustratingly, incarcerated Indigenous peoples are over-represented in the higher security levels of medium-security or maximum-security when compared to non-Indigenous prisoners (D'Arcy, 2018). For Section 84, incarcerated Indigenous peoples are granted parole at a lower rate than non-Indigenous prisoners, meaning fewer of them have the opportunity to utilize these facilities and benefit from their transitional supports.

On the provincial/territorial level, there are fewer opportunities for Indigenous-specific programming. As provincial/territorial sentences are less than two years in length, and Canadian policy mandates that prisoners must be released at two-thirds of their sentence length ${ }^{15}$ for community reintegration purposes, there is insufficient time to offer programming for many prisoners, Indigenous and non-Indigenous alike. Available programming must meet the time constraints of shorter sentences. The quality of programming - or program availability - varies by institution.

When an individual is released into the community, the support from corrections is drastically reduced. The individual is assigned a parole or probation officer (Zinger, 2020), though these officers are often over-worked, under-resourced, and exist for enforcement purposes (Union of Safety and Justice Employees, 2019). Combined with the lack of Indigenous-specific programming, newly-released Indigenous persons must rely on community organizations and provincial/territorial health services to support them through their reintegration. Those on conditional release might have access to community programming as a condition of their order,

\footnotetext{
${ }^{15}$ Except in exceptional circumstances, known as detention orders.
} 
but otherwise they are reliant on themselves (or supportive community organizations) to meet their needs (Norman \& Ricciardelli, 2021). In my time working in frontline supportive roles for criminalized youth and adults, I was regularly frustrated that our under-resourced organizations were the ones providing bare essentials (e.g. groceries, counselling, etc.) to newly released persons. It is not that I minded doing it, but rather I felt that there should have been greater accountability of the state to ensure they were releasing individuals into safe and supportive situations. Even then, not every community has these services, particularly rural communities, leaving Indigenous clients under-supported.

The current correctional practices are not serving Indigenous peoples as effectively as they need to be. Indeed, Indigenous peoples should not even have to be subjected to incarceration over their own traditional justice practices. However, for as long as Canada insists upon leaving maintaining control over Indigenous peoples by denying their rights to self-governance, the absolute least they could do would be to ensure Indigenous persons receive equitable resources and outcomes to their non-Indigenous counterparts. These programs are not centred on healing, restorative justice through the current system, or transformative justice by returning selfgovernance to Indigenous peoples ${ }^{16}$, practices which Indigenous communities have identified as being important and culturally appropriate responses to crime (Justice Education Society, 2020). Finally, it is important to note the increased prioritization of "Indigenizing" corrections. Making corrections more supportive of Indigenous peoples has been identified as a need and priority, particularly on the federal level (Zinger, 2020). While it is certainly encouraging that the experience of incarcerated Indigenous persons is critiqued and efforts are made to improve that

\footnotetext{
${ }^{16}$ Note that elements of healing and restorative justice are present in some correctional programming, but are not rooted in these practices.
} 
experience, it is extremely telling that this is still prioritized over keeping Indigenous peoples out of the criminal justice system altogether. It is worth noting that settlers continue to apply colonial policy to Indigenous peoples in the criminal justice system, which keeps them out of their communities, and ripe for displacement, disconnect, and assimilation. The current model does not meet the unique, spiritual, and cultural needs of Indigenous peoples and further perpetuates colonialism and trauma. For reconciliation to be possible, Indigenous peoples and communities require increased autonomy in the justice process (Justice Education Society, 2020) and to have their numbers in mainstream corrections reduced (Truth and Reconciliation Commission of Canada, 2015b).

\section{Historical vs. Modern Colonialism}

Historical examples of colonialism, except perhaps the Millennium Scoop, are perhaps what the average Canadian thinks when they hear the word colonialism. While it is important to acknowledge - and truly understand - historical instances of colonialism and the legal and cultural precedents they set, it is also important to understand that colonialism still exists in the modern day.

Modern examples of colonialism are perhaps less obvious to the untrained eye, but they are no less damaging than their historical counterparts. Much like residential schools, prisons and the child welfare system displace, traumatize, and assimilate Indigenous persons (Truth and Reconciliation Commission of Canada, 2012). Much like northern relocation and general displacement, prisons disconnect Indigenous peoples from their communities, customs, and lands (Bolongaro, 2014). Much like the numbered treaties, legal agreements are not practiced fairly and leave Indigenous peoples left out in the cold (Vowel, 2016c). The criminal justice system and Canada in general - have just found less obvious ways to enforce colonialism and the 
oppression of Indigenous peoples. To best understand the following chapters, understanding the ways modern colonialism mirrors and upholds the "bad stuff that happened a long time ago" ${ }^{17}$ is essential.

\section{Conclusion}

The purpose of this chapter was to provide you, the reader, context, nuance, and understanding about the realities of colonialism if you were unaware or had forgotten. Certainly, this chapter partially exists because it is required for program fulfillment, but it goes so far beyond that. Every chapter that follows this first would be incomplete without first recognizing the incredible, powerful, and devastating web woven by colonialism. Colonialism is a poison that has penetrated every element of Canadian society. To fix a social problem, work towards reconciliation, or even to analyze a small area section of Canadian justice policy as I have done in the following chapters, it is first essential to understand how prolific and enduring colonialism really is.

Colonialism certainly contributed to the factors that seem obvious to someone who studies society, such as risk factors for criminal behaviour. Colonialism produced trauma; trauma then contributes to putting someone at risk for engaging in illegal activity. However, the problem goes so much deeper than that and is central to why so many provide the counter-argument to Indigenous advocates: "Why don't they just get over it? It happened so long ago - they weren't even alive when it happened!" Despite the obvious incorrectness of that statement (I am twentyfour years old at the time I wrote this and was alive when residential schools were still operational), colonialism is more than just overt and clear-cut examples that happened a long

\footnotetext{
${ }^{17}$ As I have heard colonization referred to many times, as I am sure many other Indigenous persons have, in regular life.
} 
time ago. Understanding colonialism also understands that those historic instances set cultural and legal practices which shaped (and continue to shape) Canada's cultural attitude towards Indigenous peoples, development of laws and policy, and daily interactions with Indigenous peoples.

Colonialism thrives through social systems like the criminal justice system. Officially, it is seen through factors like the lack of resources allocated to Indigenous-specific needs in the criminal justice system, particularly related to resources that mitigate risk for criminalization. Essentially, I believe prisons function similarly to residential schools, northern relocation, the Sixties Scoop, and the Millennium Scoop as they displace Indigenous peoples, remove them from their communities, cultures, and lands, and attempt to rehabilitate (read: assimilate) them into persons considered socially acceptable under the parameters of colonialism. If Canada hopes to achieve reconciliation with the Indigenous peoples whose lands they occupy, they must first alter the current justice practices that perpetuate colonialism and trauma. 


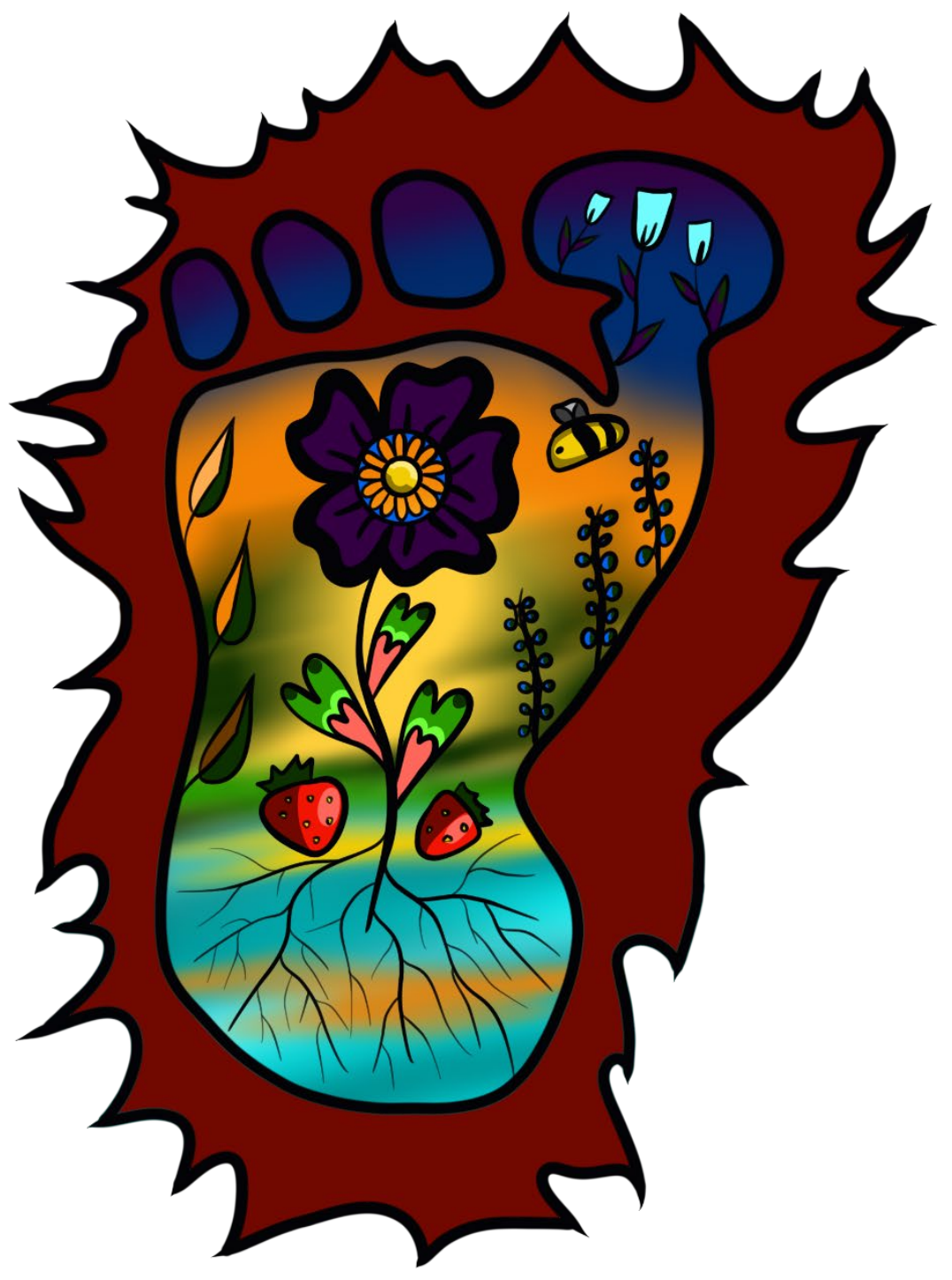




\section{Chapter 3: Review of Literature on Specialized Courts and Programs}

\section{Introduction}

Originally, I had planned this chapter to focus on drug treatment courts, systemic racism, and institutional policy. In fact, this entire thesis was originally conceived as a study to look at the drug court admission criteria specifically and how (if at all) these criteria contributed to systemic racism. However, over the course of my interviews for this study, I came to the realization that centring this study specifically on drug courts was not the right approach. Many of the participants discussed the need to highlight other specialized, individualized, and supportive programming for their clients. Thus, I shifted the literature review to focus on alternatives to incarceration more broadly.

Correspondingly, I extended the literature to review to include other alternative courts. Anyone who has produced a written text for review, particularly anything longer than a few pages, likely knows of the devastation of having to redo it entirely. It is hard for me to believe I did so willingly. But the below is a much stronger preface and representation of the information learned and shared in the following chapters. Much like the original friendship treaties before European contact (Vowel, 2016b), I must constantly ensure my practices are in line with the needs of the people they serve.

This chapter focuses on systemic racism in the justice system, particularly in policy development and highlights alternative models to incarceration. By understanding the function, benefits, and limitations of alternatives to incarceration, it is easier to see how they can better serve the justice system and its clients. Moreover, a review of these programs is important because, despite being excellent in many ways, they are not without fault and might be improved through thoughtful 
critique. In fact, as identified to me by a previous boss in the not-for-profit sector, such programs rarely conduct their own program evaluations or contract out for them. The absence was explained to me to be owing to a lack of resources to prioritize for program evaluation over client care (given that such organizations are often under-resourced) and the fear that pointing out areas needing improvement could reduce their already meagre funding. However, there is often limited data on these programs in the Canadian context, and such information is not updated periodically in the same way correctional statistics are (Jamil, 2018, 2020).

\section{Systemic Racism}

"Systemic racism includes the policies and practices entrenched in established institutions, which result in the exclusion or promotion of designated groups. It differs from overt

discrimination in that no individual intent is necessary. "(Calgary Anti-Racism Education, 2021)

Systemic racism is differentiated from individual racism in that it is upheld and perpetuated by institutions rather than by individuals. An organization or institution can be racist, even if those who work there are not (or do not consider themselves to be racist). Systemic racism is present in every major institution in our society, including education, healthcare, and the criminal justice system (Canadian Broadcasting Corporation, 2017; The Hamilton Spectator, 2020; Varcoe et al., 2019). For example, individual racism could look like a nurse having less patience for an Indigenous patient than a non-Indigenous patient because they believe the Indigenous patient caused their ailment through lifestyle, whereas the non-Indigenous patient was simply unlucky. Alternatively, systemic racism within healthcare could look like nurses not receiving training on colonialism, Indigenous peoples, and their unique needs. Correspondingly, they are unable to provide the full breadth of care required for full healing, meaning that - even if an Indigenous patient and a non-Indigenous patient receive the exact same care, the care provided to the 
Indigenous patient is not as effective, contributing to poorer health outcomes for Indigenous peoples on a societal level.

The impacts of systemic racism are seen and felt substantially as indicated through lower socioeconomic status, higher unemployment levels, lower educational attainment, shorter lifespan of Indigenous peoples, higher prevalence of health complications (e.g. diabetes), higher prevalence of substance use disorders, and over-representation in the criminal justice system (Mosby \& Galloway, 2017; O'Donnell, 2019; Turner, 2013; Zinger, 2020). These negative outcomes are one of the barriers to reconciliation (Truth and Reconciliation Commission of Canada, 2015b).

Systemic racism is the reason I developed this research project. I worked in a system that better served non-Indigenous clients better than Indigenous clients ${ }^{18}$, and I did not want to be a part of that any longer. Specifically, I noticed that most of the policies that we follow, Indigenousspecific or not, did not include input from Indigenous peoples. What I observed was settler solutions provided for colonization-specific problems, where Indigenous peoples were negatively impacted when the solutions did not meet their needs. As discussed in Chapter 1, this is nothing new for Indigenous peoples to have to deal with. My frustration with these realities prompted me to investigate if the policy in place is supportive of keeping Indigenous peoples out of the criminal justice system.

Throughout my graduate studies, I have worked part-time at the Government of Canada, on the Gender-Based Violence Policy Team for the Department of Women and Gender Equality ${ }^{19}$. As

\footnotetext{
${ }^{18}$ Note that just because they are better served does not mean that they are actually well cared for by the state. ${ }^{19}$ The views expressed here do not in any way represent the Government of Canada, and should not be taken as such. This is merely a reflection on my own experiences working in the federal public service as an Indigenous woman.
} 
an Indigenous woman, I was skeptical about accepting a role within the government as I feared I could be contributing to further systemic racism of Indigenous peoples, as has so often been done to us since European contact (The Hamilton Spectator, 2020). However, I specifically chose to work in this role because of the department's emphasis on Gender-Based Analysis Plus (GBA+). GBA+ promotes equity over equality (Women and Gender Equality Canada, 2021). Essentially, this means trying to give everyone what they need to achieve a certain objective instead of giving everyone the same thing in hopes that they reach the same objective. Put simply; it is the difference between fairness in implementation versus fairness of outcomes, or equality versus equity, also sometimes known as substantive equality (outcomes) over formal equality (process). By doing so, it requires more effort and resources for some populations and less for others. I was hired to contribute Indigenous perspectives to the areas of policy so as to create better policy specifically policy that mitigates systemic racism. Such an approach is encouraging.

Unfortunately, it is a relatively new practice within the government and is still not implemented fully across government agencies, again contributing to systemic racism.

In the case of systemic racism in the criminal justice system, the most general example is the failure of the criminal justice system to account for the unique needs of Indigenous peoples adequately, particularly given the negative impacts they endure from colonialism which places them at higher risk for criminalization. A specific example of systemic racism is Indigenousspecific correctional programming in federal prisons (discussed in Chapter 1). While somewhat beneficial to the incarcerated Indigenous persons in the sense that they are given access to Indigenous culture through programming, this programming is underfunded, has longer wait times, and decreased access to Indigenous clients because of their security classifications (Zinger, 2020). Indigenous clients are often awarded higher security classifications (medium- 
security or maximum-security over minimum-security) than their non-Indigenous counterparts. The higher classifications can be individually racist (e.g. a staff member believes the client is higher risk merely because they are Indigenous) but contribute to a systemically racist problem as well. If Indigenous clients can only attend a healing lodge if they are minimum security (S. C. Lee, Hanson, \& Blais, 2020; Martel, Brassard, \& Jaccoud, 2011; Zinger, 2004, 2012, 2020), but Indigenous clients receive higher classifications than non-Indigenous clients, then the policies surrounding healing lodges are not meeting the needs of incarcerated Indigenous persons.

The example of healing lodges highlights the way that well-intentioned, Indigenous-focused policy can still be systemically racist and fail to meet the unique needs of Indigenous clients. For policy to truly meet the needs of Indigenous clients, it must include Indigenous clients in its development (Tuck \& McKenzie, 2015), and in the implementation and evaluation.

\section{Gladue Reports}

The Gladue report is a presentencing or bail hearing report, usually prepared by Gladue caseworkers at the request of the judge, defense counsel or Crown Attorney. These reports contain recommendations to the court about what an appropriate sentence might be, and include information about the Aboriginal persons' background such as: history regarding residential schools, child welfare removal, physical or sexual abuse, underlying developmental or health issues, such as FASD, anxiety, or substance use. (Native Women's Association, 2015)

Gladue reports, and their corresponding Gladue principles, acknowledge the additional adverse circumstances faced by Indigenous peoples in Canada, with the ultimate purpose of highlighting mitigating factors to reduce the punishment of Indigenous persons convicted of crimes (April \& Orsi, 2013). The reports are intended to function to help reduce the over-representation of Indigenous peoples in custody when sentencing occurs (Bressan, 2018), though the associated 
principles can apply more broadly in other areas of the criminal justice system (Native Women's Association, 2015).

Gladue principles consider the impacts of colonialism felt by Indigenous peoples, helping to provide the court with a better understanding of how they came to be criminalized and the role institutions play. While this degree of insight and consideration is theoretically a step in the right direction, Gladue principles are merely one element of the justice system aimed at supporting the unique needs of Indigenous peoples and cannot fix the system as a whole (Paige, 2018). They are simply insufficient in meeting the needs of Indigenous peoples in the justice system, particularly given that they only come into play after an Indigenous person has been criminalized. Most disconcertingly, the proportion of Indigenous persons in prisons has only grown since the institution of Gladue principles and reports (Department of Justice Canada, 2017; Zinger, 2020), clearly indicating that the Gladue principles and reports alone are insufficient in curbing the problem of Indigenous over-representation ${ }^{20}$.

It is also worth noting that many agents of the justice system do not fully understand and respect Gladue principles (CBC News, 2019), which has also contributed to the lack of success. It is important that Indigenous knowledges, approaches to justice, and circumstance is understood and respected when applying Gladue principles ("Gladue report writing examined as way to help convicted," 2013). Moreover, Gladue reports are not granted to every Indigenous client coming through the justice system but are instead available upon request (Native Women's Association, 2015) if such resources are available when needed.

\footnotetext{
${ }^{20}$ This is not to suggest that Gladue principles and reports are bad, but that they cannot decolonize the Canadian justice system all on their own.
} 


\section{Drug Courts}

Drug treatment courts, or simply drug courts, are perhaps the best-known type of specialized court. Drug courts are not trial or sentencing courts, but instead are community specialized, targeted drug rehabilitation programming that includes a regular court component, used in place of a traditional prison sentence (The Canadian Association of Drug Treatment Court Professionals, 2019). Drug treatment courts are designed for long-term offenders whose criminal behaviour is rooted in their substance dependency. Together, provincial courts and drug court program staff evaluate eligible participants, with the court offering the final admission decision (Moore, 2007b). Participants are subjected to regular, scheduled drug testing (urinalysis), as well as random drug testing, and therapy and counselling services, employment and educational supports, housing supports, substance use treatment, and any other required programming needed on an individual basis (e.g., anger management programming). The first drug treatment court in Canada, the Toronto Drug Treatment Court, opened in 1998 (Department of Justice Canada, 2021). Since that time, more than twenty drug courts have opened across Canada ${ }^{21}$, many utilizing program structure and eligibility criteria developed for the Toronto Drug Treatment Court.

Drug treatment courts service clients addicted to illegal drugs or legal prescription drugs used illegally. Notably, drug treatment courts do not service clients dealing with alcohol use disorder or cannabis use disorder (Moore, 2007a), presumably owing to the lack of available resources and the corresponding requirement to triage client needs. Drug treatment courts receive funding from provincial and federal governments, though many also utilize private funding acquired through donations (Edmonton John Howard Society, 2021). Clients must be referred to the

\footnotetext{
${ }^{21}$ Though not all remain open.
} 
program through a lawyer and do not have the ability to self-refer (Moore, 2011). To be accepted into the program, clients are first required to enter a guilty plea. While in the drug treatment court, clients are supervised by a bail officer or probation officer ${ }^{22}$. To successfully complete the program, the client must complete all programming assigned by the program and court staff, abstain from drugs and alcohol, and attend weekly court to provide updates on their progress. Note that drug treatment courts are extremely intensive and are not a "soft" approach. In fact, participants are not able to be employed while in the program ${ }^{23}$, as participation in program activities is comparable to a full-time job at least. In the event the client does not complete the program, the client will be sent to traditional corrections to finish their sentence in custody, credited for the time completed in the program (Bouffard \& Taxman, 2004).

Drug treatment courts, like other community alternatives to incarceration, cost substantially less than incarceration. At the time, when I worked at a drug court, it cost approximately $\$ 10,000$ for one participant to be enrolled in the program for one year - according to my supervisor while we were in the process of fundraising. However, this figure does not include all the therapeutic services provided through provincial health services, which certainly increases the cost. When compared to incarceration (Jamil, 2020), drug treatment courts still operate at a fraction of the cost. Drug treatment courts also substantially outperform incarceration in recidivism rates of clients. Though there is limited data on the effectiveness of drug treatment courts in Canada, the available data provided by the Association of Drug Treatment Court Professions indicates a recidivism reduction of "up to 75\%" (2019), whereas there is a recidivism rate of approximately 43.6\% for federally incarcerated individuals (L. A. Stewart, 2019). However, a report by The

\footnotetext{
${ }^{22}$ Note that often the role of bail officer and probation officer are the same position, though this varies by location.

${ }^{23}$ Except when a client is very near completion of the programming.
} 
Canadian Centre on Substance Abuse (CCSA) states, "To date, four "meta-analyses" have been conducted on DTCs operating in the U.S. All four studies found reductions in recidivism ranging from 7.5\% to 26\%" (The Canadian Centre on Substance Abuse, 2019), indicating substantially different conclusions than the ADTCP. Finally, a report by the Department of Justice of Canada notes that they are unsure of the reduction of recidivism, largely owing to a lack of adequate record-keeping by individual DTCs (Evaluation Division, 2009). Even for those who do not complete the program, there is still evidence they experience more quality of life improvements, such as housing, substance treatment, and connection to positive community and social supports (Department of Justice Canada, 2021).

Drug treatment courts thus offer a compelling alternative to incarceration, particularly when considering that approximately $70 \%$ of incarcerated individuals' offences are related to problematic substance use, though available data suggests it could be as high as $93 \%$, with particularly high prevalence rates in women and Indigenous persons (Weekes, Thomas, \& Graves, 2019). Further, when a comparison was made between one drug court's participants and court-involved clients of a residential treatment program, $100 \%$ of the drug court participants were abstinent at follow-up compared to only $64 \%$ of those who had received addiction treatment, without the other supports and supervision of DTC (The Canadian Association of Drug Treatment Court Professionals, 2019). However, it must be acknowledged that DTCs are still coercive (The Canadian Centre on Substance Abuse, 2019), and are not restorative or transformative. DTCs also do not provide a harm-reduction model and offer little space for personalization to the needs of the clients. These factors highlight the colonial and oppressive nature of the settler criminal justice system. They are certainly preferable to incarceration but are far from ideal. 


\section{Mental Health Courts}

Mental health courts function similarly to drug treatment courts, primarily differing in the demographics they serve (Government of Ontario, 2006). Diagnosed mental health disorders are between four to seven times more prevalent in prison populations than in the general Canadian public (Centre for Addiction and Mental Health, 2021), indicating that it is likely that criminalization could be reduced with mental health intervention (Redlich, Hoover, Summers, \& Steadman, 2010). Mental health courts are funded by provincial and federal governments and utilize provincial health services in their programming.

Mental health courts address mental health challenges experienced by those in the justice system, particularly understanding mental health challenges as being root causes of crime (Human Services and Justice Coordinating Committee, 2017). As in drug treatment courts, clients engage in targeted individual and group therapy and treatment, regular court appearances (though can be more variable in frequency than drug treatment courts), addictions therapy, and designated programming assigned by the courts and staff (Tyuse \& Linhorst, 2005). The recidivism rates for graduates of mental health courts are favourable, though it is challenging to measure. Like drug treatment courts, recidivism rates are lower for graduates than for those who go through the traditional correctional stream (Lim \& Day, 2014), and non-graduates still experience some degree of quality of life improvements (Schneider, Bloom, \& Heerema, 2007). As is the case with DTCs, mental health courts remain fixtures of the colonial criminal justice system and remain far from the ideal.

\section{Other Specialized Courts}

As further research is completed around incarceration, rehabilitation, healing, root causes of crime, and recidivism, the need to explore alternatives to punishment has become apparent to 
many. "Problem-courts," or courts that target a specific ailment, demographic, or need, are growing in popularity (Berman \& Feinblatt, 2001). Examples of problem-courts include Family Violence Courts and Domestic Violence Courts. It is not possible to evaluate the success of such programs, given the lack of uniformity in intensity, resources, and program delivery. However, if the court programs are delivered with the needs of the client in mind and tailor their approach to those needs, and participants it is likely that these programs will have benefits to participants and reduce recidivism.

\section{Indigenous Admissions into Specialized Courts}

There is a relative scarcity of data surrounding specialized courts in Canada (Department of Justice Canada, 2015; The Canadian Centre on Substance Abuse, 2019). I speculate that this is primarily owing to the lack of resources to engage in quality data collection, program evaluation, or analysis of outcomes. The Canadian Association of Drug Treatment Court Professionals hosts only seven research documents on their website, the most recent at the time of writing this thesis being seven years old, with the publication year of 2014 (The Canadian Association of Drug Treatment Court Professionals, 2019). Mental health courts and other specialized courts appear to lack a centralized website or professional association.

The available data, as well as a few gracious email replies to my queries, suggests limited Indigenous enrolment in drug courts. An independent study found Indigenous persons represented only $45.3 \%$ of the participants from 2006-2014 at the Winnipeg Drug Treatment Court (Michael; Weinrath et al., 2018), despite accounting for $69.7 \%$ of the incarcerated population. Notably, the evaluation found that the greatest exclusionary factors for Indigenous applicants were the higher risk assessments awarded to Indigenous participants. However, this study does not explore the factors that exclude Indigenous persons from engaging in the 
application process before it occurs, which is also an important area to consider and is explored later in this thesis. Where possible, participants are diverted to Indigenous courts (or similar programs under a different title), but such courts are uncommon, particularly in rural or remote areas.

\section{Policy Critiques and Limitations of Specialized Courts}

When clients enter into a specialized court program, they are doing so as an alternative to a traditional sentence (Moore, 2007b). Often, participation in such a court requires a guilty plea from the client and includes the stipulation that the client complete a traditional sentence in the event they fail out of the specialized court (The Canadian Association of Drug Treatment Court Professionals, 2019).

The admission criteria to specialized courts are extremely exclusionary. In drug treatment courts, for example, the purpose is to treat substance use disorders as a root cause of crime (Department of Justice Canada, 2021). Despite the acknowledgement of the substantial role of substance dependency in crime and that approximately $50 \%$ of federally incarcerated persons identify as having a problem with alcohol (Weekes et al., 2019), clients suffering from alcohol use disorder are not considered for the program, which is indicated in program eligibility criteria. Not including alcohol as a valid substance use disorder is particularly exclusive of Indigenous clients, who experience higher rates of alcoholism than non-Indigenous persons (Levesque \& QuesnelVallee, 2019; S. H. Stewart et al., 2011). However, I can personally attest that we sometimes were able to bypass this rule if the client had a secondary addiction that fell in the admissions criteria, though we had to present it as the primary addiction of the client. Additionally, clients were required to abstain from many substances, like alcohol, even if they were not suffering from alcohol dependency. 
Though the remainder of this thesis is aimed at examining policy failures, particularly as it relates to admissions, I must acknowledge that criteria that exclude potential participants from specialized courts are also particularly restrictive, especially to Indigenous clients. Clients cannot participate with any previous violent criminal convictions, domestic violence convictions, trafficking drugs for commercial gain, or gang affiliation (Edmonton John Howard Society, 2021; Moore, 2007b; Jaclyn; Tompalski, 2021). Given the over-policing of Indigenous peoples (Canadian Broadcasting Corporation, 2017; Kiedrowski, 2013) and their corresponding overrepresentation as perpetrators of crime (Greg, Brianna, \& Amelia, 2020), as well as increased risk for being criminalized as a result of colonialism (April \& Orsi, 2013), it is clear that the Indigenous centred-policy has not been developed for drug treatment or mental health courts. Finally, as a perceived risk to the community is an evaluation criterion for admission, racism and bias against Indigenous persons cannot be ignored. Indigenous persons are already perceived as being deviant, dangerous, and criminal (Cannon \& Sunseri, 2018; Chakma \& Jensen, 2001; Eve; Tuck, 2009; Vowel, 2016b), so it is likely such biases negatively impact the admission process to specialized programs (Benoit et al., 2019).

When a client actually manages to get into the program, to maintain their coveted position in the specialized court, they are also required to adhere to all program requirements, lest their probation officer (or other designated state legal supervisor) alert the court and have them returned to custody (Lindquist, Krebs, \& Lattimore, 2006). Such provisions are included in the courts' policy to ensure the community is safe, to ensure the client is participating appropriately, and to rehabilitate the client (Moore, 2007b). On the surface, this appears to be a strong idea, but in implementation it presents additional challenges. For example, drug treatment courts require the clients to practice abstinence-based recovery (The Canadian Association of Drug Treatment 
Court Professionals, 2019). Such a policy decision is likely in place to ensure the clients are actually accountable in their recovery but fails to acknowledge that relapses are a very common event in the recovery process ${ }^{24}$ (Addiction Center, 2021). Moreover, abstinence is not recommended by many doctors and public health officials specializing in addictions medicine (Oesterle, Thusius, Rummans, \& Gold, 2019). In the case of an opioid use disorder, for example, medication-assisted treatment is considered a much more viable strategy for long-term recovery and rehabilitation (Nourjah \& Kato, 2021). In such a case, clients in certain programs would be removed from the program for following the recommended court of treatment ${ }^{25}$ (Moore, 2011). Additionally, medically prescribed substances deemed inappropriate by the court must be stopped by the client before participation, or else they are not eligible for the specialized court. I witnessed this while working in such a court, where a client was not permitted to continue to use medically prescribed cannabis. Let me make my meaning plain here: the client had to stop their prescription medicine or be sent to prison. Note that decision is not made by a physician but by provincial court authorities and program staff.

Finally, specialized courts - like prisons - have those whom they do not adequately serve. However, for those fortunate enough to be accepted into a drug treatment court, the graduation rates remain less inspiring. A 2014 evaluation of six drug treatment courts in Canada found the graduation rates to be a mere 27\% (Department of Justice Canada, 2015). Shockingly, the Winnipeg Drug Treatment Court averaged a mere 31-33\% graduation rate from 2012-2015,

\footnotetext{
${ }^{24}$ Note that while this is the official policy, service providers and drug court managers have identified over email that they prefer to take a trauma-informed approach wherever possible, including not revoking the clients bail for substance use when possible (Jaclyn Tompalski, 2021b).

${ }^{25}$ Note that some courts have adapted their policies to allow for certain medication-assisted treatment approaches, though many have not. Additionally, some may only be approved to have clients on specific medications. Given that the medications in question are evolving rapidly in the face of the opioid crisis (Nourjah \& Kato, 2021), it is possible that policies are out of date from the best medical treatments.
} 
meaning that over two-thirds of participants were dismissed/did not graduate (Michael Weinrath \& Smee, 2016). Concerningly, the Department of Justice report noted, "A higher proportion of Caucasians graduated (32\%) compared to Métis (25\%) or other visible minorities (24\%). Aboriginal participants had the lowest graduation rate at $15 \%$. These results may indicate that programming could better address cultural differences or that the Aboriginal cohort has higher needs that go beyond the scope of the court." The policy failures illustrated above are possible examples of why a client does not successfully complete the program, but that still leaves nongraduates. Those who do not graduate from specialized court programs will then go to prison, typically credited for time served for the time they were enrolled and participating in the specialized court (The Canadian Association of Drug Treatment Court Professionals, 2019). For those who do not graduate from the specialized courts, their recidivism rates - while comparable - are marginally lower than those who never attended specialized courts (Ray, Hood, \& Canada, 2015). Such information emphasizes the importance of the successful completion of the specialized court program.

\section{Organization-Specific Specialized Programs}

It is also worth noting that many organizations (not-for-profit or community mutual aid) offer their own programs. Often, these programs function in one of two ways. First, they offer highly specialized services to a specific demographic with specialized needs. As it is not possible to provide summaries of all such programs, the following example can highlight targeting programming to the needs of the clients within the context of the community. Onashowewin Justice Circle centres their justice approach in Ojibway cultures and knowledge by providing a restorative justice model for their Indigenous populations run by Indigenous community members (Onashowewin Justice Circle, 2020). Such an approach targets the Indigenous 
population within the area and provides culturally appropriate and relevant programming to support their community members. Though these programs typically function as extra-judicial, some programs function through the conventional (and therefore colonial) criminal justice system.

Alternatively, the program is offered in a location (often rural or remote) where the program has broad service offerings, occasionally with the opportunities to offer personalized support to individual clients based on their needs. Generally, these services do their best with the resources available to them but lack the resources to provide targeted or specialized programming (Higginbottom et al., 2016; Levasseur et al., 2015; Ricciardelli, Adorjan, \& Spencer, 2020). For example, a more remote community might have the resources to support a client through detox but is unable to offer long-term programming in addictions support or sobriety maintenance.

\section{Indigenous Courts and Gladue Courts}

Indigenous Courts, Gladue Courts, Aboriginal Courts, or other courts with similar names and objectives focus on supporting Indigenous peoples specifically through their programming (Chronicle-Herald, 2017). Like other specialized courts, they are sentencing courts with built-in programming, not trial courts (Provincial Court of British Columbia, 2020a). It should be noted that, while these courts are growing in prominence, they remain relatively sparse in the Canadian criminal justice system. Their objectives are to promote culturally relevant healing, developing connections to the community, rehabilitate their clients, and reduce recidivism (Maurutto \& Hannah-Moffat, 2016). Unlike other justice pathways, Indigenous Courts are developed with First Nations communities, include Indigenous ceremony and healing practices in their standard program delivery, and Indigenous community members, Elders, court workers, clients, other program delivery staff, and sometimes victims are involved in the process (Therien, 2012). What 
differentiates such programs from other specialized courts is their focus on colonialism and trauma as contributing factors to the unique needs and criminalization of Indigenous peoples (Cunliffe, 2018), as well as much higher representation of Indigenous service providers to work with clients.

Certainly, these court programs deliver on many points identified as being important to serve Indigenous peoples in the justice system better as identified by Gladue Reports and the 94 Calls to Action (April \& Orsi, 2013; Truth and Reconciliation Commission of Canada, 2015b).

However, as they remain affiliated with (and therefore beholden) to the state, such courts do not allow for Indigenous self-governance surrounding criminal justice, nor do these programs allow for complete steering by Indigenous communities.

\section{Indigenous-Centred Specialized Programs}

As is the case with specialized courts, it is possible for Indigenous-centred programs to offer supports to clients who are involved with the criminal justice system - it should be noted that these programs function within the colonial criminal justice system. Claims that these are decolonizing programs are false under this premise. Recruiting for this study opened my eyes to a variety of smaller, Indigenous-centred organizations that existed to support Indigenous persons involved in the criminal justice system, with supports ranging from employment, addictions services, housing, trauma and healing, and cultural reconnection and development. Having spent enough time around the criminal justice system as a worker, academic, and activist admittedly left me bitter and discouraged, but opening my eyes to these lesser-known programs was inspiring. These programs can identify through their staff, communities, and clients where their priorities and efforts should be directed. 
Indigenous-centred programs have the advantage of being criminal justice system adjacent, meaning they are less bound to the strict bureaucracy of operating as an institution of the state. Additionally, these programs are excellent examples of Indigenous resiliency and selfgovernance and demonstrate the success that is possible when Indigenous peoples are permitted to handle matters in ways that are important to them. Unfortunately, such freedoms also come with the consequence of not having resources guaranteed for their programs, often leaving these organizations under-resourced, reliant on volunteer labour and private donations, and constantly competing for grants.

\section{Current Scholarship}

As it relates to works whose purpose is to examine specialized courts in Canada and the admission and success of Indigenous participants, I have been able to find exactly one article. Michael Weinrath and colleagues have produced several works on the topics of drug treatment courts, with "Accessing drug treatment courts do age, race or gender matter?" being of particular relevance to this thesis. Their study only uses the Manitoba Drug Treatment Court over an eightyear period but examines referrals and successful admission to the program (Weinrath et al., 2018). Notably, Indigenous clients, particularly Indigenous males, had lower success in being admitted to drug treatment courts because they were evaluated as being too high of a risk for the program, specifically as a result of increased gang connections and violent offences.

Interestingly, the authors ultimately recommend the need for a higher degree of interventions for Indigenous clients to combat their under-representation in drug treatment courts.

Given the limited research on Indigenous Peoples' access to specialized courts, further research is required. Certainly, this thesis contributes to the research, as well as generally to the important policy considerations regarding Indigenous persons and the criminal justice system. However, it 
would be ideal if a variation of my thesis research was produced with access to drug court statistics. To supplement the lack of existing data, relevant studies surrounding criminalization of Indigenous peoples and related policy observed in the literature was examined.

\section{Conclusion}

Given the substantial array of available alternatives to incarceration, it is shocking to me that these options are not better utilized by the settler state. The likely explanation for their lack of substantive prevalence in the Canadian justice system - apart from the fact that the Canadian system is a colonial system - is a simple one: lack of funds. Often, alternative programs like those described in this chapter are delivered either partially or entirely by community-based, notfor-profit organizations that are reliant on grants and government funds to offer their services. While specialized courts often operate in tandem through the provincial court system and notfor-profit organizations, they too are subject to chronic underfunding. As identified by all service providers interviewed for this study, not-for-profit programs that serve marginalized peoples or persons living in precarious situations are underfunded. Even those programs operated in part by the state experience financial challenges. For example, approximately $50 \%$ of the participants going through the Edmonton Drug Treatment court do so because of private funding from a law firm (Edmonton John Howard Society, 2021; Jaclyn; Tompalski, 2021), meaning that an individual law firm is contributing in a comparable way to the provincial and federal governments $^{26}$.

It is my hope that the growing body of work highlighting the importance of alternatives to incarceration, including this thesis, will contribute to increased funding for such programs. Over

\footnotetext{
${ }^{26}$ In the case of the Edmonton Drug Treatment Court
} 
the course of producing this thesis, public consciousness across Canada and the United States has increasingly focused on calling for defunding the police (Neustaeter, 2021). The murder of George Floyd by police officers through unnecessary and cruel use of force during an arrest prompted global outrage (MSNBC, 2021), widespread protests for justice reform or abolition, particularly for racialized peoples, and the defunding of police (Balsamo, 2020). Given the unprecedented public support of defunding the police, the time is right for such funds to be relocated to programs the prevent crime, promote racial justice and equality, and support those impacted by the system with their healing.

Alternatives to the incarceration of Indigenous peoples have never been more important. Despite promising intentions through Gladue Reports, Indigeneity has not meaningfully been addressed and supported in the criminal justice system (Welsh \& Ogloff, 2008). As proportionality in custody continues to grow (Jamil, 2020), we have demonstrated that the colonial justice system is not meeting our needs. The benefits of alternatives to incarceration are substantial, including improved recidivism rates, reduced traumatization, personalization, autonomy, and reduced cost (The Canadian Association of Drug Treatment Court Professionals, 2019; Truth and Reconciliation Commission of Canada, 2012). To begin supporting Indigenous peoples through healing and to promote genuine reconciliation ${ }^{27}$, such alternatives are an essential first step.

\footnotetext{
${ }^{27}$ Note that Justice section of the 94 Calls to Action highlights return to community and healing approaches as essential for reconciliation (Truth and Reconciliation Commission of Canada, 2015b).
} 


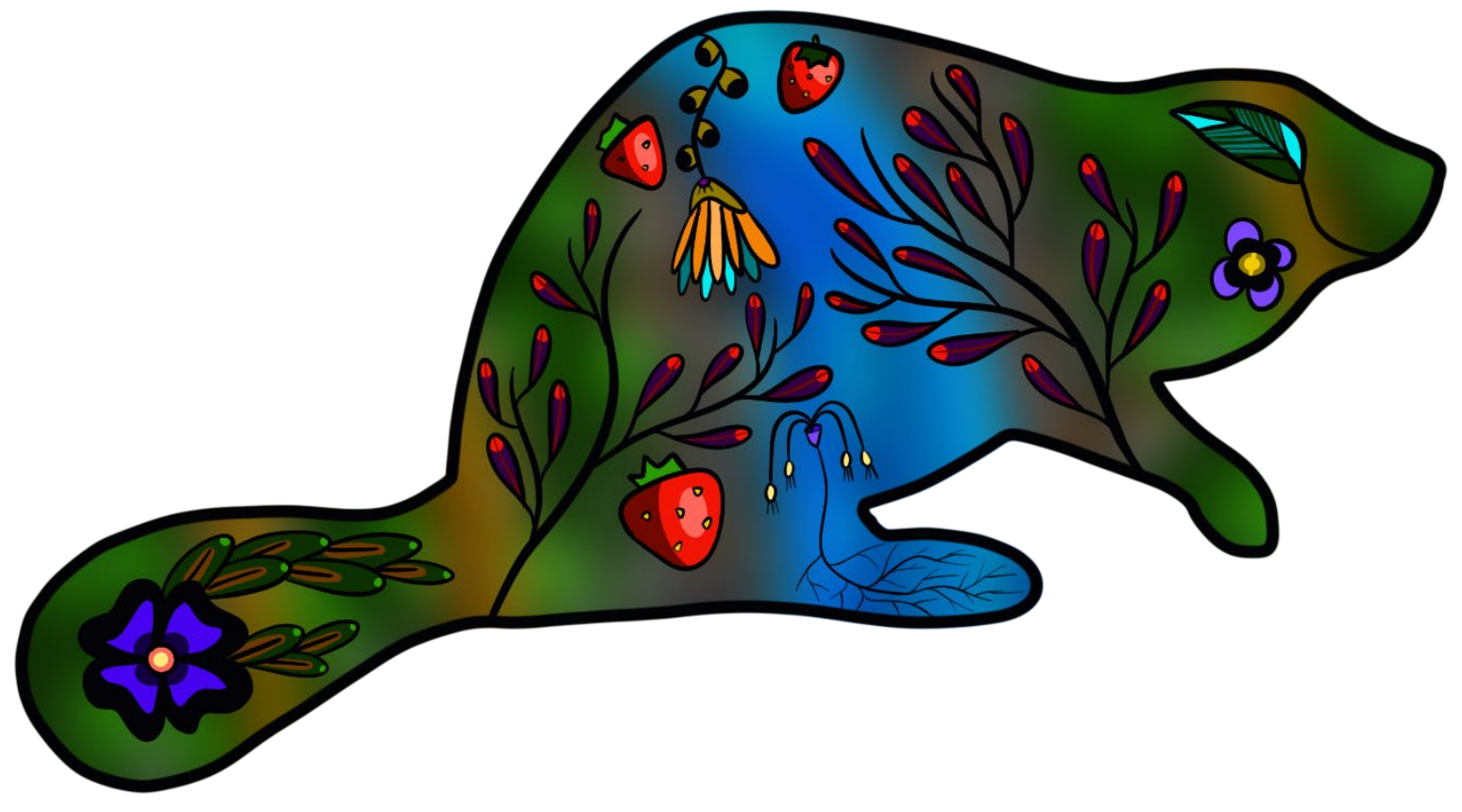




\section{Chapter 4: Theoretical Framework}

"To be in the margin is to be part of the whole but outside the main body." - Bell Hooks

\section{Introduction}

I never considered myself someone to be particularly into theory in the traditional western sense.

I dreaded the theoretical components of graduate studies and undertook them despite theory

requirements. I always viewed including theory in my work as making it harder to produce,

making my work harder to understand (projecting my own challenges in reading theory), and

less accessible to a broader audience. While I acknowledge that there are few people likely to

want to read an entire Master's thesis for a variety of reasons, I certainly never want a reason to

be that I have written it in such a way that is hard to read and difficult to understand.

Imagine my delight early on in my graduate studies in discovering that social theory, or

academic literature in general, is not only the jargon-heavy writings of privileged, non-

Indigenous, men from several decades ago (Todd, 2016). As the wise Dr. Kelly Fritsch ${ }^{28}$

demonstrated in my very first assigned reading of graduate studies, social theory can be anything

that observes a social process (Lemert, 2013). After this illuminating introduction to social

theory in a way that didn't leave me feeling like an $\operatorname{idiot}^{29}$, I found that there was a whole world

of theory that was accessible to me. I proceeded to explore scholars of colour and their

theoretical works, where I realized my challenges within academia are an extremely common

experience among other precarious scholars (hooks, 2015). Around that time, I also realized that

\footnotetext{
${ }^{28}$ I acknowledge Dr. Fritsch here because I believe people that are impactful to our journeys should be openly acknowledged, celebrated, and thanked. Thank you, Kelly, for helping me realize that I did have the ability to understand social theory, I just hadn't met the right teacher yet.

${ }^{29}$ Please note that the inability to understand a document does not make someone an idiot. I used this choice of wording because I so regularly returned home from school with the thought that I was an idiot because I struggled so much with foundation theory pieces.
} 
just because something was inaccessible to me did not mean that there was something wrong with me, but instead a limitation of whatever text was in quest. Ultimately, I concluded that my original exposures to theory - foundational authors like Marx and Foucault - were not accessible to me because they were (presumably) not written with someone like me as a reader in mind. Being a woman, queer, and neurodivergent gave me different needs as a reader. In realizing this, I noted the benefit of producing works that I believe are generally as assessable and relevant as possible.

Therefore, to develop a theoretical framework, it must draw on the work of Indigenous scholars. Often Indigenous topics and issues are studied by non-Indigenous scholars using a theory that is derived from (and ultimately supports) colonialism (Luker, 2017). Not only did I want to utilize the knowledges from Indigenous scholars, but I wanted to utilize works that are actively and deliberately contributing to Indigenization and inclusion. Correspondingly, I have chosen to use the four Indigenous scholars I find myself constantly returning to when thinking about issues surrounding Indigenous peoples and how we fit into academia: Dr. Vanessa Watts, Dr. Leanne Simpson, Dr. Eve Tuck, Jesse Thistle ${ }^{30}$. From their works, I have established the following key elements to guide my work: 1) place and being; 2) the processes of engagement surrounding Indigenous-focused works; 3) engagement of the studied Indigenous persons in the process; 4) desire-based research surrounding Indigenous peoples; and 5) Indigenous identity as a form of healing from colonial trauma. These five pillars centre Indigenous perspectives, processes, and identity in a way that I believe supports Indigenous peoples through or adjacent to the criminal

\footnotetext{
${ }^{30}$ Jesse Thistle is a Ph.D. candidate at the time of this thesis writing. However, it is likely he will be awarded his doctorate soon after the publication of this thesis (Thistle, 2021). I would like to acknowledge Thistle's incredible academic achievements, both past and soon-to-come, in celebration of Indigenous excellence. I celebrate all Indigenous authors I cite and their accomplishments, particularly those used to develop this theoretical framework, but make special note of Thistle as he does not yet have the prefix of Dr. recognizing his excellence within the academy.
} 
justice system in an Indigenous-centred way, as well for Indigenous and non-Indigenous readers alike when examining complex problems facing Indigenous peoples.

Finally, as will soon be very clear, I have tried to include some of the personhood of each of these scholars, not just brief summaries of their academic works, in the information I provide about them regarding the development of my theoretical framework. In a long-forgotten Twitter post by an author whose identity I forget, she stated that she came to view her citations in her publications as a form of love letters to the scholars that paved the way for her. I feel such acknowledgement is appropriate here, particularly given the importance of these scholars to my personal journey and the development of this study. Additionally, it is their personhood and Indigeneity, not their impressive academic achievements, rooting the knowledges they have all produced.

\section{Pillar 1 - Vanessa Watts}

Watts' work is influenced by both her Mohawk (Bear Clan, Six Nations) and Anishinaabe identity and personal experiences (First Peoples Group, 2020). At the time this thesis is published, Watts is the only scholar whose works I used to develop this framework that I have met in person. After I was eagerly waiting for a crowd of people to finish chatting with her following her presentation, she encouraged me to physically return to my community to figure out how I wanted to exist and present myself in academic spaces (Watts, 2019). By returning to where I am from, I could carry the knowledge and wisdom of my community and ancestors with me forward, both with my academic pursuits as well as through my life in general.

With that personal story, it is perhaps unsurprising which information I drew from Watts to develop my theoretical framework. To develop Pillar 1, I focus on her concepts of place and being. She explains that there is a deep and meaningful connection between Indigenous peoples 
and communities and the land, as well as the non-human beings that share the land (Watts, 2013). Non-human beings include the land and water animals of the area, as well as the flora, earth, and trees. Watts identities that residential schools are heinous not only for the crimes committed against those forced to attend but for the fact that they severed the connection between Indigenous peoples and the land. The removal or corruption of the land hurts our societies, as does the removal of those Indigenous peoples from their lands.

For the same reasons, particularly in the context of the framework for this thesis, prisons are inherently violent and colonial. If we are to value our relationships between ourselves, the nonhuman beings of our society, and the land we are from, placing an Indigenous person in custody to "heal" or "be rehabilitated" cannot occur because a fundamental and integral bond has been disconnected. Further, all those from the removed individual's community, both human and nonhuman alike, have lost a piece of themselves and their community. The forced assimilation of our peoples through prisons is not merely by trying to "rehabilitate" an Indigenous person through incarcerating them but by removing key actors in Indigenous societies by forcing them into prisons. In understanding our connections to the land and communities, it is possible to understand how incredibly violent and disruptive taking an individual from their community really is.

As will be discussed in further chapters, specialized courts and alternative community corrections streams are more in line ${ }^{31}$ with Indigenous concepts surrounding place and being

\footnotetext{
${ }^{31}$ Note, however, that while these specialized courts are closer to an Indigenous justice model, they remain far from any true Indigenous justice model. So long as the colonial state has authority over Indigenous justice matters, decolonization is not occurring. I produce this knowledge in acknowledgement of such. It is my hope that moving in the right direction and reducing harms through reforms can mitigate the colonial violence facing Indigenous persons in the criminal justice system. The absolute ideal - and only true decolonizing way - is to abolish the state authority over Indigenous justice matters.
} 
given that Indigenous clients need not be removed from their homes (permitting that the program is in proximity to their community) and can engage in the healing and rehabilitation without the severing of the connection to their land. More so, the community itself is better protected and preserved because it has not lost a piece of its society. As is often emphasized as important in the rehabilitation and healing process, a strong connection to community is optimal for best results (Black, Frederico, \& Bamblett, 2019).

\section{Pillars 2 - Leanne Betasamosake Simpson}

Leanne Betasamosake Simpson is a Michi Saagiig Nishnaabeg member of Alderville First Nation (Simpson, 2020). Her scholarly contributions are extensive, spanning topics of decolonization, Nishnaabeg thought, political resistance and resurgence of Indigenous peoples, process and methodologies, and Indigenous engagement and empowerment (Dorries \& Ruddick, 2018). I believe that Simpson's works are a fantastic example of a substantial and sophisticated academic career rooted in collaboration, creativity, resilience, and decolonization.

Simpson has produced several important works, but for the purposes of this framework, I want to highlight the emphasis she puts on the process (L. Simpson, 2017), not merely the end result. The end result is not sufficient, for the process by which we get there must also align with Indigenous knowledges and values. In her text "As we have always done : Indigenous freedom through radical resistance," Simpson recounts stories and experiences that shaped her approach to research and how she engages with Indigenous communities. Specifically, a section that has always stuck with me is where she describes the increased understanding of knowledges (which later produce actions) that came with Indigenizing or decolonizing her approach - moving away from colonial norms in the research process. By resigning one's self as not being an expert and not pretending to be one, by valuing the approaches of those you are working with (particularly 
Elders), and by being willing to ask and listen to their thoughts on the process, knowledge, respect, and understanding increased exponentially. Simpson explores the importance of the process involved in Indigenous-focused research, community development, and providing resources for a community.

Additionally, of particular relevance from these ideas is the emphasis on mistakes, evolution, and honouring those mistakes. "Mistakes produce knowledge. Failure produces knowledge because engagement in the process changes the actors embedded in process and aligns bodies with the implicate order (L. B. Simpson, 2017a)." As was the case with the original friendship treaties (Vowel, 2016c), processes must be constantly improved upon and revaluated to ensure the needs of those they support are met (Facing History and Ourselves, 2015a).

The following two scenarios highlight the importance of process:

One, an individual is incarcerated for drug crimes and upon release attempts to avoid
engaging in criminal behaviours as a result of fearing future trauma from the justice system,
and two, an individual is engaged in the criminal justice system but is diverted to a program
(e.g. a drug treatment court) that addresses the root causes of their crimes, leaving them with
the skills to reduce the likelihood of reoffending.

In both cases, the individual is taking steps to avoid reoffending, but only in the latter scenario is healing truly promoted. Simpson highlights the need to evaluate the way we are doing things constantly. Do methods meet the needs of the populations they are for? Does the approach have a framework for evaluation and improvement? Who is involved in the process, and are all actors represented? For these reasons, the deliberate, decolonizing (or at least Indigenizing) processes of engagement must be observed. For the purposes of this study, the process of incarceration vs specialized court or community program are examined, as well as the process of applying to such 
programs in later chapters. Finally, I must also embody this praxis with my research. For example, when I realized the research was shifting away from my original plans, I updated my project to serve my research participants instead of picking and choosing elements from them that fit with my narrative.

\section{Pillar 3 and 4 - Eve Tuck}

\section{$\underline{\text { Pillar } 3}$}

Tuck is a Unangax scholar and a member of the Aleut Community (Tuck, 2020). To me, the most significant element to Tuck's work is her emphasis on centring Indigenous people in work done about them. She has written not only about including the studied Indigenous peoples/communities in the research process (Tuck, 2015) but also the way we as researchers present Indigenous people (Eve Tuck, 2009). Including a variety of Indigenous thoughts in every phase of the research process is important to keep it representative of the population it studies.

By this logic, it is reasonable to examine the degree of Indigenous engagement in every phase of the process of applying to and participating in a correctional program. For this study, Indigenous engagement will be examined from service providers in (or adjacent to) the criminal justice system, as well as the engagement of the formerly incarcerated Indigenous persons. The importance of programming, courts, the criminal justice system in general, and policy being Indigenous-centred is derived from this pillar. How can anything meet the needs of a people without including that people? To embody my praxis here, I have made an effort to include as many Indigenous voices in this project as possible, as consultants, readers, committee members, inspiration, cited authors, as well as the teaching, learned from Elders. I certainly value my own voice and contributions, but I value applying our communal traditions and ways of existence to this project as well. 
As was wisely pointed out to me by Dr. Stirrett, Tuck (and Simpson in the previous section) has not demonstrated support of reform works over abolition and decolonizing works. The use of her works in relation to improving the state is fundamentally contradictory to her aims (as well as my own). First and foremost, I feel the greatest kinship with abolitionist ideals towards criminal justice - decolonizing from the state and returning to Indigenous self-governance. So why include Simpson and Tuck then? As is evidenced later in this thesis, abolition becomes foundational in my recommendations. I treat reforms of specialized courts' policy as a means of reducing the harms of the colonial criminal justice system until such a time abolition can occur.

\section{Eve Tuck - Pillar 4}

Further building on Tuck's work, this study is explored through a "desire-based" lens, specifically focusing on Indigenous strengths and resilience. Tuck presents this lens to "defy the lure to serve as "advertisements for power" by documenting not only the painful elements of social realities but also the wisdom and hope," and further explores the need for such an approach, "I submit that a desire-based framework is an antidote to damage-centred research. An antidote stops and counteracts the effects of a poison, and the poison I am referring to here is not the supposed damage of Native communities, urban communities, or other disenfranchised communities but the frameworks that position these communities as damaged," (Tuck, 2009). In what I believe to be an iconic piece of modern writing and social thought titled Suspending Damage: A Letter to Communities, Tuck highlights the all-too-common approach of nonIndigenous (usually White) researchers producing works that paint Indigenous peoples as damaged or broken (2009) - a "damage-centred" approach. Non-Indigenous researchers often highlight the negative aspects of Indigenous Peoples' realities rather than the colonial forces that produced these negatives outcomes. Unfortunately, doing so has had terrible consequences 
regarding the academic, public, and general understanding of Indigenous peoples - at least for those whose only exposure to Indigenous peoples or realities is through these means. As mentioned in Pillar 3, having Indigenous stories, experiences, and knowledges shared by nonIndigenous researchers - often without even the knowledge or consent of the Indigenous peoples in question - has led to misrepresentations of Indigenous peoples. In equal severity, nonIndigenous researchers have created a narrative about Indigenous peoples that is incredibly negative, sometimes even hopeless seeming, while also being incredibly dehumanizing. First, this implies that Indigenous peoples are not capable of solving their own problems, as they have not yet published on them academically, and that only the benevolent researcher (again, often White) can save Indigenous peoples from their terrible reality. Second, the academic 'topic' of Indigenous peoples has become poisoned. When most works surrounding Indigenous peoples represent them as broken, damaged, and in need of help, or as Tuck calls it: 'damage-centred,' it can corrupt the general perception of Indigenous peoples (Eve; Tuck, 2009).

In contrast to the "damage-centred" approach that many non-Indigenous researchers have used, Tuck also discusses the tremendous accomplishments, sophistication, and resilience of Indigenous peoples in general, particularly in the face of colonialism. Given such incredible feats, Tuck suggests that research undertaken for or about Indigenous peoples must be 'desirebased,' meaning that it is centred on Indigenous resilience, empowerment, and celebration(Eve; Tuck, 2009).

The inclusion of Pillar 4 was as much in place for me as the researcher as for you, the reader. As the researcher, utilizing a desire-based approach was at the forefront of every stage of this project. From conception, I had to ensure that this study was rooted in uplifting, supporting, and amplifying the excellent voices and practices of Indigenous communities. The desire-based 
approach had to extend from my development, through interviews and analysis, and finally into my writing. In the text box below is a brief example within my own life and career that highlights the importance of the desire-based approach.

Throughout my Master's degree, I have been awarded the opportunity to act as a teaching assistant. In one of my classes, I arranged to have speakers attend to share with my students the realities of incarceration. Specifically, these speakers were all mothers to formerly or currently incarcerated persons. The women who spoke were seasoned in telling their stories - that remains one of their tools in activism for penal reform or abolition. They came prepared to talk about how terrible prison is. Their logic is that if they expose the horrors of incarceration and its impacts on individuals and families, perhaps people without direct contact with the prison system would be moved enough by this information to support penal reform or abolition. However, following their presentation, I asked the mothers if they also wanted to use their time to share their child's strengths and positive traits. The mothers became emotional and highly grateful for the opportunity to do so. Without that opportunity, my students would still have learned. However, the opportunity created a space with more love, understand, and respect for one and another.

Processes can change an experience from good to great or from bad to terrible. Even when the intended outcome is achieved, it is important to examine how the process can produce unintended outcomes.

\section{Pillar 5 - Jesse Thistle}

While Thistle, who is Métis-Cree from Prince-Albert, Saskatchewan (Thistle, 2020), has produced excellent scholarly works, his piece that I have always been most drawn to is the nonfiction book From the Ashes: My Story of Being Metis, Homeless, and Finding My Way (2019) 
about his life experiences and reconnection with his Indigenous identity. Specifically, he explores reconnecting with his Indigenous identity, which ultimately helped him to recover from the trauma he endured in his life. I highly recommend that you, reader, take the time to read the book yourself if that is available to you, as I hate to be the one to tell a shortened version of another person's healing journey. For the purposes of understanding Pillar 5, however, I provide you with a summary of Thistle's journey ${ }^{32}$.

Using Thistle's personal journey described in From the Ashes: My Story of Being Metis, Homeless, and Finding My Way, I developed the final key element: Indigenous identity as a form of healing from colonial trauma (Thistle, 2019). Specifically, it focuses on the immersion of Indigenous persons in their culture, or at least cultural practices, as a vital element for true healing and rehabilitation. As Thistle navigates a healing journey from trauma and addictions, he also must face the cultural gaps he was left with because of colonialism and the roles those played in his life. Thistle came to realize that he could not heal from his trauma or addictions until he explored the relationships between being Indigenous and disconnected from his culture. By connecting with his community, he is able to weave his cultural healing and immersion into healing from trauma and addictions. He came to realize that colonialism was at the root of his trauma and addictions.

Though we have experienced different journeys, I realized that I really related to Thistle's journey, as have many other Indigenous peoples (PW Staff, 2021). It is difficult to heal from something when you cannot fully understand what has happened to you (Episkenew, 2009). By understanding the colonial traumas faced by my relatives and ancestors, I was able to better

\footnotetext{
32 I acknowledge that this is not my story to tell. I am grateful to Jesse Thistle for sharing this story, both on an academic and personal level. Any mistakes or falsehood in my brief summary are my fault.
} 
understand the way I grew up, the traumas I experienced, and even the traumas of my relatives. By understanding the role colonialism played in these traumas, I realized I also had to obtain knowledges from my community, particularly from Elders to progress through healing. By relating my experience to Thistle's, I realize how it can be embodied theoretically and practically for the purposes of this study and beyond.

In the context of a community court or program, even if not Indigenous-specific, it does achieve several important factors to promote treatment in line with Indigenous values when compared to incarceration. Unlike the colonial correctional settings, specialized courts and programs allow clients to remain within their community through the healing process (assuming the community is in proximity to court), address the root causes of addictions and corresponding criminal behaviour, and allow for personal accountability with collectivist support (Marsh et al., 2021). These factors, while not a complete representation of Indigenous cultures, knowledges, and understandings, are fundamentally more in line with traditional teachings and justice forms (Cunliffe, 2018).

However, when considering the needs of Indigenous clients, the programming provided to them must be Indigenous-centred. I do not want my words to be misunderstood, so I will state this point clearly: Indigenous-centred means with Indigenous peoples - and their knowledges, cultural practices, and ceremonies - central to the conceptualization, development, implementation, and evaluation of programming for Indigenous persons. I say this because it is not possible for those to provide Indigenous knowledges, particularly those derived from lived experiences. For example, the federal corrections strategy of Indigenous-specific programming is not Indigenous-centred because the development occurred within the colonial state and is overwhelmingly delivered by non-Indigenous persons (Zinger, 2018). Indigenous healing is 
promoted without a sufficient connection to Indigenous cultures ${ }^{33}$, as much of the staff is nonIndigenous.

\section{Conclusion}

The framework derived from the four scholars listed above should help to explore the policy and procedures surrounding specialized courts and programs and should also serve to support research that is Indigenous-centred, supportive, and that will mitigate research-associated harms. For these reasons, I believe the theoretical framework that I have developed contributes to the decolonization of the research process. Further, if applied correctly, particularly alongside other bright and inspired Indigenous voices, it could help to achieve reconciliation and decolonization of the Canadian criminal justice system. The theoretical framework that centres Indigenous place and being, Indigenous processes, Indigenous involvement and collaboration, a desire-based approach to Indigenous initiatives, and which centres healing is not only something I used to analyze my work, but that can also be implemented in real-world initiatives. Finally, as these words directly precede the chapter on my methodology for this study, I want to highlight that I have tried to internalize my theoretical framework, those of other Indigenous scholars, and the teachings from my community members and Elders in my approach to this study deeply. The theory I am lovingly employing does not only need to be well understood but to be embodied strongly in praxis.

\footnotetext{
${ }^{33}$ However, I acknowledge the tremendous work accomplished by those Indigenous staff members in making the experience as good as possible for their clients. Without them, the situation would be even more dire than it already is.
} 


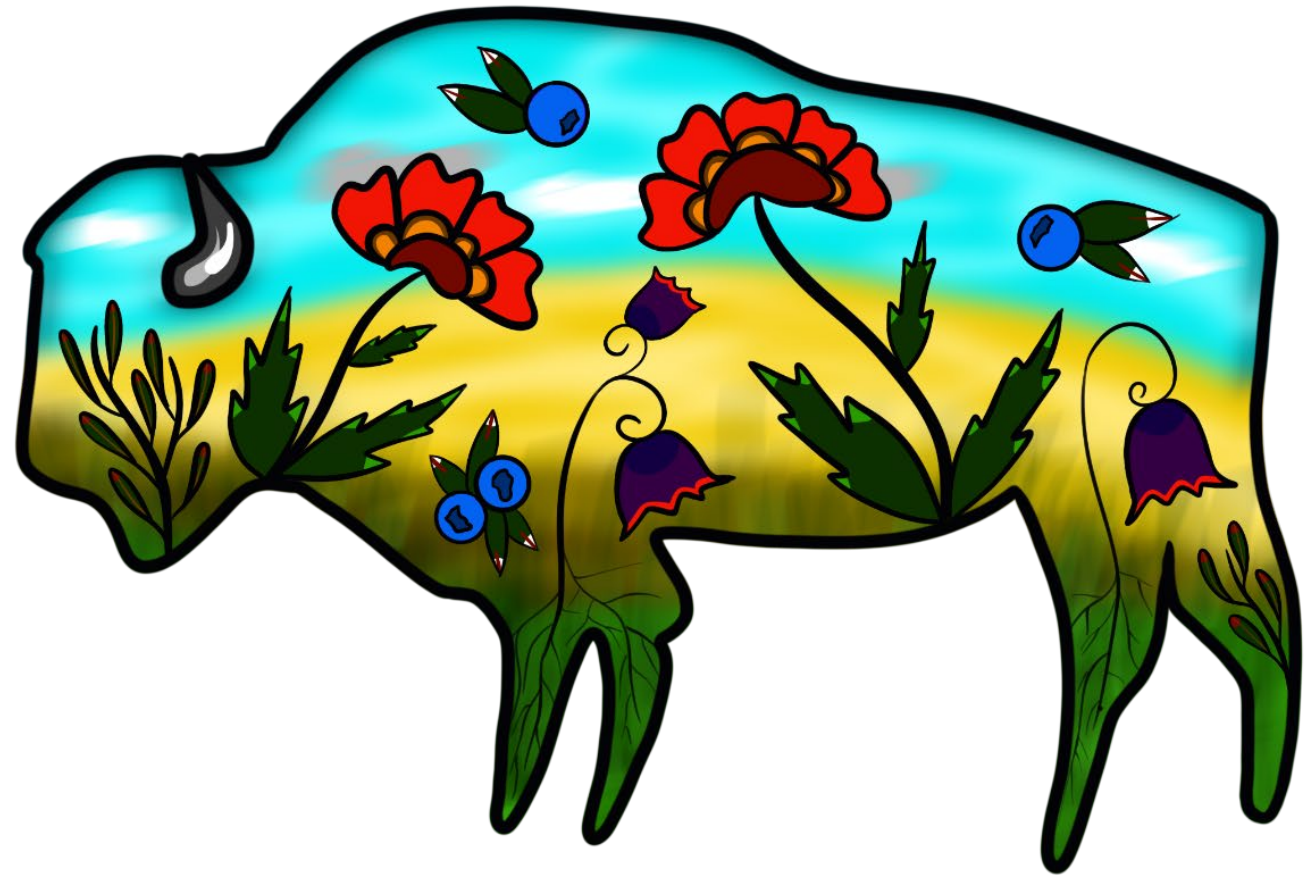




\section{Chapter 5: Methodology}

\section{Introduction}

As highlighted in the previous chapter, I place substantial emphasis on the process of an endeavour, not just the end result. If my work is to contribute to conversations on Indigenization and inclusion within the context of western institutions, merely producing a document that recommends steps is not sufficient. I have very deliberately focused my efforts towards embodying my practice throughout this study. It was important to me to be deliberate about how I approached this research, even in the early development. As is discussed in the remainder of the chapter, I believe I have approached this research in such a way that mitigates the potential for research violence, creates opportunities for those involved to share what is important to them, and produces a representative and accessible final product. Particularly as it relates to my theoretical framework, I believe this chapter exemplifies Pillar 2 (the processes of engagement surrounding Indigenous-focused works, as I was very specific and very deliberate about the way I did things, as described further in this chapter, and Pillar 5, focus on a desire-based approach, as I centred my admiration and respect for Indigenous knowledges in the process through my actions.

\section{Development of Research}

Before describing the specific ways that I have developed this research, I must first take notice of the community and cultural knowledge bestowed upon me in my life. I count this knowledge as part of the development of this research because I know it has directly contributed to my approach. Through teachings from Elders (sessions where the Elder communicated knowledge 
through conversation or storytelling, sometimes in ceremony, sometimes simply for the purpose of sharing knowledges and connection), working alongside Indigenous colleagues, attending ceremonial events, and in the special conversations during crafting, I have learned more than I would have ever believed. The teachings I have learned included one-on-one sessions which I initiated, one-on-one sessions preceding major events in my life, and group sessions where the Elder decided the topic, and group sessions either for the personal events of others or through a workplace. I primarily sought out these teachings through community members and organizations, but I have also been able to access them through work or school programs. Even when I was not specifically attending a teaching, simply listening to other Indigenous friends, colleagues, and community members was extremely illuminating. I found that spending time around those within your community, even if it is not done for the express purpose of obtaining knowledges, imparts you with wisdom. I have learned from their teachings and stories about living my life in a good way and about amazing persons within our communities that I hope to emulate. Had I tried to conduct this research without those previous knowledges, I believe I would have been likely to pursue a more individualized, overly formal, and theoretical approach. I had a goal to do research that promotes diversion from jails and prisons long before I planned to attend graduate school - something I learned was somewhat uncommon. The majority of my colleagues with whom I started the program wanted to attend graduate school before they knew where they wanted to focus their research. While working at the Edmonton Drug Treatment Court in 2018, I noticed that Indigenous peoples were highly under-represented in our client population. Having worked in corrections, I was aware of the problem of Indigenous overrepresentation. I wasn't just aware, but I was angry, disillusioned, and traumatized from seeing it first hand. When I worked at the Edmonton Drug Treatment Court, we had twenty available 
sports for participants in the program at any given time. At most, Indigenous participants filled only two of those available spots (10\%). Worse still, there were times while I worked there that there was only one Indigenous participant or even no Indigenous participants at all. The underrepresentation of Indigenous participants was completely unacceptable when considering Indigenous peoples account for over $40 \%$ of the incarcerated population of Alberta (Jamil, 2020). When I discussed it with my superior, she (rightfully) expressed a desire to have more Indigenous participants but also said that the policy to admit and retain Indigenous clients was incredibly limiting. I asked about publicizing this information, but our organization lacked the resources to produce research on the matter. I realized the privilege of being an academic researcher, particularly as a graduate student, where my funding need not come from the organization(s) I was researching. Thus, I began conceptualizing this research and initiated the process of commencing graduate studies. With time, I discovered that academic research is what I really want to do with my life, particularly research that benefits Indigenous peoples.

I found myself a supervisor - Dr. Aaron Doyle - who I knew would support me to do my research the way I wanted to do it. Though I told Aaron when I first contacted him that I was interested in working with him because of our shared interests (which remains true), a large contributing factor was the book Aaron and his colleague Dr. Kevin Haggerty wrote. The book, titled 57 ways to screw up in grad school : perverse professional lessons for graduate students (2015), is essentially a toolkit for success in graduate studies. I realized from reading the book and privately concluding that the book was not written for personal gain or to stroke the authors' egos - that Aaron was the kind of supervisor who genuinely cared about his students and did not view them as just another part of the job. I am aware that most graduate students do not explain why they work with the supervisor they do in their theses or dissertations, but I do believe it is an 
integral element to the development of this study. By having a supervisor that respected me and wanted the best for me, I was aligning myself with someone who would supervise and educate me when needed but would also let me take control when I needed to. And I often did need to because I was (and continue to be) committed to removing whatever colonial research standards that exist in modern practice from my work. Sometimes, doing so required bold "requests ${ }^{34 "}$ on my behalf, which Aaron not only supported but celebrated. Racialized students, particularly those who also study race, require supportive, understanding supervisors (Jack-Davies, 2018), especially in the face of institutional racism.

One such "request" I made of Aaron was the inclusion of a non-academic Indigenous 'committee member', compensated by my department, to consult on the project. I wanted this person because I feared producing a work that was academically sound but inaccessible or irrelevant to Indigenous peoples outside of academia. I wanted an Indigenous person who had experience with frontline Indigenous advocacy and support work, and was fortunate enough to find Michelle Robinson, Red Thunder Woman, whose commitment to community activism, settler education about Indigenous topics, and seemingly fearless approach benefits this project tremendously. I am grateful that Aaron and my department also saw the value in including her.

\section{Ethics}

As with most primary research involving people, I was required to undergo the ethics application. The process included providing recruitment documents, interview questions, and protocol forms to the CUREB-A ethics board. As my research not only includes but is centred around Indigenous persons, I also completed additional safety material. Such material included

\footnotetext{
${ }^{34}$ Though I framed these as requests, I only ever intended to certain things a specific, decolonizing way. Had I been aligned with a less supportive supervisor, I would have instead changed my topic or approach before compromising my values.
} 
additional work to ensure my work was as culturally respectful as possible and that I mitigated potential colonial research harms. Though the ethics process is generally boring, tedious, and uneventful, I am unable to say that was the truth of my experience.

I submitted my initial application in early September 2020 and submitted revisions following an initial review in mid to late September 2020. Then I did not hear from the ethics review board for more than two months, despite follow-up contact. Finally, I followed up again in early December 2020 and was told that the review board could not grant me approval until a general Indigenous organization wrote a letter of support for my project. I was deeply uncomfortable with this request for two reasons. First, I did not believe this was an appropriate request given that I was not working with a specific Indigenous organization or community, but rather examine a nationwide process in the criminal justice system. Why should I have to go to an uninvolved organization - without already have ethics clearance - to have them do a tremendous amount of labour for the ethics board and me? Second, and critically, a colleague in the department doing similarly Indigenous and drug policy-focused research, who is white, who is supervised by the same person within the same department, who is in the same program, and who submitted their ethics application after I did was not required to do the same.

The process was actually deeply hurtful to me. I felt tokenized as an Indigenous researcher, and I was delayed my research a full term. I said as much to Aaron, my supervisor, in an email. In fact, looking back, it was a pretty emotional and aggressive email to him, especially considering he was blameless. To Aaron's tremendous credit as an Indigenous ally and as a conscious and thoughtful supervisor to a racialized graduate student, he jumped in immediately. The next morning I woke up to clearance. I am not exactly sure what he did, but I appreciate that he managed to communicate the inappropriateness of their request to them. 
Most uncomfortably, the ethics committee then requested that I participate with them in a meeting where I - and my Indigenous committee members - help them to develop a better protocol going forward. Though I agree a better protocol was essential, I also thought it took a lot of nerve for them to request I do them a tremendous amount of free labour following the distress and delays they caused for me (which they never acknowledged or apologized for). In fact, owing to becoming distracted by the holidays at the time of their request, I never actually answered that email. At least I had ethics clearance.

\section{Collaborative and Communal Approach}

One of my great delights in conducting Indigenous-centred research is the opportunity to work collaboratively and collectively with other Indigenous persons. Correspondingly, I wanted as many opportunities to work with other Indigenous peoples as I could. As any graduate student has likely experienced, we are often asked about our research (Cham, 2016). As I explained to Indigenous peers and colleagues, many of them offered helpful suggestions and guidance. So why not formalize the arrangement? I let any Indigenous person I interacted with know that I would appreciate their consultation on this project, regardless of their education level, to ensure my approach was accommodating and safe to participants and the works were as accessible as possible to readers. I also arranged for an honorarium for those who consulted as thanks for their knowledges and contributions.

A communal approach is one common within Indigenous communities (Brown \& Nicholas, 2012; Cheng \& Ma, 2016; Ferguson, Girolami, Thorstad, Rodgers, \& Humbert, 2021). Because of ethical concerns, I was not able to have a consultation with my peers regarding my data analysis. However, I utilized the knowledges of my peers by discussing my approach to interviewing, my interview questions and identifying relevant contexts to provide in the literature 
review component of the project. Learning from Indigenous peoples, translating their values into research, and implementing those knowledges does not need to be a formal, arduous process, as reflected through my approach (Macklin et al., 2021)

\section{Data Collection}

With regards to my actual data collection, it was generally supposed to be simple and exploratory in nature. I intended to conduct semi-structured focus groups resembling talking circles for my interviews. I have previous experience leading a talking circle, and I value talking circles for promoting a safe space, opportunities for everyone to speak and to listen, and to make the interview process more comfortable for Indigenous participants (Schumacher, 2014). Approximately one month before I transitioned from full-time classes to full-time research, the COVID-19 pandemic began. The pandemic caused global shutdowns (Feuer \& Kim, 2020), requiring many researchers to modify their research approach if it required meeting participants in person (Wang, 2020).

I recruited participants through community organizations. I contacted these organizations through email with the request that they circulate the recruitment documents to their participants. Such organizations included community justice organizations, organizations providing community corrections services but who were not corrections (e.g. not-for-profits like the John Howard Society), Indigenous justice organizations, and supportive Indigenous services. In fact, I contacted every single Native Friendship Centre in Canada that had the capacity to receive an email, totalling over 100 friendship centres. I also contacted all DTCs and mental health courts who had publicly available contact information. Full records of participant contact information are contained in Appendix 1. 
In response, I conducted video-call interviews on a computer and over the phone when the participants lacked access to a computer. Zoom fatigue, a condition where the user feels exhaustion following or even anticipating video calls, can be a real barrier to communication (White, 2021). Some have even likened Zoom fatigue to burnout as it displays many of the same impacts on an individual and is worsened by group calls. To mitigate negative impacts to my participants, I made the decision to conduct one-on-one interviews with my participants and to keep the interviews to one hour in length ${ }^{35}$. The interviews were semi-structured, qualitative interviews. Further, I allowed participants the opportunity for follow-up, narrative interviews, described later in this chapter.

Questions explored the life and criminal justice system experiences of the participant, their views on the effectiveness of incarceration in rehabilitation, their knowledges of alternatives to incarceration programs, and their experiences in different kinds of programming. As my interviews were semi-structured, there was some variation in what I asked participants. However, there were the following questions in each interview. Where needed, specific questions were asked to participants relating to previous statements in the interview.

For criminalized Indigenous persons:

1. How do you identify as an Indigenous person?

2. Have you ever struggled with substance use/abuse?

3. Have you ever been to jail? What was it like?

4. Was your jail experience helpful to you once you got out?

5. Have you ever been to prison? What was it like?

\footnotetext{
${ }^{35}$ However, participants were informed they could elect to go longer if they wanted, because I did not want anyone to feel like they did not get the change to say everything they wanted.
} 
6. Was your prison experience helpful to you once you got out?

7. If you experienced substance use/abuse challenges, did being incarcerated help you in the short term with those challenges? In the long term?

8. Do you know anything about drug treatment courts? Have you ever attended one?

9. Did you, or your legal team, ever consider a drug treatment court/mental health court/other specialized courts as an alternative to incarceration?

10. If you attend(ed) a drug treatment court/mental health court/other specialized courts, do you find the process helpful? Culturally sensitive?

11. If you did discuss drug treatment court/mental health court/other specialized courts but did not attend one, why not?

12. Do you think drug treatment court/mental health court/other specialized courts would be a preferable option to incarceration for you?

For Service Providers (both Indigenous and non-Indigenous):

1. What is your position in (or adjacent to) the criminal justice system? Are you employed, a volunteer, or an activist?

2. Do you identify as Indigenous? If yes, how do you identify?

3. What percentage of your clients are Indigenous?

4. To what extent do you believe substance abuse contributes to crime? Mental health challenges? Please elaborate.

5. Of your Indigenous clients, what percentage of them have cases related (directly or indirectly) to substance use/abuse? Mental health challenges?

6. Do you think incarceration is an adequate tool for rehabilitation in general? How about in the context of substance abuse? 
7. What do you think of drug treatment court/mental health court/other specialized courts as an alternative to incarceration? Do you believe drug treatment court/mental health court/other specialized courts are more effective at rehabilitating clients, specifically in the context of substance abuse, than incarceration?

8. Are you aware of the recidivism rate of drug treatment court/mental health court/other specialized courts vs the recidivism rate of participants who go through traditional corrections?

9. Have you ever referred Indigenous client(s) to a drug treatment court/mental health court/other specialized courts?

10. Are there any barriers for clients to enter a drug treatment court/mental health court/other specialized courts?

11. Are there any specific barriers for Indigenous clients (unique to Indigenous clients compared to non-Indigenous)?

My sample of interview participants included three formerly incarcerated Indigenous persons with self-identified substance use disorders or substance use which was relevant to their criminalization, three Indigenous service providers, and five non-Indigenous service providers ${ }^{36}$. In the context of this study, service providers are defined as persons working in or adjacent to the criminal justice system with Indigenous clients. Note that half of the service providers worked at programs that served exclusively Indigenous clients as their programs were Indigenous-specific, whereas the other half served a combination of Indigenous and non-Indigenous clients.

\footnotetext{
${ }^{36}$ Note: one participant is counted twice as they met the criteria both as a formerly-incarcerated Indigenous person with a substance use disorder and the role of Indigenous service provider.
} 
Perhaps the inclusion of non-Indigenous participants means that this is not Indigenous-centred research. I am confident some readers will believe this to be true. As such, I wanted to identify why I included these participants. The fact remains that Indigenous persons going through the colonial criminal justice system will be required to interact with service providers who are nonIndigenous. This will be a reality for as long as Indigenous justice matters are handled under the colonial state. Correspondingly, those non-Indigenous actors will have an impact on Indigenous clients. I felt that leaving out their perspective would leave a gap in understanding. It is not to suggest that non-Indigenous participants' information carries equal weight to that of Indigenous participants, as it simply cannot on Indigenous matters. However, non-Indigenous actors remain (often) well-intentioned participants in supporting Indigenous justice. Even when they lack a comprehensive understanding of Indigenous issues, they have still demonstrated effort and desire to support Indigenous clients. By including them in this piece, I could better understand how policy and practice gaps occurred and thereby produce strong recommendations for these corrections. By utilizing the experiential knowledge of these allies, I was able to develop and produce stronger knowledges to mitigate colonial violence. Again, it is not as good as Indigenous-governed justice, but it could make things a little better. To me, the fight for substantial change does not mean the fight for smaller change is worth neglecting.

In addition to my interviews, I obtained the official admissions eligibility criteria documents for every specialized court I could find: for full documents, see Appendix 1; as well as the program requirements for participants enrolled in such programs; for full documents, see Appendix 2. While some of these documents were publicly available online, the majority of specialized courts did not have them listed. I contacted those organizations to request these documents, though few replied. However, I was informed via email by a manager at the Toronto Drug Treatment Court 
that most specialized courts developed their policy in reference to their program, given that the Toronto Drug Treatment Court was the first specialized court established (Department of Justice Canada, 2021). My personal analysis identified this to be correct, as all available documents or information were extremely similar to that provided by the Toronto Drug Treatment Court. However, the information obtained cannot be confirmed to be representative of all Canadian specialized courts.

\section{$\underline{\text { Data Collection Limitations }}$}

This study was highly limited by the COVID-19 pandemic occurring throughout the research process. With provincial, territorial, and federal restrictions (Feuer \& Kim, 2020), I was required to abandon my original approach of conducting interviews in circle-style and transition to video calling. Connecting over a video call is different than connecting in person (Wolfe, 2020), and it is likely that some information was lost because of our interview methods. That said, in some ways, the requirement to video call was a blessing - I was able to interview participants all across Canada, which would not have been my approach otherwise. The inability to include familiar Indigenous practices (such as the talking circle for interviews) in my data collection could have impacted the comfort level of the participants. Further, it compromised my ability to produce a study that was as decolonizing as I had intended it to be.

On an institutional level, any information from the criminal justice system was difficult to access. The Canadian criminal justice system has historically been difficult to obtain information from, either as someone moving through the criminal justice system, a relative of someone in the system or as a researcher. The system has always lacked transparency. Further, the criminal justice system appears to lack adequate demographic information, particularly as it relates to specialized court programs, meaning it was challenging to even quantify the depth of the 
problem of Indigenous exclusion from such programs. One participant who identified this problem in her interview speculated that the lack of solid demographic record-keeping is deliberate because systems were to do that they could be held more accountable for their failings and mistreatment towards racialized persons.

With specific regards to specialized courts, many of these programs seemed to lack any public formats to interface with them or even to learn about them. Less than half of the specialized courts had an online presence, with only some of those including eligibility criteria, program effectiveness data, or explanations of their role within the community. While this certainly highlights some of the arguments I have made in the previous chapter, it also limited my ability for a more in-depth, Canada-wide analysis of their criteria. While I believe the information obtained is sufficient in demonstrating my point, I would have preferred to include information from all specialized courts as it would have been more representative.

COVID-19 also contributed to challenges in recruitment. Though potential participants were more accessible through video calls, they were also less available. Many community-based organizations, particularly those serving precarious individuals, saw an increase in need from their clients without an accompanying boost in resources (Ireton, 2021). It is understandable that potential participants for this study would have prioritized the wellbeing of their clients over participating in this study; they only have so many hours in a workday to give. More participants could produce even more knowledges, meaning more nuanced analysis and recommendations.

\section{$\underline{\text { Transcription and Coding }}$}

Following the interviews, I transcribed my interviews myself. Though the process was long and arduous, it also allowed me additional time to reflect on my interviews. Better still, I was able to 
remind myself of tone, emotions, and the thoughtful pauses of my participants, to name a few. Once transcribed, I began my analysis. First, I read through and just made a note of anything that the participants were particularly passionate about or that I identified in my notes from the interview as significant. Next, I noted anything that indicated a challenge or barrier within the system. Finally, I noted anything that related to policy. I did not engage in a formal coding process, such as a content analysis of interview transcripts, because I did not want to blind myself to findings. I feared ignoring or overlooking important information on the basis of searching for something specific.

\section{$\underline{\text { Interpretation }}$}

My interpretation and analysis of the interview data involved applying my theoretical framework to the information provided. Specifically, I identified the information participants considered to be positive to identify whether it was in line or not with my theoretical principles, and then did the same with any information provided that was considered negative by the participants. For example, if the participants shared a statement that was significantly connected to place and being, I flagged it. Additionally, I noted if participants were aware of an alternative to incarceration programs, how they operate, their effectiveness, and the participants' opinions on such programs. I did this specifically to gain an understanding of the general knowledge and attitudes of interviewees towards specialized court programs. Then I analyzed their responses in relation to the participants' views on incarceration. Finally, I identified the commonalities between the data points considered particularly important by the participants.

I also conducted a policy review through a content analysis of the official documents regarding admissions eligibility and program rules for when enrolled. To produce the content analysis, I reviewed all policy documents. First, I reviewed them generally so as to understand their 
contents as if they existed in a vacuum. Next, I reviewed the documents under the colonial realities of what is now known as Canada, and also specifically the Canadian justice system. I compared the contents of these documents with Indigenous social realities, Gladue principles, and Indigenous values regarding healing and justice. Then, I identified any instances where a specific policy was in place for Indigenous clients and evaluated it under the same criteria.

Finally, I analyzed the documents under the lens of my theoretical framework, specifically by identifying areas where the documents either demonstrated instances of the ideals as developed through my framework or (more often) where areas demonstrated a deviation from these ideals.

\section{Confirmation of Interpretation of Findings}

As highlighted through Pillars 2 and 3 of my theoretical framework described in Chapter 3, it is important to centre Indigenous peoples in the process of the research project and take the study on with good intentions. As such, I wanted to ensure that those who participated in this research had the opportunity to confirm my interpretation of their interview data, particularly given the tremendous harms Indigenous peoples have experienced as a result of research conducted about them (Cherubini, 2008). Though it is likely that it was seldom the intention of non-Indigenous researchers to misrepresent and harm Indigenous peoples or communities, a culture of distrust has been developed between many Indigenous peoples and researchers (Goodman et al., 2018; McGregor, 2018; Vowel, 2016a). Colonialism is perpetuated through the misrepresentation of Indigenous values, knowledges, histories, and traditions. Without the lived experiences and cultural understandings Indigenous peoples hold, it is likely that a non-Indigenous researcher would misrepresent their findings (Cochran et al., 2008).

So I did just that. Why not reach out to participants after I had the chance to analyze their interview data and develop conclusions? For many past researchers, I anticipate their answer was 
a lack of time or resources rather than a lack of interest. So I contacted all participants again (they were aware from the onset this would occur) to give them the opportunity to confirm my interpretations. Only two participants ultimately had the capacity for a follow-up interview, but I still opted to do them. In these follow-up interviews, I prepared a short narrative detailing the key information shared during the initial interview, how I interpreted it, and the overall conclusions and recommendations developed as a result. The participants generally confirmed my interpretation but also used this as an opportunity to supplement additional information that they had reflected on between interviews.

\section{Future Publications}

I have also made the personal commitment to myself to never publish Indigenous-centred research or resources through a medium that is behind a paywall. I have made this decision because I believe any person, particularly Indigenous persons, who want to read my works should not be excluded from doing so based on cost. I commit to uphold this value for all publications, academic or not, that I produce in my career.

\section{Acknowledgement of Thanks For Indigenous-Centered Research}

I do not know if this section really has a place that fits best into this chapter or anywhere else in this thesis, but I would be remiss if I did not include it. Though there is the potential that this could sound like a humble brag about my own research excellence (which I do not assume), I believe there is value in sharing the following as it could support other researchers engaging in Indigenous-centred research. Every single participant I interviewed thanked me multiple times for the opportunity to share their knowledges and experiences, particularly those participants who are Indigenous. As I understood it, it was not only that I allowed otherwise silenced or 
overlooked persons to share, but I ensured from initial contact that I was engaging in the process with their best interests in mind. Participants were grateful to be given the time and space to share their knowledges with someone who wanted to use them to uplift Indigenous communities and who understood the tremendous responsibility that comes with this kind of research. My heart is so full of these thanks and acknowledgements from my participants. I regularly felt the need to reiterate to my participants that they were the ones doing me a favour and that I was the one who should be thanking them.

The previous paragraph demonstrates the importance of process as developed from Simpson in Pillar 2 of my research. Not only was I able to complete the required steps to produce ethical Indigenous-centred research, but I believe I was able to ground my research process in Indigenous approaches. I believe my participants felt their inherent worth and importance. Though I do not know for sure, I also believe I contributed to Indigenous healing from the research process as well.

\section{Conclusion}

I have found the methods section of academic texts to be notable if they are either: 1) dazzlingly new, progressive, decolonizing, thoughtful, and inspiring; or 2) so horrifically limited that it undermines the quality of the research conducted. However, I included this methods section for a special reason - beyond that; it is required of me when producing academic works. I included this section as a sort of love letter to the Indigenous scholars and community members that have highlighted the importance of process in a study to celebrate Indigenous peoples and contribute to our collective goals.

While this section certainly provides information on my approach to this study, when combined with my theoretical framework showcased in Chapter 3, it serves to demonstrate the deep respect 
I have for Indigenous-centred research and the responsibility I feel while engaging in it. It is my hope that other researchers, Indigenous and non-Indigenous alike, employ a similar approach of careful consideration of process when engaging in Indigenous-centred research. 


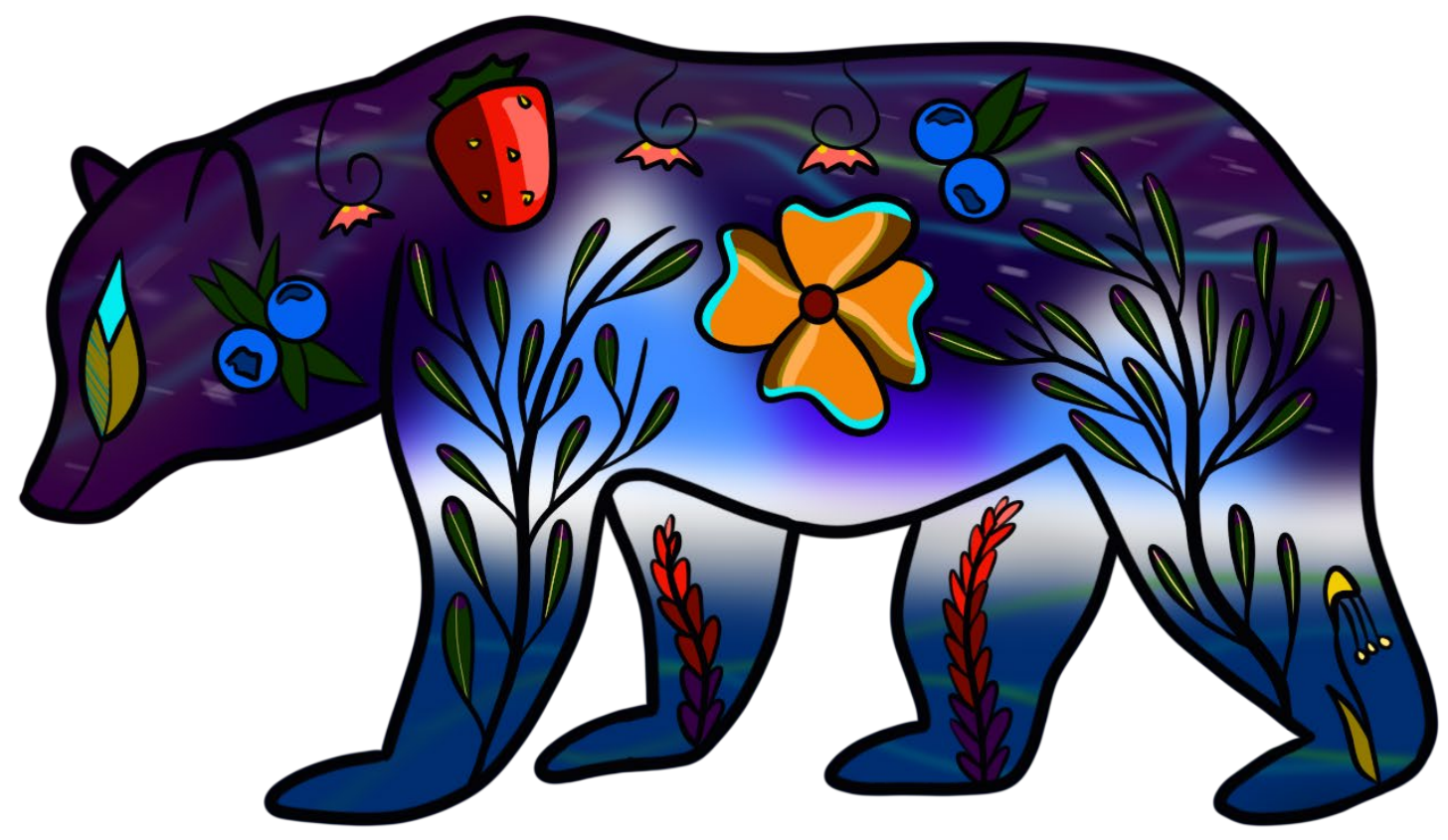




\section{Chapter 6: Description of Findings}

\section{Introduction}

This chapter is to function as a summary of key findings. I deliberately chose to keep my findings and analysis of findings as separate chapters. I recognize that I am not alone in my choice to organizing my findings this way, but I still want to take the time to acknowledge why I have chosen to organize them as I have. Specifically, I chose to keep this chapter as a description of my key findings because I want to present this information as independent from my analysis.

The purpose of this decision can be best illustrated by a story of Dene peoples from the region I am descended from. I learned this story from a Knowledge Keeper who shared it virtually. Approximately sixty years ago, an anthropologist visited the community with the intention of studying them. Not knowing the language, he worked with a community member as a translator. Unfortunately, after he left, he produced analyses and publications without consulting the community and made several important errors. However, the most significant error he made was stating that the population he went there to study was extinct - despite the fact that those very people were the ones who he worked with. It is unclear how he came to make this terrible error, but the damage was done. For a very long time, the only literature available about the Dene people of that region falsely stated that they were extinct. Additionally, his works did not reflect the knowledge provided to the researcher by the community. Their stories were not told, their words were misinterpreted, and they really did not get anything positive out of the interaction.

Because I do not want to commit the same egregious errors as that researcher, I want to include the worlds and priorities of those I interviewed independently of my own analysis. This way, if 
nothing else, their words are published without my thoughts, interpretations, or analysis. I believe they have a right to stand on their own before I take my turn to interpret them, which occurs in the next chapter. Specifically, I want to draw a loose comparison with a traditional talking circle. In a talking circle, the Circle Leader will prompt the discussion and then give everyone in the circle the opportunity to discuss the prompt. Then they go around the circle with each person responding to the prompt. A talking circle format allows everyone the opportunity to share without interruption. Though I cannot exactly replicate those conditions in this text, I can hold two different spaces for the words of my participants and my analysis.

Perhaps a reader other than myself might draw different inspiration, conclusions, or areas of importance without viewing this with my analysis, especially given my unique theoretical framework. However, I acknowledge that it is impossible to remove my own biases from this chapter entirely, as I chose which information to present, as well as how it is organized.

\section{Information Found in Admissions Eligibility Criteria}

To contextualize the key findings from the interview data, I must first explore the eligibility criteria for specialized court programs. The eligibility criteria are the first point of policy that many potential clients (or their legal representatives) interact with, so it is the first examined here.

The following findings were obtained from specialized court programs. To view the documents in their complete form, please see Appendix 2. Please note that the only eligibility criteria used to obtain the following information was information that was available to the public through the respective court's online platforms. In some cases, the online platforms contained full documents which would be opened and downloaded and were exactly the same documents utilized by the 
court and program staff, as well as being distributed to the clients. However, most of the online platforms contained text sections with the eligibility criteria.

The following key eligibility criteria were present across programs:

- $\quad$ The participant must be at least 18 years old ${ }^{37}$;

- The participant must be referred by a legal representative; participants cannot self-refer to the program.

- The participant consents to participate in the program and has pleaded guilty.

- The participant is demonstrated to be criminally entrenched, often with several prior convictions, or;

- The participant's criminal behaviour is motivated or caused by drug use.

- The participant is considered to be at risk for reoffending without the specialized court's targeted programming.

- Participant committed one of the following offices ${ }^{38}$ :

○ possession of drugs for personal use or for street-level trafficking;

theft;

○ possession of stolen property;

○ non-residential break and enter;

○ mischief;

- prostitution;

\footnotetext{
${ }^{37}$ Note that two programs accepted participants who were between 16-18-years-old with the condition the youths supervisory officer approve the enrollment.

${ }^{38}$ Note that programs indicated these were the most typical types of offences, though others could be considered in the event it was demonstrated to have been related to the substance abuse of the applicant.
} 
- Not eligible if has previous charges or convictions ${ }^{39}$ :
○ homicide;
- assault with a weapon;
$\circ$ armed robbery;
○ that are otherwise violent in nature ${ }^{40}$;
○ sexual assault;
$\circ$ domestic violence charges;
$\circ$ residential break and enter;
- in circumstances that raise concerns about drug-impaired driving or risk to young people.

While the above applies to all forms of specialized court programs, there are instances where the eligibility criteria are related to the demographic the court serves.

Specifically, in the case of drug treatment courts:

- Not eligible if primary condition is:
○ Alcohol use disorder; or
- Cannabis use disorder.

Specifically, in the case of mental health courts:

- Not eligible if prior charges or convictions related to drugs unless supported by the court.

- Not eligible if offence holds a mandatory minimum penalty.

\footnotetext{
${ }^{39}$ Dependent on program.

${ }^{40}$ In some cases, courts consider participants where long periods without violence.
} 
- Individuals suffering from FASD, ARND, Autism, Brain Injury will not be considered unless they have a co-occurring mental illness.

- Individuals who have a form of an organic brain issue such as dementia associated with Alzheimer's or late-stage AIDS are not candidates for this specific form of diversion.

Specifically, in the case of Indigenous/Gladue/Aboriginal courts ${ }^{41}$ :

- Participants must self-identify as Indigenous.

It should be noted that some programs included stipulations that the court could overrule criteria that rendered the applicant ineligible if there was substantial reason to do so, such as demonstrated mitigating circumstances. However, such was unlikely owing to the high number of applicants relative to a low number of available program spots.

Further to the eligibility criteria provided through the online portals, all specialized court programs highlighted that part of the eligibility criteria included that participants under consideration must be evaluated as being low risk to the community - as is a requirement for all forms of conditional release (Government of Canada, 2018; Legal Aid Ontario, 2021; Ministry of the Solicitor General, 2019; Public Safety Canada, 2008). However, there was no information available beyond the already provided eligibility criteria, indicating how risk was evaluated with the exception of the Calgary Drug Treatment Court (Calgary Drug Treatment Court, 2021). Though different service practitioners will determine risk differently (risk assessment is generally subjective), one key factor is gang affiliation. As such, all programs have an "unofficial eligibility rule" of:

\footnotetext{
${ }^{41}$ Note that the majority of these courts are not specialized programming courts, but instead function as specialized sentencing courts (Provincial Court of British Columbia, 2020b).
} 
- Ineligible if the individual has gang affiliation.

Though specialized court programs do not provide information regarding the exact number of applicants, the staff within these programs have identified that many more applicants are not accepted than are accepted. Most of the individuals who apply to specialized court programs are not accepted, even when they meet all eligibility criteria (Department of Justice Canada, 2015).

\section{Information Found in Participant Handbooks (Program Rules for Enrolled Participants)}

Once an individual is enrolled in a specialized court program, there are rules the individual must follow to maintain their placement in the program. All documents utilized for this section can be found in their entirety in Appendix 3. Though each program has specific requirements, the following are requirements seen broadly across specialized courts:

- The participant is required to abstain from illegal activity.

- The participant is required to report to their community supervision officer as determined by conditions.

- The participant is required to follow all conditions assigned by the court and by the community supervision officer.

- The participant is required to follow all program rules as enforced by the program staff.

- The participant is required to abstain from the use of illegal drugs, prescription drugs used illegally, cannabis, and alcohol.

- The participant is required to attend court as scheduled.

- The participant is required to complete all assigned programming or otherwise determined activities (e.g., therapy, doctor appointment, etc.). 
In the event a participant does not adhere to the above requirements, they will either be awarded an in-program consequence or have their enrollment in the specialized court program terminated. It is the responsibility of the court and program staff to collaboratively determine consequences.

Currently, available data suggests that only one in three participants admitted to drug treatment courts graduate (Department of Justice Canada, 2021). Recent graduation rates for other forms of specialized courts are not available on a Canada-wide level.

\section{Interview Data from Formerly Incarcerated Indigenous Persons}

The interview data obtained from the three previously incarcerated Indigenous individuals was similar, despite the interviews being generally conversational, semi-structured and interview questions being open-ended.

The participants interviewed identified themselves as Cree, Métis Cree, and/or Plains Cree. The participants all identified themselves as struggling with substance use, including illegal drugs, prescription drugs used illegally, and alcohol. The participants had all been formerly incarcerated, with one participant only having been released a week prior to the interview. Across the three participants, they had experience in provincial jails, provincial prisons, and federal prisons ${ }^{42}$.

The participants were incredibly forthcoming about the realities of their lives. Notably, the participants discussed their lives from early childhood as being relevant to their story of being criminalized. The childhoods of the participants demonstrated circumstances placing those participants at risk for trauma, addictions, and criminalization (Cao, Burton, \& Liu, 2018; Dion,

\footnotetext{
42 Jails are generally reserved for pre-trial detention, though can sometimes serve as overflow custody space for those on very short sentences. Provincial prisons are reserved for sentenced individuals whose sentences are less than two years in length. Federal prisons are reserved for individuals whose sentences are two years or more.
} 
Cantinotti, Ross, \& Collin-Vézina, 2015; Ross, Dion, Cantinotti, Collin-Vézina, \& Paquette, 2015). Participants reported unstable home lives through childhood, including problematic substance use from their caregivers, physical and emotional abuse, sexual assault, trauma, and early exposure to substances. One participant identified themself as a Millennium Scoop survivor. Following their placement in a non-Indigenous foster home, they were exposed to gangs, violence, and drug use in their early teens. As mentioned by (Sam):

My drug of choice was pills, I say pills, because it was kind of whatever was in front of me whenever I could crush and put my body is what I did. I actually was introduced to pills, and my addictions, in group homes." Participants were forced into gangs as a means of achieving community. "And you know, while being in that gang mentality of you know, like well this gangs my life, and these are my family and I got to protect them, and so I took ownership for something that I wasn't fully part of and did my time," states a participant whose first charges were for something she hadn't actually done, but took the blame for to protect other gang members from incarceration.

One of the participants indicated they believed they had faced discrimination within the criminal justice system, including from police, the court system, and correctional staff. "I was charged as an adult at 15." "...did not treat [us] like people." They also identified, it was difficult to find Indigenous staff within the correctional system, though they identified that in the rare instance they had exposure to Indigenous staff, knowing a staff member was Indigenous made them feel safer or better understood. "It was more easier, I guess, to open up, I guess because you can relate, and you guys know you have family or well, not even if not related by family, but you guys have a connection." Correspondingly, participants felt uncomfortable or even less safe around the non-Indigenous staff. "A lot of guards are fucking rude to the fucking room." 
When asked the question "So did [prison] do anything that you thought was helpful?" the participant stated simply: "Prison? No. Not it's not." Participants indicated that incarceration was largely unsupportive of their recovery, rehabilitation, or healing.

“As for like resources in there... um I feel like they're there, but they don't help you as much as you think they would."

When in provincial custody, the available programming was limited and often not meeting their programming or treatment needs. Participants even described the programming as being too generic.

Further, it was difficult for participants to enter programming they expressed interest in that would address the root of their criminal behaviour. "When I was waiting to be sentenced, I wanted to go into [treatment program], is it's like a drug-based program... but at the time my charges only involved alcohol." In the previous quote, the participant describes their desire to take their treatment and healing into their own hands, but they were denied because the treatment did not fit with their charges, even though the treatment would meet their needs. "Even though I told them, I was, I was using drugs at a time it wasn't on record that I was doing them." Additionally, participants spoke of the additional dangers of prison. "It just connects you with more drugs and alcohol or more of the lifestyle that got you there in the first place."

However, some participants identified temporary custody as helpful to detox from whatever substance they (or others) were on, as, in jail, they had greater difficulty in accessing such substances. Participants passionately indicated how horrific jails and prisons were, indicating that being in such institutions was highly traumatic and one of the worst experiences of their lives. 
With regards to their Indigenous ancestry, participants stated that corrections were not supportive of meeting cultural needs. Participants did not feel as though they were provided with programming that was culturally relevant or supportive, indicating that - dependent on the institution and the length of stay - there were little to no cultural resources available. "They have never been troubled. They'll never know what it's like to actually be on the inside of the walls, I mean, sure they're on inside the walls, but they don't see what goes on behind everything."

All participants enthusiastically stated that treatment and programming were only helpful if the person in need wanted to attend such programming, speaking both of themselves and their peers. When participants were in active addictions, including substance use, they identified that alternative programs that required abstinence from their substances of choice were only seen to avoid prison, not as something that would actually benefit them. "There are some guys who will do programming just to try to get them to lessen their sentence." Participants identified challenges in remaining abstinent from substances as a barrier to entry and maintenance within diversion programs.

"Right, it doesn't matter what the [justice system] is trying to do or think that they can do. You have to be willing to do and know what you have to do to better your life for you and your kids in it." Two participants identified that their primary motivator for abstaining use of their respective substances was to give their children a better life and to connect better with their families. "I want to live my life to where my grandma would have been proud of me now." Both participants identified that they wanted to be a better parent to their children than they had themselves while growing up. They stated they wanted to not only be present for their children but to avoid exposing their children to substance use. Horrifically, one participant was forced into that course of action because of the racist practice of birth alerts. "They told me like you're 
on you have a birth alert on you, for this and for that, and so I had the opportunity to kind of get better .... and that was kind of what was the pushing points and be like okay I need to do something. Anything."

Participants indicated that their success with sobriety was related to having tremendous social supports, employment, access to cultural resources, and compassion. Unfortunately, often their release conditions made achieving those supports challenging or even illegal. "So, and I had to stay at this Salvation Army, but my mom she lives just a block away from the Salvation Army on like main street, right? She has a spare room, but they said I can't stay there because it's a drug and alcohol area." More troublingly, they offered the following statement: "At the Salvation Army like there's more drugs and alcohol, like in that whole building. Then there isn't at my mom's place. I mean, I just feel like they would rather have us closer where they can keep an eye on us to where if they don't like something we're doing, they could focus on that... so they're not even setting you up to be successful."

Finally, they stated they stated the importance of offering compassion to other Indigenous persons in similar situations. All interviewed participants stated that they had never been given the opportunity to apply to a drug treatment court. In fact, the only participant who comfortably understood what specialized courts are was the participant who then turned to the role of service provider and peers support. Generally, participants were aware of diversion in the form of attending treatment but were not given the opportunity to explore such options. Again, here participants noted that such treatment options were problematic as they were seen as a way to stay out of jail or prison and not born from an enthusiastic desire to enter treatment. 


\section{Interview Data from Service Providers Working with Indigenous Persons}

Eight interviews were conducted with service providers, four identifying as Indigenous (two men and two women) and four being non-Indigenous (one man and three women). All but one participant working in community supports for formerly incarcerated persons or in a communitybased specialized court or diversion program. Only one service provider worked within the court system (excluding specialized courts). There is no representation of police or similarly employed individuals in the participant sample, despite recruitment efforts being directed at such programs. Of the eight interviewed participants, five held managerial or supervisory roles. All participants worked directly with clients. Half of the participants served exclusively Indigenous clients, and the other half estimated their caseloads consisted anywhere between 30-50\% Indigenous clients, despite living in areas where Indigenous clients made up very low percentages of the population.

\section{$\underline{\text { Universal Responses }}$}

The interviews with service providers produced greater variability in the sorts of responses given, the issues identified, and areas of priority. However, all service providers identified four main points, which they highlighted as important. First, participants indicated that their organizations were under-resourced and under-funded. The service providers all expressed tremendous frustration with their lack of resources, stating they believed they could support more individuals in the event they were to obtain more funding. "[Good community programs are] there, but they're so under-funded and like demoralized that nobody ever knows about them, or when they use them because they're so underfunded and not easily accessible it can't they can't utilize it the way that they need to not end up in these systems." Some service providers elaborated that large, provincially run programs have substantially more resources than they do, 
but that their clients report that those programs did not meet their needs, hence their participation in their community-based and -run programs.

Second, participants noted the substantial link between substance abuse and crime. "Substance abuse and crime go hand in hand." "It's a survival behaviour (referring to a crime connected to addictions). All service providers identified the importance of supporting the strengths of their clients and a harm reduction approach rather than a punitive approach, abstinence-only approach, or an approach that condemned or vilified their clients. "People spend too much time trying to treat the substance abuse and not the trauma that goes with the substance abuse." In fact, the service providers highlighted how pointless it is to strip a client of the supportive programming they need when they engage in the behaviour that they needed the supportive programming for (e.g., kicking a participant out of a drug rehabilitation program for using drugs, when they are only there because they need help to stop using drugs). In fact, service providers highlighted that it is likely one of the only instances where such a practice is used. It is difficult to argue against their point. If someone is suffering from a substance use disorder, it makes absolutely no sense to withdraw the recovery supports as a punishment for them succumbing to their disorder. To be clear, the service providers were not advocating that all of their participants should just be using substances, but rather that policy for such programs should be more supportive of the realities of substance use disorders and the needs of those clients.

Third, all service providers stated without question that they do not believe incarceration to be an effective tool in rehabilitating or healing their clients. "How do you how do you break out of that identity when you're constantly being told it's what you are," stated one service provider, speaking to the punitive environment of a jail. "[Prisons] are not working on things that could 
help them learn from them, and some people don't even realize what they're doing is criminal activity until someone tells them that what they're doing is criminal activity."

Some service providers acknowledged that temporary jail stays could help a client detox, but they did not even advocate that it was the best way to achieve a detox. Participants whose employment was tied more directly to official channels of the criminal justice system seemed more hesitant to bash corrections harshly, but all stated that they believed it provided almost exclusively harm and trauma to their clients and that those small benefits provided would be better achieved in the community.

Finally, all service providers identified the lack of prevalence of Indigenous-centred programming for their clients. Even those that worked at such programs noted that they were much more the exception than the rule and that it is challenging for clients to find and access Indigenous-centred programs. Some of the service providers stated that they did not know if those resources were available where they were located or that they did not know how to identify if a program met the cultural needs of an Indigenous client.

\section{Differences Between Indigenous and non-Indigenous Service Providers}

Three substantial differences were evident between the non-Indigenous service providers and Indigenous service providers. First, non-Indigenous service providers generally spoke about all their clients, not just their Indigenous clients, whereas the Indigenous service providers directed much more of their answers and the general conversation to specifically Indigenous clients and their unique needs and vulnerabilities. Though the non-Indigenous service providers acknowledged Indigenous clients and their unique needs and vulnerabilities, it was common for them to deviate from the Indigenous-specific topic and to discuss them as part of their mass of 
clients, whereas Indigenous service providers were much more focused on Indigenous clients specifically.

Second, the Indigenous service providers placed much greater emphasis on colonialism in their interviews, though non-Indigenous service providers all acknowledged it in some capacity. Only one non-Indigenous service provider indicated the importance of contextualizing Indigenous experiences in the justice system and their needs for healing under the lens of colonialism. Also, notably, that individual stated that he considered the ability to learn and apply Indigenous knowledges from Indigenous persons to be a great privilege. He considered Indigenous methodology in delivering programming to Indigenous persons to be the best way to support Indigenous clients and even stated his belief that Indigenous approaches would be more supportive to non-Indigenous clients than traditional justice models (though he had only Indigenous clients himself, so he could not confirm).

Finally, Indigenous service providers placed much higher importance on Indigenous clients having Indigenous staff to work with than non-Indigenous service providers did. However, they acknowledged how far it goes to have a non-Indigenous service provider make a genuine and informed effort. "Like I guess there's so many... I feel like if a non-Indigenous service provider is willing to go through, like even the same programs that we're offering to learn how to like build teepees or go to sweat ceremonies or sit with elders and listen to teachings. And then, when they pass on those teachings, even just acknowledging hey I'm not Indigenous, I haven't experienced the same things that you have, but this is what I took from what I learned, I think that would go miles difference." Indigenous service providers acknowledged that there were needs that only Indigenous service providers could fully understand or meet because they shared lived experiences as Indigenous peoples. 


\section{$\underline{\text { Notable Statements }}$}

In addition to the information that was consistent across many or all participants interviewed, there were specific pieces of information obtained from the interviews that were unique to a specific participant or which only a few participants remarked upon. Even though they are not statements that are representative of the entire interviewed population, I still consider the following points to be particularly notable either because of the clear policy implications highlighted or because of the emphasis placed upon the statement by the person(s) interviewed.

As discussed in previous sections, all service providers advocated for a less-rigid, non-punitive, harm reduction approach. All participants discussed this in the context of it being a more effective approach because it acknowledges the importance of meeting clients where they are and creating a space where they feel safe and supported, instead of forcing them into a box where they have to meet certain challenging criteria before they have begun healing. However, to take it a step further, two service providers explained the negative consequences of a coercive approach to rehabilitation. When a client is forced to choose between a recovery program or going to prison, the client may enter into the program for reasons unrelated to the purpose of recovery programs. In the case of drug treatment courts, for example, service providers indicated that they did not believe it was the most supportive approach for clients with substance use disorders because they are required to be abstinent from substances while enrolled in the program. "[Drug treatment court] goes against what we do like fundamentally the opposite of what we're doing," explained an Indigenous service provider. Specifically, she delivered services that met clients where they were, focused on meeting their basic needs, gave them the space to heal from trauma, and then explored substance rehabilitation if desired by the client. "When you [finally]give what they need to survive, [clients] can work on living." In the event that a client is 
"criminally entrenched" and has a long history of substance use disorder(s), which, incidentally, is the demographic drug treatment courts are supposed to service, the client is likely to struggle with the abstinence-based approach. The service providers advocated that there is a need for clients to have positive associations with a recovery program, particularly when they want to attend such a program, instead of having a negative association because they went before they were ready.

Further, two service providers identified the importance of harm reduction in the context of meeting the needs of their clients. One Indigenous service provider examined this point in the context of the "housing first" model of supportive services. Essentially, housing first means that the most important thing a service provider or program can do is meet the client's basic needs of safe housing and food without any restrictions on the client. She elaborated that it means that the client can still be using illegal substances while benefiting from such services. She explained that when clients are engaging in illegal activities to meet their basic needs (such as housing and food), they have little time to focus on recovery, rehabilitation, or healing.

"Now, if somebody is experiencing like chronic alcoholism, we will put them on like a managed alcohol program which would stabilize them. And then next thing you know, they're stable. And now we have to teach them what to do with their free time. When there's so much energy placed into seeking out finding and using whatever... drugs, alcohol, whatever. You replace that with a safe supply, or you know something that is monitored by doctors. Whether it's managed alcohol, managed opiates, or safe consumption, whatever harm reduction response you want to employ. You then need to teach people what to do now because they spent so much time trying to figure out how to get it. And now we're taking away the barriers to all that and going here you go. Now, now we can work on you. Let's take care of what you're struggling with." 
As such, when clients have more free time in their days, stability, and most importantly, support, they are better equipped to develop trust with their service providers and enter the recovery program in the right mindset. Such approaches do not punish clients for their ailments and troubles but instead provide radical support for their needs.

Similarly, multiple service providers identified their need for more time with their clients. Often, many programs could only service clients for a few months, with the lucky ones being up to a year. However, one stated that clients often need many years to fully heal with the support of these programs and staff to develop meaningful, sustainable rehabilitation and healing. If a client is working through a lifetime of trauma, substance use disorders, and many years of criminal activity, it is unlikely that everything can adequately be addressed within a few months, assuming the clients are not kicked out of their programming for previously mentioned reasons.

In keeping with the previous findings, many service providers identified that the available substance recovery programs (if such services existed at all for those in remote areas) were often insufficient in meeting the needs of their clients. They identified that while Alcoholics Anonymous (AA), for example, might be available for a client with alcohol use disorder, AA is only one approach to recovery and might not serve need needs of their clients. Service providers stated that there needs to be greater availability of substance rehabilitation programs available to their clients and that these programs need to have the ability to target the individualized needs of a client instead of delivering a one-size-fits-all approach and hoping it sticks.

In the context specifically of specialized courts, the service provider working in the court system had the greatest degree of knowledge about such programs. She discussed the origins of these programs being rooted in lawyers and others in the court system being incredibly frustrated that they were seeing the same clients over and over again and that the system was clearly not 
benefiting those clients or supportive their rehabilitation. However, similar frustration arose again with specialized courts because of the absurd wait times. "Why even bother if the next opening is posted over two years from now?" She stated that it was so difficult and unlikely to have a client accepted into a specialized program that most lawyers did not even bother trying with their clients, even though they knew of the benefits of the program.

Finally, she discussed that it was common for the majority of clients within any given specialized court to all be represented under the same handful of lawyers. Essentially, the same two or three lawyers were representing almost all of the existing enrolled clients. Informally, this would indicate that an unofficial eligibility criterion includes having the right lawyer. Note that this does not indicate conspiracy or corruption, but rather so the realities of practice within these specialized courts. These handfuls of lawyers understand the application process, are attuned to when the program has available spots open up, and are experienced regarding what gets a client admitted. I can also echo this statement from my own time as a member of staff at a drug treatment court.

\section{Conclusion}

Put simply; Indigenous clients are not having their needs met. In the context of basic needs, they are not receiving the programming that they require and are instead receiving trauma from the carceral experience. With regards to their cultural needs or unique considerations, the limited available resources are incredibly hard to access. Many of the best-intentioned service providers are often non-Indigenous and unable to meet the cultural needs or fully understand their clients, and even those Indigenous service providers (alongside non-Indigenous service providers) lack adequate resources to deliver the programming they know their clients need. Even if they had the resources they required, the systemic policy setup does not show any evidence of considering the 
unique needs of Indigenous clients. Not only that, but it actively disadvantages Indigenous clients within specialized court programs, in the event the exclusionary policy permits an Indigenous participant at all.

These findings are deeply troubling but are not surprising. Indigenous peoples have faced constant systemic oppression since the colonization of Canada. Institutional barriers and failings and their replication of historic colonial practice are clear. However, seeing all of these findings in one place brings me tremendous pride. I have so desperately wanted to reach this moment for many years. Some of the findings were known within these programs, including to myself, for years but did not exist in an officially published document. For so many realities, this has been my experience surrounding Indigenous peoples or the criminal justice system.

Despite the discouraging realities of alternatives to corrections being inaccessible to Indigenous persons for many reasons, I am proud to be able to present the areas that require further attention. As my mother wisely reminded me while I wrote this thesis, "The first step is to speak the truth" (R. Tompalski, 2021). Representing the thoughtful knowledges, insights, experiences, and truths of the participants for this study is my absolute privilege. 


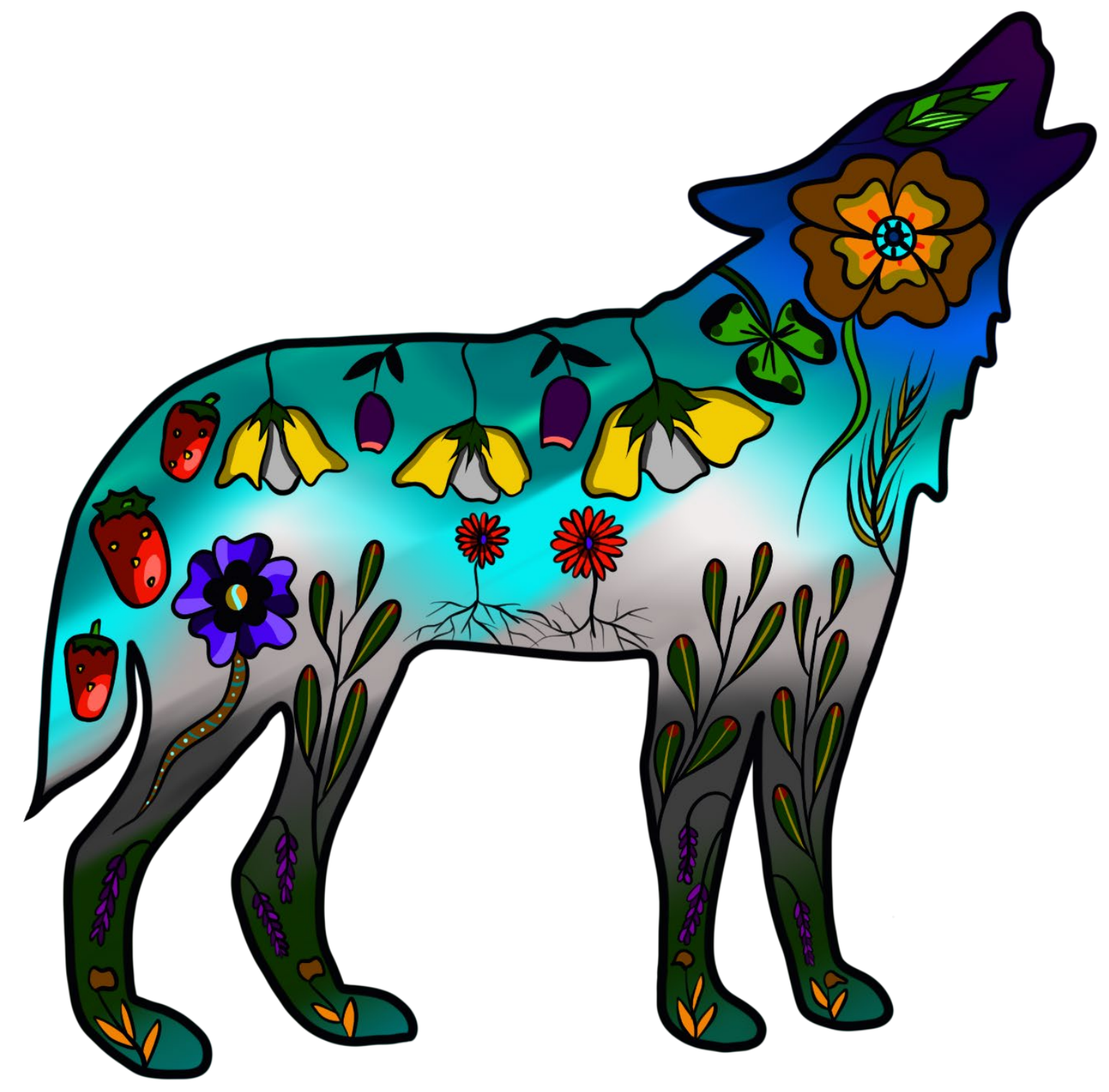




\section{Chapter 7: Analysis of Findings}

\section{Introduction}

My previous chapter demonstrated the findings obtained through my study with as little of my own analysis as possible - done this way for the purpose of letting their words breath without my corruption. Here, I present my analysis in this chapter. Before directly exploring my analysis, I must first identify the fact that I noticed my theoretical framework shared similarities with the positives as shared by the participants who were interviewed for this study. Correspondingly, it is under this framework I have examined many key findings in this chapter. Though I will highlight any positive findings obtained, much of the analysis is composed of a critical analysis of the policy for specialized courts as the barriers and challenges as determined by the interview findings.

\section{A Reminder of Theoretical Framework}

As previously discussed, the theoretical framework developed to analyze the following findings utilizes these five pillars: 1) place and being (Watts, 2013); 2) the processes of engagement surrounding Indigenous-focused works; (L. B. Simpson, 2017a), 3) engagement of the studied Indigenous persons in the process (Tuck \& McKenzie, 2015); 4) desire-based research surrounding Indigenous peoples (Eve; Tuck, 2009), and 5) Indigenous identity as a form of healing from colonial trauma; (Thistle, 2019). This framework is intended to examine my findings under an Indigenous-informed, Indigenous-centred, and empowering lens. 


\section{Analysis of Admissions Eligibility Criteria}

Participants are not able to self-refer to a specialized court program or other forms of alternatives to incarceration. As established from the interview findings, many lawyers do not bother with applying for their clients to such programs because the likelihood of success is so limited. This area of policy demonstrates a violation of Pillars 2, 3, and 5. The processes of engagement are poor because exploring better alternatives does not occur because those alternatives are unlikely to occur. Indigenous engagement in the process does not occur in the event the Indigenous person wants to have more autonomy in the legal process. When considering both pillars, it is important to acknowledge that Indigenous persons in the criminal justice system are more likely than non-Indigenous persons to receive court-appointed legal representation (Nielsen, 2006; Toki, 2009). Finally, in the case of Pillar 5, healing through connection with Indigenous identity, Indigenous clients are potentially being denied the opportunity to receive programming that is culturally relevant, further to a failure to have Gladue principles practices on their behalf (S. Lee, 2020).

The requirement that a participant pleads guilty to be able to participate in an alternative to incarceration is a clear instance of coercive control (Ellis, Lewis, \& Nepon, 2021). Not only is this a terrible precedent under which to enter rehabilitation and healing, but it eerily mirrors the practices of enfranchisement. It used to be that if Indigenous persons wanted to engage in basic elements of society, like voting, they were first required to give up their Indian Status (Vowel, 2016c). Indigenous persons should not be required to give something up on the basis of being able to participate in something less traumatizing than prison. Not only is this specific practice inappropriate as a result of its perpetration of coercive control (Nemerson, 1980), but it is also 
directly employing and enforcing colonial practices. Specialized court programs can never be decolonizing or supporting reconciliation while such practices exist.

The very nature of these specific eligibility criteria is absolutely infuriating to me. It is well documented that Indigenous persons are more likely to be over-policed than non-Indigenous persons (Canadian Broadcasting Corporation, 2017), meaning they are more likely to meet the exclusionary criteria (Greg et al., 2020). Not only that, but Indigenous peoples are more likely to be charged with more serious offences than non-Indigenous people (Anthony, Bartels, \& Hopkins, 2015; Bell, 2016). This policy is certain to disproportionately exclude Indigenous applicants from admission into the program.

Some programs identify in their eligibility criteria that the applicant must be criminally entrenched or a prolific offender. Such a definition is problematic as there is not one accepted definition of being criminally entrenched. Some programs identify their participants as having dozens of previous convictions, though others state they just need to have an offence that was caused or contributed to because of their substance use (assuming it was not alcohol). The lack of clear criteria for who a drug treatment court is even for can be used as a tool to exclude applicants even if they would benefit tremendously from the program.

Additionally, in my own experience of working in a drug treatment court, I found tremendous inconsistencies with that definition. Despite working in a program that was designed for "criminally entrenched" individuals, about a third of our clients were white young adults with little to no previous convictions. The purpose of placing those clients in the program was to save them from a life of criminalization, which is actually a really good idea. However, it is problematic because those who would have been eligible under those working practices are not aware they would be eligible in such programs. If a program specifies it only takes criminally 
entrenched individuals but then modifies its practices to include offenders who can be provided intervention away from the lifestyle before becoming criminally entrenched, then the policy should be updated to reflect that.

The decision to exclude alcohol use disorder in particular as an eligible condition is baffling, particularly when considering that it is still a substance not permitted to be used while enrolled in the program. Given the higher rates of alcohol use disorder among Indigenous peoples compared to non-Indigenous people (Dion et al., 2015; Ross et al., 2015; Sheleff, 2002), the high presence of alcohol use disorder among prisoners (Weekes et al., 2019), and the overall correlation of alcohol to criminal offending (Martin, 2001; Vartanian, 2013), not only are these criteria excluding Indigenous persons from drug treatment courts, but it is a generally poor policy decision for all participants. The failure for the Canadian governments to assume responsibility for placing Indigenous peoples at increased risk for criminalization is bad enough, but to then exclude them from programs aimed at rehabilitation and healing is deplorable and inherently colonial.

Given the higher rates of Fetal Alcohol Spectrum Disorder (FASD) among Indigenous peoples than non-Indigenous people (Milward, 2014), the very nature that this is a reasonable exclusionary criterion is completely inappropriate. Further, given the linking of FASD as a risk factor for (Gagnier, Moore, \& Green, 2011; Nevin, LaBerge, \& Rutman, 2007) criminal behaviour, this policy is certain to disproportionately exclude Indigenous applicants from admission into the program.

Being assessed at low risk to the community to be eligible for a specialized court program or alternative to incarceration is a more challenging element of policy to critique because of the 
potential for variances from different actors, in addition to the fact that few programs define what it means to be "low-risk." However, there are two important topics to address.

Indigenous peoples already face substantial racism on personal and institutional levels (Allan \& Smylie, 2015; Truth and Reconciliation Commission of Canada, 2015b). On both levels, Indigenous peoples are already likely to be evaluated as a higher risk to the community than their non-Indigenous counterparts (D'Arcy, 2018; S. C. Lee et al., 2020; McCuish \& Corrado, 2018; Zinger, 2004, 2012, 2020). The failure of the policy to include appropriate provisions to prevent bias or racism certainly guarantees Indigenous clients are less likely to be eligible for such programs.

In a specific instance, gang affiliation is an unofficial exclusionary factor under the premise of risk. Given the previously-mentioned over-policing of Indigenous peoples (Canadian Broadcasting Corporation, 2017; Nettelbeck \& Smandych, 2010), the higher risk for criminalization - and therefore gang involvement or affiliation - as a result of colonialism (McGuire \& Murdoch, 2021; Monchalin, 2016; Vowel, 2016b), Indigenous persons are again more likely to be excluded on this basis.

It is abundantly clear that many of the eligibility policies for specialized court programs or alternatives to incarceration inadvertently support institutional racism, as they fail to consider their negative implications on Indigenous persons specifically. For these programs to better serve Indigenous persons, they are likely to need a complete policy overhaul developed by Indigenous peoples.

An abstinence-based recovery approach is simply not realistic when treating someone with a substance use disorder (Gallagher et al., 2019; Gubi \& Marsden-Hughes, 2013), particularly then 
the admission criteria for a specialized court indicates they take those who are entrenched in addictions and criminalization. As noted by the interview participants, it makes very little sense to expel someone from a rehabilitation program in the event they engage in the very behaviour they are being treated for. Given the additional factors contributing to Indigenous substance use disorders (Ross et al., 2015; S. H. Stewart et al., 2011; Vowel, 2016b), it is unrealistic to expect Indigenous persons to thrive in these programs without forgiveness, compassion, and support for relapses (Burton \& Martin, 2020; Havassy, Hall, \& Wasserman, 1991).

Further, this is linked to the criteria that participants must abstain from all criminalized activity. As mentioned previously, Indigenous peoples are subject to over-policing (Canadian Broadcasting Corporation, 2017; Kiedrowski, 2013; Nettelbeck \& Smandych, 2010), meaning they are more likely to be caught engaging in disqualifying actions than their non-Indigenous counterparts. Moreover, if an Indigenous client is to relapse on an illegal drug, that necessitates the purchase and possession of those drugs, which is illegal (Tremeear, 1997).

"Like going back and thinking about my childhood about my grandma fought my mom about how much they drank." Trauma, early exposure to drug and alcohol use, child displacement, experienced racism, and how they all relate to colonialism are key factors in understanding the criminalization of Indigenous peoples (Maxwell, 2017; Monchalin, 2016; Vowel, 2016b). Particularly, Pillar 5, healing through connection to Indigenous identity, is essential. By understanding the links to trauma, addictions, and criminalization - which, incidentally, mirrors the journey of the author for whom this pillar was inspired (Thistle, 2019) - Indigenous persons can be better supported through their healing journey. A failure to acknowledge the unique Indigenous realities surrounding risk, trauma, criminalization, and colonialism could only ever produce insufficient results. 
The interviewed participants identified incarceration as being an extremely traumatic experience, calling it "terrifying", "horrible", or the "worst thing that ever happened in their life". In fact, incarceration has been linked with producing comparable trauma in Indigenous peoples to that of residential schools or other horrific colonial forces (Montford \& Moore, 2018; Truth and Reconciliation Commission of Canada, 2015b; Vowel, 2016b). By removing Indigenous peoples from their communities and lands - working in opposition to Pillar 1 - Indigenous persons are forced to experience additional colonial traumas and cultural disconnects. For an alternative to incarceration programs to provide support in a way that is meaningful to their participants, they must acknowledge these modern colonial traumas, reconnect their Indigenous clients to their communities and cultures (Pillars 1 and 5), and empower their clients (Pillar 4).

\section{Actual Healing and Support from Community}

"Feels good to know if something bad happens, they can step in and help," said a participant in reference to the organization that currently supports him while on conditional release.

Additionally, they were grateful to be in a program where "everything they needed was in one place," so it became easier for them to meet all of their needs and conditions. These statements highlight the importance of the process (Pillar 2) when serving a client, as it can be difficult for individuals (based on circumstances - where they live, if they have access to transportation, if they have mental health challenges, if they have children to care for, if they are experiencing financial difficulties, etc.) to stay on top of all that is required of them without support.

An example of where colonialism and the community failed a client was in the case of birth alerts. "They told me like you're on you have a birth alert on you, for this and for that, and so I had the opportunity to kind of get better .... and that was kind of what was the pushing points and be like okay I need to do something. Anything." Here, the process is shown to be rooted in 
punishment. Though ultimately, the participant was able to build a better life for herself and her daughter, there is colonial trauma rooted in how that came to be - especially when considering the participant was a Millennium Scoop survivor herself.

Finally, they stated they were able to gain strength and confidence from their families being nearby to "give me moral support all the time," the ability to connect with someone trusted when doing something they were not sure how to do. Having a sense of community, connection, and resources for not only help but empowerment (Pillar 4), demonstrates the importance of the setting (Pillar 5) and process (Pillar 2) for the participant.

\section{Interview Data from Service Providers Working with Indigenous Persons}

In this section, I have identified particular findings obtained from the interviews of service providers and then provided analysis through my established theoretical framework.

\section{$\underline{\text { Resource Drought }}$}

Many programs operate very effectively under their limited funding, as indicated by the tremendous pride in their work expressed by the interviewed service providers. However, all service providers indicated their limitations and failings were largely owing to a lack of resources. It is true that the absence of resources has always been a problem for such organizations, though it has been worsened tremendously by the COVID-19 global pandemic (Buckner, 2020; Haws \& Kapelos, 2020). Indigenous peoples are no strangers to having insufficient resources directed to us (Truth and Reconciliation Commission of Canada, 2015a, 2015b). The failure to adequately support those organizations that are on the frontlines of supporting vulnerable Indigenous peoples is a failure to respond to the 94 Calls to Action and shows tremendous disregard for Indigenous peoples on behalf of the government. 


\section{$\underline{\text { Harm Reduction Over Punishment }}$}

A harm reduction model demonstrates the importance of process (Pillar 2) and that substance use disorders are not something wrong or shameful about an Indigenous client (Pillar 4). Harm reduction models have been shown to prevent injury and death, reduce costs to the community and to government organizations, destigmatize substance use disorders, and make rehabilitation and healing more accessible (O'Mara, 2020; Wild et al., 2017). Despite such evidence, these practices are not implemented in areas of the justice system needed by Indigenous peoples especially (Ziegler, Wray, \& Luginaah, 2019). The failure to adequately develop and enforce policy, despite such overwhelming evidence of the effectiveness of harm reduction models, not only negatively impacts Indigenous clients through their rehabilitation journeys but also reinforces colonial models and their negative impacts.

Where are All the Indigenous Persons in Programming Delivery? Contextualizing Colonialism

As highlighted by the Indigenous service providers and by one non-Indigenous service provider, it is important for Indigenous clients to have Indigenous service providers to work with. Such service providers are better equipped to deliver programming that is contextualized and genuinely understood under the impacts of colonialism.

Additionally, it is important that Indigenous persons have access to Indigenous staff who share their lived experiences. As highlighted by Pillar 3, Indigenous involvement in processes is important. While I have largely discussed this in the context of policy development, this holds true as well for actual program implementation. Indigenous clients could benefit tremendously from working with other Indigenous peoples who understand the context they live under, who 
can support them in their healing through culturally relevant tools and practices (Pillar 5), and who do not view Indigeneity as something meaning the client is damaged or broken (Pillar 4).

Finally, it is key to understand the importance of having Indigenous peoples in those roles. One participant stated how incredible it was for her "To have people take me seriously as an Indigenous woman, regardless of what I look like.” Not only are Indigenous clients benefiting from program delivery from service providers who understand them, but overall Indigenous empowerment is achieved by showing Indigenous peoples in these roles and making a difference.

\section{$\underline{\text { Radical Support Over Punishment }}$}

The service providers identified the importance of providing radical support for their clients, meeting them where they are at, empowering the strengths of their clients, and individualizing their approaches to the needs of the clients. Such practices reflect Pillars 2, 3, and 4. Without the

ability to deliver these strategies to their clients, either because of lack of resources or because of restrictive policy, the service providers will never be able to deliver the kinds of programming required by their clients (Havassy et al., 1991; Maxwell, 2017).

\section{$\underline{\text { Time to Support }}$}

As previously mentioned in the section "Resource Drought," the problem of service providers lacking sufficient time with their clients (owing to lack of resources) can only be solved by increasing resources to these programs. Pillar 2 emphasizes the importance of process, which is important to examine here. Participants are better served in a program that radically supports them, that does not seek to punish them, that allows the client to move at their own pace, and where they have time to develop trust with their service providers. Certainly, programs still have 
an impact without longer time spent with the clients, but the process could absolutely be improved upon to be more meaningful and more effective.

\section{$\underline{\text { More Recovery Options }}$}

Interestingly, many service providers identified the need for recovery programs for their clients that better met the individual needs of the participants. Despite the widespread availability of programs within urban areas, often these programs did not meet the needs of the clients, particularly Indigenous clients. In such cases, it is likely that the existing programs could be improved upon by employing theoretical frameworks to their practices to support their Indigenous clients better. In the case of rural or remote areas, a solution is only possible if provincial, territorial, and federal governments increase funding for such programs in those areas.

\section{Follow-Up Interviews}

As previously mentioned, the participants were given the opportunity to confirm my interpretation of their findings. Only two service providers elected to participate in a follow-up interview - it is my suspicion that many more would have been interested but lacked time to do

it. However, those who participated in the follow-up interviews confirmed my interpretations and took the opportunity to elaborate on certain points in greater detail, which is reflected in the above analysis.

\section{Finding Embodying Theoretical Framework}

During the interview process, I regularly found myself shocked and amazed by the nuanced insights shared with me by the participants. Were someone to conduct a study on what it is like to be interviewed by me for this project, the likely conclusion would be that I sometimes came 
close to gushing my admiration and respect for the interviewed participants. Every single interview contained such a moment, but I am compelled to highlight one specific example because I believe it is the perfect embodiment of the conclusions I have drawn from this research.

In what was without question the longest interview I conducted for this research (owing to the wealth of knowledge from the participant and their sheer enthusiasm for Indigenous justice), the participant - I will use the pseudonym John - shared with me his philosophy for conducting the specialized court program for which he was a manager. To paraphrase, he stated that, as a nonIndigenous person himself, he felt so privileged to provide justice services to Indigenous clients that are centred in the Indigenous community of the area. When their program was developed, the organization worked collaboratively with the Indigenous community in their area, particularly with Elders and Knowledge Keepers, to identify key elements of Indigenous approaches to criminal justice and healing. Before actually implementing the program, the participant joined the community for teachings, cultural activities and to generally get to know them better. In the Indigenous community, the participant learned that learning Indigenous teachings and values, much less being educated by Knowledge Keepers on how to implement them, was privileged.

He stated to me that he considered the knowledges he gained to be some of the most important things he knew. Not only that, but he considered himself lucky to have been educated. By understanding colonialism and its impacts, he was shocked as a settler to have been granted such education. His most impactful statement was that all justice programs, not just those targeting Indigenous peoples specifically, should be thankful to Indigenous peoples and communities for sharing their knowledges and the way forward. 
"We have to create a dynamic where the Court feels indebted to the Indigenous peoples for agreeing to be part of their criminal justice system, and they the Court is gracious and in being thankful that Indigenous peoples are willing to participate in a system that has historically and presently been an injustice system.” - Participant 'John'

John felt that not only should Indigenous peoples be thanked for sharing their insightful, sophisticated knowledges, but that Indigenous communities be recognized for showing such grace, forgiveness, and strength to work with a system that has caused so much damage.

To explore the remarkable nature of that statement, I must share my own experience working in the justice system. As a Circle Leader for a youth justice committee, I worked to deliver a restorative justice program to youths referred to our program, and our circles always contained another service provider from the program alongside myself. When we transitioned our sessions with youths from authoritative interviews to circle format - a decision made by our board to be more in line with Indigenous roots in restorative justice - my colleagues all complained to me about the decision to switch. They explained to me that this was not a strong approach because it gave equal voice to all participants, preventing us from demonstrating our authority to the youths. Further, they felt as if the process was not necessary, considering we were already supporting Indigenous justice by accepting Indigenous youths into the program.

Why my colleagues felt comfortable making such pejorative comments to me, I will never be able to explain. However, this experience was ultimately not a standout but merely a first of many regarding Indigenous-centred or Indigenous-inspired programming in corrections. Throughout my time working within the criminal justice system, I believe I have forgotten more stories like the one I just shared than I actually remember. These limited and destructive attitudes (at least in Alberta, where I worked) were commonplace. 
Now I return to John's perspective. Where my colleagues begrudged the requirement to apply Indigenous methods into our work, John was excited. Not only was he excited, but he was grateful. I believe, from his telling of events, that his gratitude was influenced by the strong understanding he obtained about the community values and practices for justice, in addition to understanding the realities of colonialism. He demonstrated an understanding of colonial trauma and how it influences Indigenous clients and their healing journey, much in the way that Gladue principles and reports are intended to function (Native Women's Association, 2015).

[The Court expects] us to be so pleased with the Court for being less unjust than they've been in the past right. [The Court has] to learn that they're the ones that should be grateful that an occupied people are willing to even work with them. - Participant 'John'

John's values with his program, in addition to the other Indigenous service providers interviewed, align with every pillar of my theoretical framework. 1) Place and being, John emphasized not only the importance of delivering the programming in the lands of the individuals instead of a traumatizing and non-supportive institution, but he also emphasized that the ability to learn from Indigenous peoples was much more engaging and effective by visiting them within their community instead of having them come to him. Indigenous service providers highlight this point by emphasizing the importance of proximity to those who know and love you, those with knowledge and teachings from your culture, and the importance of situating youself in a place where you can live your life in a good way. 2) The processes of engagement surrounding Indigenous-focused work, with John focusing on the way he, a settler, participates in justice processes for his Indigenous clients. Merely treating the Indigenous knowledges and supports as not only an asset, but as best practices, contributes to decolonizing. Certainly, John remains a part of the colonial justice system, but is contributing to decolonizing by diminishing 
his own authority in favour of the Indigenous practices. 3) Engagement of the Indigenous persons in the process, because actual autonomy (though incomplete) is given to the Indigenous persons in how justice is administered and undertaken. 4) Desire-based research surrounding Indigenous peoples, as the Indigenous knowledges are seen as the solution to the toxic and harmful settle justice approach. 5) Indigenous identity as a form of healing from colonial trauma, by prioritizing connection, knowledge, and empowerment of Indigenous clients by creating access to Indigenous healing and justice approaches instead of sticking to colonial models.

\section{Limitations}

"Mistakes produce knowledge. Failure produces knowledge because engagement in the process changes the actors embedded in process and aligns bodies with the implicate order." (L. B. Simpson, 2017b)

I tried my very hardest to make this thesis all that it could be. However, as is often the case when I am producing artwork or traditional crafts, it can never really be 'finished' as it could always be added to or improved upon. However, my future academic journey, other projects, and general interests in things outside of this thesis have necessitated that I complete it at some point. Though I will never consider this work done, it is certainly done for now. Correspondingly, there are some limitations to my work. While I would never be so arrogant to assume I did everything correctly, I do take comfort in knowing that I prioritized a process that mitigates research violence, creating a desire-based approach, and the uplifting, empowerment, and amplification of Indigenous voices (Eve; Tuck, 2009; Tuck \& McKenzie, 2015).

That said, with time and further contributions to knowledge, this thesis may evolve to be something that is no longer the best practices for Indigenous peoples. If that becomes the case, I hope that my future works evolve with the times. If this text becomes out of date and no longer 
supportive of the needs and goals of Indigenous peoples I request that it not be used as a tool to undermine their arguments.

\section{Conclusion}

From the analysis provided above, it is clearly demonstrated that the policy for specialized courts does not meet the needs of Indigenous clients, nor does the policy combat the potential for racist practices on behalf of agents of the criminal justice system. The policy and practices in place are fundamentally under-serving Indigenous persons in the criminal justice system by providing inadequate rehabilitation and healing tools, promoting punitive and even counter-intuitive practices, and overall contributing to the over-representation of Indigenous peoples in the criminal justice system. Though specialized courts and their inadequacies are unlikely to be the largest contributing factor to the problem of over-representation of Indigenous persons in the criminal justice system (Michael; Weinrath et al., 2018; Michael Weinrath \& Smee, 2016), it certainly demonstrates that there is tremendous room for improvement in these programs.

Furthermore, these programs are merely one example of community alternatives to incarceration, having their policies, practices, and resources misdirected in such a way that disproportionately negatively impacts Indigenous persons. Viewed under the broader lens of the colonial criminal justice system, the ongoing practices are normalizing and contributing to the further oppression and disadvantaging of Indigenous persons.

A more in-depth section on recommendations and areas needing reform is provided in the following chapter. However, I would be remiss if it did not acknowledge here the importance of Pillar 3, developing policy or practices, or anything at all, in collaboration with Indigenous peoples. The failure to do so, or doing so merely at the end of the process to check an implied diversity box, is completely insufficient. The findings and analysis I have provided in this 
chapter and the last add to the ever-growing body of knowledge, which states plainly that Indigenous peoples need much better from the Canadian criminal justice system, as well as from every individual who is aware of the problem of Indigenous over-representation in custody.

The knowledges obtained throughout this study have demonstrated the importance of constantly evaluating our practices and policies and examining exactly why we are even doing them. We have to examine if those our policies are meant to serve are supported in creating those policies, not creating something for them without consulting them. The problems of systemically racist policy, unchecked biases and racism from criminal justice actors, and the unintended consequences of thoughtlessness and carelessness about Indigenous peoples cannot be undone under the current system. Only by amplifying Indigenous voices and elevating them to powerful positions, returning Indigenous peoples to their communities and lands, and restoring Indigenous autonomy and self-governance in the justice process can we begin to the right the wrongs that the criminal justice system currently causes and perpetuates. 


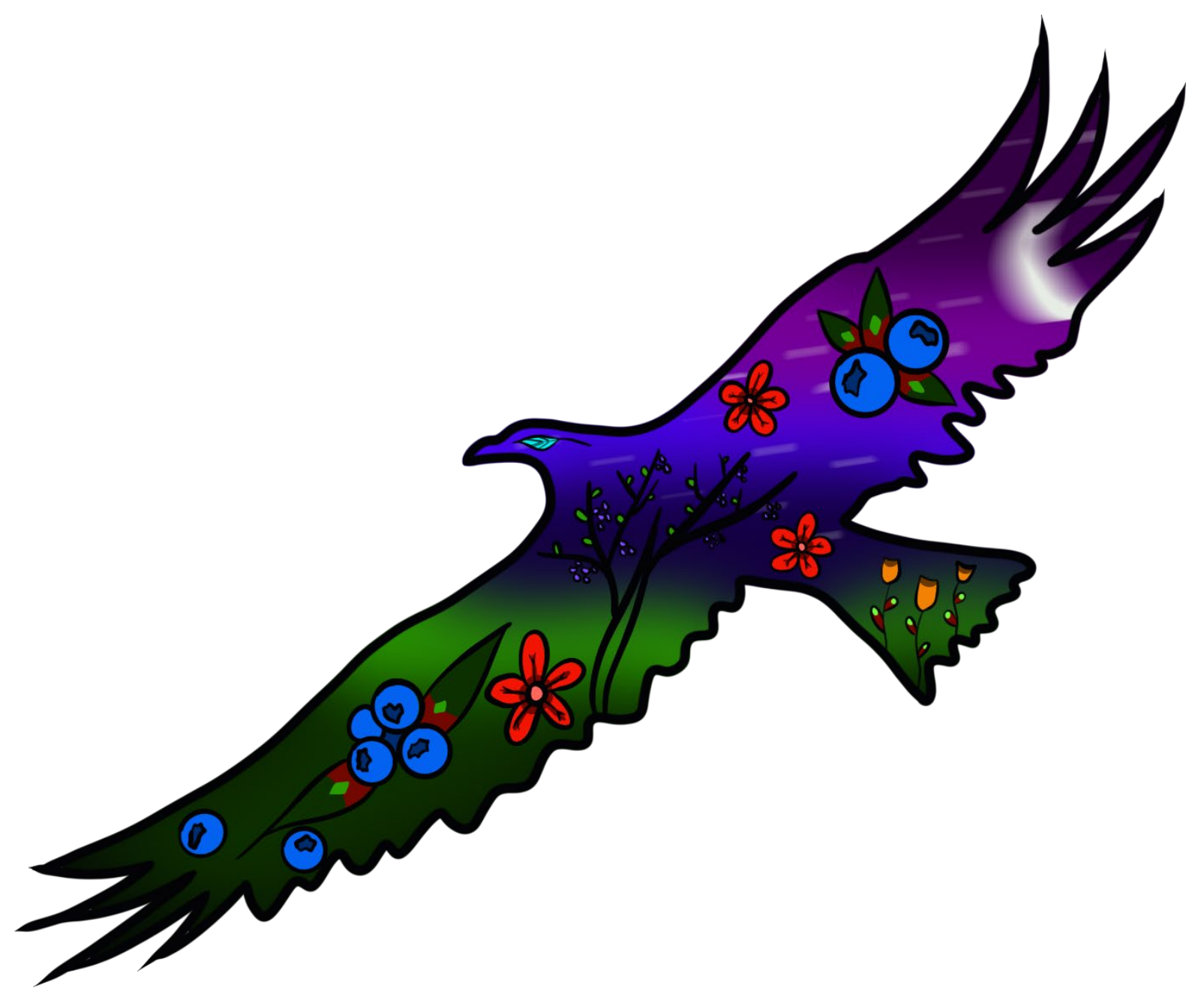




\section{Chapter 8: Policy Recommendations and Areas for Future Research}

In this final chapter, I outline my recommendations for program and policy recommendations and future research.

\section{Program and Policy Recommendations}

I have produced the following recommendations as an essential first step in addressing current wrongs within the Canadian justice system. However, I acknowledge myself as being only one Indigenous voice. It is likely that such recommendations will evolve in the future as more Indigenous peoples consult in these processes.

$\underline{\text { Specific Policy Recommendations for Specialized Courts (Section 1.0) }}$

The following recommendations specifically the policy failures in specialized courts as identified through this research.

1. Implement Gladue-style principles to eligibility criteria policy for specialized courts, such as:

a. Allow Indigenous participants with alcohol use disorder to become eligible for drug treatment courts,

b. Allow Indigenous participants with cannabis use disorder to become eligible for drug treatment courts,

c. For Indigenous applicants, remove the following from eligibility criteria:

i. No violent convictions,

ii. No domestic violence convictions,

iii. No sexual convictions, 
iv. No gang affiliation,

d. Create provisions for addressing racism while assessing risk to the community of Indigenous applicants,

e. Remove requirements that participants stop using medically prescribed cannabis to be eligible to enter the program,

2. Implement Gladue-style principles for court program conditions while enrolled for specialized courts, such as:

a. Create leniency for relapses by Indigenous clients,

b. Develop procedures that address potential racism as a contributing factor to violation of legal or program conditions, and

c. Remove requirements that participants not using medically prescribed cannabis while enrolled in the program,

3. Create Indigenous-centred policy for all specialized court programs so as to broaden the reach of Indigenous-centred policy in the justice system.

In Recommendations 1.1a and 1.1b, I include these to produce more programs that support the needs of Indigenous peoples. It is estimated that as many as $50 \%$ of incarcerated persons in Canada live with alcohol use disorder (Weekes et al., 2019). Though I believe that any participant should be eligible under alcohol use disorder or cannabis use disorder, at very least, Indigenous clients should not be ineligible under this basis given our over-representation in the criminal justice system (Jamil, 2020) and overall higher prevalence of substance use disorders in Indigenous communities (Dion et al., 2015; Ross et al., 2015; Sheleff, 2002). With regards to Recommendation $1.1 \mathrm{c}$, I am making this recommendation in response to the exclusionary nature of program eligibility criteria. Given the over-policing of Indigenous peoples (Canadian 
Broadcasting Corporation, 2017), as well as how racism can play into charges and convictions (Cunliffe, 2018), removing the criteria that indirectly is biased against Indigenous applicants is a helpful first step. The remainder of policy suggestions exists to help combat the systemic racism experienced by Indigenous peoples in the criminal justice system.

\section{Funding and Priorities (Section 2.0)}

Specialized courts and programs have demonstrated their potential for healing and reducing recidivism, particularly when they are well resourced and can modify their approach to the needs of the individual. At this time, as a reform measure, I can provide the following recommendation:

1. Increase available funding for drug treatment courts, mental health courts, Indigenous courts, and other types of "problem courts," which seek to support individuals to address their traumas and root causes of crime.

2. Develop policy quotas for the minimum amount required of available funding for specialized court programs to be dedicated to Indigenous-centred and -led initiatives.

3. Develop policy and funding allocations that incorporate the harm-reduction model (instead of abstinence-based) so as to address the primary critiques of drug treatment courts by service providers and drug rehabilitation professionals.

Above all else, I highly recommend additional programs to be made available and accessible to clients, particularly in rural and remote communities that might lack suitable, comparable alternatives. I have strongly emphasized throughout this thesis the importance of Indigenouscentred policy in alternative justice streams to combat the over-representation of Indigenous persons in custody. However, it is currently understood that specialized courts do not 
meaningfully account for the over-representation of Indigenous persons in custody - despite under-serving Indigenous clients - because they already serve so few clients owing to their limited resources (Michael; Weinrath et al., 2018). When I worked at the Edmonton Drug Treatment Court, our program had twenty spots for participants to be enrolled(Jaclyn Tompalski, 2021b), of which a mere ten were funded through state resources (Edmonton John Howard Society, 2021).

I strongly believe Indigenous-centred policy in community alternatives to incarceration to be a viable approach to reducing Indigenous over-representation, but only if it is implemented along with a substantial bump to resources. By returning Indigenous peoples to places of healing, engaging in the mindful processes surrounding justice and healing, Indigenous engagement in the process, a desire-based approach to supporting Indigenous clients, and healing cultural trauma and providing cultural growth, these community organizations are well on their way to reducing Indigenous over-representation. It is the responsibility of government officials and policymakers to not only provide better policy but better funding as well. Given their commitments to the 94 Calls to Action and to reconciliation in general (Assembly of First Nations, 2018), the governments must put their monies where their mouths are, walk the walk, provide the kinds of justice services identified as needed by Indigenous peoples, and centre Indigenous peoples, communities, groups, organizations, and nations in the process.

\section{Indigenous-Centred Policy Over Indigenous-Focused Policy (Section 3.0)}

My own experiences working in governmental policy development have enlightened me to the realities of intended practices versus actual practices. Such experiences, combined with the policy gaps throughout this thesis, have informed the following policy: 
1. Shift the focus of Indigenous-focused policy towards an Indigenous-centred policy, meaning:

a. Indigenous peoples are involved in identifying policy gaps;

b. Indigenous peoples are involved in the development of policy from inception;

c. Elders, Knowledge Keepers, or other appropriate, prominent Indigenous community figures are consulted before the policy is approved;

d. Indigenous peoples are involved in policy implementation;

e. In implementing the above, it is essential to note the following so as to mitigate potential colonial harms:

i. the Indigenous persons, Knowledge Keepers, or Elders providing this work should be compensated by the Court or the community organization developing the policy,

ii. the Indigenous persons should be consulted in determining how they are compensated, and

iii. The Indigenous persons should be thanked and acknowledged appropriately for their knowledges.

The difference between Indigenous-focused policy and Indigenous-centred policy is nuanced. Where Indigenous-focused policy acknowledges the unique needs and circumstances of Indigenous peoples and how policy is applied to them, Indigenous-centred policy is born from Indigenous peoples in collaboration with settler organizations or the state. Indigenous-centred policy embodies every element of my theoretical framework: 1) place and being, as it centres the development of the policy in the areas where it will be applied; 2) the processes of engagement surrounding Indigenous-focused works, as it acknowledges that merely identifying Indigenous 
needs does not produce the intended results; 3) engagement of the studied Indigenous persons in the process, by actually centring Indigenous peoples in such policy development; 4) desire-based approaches surrounding Indigenous peoples, as it gives Indigenous peoples the opportunity to produce policy that is not damage-centred (Eve; Tuck, 2009); and 5) Indigenous identity as a form of healing from colonial trauma, by offering connection to Indigenous identity even through something as indirect as policy.

Indigenous Policy and the Criminal Justice System (Section 4.0)

As observed through the journey of participant John in Chapter 6, a thorough understanding of colonialism and its impacts on Indigenous people relating to the justice system can alter the way a service provider delivers programs to Indigenous clients. John was not a service provider implementing Indigenous policy and programs without a specific understanding of the programming, why specific elements are important, and why such Indigenous-focused options are required. John learned from Indigenous Knowledge Keepers about colonialism and was not relying on information provided by settlers in a classroom or through the news.

With reference to John's example, previous experiences, and community precedence as context, I have developed the following recommendation:

1. When implementing Indigenous-specific policy, service providers should be required to be educated on the policy by willing Indigenous Knowledge Keepers. Such education should:

a. contextualize the realities faced by criminalized Indigenous persons under colonialism,

b. contextualize the strained relationship between Indigenous peoples and the state, 
c. explain that such policy was developed and is applied to support reconciliation,

d. explain directly why this policy was developed and how it relates to Indigenous knowledges,

e. highlight that it was developed collaboratively with Indigenous peoples or communities,

f. explain why it was developed centring Indigenous voices,

g. be related to general Indigenous justice and healing philosophies where further context is needed

h. develop an understanding of why the service provider is privileged to be receiving these knowledges as training, and

i. develop an understanding of why the Court or community organization is privileged to have received Indigenous labour and knowledges to produce the policy in question collaboratively,

j. In implementing the above, it is essential to note the following so as to mitigate potential colonial harms:

i. the Knowledge Keepers should be compensated by the Court or the community organization employing the service provider, and

ii. the Indigenous persons should be consulted in determining how they are compensated, and

iii. The Indigenous persons should be thanked and acknowledged appropriately for their knowledges.

Further, I have developed the following recommendations which I believe could alleviate some of the ongoing barriers to Indigenous justice: 
2. Generally, any criminal justice policy should be amended to include a section of policy that is Indigenous-centred. Such policy should:

a. be developed by Indigenous peoples and communities for Indigenous peoples,

b. include Indigenous peoples from the very beginning of the policy process,

i. Note: this does not mean having non-Indigenous staff produce policy and then having Indigenous peoples sign off on it.

c. include Indigenous peoples in the implementation of such policy,

d. have the organization modifying their policy provide education to their service providers on why the policy is being implemented, and

i. Such education should be provided by Indigenous Knowledge Keepers or Elders.

e. have the staff and service providers educated on the importance of having Indigenous-centred policy even for programs where non-Indigenous peoples are services alongside Indigenous peoples,

f. Note:

i. the Indigenous persons. Knowledge Keepers, or Elders providing this work should be compensated by the Court or the community organization developing the policy, and

ii. the Indigenous persons should be consulted in determining how they are compensated, and

iii. The Indigenous persons should be thanked and acknowledged appropriately for their knowledges. 
3. Create policy and funding opportunities that acknowledge the importance of Indigenousled and -governed programs, and

4. Develop policy quotas for the minimum amount required of available funding for criminal justice expenditures to be dedicated to Indigenous-centred and -led initiatives.

I do not produce these recommendations lightly. However, my findings throughout this study have necessitated such aggressive policy recommendations. Indigenous-centred organizations have done an incredible amount of work and produced so many positive results on highly limited budgets. I have every confidence that such organizations and programs could transform our communities - and the Canadian criminal justice system in general - if they were adequately supported legally and financially to meet their demands.

\section{Recommendations for Further Research}

Throughout writing this thesis, I was regularly struck by a need for additional information that I could not find anywhere. The criminal justice system, in general, lacks transparency. I personally doubt that I could have produced half of the information in this thesis without my previous experiences working in corrections because I knew where to look, how to communicate with staff, and what kinds of information were even likely to be available. However, given that not every researcher has the opportunity to work in the criminal justice system, and many might refuse to do so on principle, it is essential that further research be conducted. Not only must this information be produced, but it should be produced in such a way that it is accessible to potential readers.

My first recommendation is a Canada-wide program evaluation of each type of specialized court. The information that is currently available is out of date and specific urban geographic regions (Ray et al., 2015; The Canadian Association of Drug Treatment Court Professionals, 2019). If 
the data still suggests lower recidivism rates among graduates, then these specialized courts/programs need these figures to secure more funding to increase their impact. If the research suggests a decrease in efficacy, then further research must be done to identify why. In either case, I believe the information provided in this thesis is an excellent starting place.

My second recommendation is a general "program evaluation" of Indigenous-run community programs. I use the term program evaluation loosely because I fear the suggestion of nonIndigenous researchers or even Indigenous researchers providing negative critiques of such programs without being immersed in them. What I mean is that the achievements of these programs need to be studied, understood, platformed, and prioritized. Though some recent scholars have taken up this cause (Marsh et al., 2021), the amount of available information on the topic remains limited. With the increase in data, it is likely the credibility of these programs in the eyes of the state will be increased - ideally resulting in increased funding.

Though I would love to immediately jump into some of the above-mentioned research, I believe it will be some time before I am able to do such research. When I started this work, I would say my objectives were closest in line with criminal justice reform, as I hope the findings I produced would help existing programs to better meet the needs of Indigenous peoples venturing through the criminal justice system. It remains my intention to do something positive with this research, including producing community resource sheets with my findings, publishing findings in openaccess journals, and contacting Indigenous advocacy, justice, and community groups to see if there is a way they want to move forward with the findings.

However, it is no longer my goal to provide Indigenous knowledges and perspectives to a state that should have already sourced this information themselves. The state, despite commitments to supportive Indigenous empowerment, growth, and resilience, has demonstrated that they do not 
prioritize this work (Assembly of First Nations, 2018). Instead, I intend to utilize my privileged position to give a platform to the accomplishments and approaches of Indigenous-run community organizations that are not directly related to the state. As Indigenous service providers have long stated, and as participant John appreciated in his interview, "[The Court expects] us to be so pleased with the Court for being less unjust than they've been in the past right. [The Court has] to learn that they're the ones that should be grateful that an occupied people are willing to even work with them." I certainly agree with the statement that the state should show gratitude to Indigenous peoples who have shared their knowledges, but I believe the state demonstrates tremendous arrogance in proceeding as if their approach to Indigenous justice is the correct one. Their dominance does not equal their superiority in approach.

As such, my current plans for future research to support Indigenous-led programs that respond to crime proactively and preventatively, without the need for the state justice system. My proposed doctoral research explores Indigenous community responses to behaviour that is criminalized within traditional justice models, including programs that employ trauma-informed approaches, harm reduction, and crisis intervention for crimes that arise as a result of drug/alcohol use, homelessness, and mental health challenges. Stage one will examine community-led initiatives that can be traditionally viewed as crime prevention by addressing root causes of crime; this includes Indigenous midwifery and pregnancy support programs (e.g. Indigenous Women Rising), overdose prevention and safe drug use sites (e.g. South Riverdale Community Health Centre), and mental health crisis and support teams (e.g. Anishnawbe Health Toronto). Programs will be examined for their organizational structure, priorities, application of Indigenous knowledge, culture, and values, and program delivery methods. Data will be collected through 
ethnographic observations followed by interviews with key participants using a traditional talking circle format.

Stage two will explore non-authoritative, community-led responses to emergency situations as an alternative to traditional policing. Notably, grassroots programs unite service providers with Indigenous clients who may be engaged in illegal conduct without seeking to criminalize the individuals. Given the dearth of relevant available programs, case studies of past/ongoing programs (e.g. the Bear Clan Patrol and Mama Clan Patrol) will also be reviewed. Data will be analyzed through the lens of transformative and healing justice, drawing on key concepts around root causes of crime and trauma, with 'healing' being conceptualized as an individual, communal, and societal issue, as well as an ongoing process. Analyses of ethnographic data will draw on theory and praxis obtained from Indigenous interview participants; I argue the importance of developing theory about Indigenous persons that is based in Indigenous knowledges and allows Indigenous engagement and autonomy in the research process. True Indigenous autonomy—not colonialist saviourism and patronization—has been identified as the best way to support colonized Indigenous peoples and develop long-term improvements for their communities (Mackinlay \& Barney, 2014). Indigenous autonomy is further differentiated from other forms of autonomy by its demand not only for individual autonomy but also for selfdetermination as groups or nations separate from the colonizing state (Te Hiwi, 2014).

I believe my proposed doctoral research is more aligned with the values that I have developed as I have increased my personal knowledge regarding what supports Indigenous peoples, what Indigenous peoples or communities want to respond to justice, and the importance of Indigenous autonomy and self-governance. Though I believe I have mitigated as much harm as I could with this thesis, I hope that my future research amplifies the sophistication of Indigenous systems and 
approaches. While such should not have to be proved to settlers and the colonial state, personal experience and following the news has shown me that it is likely the required course of action.

\section{Anti-Limitations}

In completing this text, I am awarding an additional opportunity to reflect on the experience. While the following story is not about my actual data or recommendations, I believe it is still worthy of inclusion for reasons that will soon become clear. I call this section 'anti-limitation' because the following are qualities that were identified as weaknesses about me. However, I do not view them as such and believe they should be discussed on that basis.

As has often been the experience of racialized, women-identifying scholars (Eades, HackettWilliams, Raven, Liu, \& Cass, 2021; McGee \& Martin, 2011), I was met with some unpleasantness with this research that I want to acknowledge. In the phases of my research where I was recruiting interview participants, I reached out to literally hundreds of community-based organizations, native friendship centres, specialized courts, and Indigenous advocacy programs to request that they display my recruitment post in their facility, on their webpage, or on social media. Though most of my interactions were positive, I had one interaction that was so incredibly negative but also so incorrect that I feel compelled to discuss it briefly.

When I sent the emails requesting my recruitment poster displayed, I shared information about myself, interview details, intentions for the research, information on my Indigenous and professional backgrounds, and specific details on the steps I took to mitigate research violence against Indigenous peoples and community members. I provided the additional information to demonstrate the seriousness I was approaching the study under, as well as my attention to Indigenous issues surrounding academic research. 
I received a reply stating that they would require more work from me before they would consider sharing my poster because I was "green, that Indigenous peoples were not subjects to be harvested for my research, and did not appear to be undertaking Indigenous-focused research with the right intentions," and several other criticisms (Jaclyn Tompalski, 2021a). I was shocked and devastated to receive such an email because, above everything else, I had prioritized producing this work in the right way above all else. I cried, obsessed over it, and then left it alone over the weekend. Then, I did far too much emotional and actual labour to explain in a threethousand-word email that I respected their input, was keen to improve, but was confused by their feedback given all the information I had provided and the mitigating actions I had undertaken.

However, the experience of writing that email turned out to be deeply therapeutic because I took the time to reflect on my research process, write it out, and celebrate the positive steps I took. Though I will spare you, reader, from having to read my entire reply, I do want to highlight a "limitation" of my research and I were considered to have by this person and to explain why I believe them to be strengths.

On the topic of my "very green" -ness, I highlighted that I am green, but I do not consider it to be a disadvantage at all. Of the five previous research projects I had been involved in, only two were done within an academic institution. The other three were done through a community organization. We were not producing the work because it was a requirement to get a degree, to boost our status, or to stroke our own egos. We were producing those works - with very limited resources - because we genuinely cared about the communities we were supporting. I learned through those experiences that sometimes traditional academic conventions or approaches were not the best ways to make my participants more comfortable or to obtain the highest quality of work. I never reconciled until graduate studies that those non-institutional practices worked 
because they were embodying decolonizing practices which were needed given I was conducting research with Indigenous community members at the time. Much like my journey in discovering I enjoyed theory when it was the right kind of theory, decolonizing approaches have their value in the research process for both participants and researchers (Tuck \& McKenzie, 2015). My "green" qualities and negatively perceived lack of experience were actually a benefit to me in some ways (Tine, Justin, \& Jeremy, 2020) because I had not yet had the time to be corrupted by colonial academic processes.

Finally, though I did not articulate this to my correspondent, I rather resented being told by a non-Indigenous person that I - an Indigenous woman with roots in my community, knowledges of traumas from institutions, and a clear understanding of my own intentions - was not undertaking Indigenous-centred research with the right intentions. Incidentally, my critic never responded to my essay/email. Further research on my behalf showed that he, a non-Indigenous Professor Emeritus ${ }^{43}$, teaches a workshop to doctoral students and junior professors on how to conduct ethical Indigenous-focused research. Perhaps he was so critical of me because he was looking to add another client to his workshop. I am hard-pressed to find another explanation, given that much of his feedback had already been addressed in the initial contact, as one criticism he raised was that I had not demonstrated that I had any supports in place for Indigenous participants in the event they found the interview distressing, despite the fact that I had laid out such provisions in the early part of the email with an identifying header.

I do not believe it was the intention of the person criticizing me to cause me trauma as an Indigenous person. In fact, I believe he skimmed my initial email and believed me to be non-

\footnotetext{
${ }^{43}$ Note, he was not occupying that role for our communication. He is a board member at an Indigenous-supporting community-based organization, which is how we came into contact.
} 
Indigenous. However, he did cause me harm with his words, harms that I know other Indigenous peoples in academia have experienced (Pewewardy \& Frey, 2004). But I also think, in a weird way, he helped me. Through that experience, I developed an additional strategy for Indigenouscentred research: all future projects I work on will contain a one-page document explaining all of the provisions I have taken to produce decolonizing research, benefit my Indigenous participants, benefit Indigenous peoples in general, and mitigate research violence. This document will be provided in all correspondence regarding my research. Not only will this demonstrate to those involved in the research the deliberate, decolonizing processes expected for such research, but it will also normalize such practices for Indigenous research.

It is certainly not my belief that every harm experienced by an Indigenous (or otherwise precarious) person in academia should be turned into a learning experience. On the contrary, we should not be required to respond to such harms at all. However, when discussing this traumatic experience with two different Elders - in addition to other traumatic experiences which occurred throughout this research not mentioned in this text - I was reminded of the strength and wisdom obtained through the experience (Jaclyn; Tompalski, 2021). By being coming empowered through this experience and by having it connected to cultural teachings, I began to heal. It may not be related to my findings directly, but it is related to my theoretical framework for this thesis, particularly Pillar 2, the importance of the processes of engagement surrounding Indigenous works, and Pillar 5, healing through culture. Because it is related to the analysis of the findings, I believe it has its place in this chapter.

I also chose to tell this story because Indigenous women have often shared with me their negative experiences within academia and have publicized these occurrences on social media 
platforms. It has been challenging to find a "credible citation" about this experience, so I wanted to share this story for other Indigenous women.

\section{Conclusion and Goodbye}

The system is not serving Indigenous peoples - in fact, it is clear the system is disproportionately disadvantaging Indigenous peoples while perpetuating colonial violence. Alternatives to the incarceration of Indigenous peoples have never been more important. Gladue Reports and Indigenous courts provide a small relief, but Indigeneity has not meaningfully been addressed and supported in the criminal justice system (Welsh \& Ogloff, 2008). As the number of Indigenous persons in custody continues to grow (Jamil, 2020), we have clear evidence of systemic failings.

It is also clear that systemic racism has played a major role through policy failings and chronic underfunding. When I began this research, I anticipated that this document would be one critiquing the tremendous state failures as related to policy and program delivery - which I certainly did. This thesis demonstrates the total lack of consideration of Indigenous persons in many specialized courts policies. Further, it demonstrates the lack of self-awareness on behalf of the colonial state to acknowledge colonialism as the greatest factor contributing to Indigenous criminalization. In fact, perhaps it is not an absence of self-awareness but instead a comfortable continuation of colonialism of Indigenous folks by demonizing, oppressing, and ignoring their needs.

However, I am most delighted by is the tremendous success Indigenous-centred programs have had in the face of an unjust state. It feels like such a privilege to document the tremendous efforts and the constant engagement of Indigenous persons, criminalized Indigenous persons, and allies to improve access to alternatives to incarceration, to reduce harm for those going through the 
system, and to innovate ways to restore Indigenous ideals within and outside of the Canadian justice system. If nothing else, this work has allowed me to recover from some of the emotional burnout I have felt in my work.

It is my ultimate hope that the growing body of research surrounding specialized courts will result in reformed policy and increased funding to such programs. Increased community prioritization of defunding punitive, unequal, and oppressive elements of the criminal justice system (Neustaeter, 2021) offers prime grounds for these changes. Given the unprecedented public support of defunding, the time is right for such funds to be relocated to programs the prevent crime, promote racial justice and equality, and support those impacted by the system with their healing.

Keeping Indigenous persons out of jails and prisons is absolutely essential, with diversion being a critical early step. Gladue Reports have functioned as a well-intentioned effort, but Indigeneity has not meaningfully been addressed and supported in the criminal justice system (Welsh \& Ogloff, 2008). As Indigenous proportions in jails and prisons continue to rise (Jamil, 2020), the colonial justice system has demonstrated it is not actually serving Indigenous clients like it may believe itself to be. The benefits of alternatives to incarceration are substantial, including improved recidivism rates, reduced traumatization, personalization, autonomy, and reduced cost (The Canadian Association of Drug Treatment Court Professionals, 2019; Truth and Reconciliation Commission of Canada, 2012). To begin supporting Indigenous peoples through healing and to promote genuine reconciliation ${ }^{44}$, such alternatives are an essential first step.

\footnotetext{
${ }^{44}$ Note that Justice section of the 94 Calls to Action highlights return to community and healing approaches as essential for reconciliation (Truth and Reconciliation Commission of Canada, 2015b).
} 
However, though these reforms could produce an improved experience for Indigenous persons within the criminal justice system, I must disavow my support for state-run criminal justice programs, including alternatives to incarceration that are coercive and state-mandated.

Realistically, I acknowledge that reform of the criminal justice is more likely to occur than abolition, but I cannot pretend increased Indigenous admissions into specialized courts would be more desirable than returning justice matters to Indigenous communities. The evidence produced from my research has demonstrated that the ultimate priority should not be to Indigenize the criminal justice system but to decolonize it through abolition and return to Indigenous selfgovernance. I very much view my research as a sort of "harm-reduction" in that reforms could reduce the harms of the criminal justice system on Indigenous persons.

Producing this work has been devastating, discouraging, and humbling. It has been particularly difficult to write because it required me to spend more time than any Indigenous person should being confronted by media that is written exclusively about the horrors faced by Indigenous peoples in the face of colonialism, particularly given that the majority of that media did not include sections on Indigenous strength of resilience in the face of such horrors. Before embarking on this kind of work, I could never have understood the depth of re-traumatization that is experienced by racialized, colonized, displaced, or otherwise impacted by the state individuals ("Data on Trauma Research Reported by Researchers at University of Stellenbosch (Secondary Trauma Among Trauma Researchers: Lessons From the Field)," 2019; Giordano, Gorritz, Kilpatrick, Scoffone, \& Lundeen, 2021; van der Merwe \& Hunt, 2019). This experience has given me tremendous respect for racialized scholars and activists and has highlighted to me the importance of desire-based practices going forward. (Eve; Tuck, 2009) 
Producing this work has also been my absolute pleasure and privilege. Throughout my research, and more generally through just living my life (Jaclyn; Tompalski, 2021), I have come to realize that many of those who have much to offer by way justice ideas and approaches, program delivery, and policy development are often not taken seriously or platformed appropriately. I feel so grateful to all of the participants in this research, those who advised or provided edits, and those Indigenous scholars and educators who shared their knowledges. I could never have dreamed that I would have my perspectives expanded so significantly or that so many people would support me and this research.

Thank you very much to anyone who dedicated their time and energy to reading the information shared in this thesis. I am honoured by your participation and interest in decolonization and reconciliation. To contribute to decolonization, we must continue to advocate for decolonizing the justice system through alternatives to incarceration until such a time that Indigenous communities are returned their rights to self-governance of justice matters. 


\section{References}

Addiction Center. (2021). Getting Back On The Road To Recovery. Retrieved from https://www.addictioncenter.com/rehab-questions/what-happens-if-i-relapse/

Allan, B., \& Smylie, J. (2015). First Peoples, Second Class Treatment: The Role of Racism in the Health and Well-being of Indigenous Peoples in Canada: Wellesley Institute.

Alon, C. (2012). Why Did the Nazis Burn the Hebrew Bible? Nazi Germany, Representations of the Past, and the Holocaust. The Journal of modern history, 84(2), 369-400. doi:10.1086/664662

Alston-O’Connor, E. (2019). The Sixties Scoop. Critical social work, 11(1). doi:10.22329/csw.v11i1.5816

Anthony, T., Bartels, L., \& Hopkins, A. (2015). Lessons lost in sentencing : welding individualised justice to Indigenous justice. Melbourne University law review, 39(1), 4776.

April, S., \& Orsi, M. M. (2013). Gladue practices in the provinces and territories. Ottawa: Research and Statistics Division, Department of Justice Canada.

Assembly of First Nations. (2018). On Third Anniversary of Truth and Reconciliation Commission's Calls to Action, Assembly of First Nations Urges Governments and All Canadians to Commit to Progress and Results. Canada NewsWire.

Balsamo, M. (2020). When protesters cry 'defund the police,' what does it mean? Retrieved from https://www.ctvnews.ca/world/when-protesters-cry-defund-the-police-what-does-itmean-1.4973460

Bell, A. (2016). TRUTH AND RECONCILIATION IN LIFE WRITING: THE YEAR IN CANADA. Biography (Honolulu), 39(4), 585-591. doi:10.1353/bio.2016.0069 
Benoit, A. C., Cotnam, J., O'Brien-Teengs, D., Greene, S., Beaver, K., Zoccole, A., \& Loutfy, M. (2019). Racism experiences of urban indigenous women in Ontario, Canada: "We all have that story that will break your heart". International indigenous policy journal, 10(2), 1-27. doi:10.18584/iipj.2019.10.2.1

Berman, G., \& Feinblatt, J. (2001). Problem-Solving Courts: A Brief Primer. Law \& Policy, 23(2). doi:10.1111/1467-9930.00107

Black, C., Frederico, M., \& Bamblett, M. (2019). Healing through Connection: An Aboriginal Community Designed, Developed and Delivered Cultural Healing Program for Aboriginal Survivors of Institutional Child Sexual Abuse. The British journal of social work, 49(4), 1059-1080. doi:10.1093/bjsw/bcz059

Blackburn, M. (2012). Identities, bodies of children who died in residential schools may be lost forever. Retrieved from https://www.aptnnews.ca/national-news/identities-bodies-ofchildren-who-died-in-residential-schools-may-be-lost-forever/

Blackburn, M. (2013). First Nation infants subject to "human experimental work" for TB vaccine in 1930s-40s.

Boldt, M., Long, A., \& Long, J. A. (2014). The Quest for Justice: Aboriginal Peoples and Aboriginal Rights. Toronto: University of Toronto Press.

Bolongaro, K. (2014). Canada's broken relationship with its Aboriginal Peoples. Retrieved from https://www.aljazeera.com/opinions/2014/5/23/canadas-broken-relationship-with-itsaboriginal-peoples

Bouffard, J., \& Taxman, F. (2004). Looking inside the "Black Box" of Drug Court Treatment Services Using Direct Observations. Journal of Drug Issues, 34(1), 195-218. doi:10.1177/002204260403400109 
Bressan, A. (2018). Guilty Pleas Among Indigenous People in Canada: Canada. Department of Justice.

Brown, D., \& Nicholas, G. (2012). Protecting indigenous cultural property in the age of digital democracy: Institutional and communal responses to Canadian First Nations and Māori heritage concerns. Journal of material culture, 17(3), 307-324.

doi:10.1177/1359183512454065

Buckner, D. (2020). For some non-profits, COVID-19 isn't just a struggle. It's a do-or-die moment. Retrieved from https://www.cbc.ca/news/business/nonprofits-charitiespandemic-closures-1.5625165

Burton, W., \& Martin, A. (2020). Opioid Overdose and Addiction Treatment: A Collaborative Model of Compassion, Patience, and Respect. Journal of nursing scholarship, 52(4), 344351. doi: $10.1111 /$ jnu. 12562

Calgary Anti-Racism Education. (2021). Forms of Racism. Retrieved from https://www.aclrc.com/forms-of-racism

Calgary Drug Treatment Court. (2021). CDTC Acceptance Process. Retrieved from http://calgarydrugtreatmentcourt.org/cdtc-acceptance/

Canadian Broadcasting Corporation. (2017). Indigenous women nearly 10 times more likely to be street checked by Edmonton police, new data shows. In. Toronto: CQ-Roll Call, Inc.

Cannon, M. J., \& Sunseri, L. (2018). Racism, colonialism, and indigeneity in Canada : a reader (Second edition. ed.). Don Mills, Ontario, Canada: Oxford University Press.

Cao, L., Burton, V. S., \& Liu, L. (2018). Correlates of Illicit Drug Use Among Indigenous Peoples in Canada: A Test of Social Support Theory. International journal of offender 
therapy and comparative criminology, 62(14), 4510-4527.

doi: $10.1177 / 0306624 X 18758853$

Cartier, J., Biggar, H. P., \& Cook, R. (1993). The voyages of Jacques Cartier. Toronto: University of Toronto Press.

CBC News. (2016). Sixties Scoop survivors recall painful memories in Ontario. Retrieved from https://www.cbc.ca/news/canada/toronto/sixties-scoop-supporters-1.3732037

CBC News. (2019). Judge ignored Gladue report while giving Nunavik man an open-ended sentence, appeals court rules. In: CQ-Roll Call, Inc.

CBC News. (2021). 'A big voice': Friends, family mourn death of Elder Ted Fontaine. Retrieved from https://www.cbc.ca/news/canada/manitoba/ted-fontaine-death-obituary-residentialschools-survivor-author-1.6023552

CBC Radio. (2018). The Millennium Scoop: Indigenous youth say care system repeats horrors of the past. Retrieved from https://www.cbc.ca/radio/thecurrent/a-special-edition-of-thecurrent-for-january-25-2018-1.4503172/the-millennium-scoop-indigenous-youth-saycare-system-repeats-horrors-of-the-past-1.4503179

Centre for Addiction and Mental Health. (2021). Mental Illness and the Prison System. Retrieved from https://www.camh.ca/en/camh-news-and-stories/mental-illness-and-the-prisonsystem

Chakma, S., \& Jensen, M. (2001). Racism against indigenous peoples. Copenhagen: IWGIA.

Cham, J. (Producer). (2016). PHD Comic: Grad student etiquette. Retrieved from http://phdcomics.com/comics/archive.php?comicid=47

Chartrand, L. N., Logan, T. E., \& Daniels, J. D. (2006). Métis history and experience and residential schools in Canada. Ottawa, Ont: Aboriginal Healing Foundation. 
Cheng, H., \& Ma, L. (2016). A Comparative Study on Land Rights of Peasants in China and Aboriginal Citizens in Canada and Their Impact on Development. Forum for development studies, 43(2), 311-331. doi:10.1080/08039410.2015.1114516

Cherubini, L. (2008). Aboriginal identity, misrepresentation, and dependence: a survey of the literature. Canadian journal of native studies, 28(2), 221.

Chrisjohn, R. D., Young, S. L., \& Maraun, M. (1997). The circle game : shadows and substance in the Indian residential school experience in Canada. Penticton, BC: Theytus Books.

Chronicle-Herald. (2017). Funding for Gladue court announced. Chronicle-herald (Halifax, N.S.).

Cochran, P. A. L., Marshall, C. A., Garcia-Downing, C., Kendall, E., Cook, D., McCubbin, L., \& Gover, R. M. S. (2008). Indigenous Ways of Knowing: Implications for Participatory Research and Community. American journal of public health (1971), 98(1), 22-27. doi:10.2105/AJPH.2006.093641

Columbus, C., Corte-Real, G., \& Cabot, J. (1980). The journal of Christopher Columbus (during his first voyage, 1492-93) and documents relating to the voyages of John Cabot and Gaspar Corte Real. London: Hakluyt Society.

Cordell, L. S., Lightfoot, K., McManamon, F., \& Milner, G. (2008). Archaeology in America: An encyclopedia [4 volumes]: An encyclopedia. In (pp. 27-82): ABC-CLIO.

Correctional Service Canada. (2019). Sections 81 and 84, federal corrections and the Indigenous community. Retrieved from https:/www.csc-scc.gc.ca/002/003/002003-0004-en.shtml Courtney, S., \& Foxie, N. (2015). Hiawatha and the Peacemaker. In (Vol. 11, pp. 244). Athens: University of Georgia, Dept of Language and Literacy Education. 
Crey, K. (2009). Enfranchisement. Retrieved from https://indigenousfoundations.arts.ubc.ca/enfranchisement/. https://indigenousfoundations.arts.ubc.ca/enfranchisement/

Cunliffe, E. (2018). Don't whitewash racism in our justice system; Stereotypes defined Gladue in court, says Emma Cunliffe. Edmonton journal.

D'Arcy, L. (2018). The Constitutionality of Classifification: Indigenous Overrepresentation and Security Policy in Canadian Federal Penitentiaries. Dalhousie law journal, 41(2), 411A442.

Data on Trauma Research Reported by Researchers at University of Stellenbosch (Secondary Trauma Among Trauma Researchers: Lessons From the Field). (2019). Health \& Medicine Week, 410.

Deer, K. n. i. (2021). Sixties Scoop class action settlement to move forward after delays. Retrieved from https://www.cbc.ca/news/indigenous/sixties-scoop-settlement-movesforward-1.5893774

Department of Justice Canada. (2015). DRUG TREATMENT COURT FUNDING PROGRAM EVALUATION

Final Report. Retrieved from

Department of Justice Canada. (2017). Evaluation of the Aboriginal Justice Strategy December 2016: Canada. Department of Justice.

Department of Justice Canada. (2021). Drug Treatment Court Funding Program. Retrieved from https://www.justice.gc.ca/eng/fund-fina/gov-gouv/dtc-ttt.html

Dickason, O. P. (2002). Canada's first nations : a history of founding peoples from earliest times (3rd ed. ed.). Don Mills, Ont: Oxford University Press. 
Dijkink, G., \& Knippenberg, H. (2001). The territorial factor : political geography in a globalising world. In Political geography in a globalising world (pp. 224-228). Amsterdam: Vossiuspers UvA.

Dion, J., Cantinotti, M., Ross, A., \& Collin-Vézina, D. (2015). Sexual abuse, residential schooling and probable pathological gambling among Indigenous Peoples. Child abuse \& neglect, 44, 56-65. doi:10.1016/j.chiabu.2015.03.004

Dorries, H., \& Ruddick, S. (2018). Between concept and context: reading Gilles Deleuze and Leanne Simpson in their in/commensurabilities. Cultural geographies, 25(4), 619-635. doi:10.1177/1474474018778576

Dupuis, J. (2016). An untold history of resistance to residential schools

Social Sharing. Retrieved from https:/www.cbc.ca/news/canada/montreal/resisting-residentialschools-1.3823181

Dussault, R., \& Erasmus, G. (1996). Report of the Royal Commission on Aboriginal Peoples. Ottawa: The Commission.

Eades, A.-M., HackettWilliams, M., Raven, M., Liu, H., \& Cass, A. (2021). The impact of vicarious trauma on Aboriginal and/or Torres Strait Islander health researchers. Public Health Research \& Practice, 31(1). doi:10.17061/phrp30012000

Edmonton John Howard Society. (2021). Drug Treatment Court Services. Retrieved from https://johnhoward.org/programs-services/drug-treatment-court-services/

Ellis, D., Lewis, T., \& Nepon, T. (2021). Effects of Historical Coercive Control, Historical Violence, and Lawyer Representation on Post-Separation Male Partner Violence Against Mother Litigants Who Participated in Adversarial Family Court Proceedings. Violence against women, 27(9), 1191-1210. doi:10.1177/1077801220921939 
Eneas, B. (2021). Sask. First Nation announces discovery of 751 unmarked graves near former residential school. Retrieved from https://www.cbc.ca/news/canada/saskatchewan/cowessess-marieval-indian-residentialschool-news-1.6078375

Episkenew, J.-A. (2009). Taking back our spirits : indigenous literature, public policy, and healing. Winnipeg, Man: University of Manitoba Press.

Evaluation Division. (2009). Drug Treatment Court Funding Program, Summative Evaluation. Retrieved from Ottawa:

Facing History and Ourselves. (2015a). Stolen lives : the Indigenous peoples of Canada and the Indian residential schools. In. Toronto: Facing History and Ourselves.

Facing History and Ourselves. (2015b). Stolen lives : the Indigenous peoples of Canada and the Indian residential schools. Toronto: Facing History and Ourselves.

Ferguson, L. J., Girolami, T., Thorstad, R., Rodgers, C. D., \& Humbert, M. L. (2021). "That's What the Program Is All about... Building Relationships": Exploring Experiences in an Urban Offering of the Indigenous Youth Mentorship Program in Canada. International journal of environmental research and public health, 18(2), 733.

doi:10.3390/ijerph18020733

Feuer, W., \& Kim, J. (2020). WHO warns coronavirus pandemic is speeding up as countries ease lockdown rules: 'The worst is yet to come'. Retrieved from https://www.cnbc.com/2020/06/29/who-warns-coronavirus-pandemic-is-speeding-up-ascountries-ease-lockdown-rules.html

First Peoples Group. (2020). Vanessa Watts. Retrieved from https://firstpeoplesgroup.com/teammember/vanessa-watts/ 
Gagnier, K. R., Moore, T. E., \& Green, M. (2011). A need for closer examination of FASD by the criminal justice system: has the call been answered? Journal of population therapeutics and clinical pharmacology, 18(3), e426-e439.

Gallagher, J. R., Whitmore, T. D., Horsley, J., Marshall, B., Deranek, M., Callantine, S., \& Woodward Miller, J. (2019). A Perspective from the Field: Five Interventions to Combat the Opioid Epidemic and Ending the Dichotomy of Harm-reduction versus AbstinenceBased Programs. Alcoholism treatment quarterly, 37(3), 404-417. doi:10.1080/07347324.2019.1571877

Gerster, J. (2019). The RCMP was created to control Indigenous people. Can that relationship be reset? Retrieved from https://globalnews.ca/news/5381480/rcmp-indigenous-relationship/

Giordano, A. L., Gorritz, F. B., Kilpatrick, E. P., Scoffone, C. M., \& Lundeen, L. A. (2021). Examining Secondary Trauma as a Result of Clients' Reports of Discrimination. International journal for the advancement of counselling, 43(1), 19-30. doi:10.1007/s10447-020-09411-z

Gladue report writing examined as way to help convicted. (2013). Alberta Sweetgrass, 20(3), 7. Gomashie, G. A. (2019). Kanien'keha/Mohawk Indigenous Language Revitalisation Efforts in Canada. McGill journal of education, 54(1), 151-171. doi:10.7202/1060864ar

Goodman, A., Morgan, R., Kuehlke, R., Kastor, S., Fleming, K., \& Boyd, J. (2018). "We've been researched to death": Exploring the research experiences of urban Indigenous Peoples in Vancouver, Canada. International indigenous policy journal, 9(2). doi:10.18584/iipj.2018.9.2.3

Government of Canada. (2018). Types of conditional release. Retrieved from https://www.canada.ca/en/parole-board/services/parole/types-of-conditional-release.html 
Government of Canada. (2020). Reducing the number of Indigenous children in care. Retrieved from https://www.sac-isc.gc.ca/eng/1541187352297/1541187392851

Government of Ontario. (2006). A program framework for : mental health diversion / Court Support Services. Toronto, Ont: Ontario.

Greg, M., Brianna, J., \& Amelia, A. (2020). Police-reported crime statistics in Canada, 2019. Juristat, 4-69.

Gubi, P. M., \& Marsden-Hughes, H. (2013). Exploring the processes involved in long-term recovery from chronic alcohol addiction within an abstinence-based model: Implications for practice. Counselling and psychotherapy research, 13(3), 201-209. doi:10.1080/14733145.2012.733716

Gurston, D. (2002). British Columbia after the Delgamuukw Decision: Land Claims and Other Processes. Canadian public policy, 28(2), 239-255. doi:10.2307/3552327

Haggerty, K. D., \& Doyle, A. (2015). 57 ways to screw up in grad school : perverse professional lessons for graduate students. The University of Chicago Press: Chicago.

Hallinan, C. (2013). Native games indigenous peoples and sports in the post-colonial world. Bradford: Emerald Group Publishing Limited.

Hanson, E. (2009). Sixties Scoop. Retrieved from https://indigenousfoundations.arts.ubc.ca/sixties_scoop/

Hanson, E. (2020). The Residential School System. Retrieved from https://indigenousfoundations.arts.ubc.ca/the_residential_school_system/

Havassy, B. E., Hall, S. M., \& Wasserman, D. A. (1991). Social support and relapse: Commonalities among alcoholics, opiate users, and cigarette smokers. Addictive behaviors, 16(5), 235-246. doi:10.1016/0306-4603(91)90016-B 
Haws, E., \& Kapelos, V. (2020). Charities and nonprofits struggling to stay afloat during pandemic, says Imagine Canada. Retrieved from https://www.cbc.ca/news/politics/pandemic-covid-coronavirus-charities- 1.5548590

Higginbottom, G. M., Safipour, J., Yohani, S., O'Brien, B., Mumtaz, Z., Paton, P., . . Barolia, R. (2016). An ethnographic investigation of the maternity healthcare experience of immigrants in rural and urban Alberta, Canada. BMC pregnancy and childbirth, 16(1), 20-20. doi:10.1186/s12884-015-0773-z

hooks, b. (2015). Feminist theory : from margin to center (3rd ed. ed.). New York: Routledge. Human Services and Justice Coordinating Committee. (2017). Mental Health Courts in Ontario. Retrieved from https://ontario.cmha.ca/wp-content/uploads/2017/11/Mental-HealthCourts-in-Ontario-1.pdf

Hunt, D. (2016). Nikîkîwân: Contesting Settler-Colonial Archives through Indigenous Oral History. Canadian literature, 230-231(230-231), 25.

Indian Act. (2009). Parliamentary Information and Research Service. Indigenous Foundations. (2009). Indigenous Foundations - Oral Traditions. Indigenous Foundations. Retrieved from https://indigenousfoundations.arts.ubc.ca/oral_traditions/ Ireland, K. (2013). Incorporating Multiple Perspectives in Elementary History Teaching. Retrieved from http://thenhier.ca/en/content/incorporating-multiple-perspectiveselementary-history-teaching.html

Ireton, J. (2021). Charities and non-profits in trouble seek federal support. Retrieved from https://www.cbc.ca/news/canada/ottawa/charities-non-profits-financial-losses-seekfederal-money-budget-1.5972063 
Jack-Davies, A. (2018). Navigating racism: Black graduate students need support. Retrieved from https://theconversation.com/navigating-racism-black-graduate-students-needsupport-92550

Jamil, M. (2018). Adult and youth correctional statistics in Canada, 2016/2017. Juristat, 1-20.

Jamil, M. (2019). Adult and youth correctional statistics in Canada, 2017/2018. Jusistat, Ottawa.

Jamil, M. (2020). Adult and youth correctional statistics in Canada, 2018/2019. Juristat, 3-23.

Jeakle, W. (2020). Six Things You Didn't Know About Christopher Columbus. Retrieved from https://www.forbes.com/sites/williamjeakle/2020/10/11/six-things-you-didnt-knowabout-christopher-columbus/?sh=7d4b925c71 cf

Johnson, L. (2021). Alberta Education officials defend curriculum during first virtual town hall, leaving many questions unanswered.

Justice Education Society. (2020). Restorative Justice. Retrieved from https://www.justiceeducation.ca/about-us/research/aboriginal-sentencing/restorativejustice

Kelley, N., \& Trebilcock, M. J. (2010). The making of the mosaic : a history of Canadian immigration policy. In (2nd ed. ed., pp. 23-30). Toronto: University of Toronto Press.

Kiedrowski, J. S. (2013). Trends in Indigenous policing models : an international comparison. Ottawa: [Public Safety Canada].

Lee, S. (2020). RE-EVALUATING MORAL CULPABILITY IN THE WAKE Of GLADUE. University of Toronto Faculty of Law review, 78(2), 109.

Lee, S. C., Hanson, R. K., \& Blais, J. (2020). Predictive Accuracy of the Static-99R and Static2002R Risk Tools for Identifying Indigenous and White Individuals at High Risk for 
Sexual Recidivism in Canada. Canadian psychology = Psychologie canadienne, 61(1), 42-57. doi:10.1037/cap0000182

Legal Aid Ontario. (2021). Bail.

Lemert, C. C. (2013). Social theory : the multicultural, global, and classic readings. In (Fifth edition. Twentieth anniversary edition. ed., pp. 1-21). Philadelphia, Pa: Westview Press.

Levasseur, M., Généreux, M., Bruneau, J.-F., Vanasse, A., Chabot, É., Beaulac, C., \& Bédard, M.-M. (2015). Importance of proximity to resources, social support, transportation and neighborhood security for mobility and social participation in older adults: Results from a scoping study. BMC public health, 15(1), 503-503. doi:10.1186/s12889-015-1824-0

Levesque, A., \& Quesnel-Vallee, A. (2019). Gender variations in the relationship between social capital and mental health outcomes among the Indigenous populations of Canada. International journal for equity in health, 18(1), 124-124. doi:10.1186/s12939-019-10289

Lim, L., \& Day, A. (2014). Mental Health Diversion Courts: A Two Year Recidivism Study of a South Australian Mental Health Court Program. Behavioral sciences \& the law, 32(4), 539-551. doi:10.1002/bsl.2126

Lindquist, C. H., Krebs, C. P., \& Lattimore, P. K. (2006). Sanctions and Rewards in Drug Court Programs: Implementation, Perceived Efficacy, and Decision Making. Journal of Drug Issues, 36(1), 119-146. doi:10.1177/002204260603600106

Luker, T. (2017). Decolonising Archives: Indigenous Challenges to Record Keeping in 'Reconciling' Settler Colonial States. Australian feminist studies, 32(91-92), 108-125. doi:10.1080/08164649.2017.1357011 
Mackinlay, E., \& Barney, K. (2014). Unknown and Unknowing Possibilities : Transformative Learning, Social Justice, and Decolonising Pedagogy in Indigenous Australian Studies. Journal of transformative education, 12(1), 54-73. doi:10.1177/1541344614541170

Macklem, P. (2000). Indigenous difference and the Constitution of Canada. In (pp. 168-172). Toronto: University of Toronto Press.

Macklin, C. D., Marchand, C., Mitchell, E., Price, R., Mitchell, V., \& Bryant, L. (2021). Planting the Seeds: Insights for Researchers Interested in Working With Indigenous Peoples. International Journal of Indigenous Health, 16(1), 208-222. doi:10.32799/ijih.v16i1.33193

Marsh, T. N., Eshakakogan, C., Eibl, J. K., Spence, M., Morin, K. A., Gauthier, G. J., \& Marsh, D. C. (2021). A study protocol for a quasi-experimental community trial evaluating the integration of indigenous healing practices and a harm reduction approach with principles of seeking safety in an indigenous residential treatment program in Northern Ontario. Harm reduction journal, 18(1), 35-35. doi:10.1186/s12954-021-00483-7

Martel, J., Brassard, R., \& Jaccoud, M. (2011). WHEN TWO WORLDS COLLIDE: Aboriginal Risk Management in Canadian Corrections. British journal of criminology, 51(2), 235255. doi:10.1093/bjc/azr003

Martin, S. E. (2001). The Links Between Alcohol, Crime and the Criminal Justice System: Explanations, Evidence and Interventions. The American journal on addictions, 10(2), 136-158. doi:10.1080/105504901750227796

Mason, R., Pind, J., \& Christou, T. M. (2020). Spirit of the Grassroots People: Seeking Justice for Indigenous Survivors of Canada's Colonial Education System. Montreal: McGillQueen's University Press. 
Maurutto, P., \& Hannah-Moffat, K. (2016). Aboriginal Knowledges in Specialized Courts: Emerging Practices in Gladue Courts. Canadian journal of law and society, 31(3), 451471. doi:10.1017/cls.2016.35

Maxwell, K. (2017). Settler-Humanitarianism: Healing the Indigenous Child-Victim. Comparative studies in society and history, 59(4), 974-1007. doi:10.1017/S0010417517000342

McCuish, E. C., \& Corrado, R. R. (2018). Do Risk and Protective Factors for Chronic Offending Vary Across Indigenous and White Youth Followed Prospectively Through Full Adulthood? Crime and delinquency, 64(10), 1247-1270. doi:10.1177/0011128717741616

McGee, E. O., \& Martin, D. B. (2011). "You Would Not Believe What I Have to Go Through to Prove My Intellectual Value!" Stereotype Management Among Academically Successful Black Mathematics and Engineering Students. American educational research journal, 48(6), 1347-1389. doi:10.3102/0002831211423972

McGregor, D. (2018). From 'decolonized' to reconciliation research in Canada: Drawing from indigenous research paradigms. ACME an international e-journal for critical geographies, 17(3), 810-831.

McGuire, M. M., \& Murdoch, D. J. (2021). (In)-justice: An exploration of the dehumanization, victimization, criminalization, and over-incarceration of Indigenous women in Canada. Punishment \& society, 146247452110016. doi:10.1177/14624745211001685

McKenzie, H. A., Varcoe, C., Browne, A. J., \& Day, L. (2016). Disrupting the continuities among residential schools, the sixties scoop, and child welfare: An analysis of colonial and neocolonial discourses. International indigenous policy journal, 7(2). doi:10.18584/iipj.2016.7.2.4 
McNeil, K. (2007). A Brief History of Our Right to Self-Governance. Retrieved from https://fngovernance.org/wp-content/uploads/2020/09/A-Brief-History-of-InherentRights.pdf

Miller, J. (2020). Residential Schools in Canada.

Miller, J. R. (1996). Shingwauk's vision : a history of native residential schools. Toronto: University of Toronto Press.

Milward, D. (2014). The sentencing of aboriginal accused with FASD: a search for different pathways. University of British Columbia law review, 47(3), 1025.

Ministry of the Solicitor General. (2019). Community Corrections. Retrieved from https://www.mcscs.jus.gov.on.ca/english/corr_serv/comm_corr/probation/probation.html

Monchalin, L. (2016). The colonial problem : an indigenous perspective on crime and injustice in Canada. Toronto, ON: University of Toronto Press.

Montford, K. S., \& Moore, D. (2018). The prison as reserve: Governmentality, phenomenology, and indigenizing the prison (studies). New criminal law review, 21(4), 640-663. doi:10.1525/nclr.2018.21.4.640

Moore, D. (2007a). Criminal Artefacts: Governing Drugs and Users. In (pp. 92-121). Place of publication not identified: UBC Press.

Moore, D. (2007b). TRANSLATING JUSTICE AND THERAPY: The Drug Treatment Court Networks. British journal of criminology, 47(1), 42-60. doi:10.1093/bjc/az1028

Moore, D. (2011). The benevolent watch: Therapeutic surveillance in drug treatment court. Theoretical criminology, 15(3), 255-268. doi:10.1177/1362480610396649

Morison, S. E. (1942). Admiral of the ocean sea : a life of Christopher Columbus. Boston: Little, Brown and company. 
Mosby, I., \& Galloway, T. (2017). Hunger was never absent": How residential school diets shaped current patterns of diabetes among Indigenous peoples in Canada. Canadian Medical Association journal (CMAJ), 189(32), E1043-E1045. doi:10.1503/cmaj.170448

MSNBC. (2021). Chauvin's violent track record as a police officer long preceded killing George Floyd. Retrieved from https://www.msnbc.com/the-reidout/watch/chauvin-s-violenttrack-record-as-a-police-officer-long-preceded-killing-george-floyd-110887493984

Native Women's Association (Producer). (2015). What is Gladue? Retrieved from https://www.nwac.ca/wp-content/uploads/2015/05/What-Is-Gladue.pdf

Nemerson, S. S. (1980). Coercive sentencing. Minnesota law review, 64(4), 669.

Nettelbeck, A., \& Smandych, R. (2010). Policing Indigenous Peoples on Two Colonial Frontiers: Australia's Mounted Police and Canada's North-West Mounted Police. Australian \& New Zealand journal of criminology, 43(2), 356-375. doi:10.1375/acri.43.2.356

Neustaeter, B. (2021). One year after George Floyd's death, where does 'defund the police' stand in Canada? Retrieved from https://www.ctvnews.ca/canada/one-year-after-george-floyds-death-where-does-defund-the-police-stand-in-canada-1.5441519

Nevin, D., LaBerge, C., \& Rutman, D. (2007). FASD and the criminal legal system are we criminalizing disability? Victoria, BC: School of Social Work, University of Victoria.

Nielsen, M. O. (2006). Indigenous-Run Legal Services in Australia and Canada: Comparative Developmental Issues. International criminal justice review, 16(3), 157-178. doi:10.1177/1057567706295486

Nolan, C. J. (2008). Wars of the age of Louis XIV, 1650-1715 : an encyclopedia of global warfare and civilization. Westport, Conn: Greenwood Press. 
Norman, M., \& Ricciardelli, R. (2021). Operational and organisational stressors in community correctional work: Insights from probation and parole officers in Ontario, Canada. Probation journal, 26455052098425. doi:10.1177/0264550520984253

Northcott, H. C., \& Wilson, D. M. (2008). Dying and death in Canada (2nd ed. ed.). Peterborough, Ont: Broadview Press.

Nourjah, P., \& Kato, E. (2021). "One size does not fit all" and other lessons learned from grants for implementation of the AHRQ medication assisted treatment for opioid use disorder in rural primary care. Substance abuse, 42(2), 136-139.

doi:10.1080/08897077.2021.1891600

O'Donnell, V. (2019). Upgrading and high school equivalency among the Indigenous population living off reserve. Ottawa: Statistics Canada $=$ Statistique Canada.

O'Mara, B. (2020). The effectiveness of changes to drug policy, regulation and legislation for reducing harms associated with opioids and supporting their medicinal use in Australia, Canada and the UK: A systematic review. Evidence Base: A journal of evidence reviews in key policy areas, 2020(2), 79. doi:10.21307/eb-2020-004

Oesterle, T. S., Thusius, N. J., Rummans, T. A., \& Gold, M. S. (2019). Medication-Assisted Treatment for Opioid-Use Disorder. Mayo Clinic proceedings, 94(10), 2072-2086. doi:10.1016/j.mayocp.2019.03.029

Office of the Correctional Investigator. (2020). Indigenous People in Federal Custody Surpasses 30\% - Correctional Investigator Issues Statement and Challenge. Canada NewsWire.

Onashowewin Justice Circle. (2020). Onashowewin Retrieved from https://www.onashowewin.com/page1.html 
Ontario Sixties Scoop Steering Committee. (2017). Sixties Scoop survivors' decade-long journey for justice culminates in historic pan-Canadian agreement. Retrieved from https://www.newswire.ca/news-releases/sixties-scoop-survivors-decade-long-journey-forjustice-culminates-in-historic-pan-canadian-agreement-649748633.html

Ostroff, J. (2015). Tomson Highway Has A Surprisingly Positive Take On Residential Schools. Retrieved from https://www.huffingtonpost.ca/2015/12/15/tomson-highway-residentialschools_n_8787638.html

Paige, P. (2018). Gladue reports reflect effects of colonialism. Edmonton journal.

Pewewardy, C., \& Frey, B. (2004). American Indian Students' Perceptions of Racial Climate, Multicultural Support Services, and Ethnic Fraud at a Predominantly White University. Journal of American Indian Education, 43(1), 32-60. Retrieved from http://www.jstor.org.proxy.library.carleton.ca/stable/24398562

Porteous, J. D., \& Smith, S. E. (2001). Domicide the global destruction of home. In (pp. 64-106). Montreal: McGill-Queen's University Press.

Porter, T. (2008). And Grandma Said: Iroquois Teachings As Passed Down Through the Oral Tradition: Xlibris Corp.

Provincial Court of British Columbia. (2020a). Specialized Courts. Retrieved from https://www.provincialcourt.bc.ca/about-the-court/specialized-courts\#FirstNationsCourt Provincial Court of British Columbia. (2020b). Specialized Courts. Retrieved from https://www.provincialcourt.bc.ca/about-the-court/specialized-courts\#IndigenousCourts Public Safety Canada. (2008). Corrections \& Conditional Release in Canada: A General Primer. Retrieved from Ottawa, Ontario: https://johnhoward.ca/wpcontent/uploads/2016/12/Corrections-and-Conditional-Release-in-Canada.pdf 
Public Safety Canada. (2010). Corrections and conditional release in Canada a general primer. Ottawa: Public Safety Canada.

PW Staff. (2021). Book Buzz: Indigenous Voices. Retrieved from https://www.publishersweekly.com/pw/by-topic/industry-news/bea/article/86381-bookbuzz-indigenous-voices.html

Ray, B., Hood, B. J., \& Canada, K. E. (2015). What Happens to Mental Health Court Noncompleters? Behavioral sciences \& the law, 33(6), 801-814. doi:10.1002/bsl.2163

Read, C. (2018). Rebellion of 1837 in Upper Canada. In (pp. xvii-0): Canadian Historical Association.

Redlich, A. D., Hoover, S., Summers, A., \& Steadman, H. J. (2010). Enrollment in Mental Health Courts: Voluntariness, Knowingness, and Adjudicative Competence. Law and human behavior, 34(2), 91-104. doi:10.1007/s10979-008-9170-8

Ricciardelli, R., Adorjan, M., \& Spencer, D. (2020). Canadian Rural Youth and Role Tension of the Police: 'It's Hard in a Small Town. Youth justice, 20(3), 199-214. doi:10.1177/1473225419872406

Rose, G. A. (2007). Cod: the ecological history of the North Atlantic fisheries. St. John's, Nfld: Breakwater Books.

Ross, A., Dion, J., Cantinotti, M., Collin-Vézina, D., \& Paquette, L. (2015). Impact of residential schooling and of child abuse on substance use problem in Indigenous Peoples. Addictive behaviors, 51, 184-192. doi:10.1016/j.addbeh.2015.07.014

Ryan, J. P., \& Testa, M. F. (2005). Child maltreatment and juvenile delinquency: Investigating the role of placement and placement instability. Children and youth services review, 27(3), 227-249. doi:10.1016/j.childyouth.2004.05.007 
Schneider, R. D., Bloom, H., \& Heerema, M. (2007). Mental health courts : decriminalizing the mentally ill. Toronto, Ontario: Irwin Law.

Schumacher, A. (2014). Talking Circles for Adolescent Girls in an Urban High School: A Restorative Practices Program for Building Friendships and Developing Emotional Literacy Skills. SAGE open, 4(4), 215824401455420. doi:10.1177/2158244014554204

Sheleff, L. (2002). Drowning one's sorrow : the legal implications of alcoholism among Indigenous people. Indigenous law bulletin, 5(15), 12-13.

Simpson, L. (2017). As we have always done : indigenous freedom through radical resistance. Minneapolis: University of Minnesota Press.

Simpson, L. (2020). Leanne Betasamosake Simpson - About. Retrieved from https://www.leannesimpson.ca/

Simpson, L. B. (2017a). As we have always done : indigenous freedom through radical resistance. Minneapolis: University of Minnesota Press.

Simpson, L. B. (2017b). INTRODUCTION: MY RADICAL RESURGENT PRESENT. In (pp. 1-10): University of Minnesota Press.

Sinclair, R. (2007). Identity lost and found: Lessons from the sixties scoop. First peoples child \& family review, 3(1), 65-82. doi:10.7202/1069527ar

Statistics Canada. (2019). Percentage of population that self-identified as Aboriginal by census division, 2016. In: Open Data Canada.

Stevenson, A. (2019). Child Welfare, Indigenous Children and Children's Rights in Canada. Revista Direito e Práxis, 10(2), 1239-1260. doi:10.1590/2179-8966/2019/40639

Stewart, L. A. (2019). A comprehensive study of recidivism rates among Canadian federal offenders. Ottawa, Ontario: Correctional Service Canada = Service correctionnel Canada. 
Stewart, S. H., Sherry, S. B., Comeau, M. N., Mushquash, C. J., Collins, P., \& Van Wilgenburg, H. (2011). Hopelessness and Excessive Drinking among Aboriginal Adolescents: The Mediating Roles of Depressive Symptoms and Drinking to Cope. Depression research and treatment, 2011, 970169-970111. doi:10.1155/2011/970169

Stueck, W. (2019). B.C. ends controversial birth alert system that affected Indigenous mothers disproportionately. Retrieved from https://www.theglobeandmail.com/canada/britishcolumbia/article-bc-ends-controversial-birth-alert-system-that-affected-indigenous/

Talaga, T. (2021). It's time to bring our children home from the residential schools. Retrieved from https:/www.theglobeandmail.com/canada/article-survivors-of-residential-schoolsshare-their-stories-call-on-the/

Taylor, J. H. (1986). Ottawa : an illustrated history. Toronto: J. Lorimer.

Te Hiwi, B. P. (2014). “What is the Spirit of this Gathering?” Indigenous Sport Policy-Makers and Self-Determination in Canada. International indigenous policy journal, 5(4), 6. doi:10.18584/iipj.2014.5.4.6

The Canadian Association of Drug Treatment Court Professionals. (2019). DTC Facts. Retrieved from https://cadtc.org/dtc-facts/

The Canadian Centre on Substance Abuse. (2019). Drug Treatment Courts FAQs. Retrieved from Ottawa:

The Canadian Press. (2011). Clarifies July 31 `Millennium Scoop`story: Clarifies July 31 'Millennium' Scoop story. The Canadian Press.

The Canadian Press. (2021). Remains of 215 children found at former residential school in British Columbia. Retrieved from https:/www.aptnnews.ca/national-news/remains-of215-children-found-at-former-residential-school-in-british-columbia/ 
The Hamilton Spectator. (2020). Systemic racism against Canada's Indigenous people cries out for action. In. Hamilton: Torstar Syndication Services, a Division of Toronto Star Newspapers Limited.

Therien, E. (2012). Native Canadians deserve the Gladue court. National post (Toronto). Thistle, J. (2019). From the ashes : my story of being Métis, homeless, and finding my way (Simon \& Schuster Canada edition. ed.). New York ;: Simon \& Schuster.

Thistle, J. (2020). Jesse Thistle - About Retrieved from https://jessethistle.com/ Thistle, J. (2021). About Jesse Thistle. Retrieved from https://jessethistle.com/about/ Thornton, R. (1987). American Indian holocaust and survival : a population history since 1492 (1st ed. ed.). Norman: University of Oklahoma Press.

Tine, K., Justin, A. D., \& Jeremy, L. S. (2020). Prestige does not equal quality: Lack of research quality in high-prestige journals. Industrial and organizational psychology, 13(3), 321327. doi:10.1017/iop.2020.53

Todd, Z. (2016). An Indigenous Feminist's Take On The Ontological Turn: 'Ontology' Is Just Another Word For Colonialism. Journal of historical sociology, 29(1), 4-22. doi:10.1111/johs. 12124

Toki, V. (2009). Are Domestic Violence Courts working for indigenous peoples? Commonwealth law bulletin, 35(2), 259-290. doi:10.1080/03050710902924338

Tompalski, R. (2021). [Text Message].

Tremeear, W. J. (1997). Annotated Criminal Code, 1919, Canada. Calgary: Burroughs. Truth and Reconciliation Commissaion of Canada. (2012). They came for the children Canada, Aboriginal peoples, and residential schools. Winnipeg, Man: Truth and Reconciliation Commission of Canada. 
Truth and Reconciliation Commission of Canada. (2015a). Canada's residential schools : the final report of the Truth and Reconciliation Commission of Canada (9780773598171). Retrieved from Montreal ;:

Truth and Reconciliation Commission of Canada. (2015b). Truth and Reconciliation Commission of Canada : calls to action. Winnipeg: Truth and Reconciliation Commission of Canada.

Tuck, E. (2009). Suspending Damage: A Letter to Communities. Harvard educational review, 79(3), 409-428. doi:10.17763/haer.79.3.n0016675661t3n15

Tuck, E. (2009). Suspending damage: A letter to communities. Harvard educational review, 79(3), 409-427. doi:10.17763/haer.79.3.n0016675661t3n15

Tuck, E. (2015). Place in research : theory, methodology, and methods. New York: Routledge. Tuck, E. (2020). Eve Tuck - Bio. Retrieved from http://www.evetuck.com/

Tuck, E., \& McKenzie, M. (2015). Place in research : theory, methodology, and methods. New York: Routledge.

Turner, A. (2013). Aboriginal peoples in Canada First Nations people, Métis and Inuit : National Household Survey, 2011. Ottawa: Statistics Canada = Statistique Canada.

Tyuse, S. W., \& Linhorst, D. M. (2005). Drug Courts and Mental Health Courts: Implications for Social Work. Health \& Social Work, 30(3), 233-240. doi:10.1093/hsw/30.3.233

Union of Safety and Justice Employees. (2019). Canada's criminal justice system stressed and nearing a breaking point, says a federal parole officer survey by the Union of Safety and Justice Employees. Retrieved from http://www.usje-sesj.com/en/canada-s-criminaljustice-system-stressed-and-nearing-a-breaking-point-says-a-federal-parole-officersurvey-by-the-union-of-safety-and-justice-employees 
Valerie, G. (2016). Revitalizing Indigenous languages is key to reconciliation. Policy options, 1. van der Merwe, A., \& Hunt, X. (2019). Secondary Trauma Among Trauma Researchers: Lessons From the Field. Psychological trauma, 11(1), 10-18. doi:10.1037/tra0000414

Varcoe, C., Bungay, V., Browne, A. J., Wilson, E., Wathen, C. N., Kolar, K., ... Price, E. R. (2019). EQUIP Emergency: study protocol for an organizational intervention to promote equity in health care. BMC health services research, 19(1), 687-687. doi:10.1186/s12913-019-4494-2

Vartanian, L. (2013). The link between crime severity and drug and alcohol dependence. In: ProQuest Dissertations Publishing.

Vowel, C. (2016a). Indigenous writes : a guide to first nations, Metis \& Inuit issues in Canada. In Debwe Series (pp. 92-100). Winnipeg, Manitoba: Highwater Press.

Vowel, C. (2016b). Indigenous writes : a guide to First Nations, Metis, \& Inuit issues in Canada.

Vowel, C. (2016c). Indigenous writes : a guide to First Nations, Metis, \& Inuit issues in Canada. In Debwe series (pp. 106-115).

Wallace, P. A. W. (1986). The white roots of peace. Pennsylvania: University of Pennsylvania Press.

Wang, L. (2020, April 6). Grad students tell of the coronavirus's impact. Retrieved from https://cen.acs.org/education/graduate-education/Grad-students-tell-coronavirussimpact/98/i13

Watts, V. (2013). Indigenous place-thought \& agency amongst humans and non-humans (First Woman and Sky Woman go on a European world tour!). Decolonization: Indigeneity, Education \& Society, 2(1), 20-34.

Watts, V. (2019). [Personal Conversation]. 
Weekes, J., Thomas, G., \& Graves, G. (2019). Substance Abuse in Corrections Retrieved from https:/www.ccsa.ca/sites/default/files/2019-04/ccsa-011058-2004.pdf

Weinrath, M., Gorkoff, K., Watts, J., Smee, C., Allard, Z., Bellan, M., . . Cattini, M. (2018). Accessing drug treatment courts do age, race or gender matter? Australian \& New Zealand journal of criminology, 51(4), 619-637. doi:10.1177/0004865818757586

Weinrath, M., \& Smee, C. (2016). Winnipeg Drug Treatment Court Program Evaluation For Calendar Year 2015. Retrieved from

Welsh, A., \& Ogloff, J. R. P. (2008). Progressive Reforms or Maintaining the Status Quo?: An Empirical Evaluation of the Judicial Consideration of Aboriginal Status in Sentencing Decisions. Canadian journal of criminology and criminal justice, 50(4), 491-517. doi:10.3138/cjecj.50.4.491

Welton, A. (2012). The Encyclopedia of North American Indian Wars, 1607-1890: A Political, Social, and Military History. In (Vol. 108, pp. 32). Chicago: American Library Association.

White, T. (2021). 'Zoom Fatigue' Is Real — Here's How to Cope (and Make It Through Your Next Meeting). Retrieved from https://www.healthline.com/health/zoomfatigue\#: :text=It $\% 20$ refers $\% 20$ to $\% 20$ the $\% 20$ exhaustion,of $\% 20$ as $\% 20$ exhaustion $\% 20$ or \%20burnout. $\%$ E2\%80\%9D

Wild, T. C., Pauly, B., Belle-Isle, L., Cavalieri, W., Elliott, R., Strike, C., . . Hyshka, E. (2017). Canadian harm reduction policies: A comparative content analysis of provincial and territorial documents, 2000-2015. The International journal of drug policy, 45, 9-17. doi:10.1016/j.drugpo.2017.03.014 
Wilkes, R., Corrigall-Brown, C., \& Ricard, D. (2010). Nationalism and Media Coverage of Indigenous People's Collective Action in Canada : Storytelling: From Tradition to Reinvention. American Indian culture and research journal, 34(4), 41-59.

Wolfe, J. (2020). From Books to Zoom Connections, Keeping Children Engaged: National Desk. The New York times.

Women and Gender Equality Canada. (2021). What is Gender-based Analysis Plus. Retrieved from https://women-gender-equality.canada.ca/en/gender-based-analysis-plus/whatgender-based-analysis-plus.html

Woolford, A., \& Benvenuto, J. (2015). Canada and colonial genocide. Journal of genocide research, 17(4), 373-390. doi:10.1080/14623528.2015.1096580

Ziegler, B. R., Wray, A. J. D., \& Luginaah, I. (2019). The ever-changing narrative: Supervised injection site policy making in Ontario, Canada. The International journal of drug policy, 74, 98-111. doi:10.1016/j.drugpo.2019.09.006

Zinger, I. (2004). Actuarial risk assessment and human rights: A commentary. Canadian journal of criminology and criminal justice, 46(5), 607-620. doi:10.3138/cjccj.46.5.607

Zinger, I. (2012). Conditional Release and Human Rights in Canada: A Commentary. Canadian journal of criminology and criminal justice, 54(1), 117-135. doi:10.3138/cjecj.2011.E.19

Zinger, I. (2018). Office of the Correctional Investigator Annual Report 2017-2018. Retrieved from Ottawa, Ontario: https://www.oci-bec.gc.ca/cnt/rpt/annrpt/annrpt20172018eng.aspx

Zinger, I. (2019). Office of the Correctional Investigator Annual Report 2018-2019. Retrieved from Ottawa, Ontario: 
Zinger, I. (2020). Annual report of the Correctional Investigator. Annual report of the Correctional Investigator. 


\section{Appendix 1 - Information for Participants}

\section{Semi-Structured Interview Questions}

For criminalized Indigenous persons:

1. How do you identify as an Indigenous person?

2. Have you ever struggled with substance use/abuse?

3. Have you ever been to jail? What was it like?

4. Was your jail experience helpful to you once you got out?

5. Have you ever been to prison? What was it like?

6. Was your prison experience helpful to you once you got out?

7. If you experienced substance use/abuse challenges, did being incarcerated help you in the short term with those challenges? In the long term?

8. Do you know anything about drug treatment courts? Have you ever attended one?

9. Did you, or your legal team, ever consider a drug treatment court/mental health court/other specialized courts as an alternative to incarceration?

10. If you attend(ed) a drug treatment court/mental health court/other specialized courts, do you find the process helpful? Culturally sensitive?

11. If you did discuss drug treatment court/mental health court/other specialized courts but did not attend one, why not?

12. Do you think drug treatment court/mental health court/other specialized courts would be a preferable option to incarceration for you?

For Service Providers (both Indigenous and non-Indigenous):

1. What is your position in (or adjacent to) the criminal justice system? Are you employed, a volunteer, or an activist?

2. Do you identify as Indigenous? If yes, how do you identify?

3. What percentage of your clients are Indigenous?

4. To what extent do you believe substance abuse contributes to crime? Mental health challenges? Please elaborate.

5. Of your Indigenous clients, what percentage of them have cases related (directly or indirectly) to substance use/abuse? Mental health challenges?

6. Do you think incarceration is an adequate tool for rehabilitation in general? How about in the context of substance abuse?

7. What do you think of drug treatment court/mental health court/other specialized courts as an alternative to incarceration? Do you believe drug treatment court/mental health court/other specialized courts are more effective at rehabilitating clients, specifically in the context of substance abuse, than incarceration? 
8. Are you aware of the recidivism rate of drug treatment court/mental health court/other specialized courts vs the recidivism rate of participants who go through traditional corrections?

9. Have you ever referred Indigenous client(s) to a drug treatment court/mental health court/other specialized courts?

10. Are there any barriers for clients to enter a drug treatment court/mental health court/other specialized courts?

11. Are there any specific barriers for Indigenous clients (unique to Indigenous clients compared to non-Indigenous)? 


\section{Ethics Clearance Certificate}

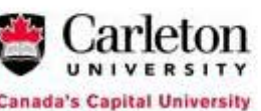

Office of Research Ethics

4500 ARISE Building | 1125 Colonel By Drive

Ottawa, Ontario K1S 5 B6

613-520-2600 Ext: 2517

ethics@carleton.ca

\section{CERTIFICATION OF INSTITUTIONAL ETHICS CLEARANCE}

The following research has been granted clearance by the Carleton University Research Ethics Board-A (CUREB-A). CUREB-A is constituted and operates in compliance with the Tri-Council Policy Statement: Ethical Conduct for Research Involving Hum ans (TCPS2).

Ethics Clearance D: Project \# 114449

Project T eam Members: Jaclyn T ompalski (Primary Investigator)

Aaron Doyle (Research Supervisor)

Study Title: Under-serving the Over-represented: Indigenous Application, Admissions, and Exclusion from Drug Treatment Courts

Funding Source: (If applicable):

Effective: December 01, 2020

Expires: December 31, 2021

\section{This certific ation is subject to the following conditions:}

1. Clearance is granted only for the research and purposes described in the application.

2. Any modification to the approved research must be submitted to CUREB-A via a Change to Protocol Form. All changes must be cleared prior to the continuance of the research.

3. An Annual Status Report for the renewal or closure of ethics clearance must be submitted and cleared by the renewal date listed above. Failure to submit the Annual Status Report will result in the closure of the file. If funding is as sociated, funds will be frozen

4. During the course of the study, if you encounter an adverse event, material incidental finding, protocol deviation or other unanticipated problem, you must complete and submit a Report of Adverse Events and Unanticipated Problems Form.

5. It is the responsibility of the student to notify their supervisor of any adverse events, changes to their application, or requests to renew/close the protocol

6. Failure to conduct the research in accordance with the principles of the Tri-Council Policy Statement: Ethical Conduct for Research Involving Humans 2 nd edition and the Carleton 
University Policies and Procedures for the Ethical Conduct of Research may result in the suspension or termination of the research project.

\section{IMPORTANT: Special requirements for COVID-19:}

If this study involves in-person research interactions with human participants, whether on- or off-campus, the following rules apply:

1. Upon receiving clearance from CUREB, please seek the approval of the relevant Dean for your research. Provide a copy of your CUREB clearance to the Dean for their records. Please contact your Dean's Office for more information about obtaining their approval. See Principles and Procedures for On-campus Research at Carleton University and note that this document applies both to on- and off-campus research that involves human participants.

2. Provide a copy of the Dean's approval to the Office of Research Ethics prior to starting any in-person research activities.

3. If the Dean's approval requires any significant change(s) to any element of the study, you must notify the Office of Research Ethics of such change(s).

Upon reasonable request, it is the policy of CUREB, for cleared protocols, to release the name of the PI, the title of the project, and the date of clearance and any renewal(s).

Please email the Research Compliance Coordinators at ethics@carleton.ca if you have any questions.

\section{CLEARED BY:}

Date: December 01, 2020

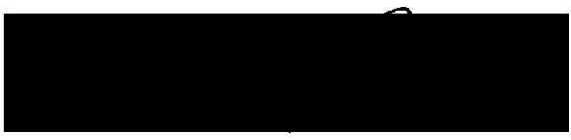

Bernadette Campbell, PhD., Chair, CUREB-A

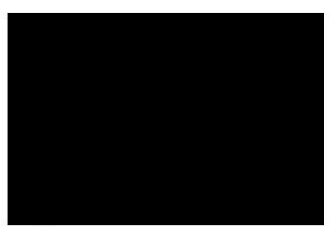

Natasha Artemeva, PhD, Vice-Chair, CUREB-A 


\section{Oral Consent Scripts}

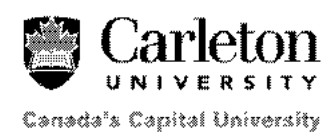

\section{Research Consent Form Script for Oral Consent - Service Providers}

Hello, my name is Jaclyn Tompalski and I am a Master's student in the Department of Sociology and Anthropology at Carleton University. I am working under the supervision of Prof. Aaron Doyle.

I would like to invite you to participate in a study titled Under-serving the Over-represented: Indigenous Applications, Admissions, and Exclusion from Drug Treatment Courts. This study aims to establish if Indigenous persons are being excluded from alternatives to incarceration, such as drug treatment courts, as a result of policy established by the provincial and federal governments.

The study involves an interview about your client's experience with incarceration and if incarceration resulted in meaningful rehabilitation, as well as any challenges or barriers you have faced as a service provider when working with Indigenous clients. With your consent the interview will be or videorecorded (audio-recorded if you lack the means to video conference), and once transcribed, the recording will be destroyed. If you do not want to be recorded, the researcher will take notes throughout the interview.

We estimate that the survey/interview will take about 60 minutes to complete. Your participation in this survey is voluntary, and you may choose not to take part, or not to answer any of the questions. If you decide to withdraw after the interview, your responses will be removed if you notify the researcher by May 1, 2021. You will not be compensated for your participation in this study. However, as a token of thanks for your participation, you will be provided with a $\$ 50$ honorarium to be paid following the interview. You will retain this honorarium in the event you choose to withdraw from this study.

You may find some of the questions to be sensitive and to cause you distress. If you do feel distress as a result of answering any of these questions, we invite you to contact Hope for Wellness at https://www.hopeforwellness.ca/ or call the toll-free Help Line at 1-855-242-3310, 24 hours a day, 7 days a week for counselling services.

We will treat your personal information as confidential, although absolute privacy cannot be guaranteed. No information that discloses your identity will be released or published without your specific consent. However, research records identifying you may be inspected by my supervisor, Dr. Aaron Doyle, and by the Carleton University Research Ethics Board for the purpose of monitoring the research. The results of this study may be published, but the data will be presented so that it will not be possible to identify any participants. All research data will be password protected on a secure network and any hard copies of data will be kept in a locked cabinet at Carleton University.

You will be assigned a code so that your identity will not be directly associated with the data you have provided. All data, including coded information, will be kept in a password-protected [or encrypted] file on a secure computer.

Your data will be stored and protected by Carleton University on a secure network, but may be disclosed via a court order or data breach.

After the study is completed, we will retain your de-identified data for future research use. 
This project was reviewed and cleared by the Carleton University Research Ethics Board. If you have any ethical concerns with the study, please contact the Carleton University Research Ethics Board by phone at 613-520-2600 ext. 2517 for CUREB A or by email at ethics@carleton.ca.

You can also reach me at 780-952-5225 or email me at jaclyntompalski@cmail.carleton.ca. You may contact my supervisor at aaron.doyle $@$ carleton.ca.

\section{Statement of consent}

Do you have any questions about this study or need any clarification?

Do you voluntarily agree to participate in the study? Yes

Do you agree to be (audio/video recorded/photographed)?

$\begin{array}{ll}\text { Yes____ No____ } & \text { No } \\ \text { Yes___ } & \text { No }\end{array}$

Note: If you do not consent to be recorded, do you consent to the researcher taking notes through the interview?

Yes No

Do you consent to being contacted for a 15-minute follow-up interview to give you the opportunity to confirm the researcher's interpretation of the information you provided in the initial interview?

Yes No

Date:

Participant's Name/Pseudonym/Initials (as appropriate):

\section{Research team member who interacted with the subject}

I have explained the study to the participant and answered any and all of their questions. The participant appeared to understand and agree. I provided a copy of the consent information to the participant for their reference.

Signature of researcher

Date 


\section{Carleton \\ UNIVERSITY}

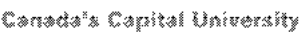

\section{Research Consent Form Script for Oral Consent - Service Providers}

Hello, my name is Jaclyn Tompalski and I am a Master's student in the Department of Sociology and Anthropology at Carleton University. I am working under the supervision of Prof. Aaron Doyle.

I would like to invite you to participate in a study titled Under-serving the Over-represented: Indigenous Applications, Admissions, and Exclusion from Drug Treatment Courts. This study aims to establish if Indigenous persons are being excluded from alternatives to incarceration, such as drug treatment courts, as a result of policy established by the provincial and federal governments.

The study involves an interview about your client's experience with incarceration and if incarceration resulted in meaningful rehabilitation, as well as any challenges or barriers you have faced as a service provider when working with Indigenous clients. With your consent the interview will be or videorecorded (audio-recorded if you lack the means to video conference), and once transcribed, the recording will be destroyed. If you do not want to be recorded, the researcher will take notes throughout the interview.

We estimate that the survey/interview will take about 60 minutes to complete. Your participation in this survey is voluntary, and you may choose not to take part, or not to answer any of the questions. If you decide to withdraw after the interview, your responses will be removed if you notify the researcher by May 1, 2021. You will not be compensated for your participation in this study.

You may find some of the questions to be sensitive and to cause you distress. If you do feel distress as a result of answering any of these questions, we invite you to contact Hope for Wellness at https://www hopeforwellness.ca/ or call the toll-free Help Line at 1-855-242-3310, 24 hours a day, 7 days a week for counselling services.

We will treat your personal information as confidential, although absolute privacy cannot be guaranteed. No information that discloses your identity will be released or published without your specific consent. However, research records identifying you may be inspected by my supervisor, Dr. Aaron Doyle, and by the Carleton University Research Ethics Board for the purpose of monitoring the research. The results of this study may be published, but the data will be presented so that it will not be possible to identify any participants. All research data will be password protected on a secure network and any hard copies of data will be kept in a locked cabinet at Carleton University.

You will be assigned a code so that your identity will not be directly associated with the data you have provided. All data, including coded information, will be kept in a password-protected [or encrypted] file on a secure computer.

Your data will be stored and protected by Carleton University on a secure network, but may be disclosed via a court order or data breach.

After the study is completed, we will retain your de-identified data for future research use.

This project was reviewed and cleared by the Carleton University Research Ethics Board. If you have any ethical concerns with the study, please contact the Carleton University Research Ethics Board by phone at 613-520-2600 ext. 2517 for CUREB A or by email at ethics@carleton.ca. 
You can also reach me at $\quad$ or email me at jaclyntompalski@cmail.carleton.ca. You may contact my supervisor at aaron.doyle $(a$ carleton.ca.

\section{Statement of consent}

Do you have any questions about this study or need any clarification?

Do you voluntarily agree to participate in the study? Yes Yes___ No

Do you agree to be (audio/video recorded/photographed)?

Yes No

Note: If you do not consent to be recorded, do you consent to the researcher taking notes through the interview?

Yes No

Do you consent to being contacted for a 15-minute follow-up interview to give you the opportunity to confirm the researcher's interpretation of the information you provided in the initial interview?

Yes No

Date:

Participant's Name/Pseudonym/Initials (as appropriate):

\section{Research team member who interacted with the subject}

I have explained the study to the participant and answered any and all of their questions. The participant appeared to understand and agree. I provided a copy of the consent information to the participant for their reference.

Signature of researcher

Date 


\section{Written Consent Forms}

\section{Informed Consent Form}

Name and Contact Information of Researchers:

Jaclyn Tompalski, Department of Saciology and Anthropology

Tel.:

Email: jaclyntompalski@cmail.carleton.ca

Supervisor and Contact Information: Dr. Aaron Doyle, aaron.doyle@carleton.ca

\section{Project Title}

Under-serving the Over-represented: Indigenous Application, Admissions, and Exclusion from Drug Treatment Courts

Carleton University Project Clearance

Clearance \#: *** 114449 Date of Clearance: December 01, 2020 ***

\section{Invitation}

You are invited to take part in a research project because you are an Indigenous person with previous experience with the criminal justice system, or are a service provider who has worked with Indigenous people involved in the criminal justice system. The information in this form is intended to help you understand what we are asking of you so that you can decide whether you agree to participate in this study. Your participation in this study is voluntary, and a decision not to participate will not be used against you in any way. As you read this form, and decide whether to participate, please ask all the questions you might have, take whatever time you need, and consult with others as you wish.

\section{What is the purpose of the study?}

This study seeks to determine the rate at which Indigenous people are applying to and being admitted into drug treatment courts in what is known as Canada. Further, it seeks to identify any potential barriers or systemic policy challenges that negatively impact Indigenous persons when applying into these programs. Such information will shed light on the Indigenous experience of exploring alternatives to incarceration, and could result in increased knowledge to reform criminal justice policy.

What will I be asked to do?

If you agree to take part in the study, we will ask you to:

For example:

- Engage in an interview lasting no more than sixty minutes describing your (or your client's) experience with the criminal justice system and rehabilitation efforts provided.

- You will also have the opportunity to engage in a follow-up, narrative meeting lasting no more than fifteen minutes, where the researcher can confirm their interpretations of your information to ensure you feel appropriately represented. 
- The requested information deals with the experiences of Indigenous persons the criminal justice system, specifically rehabilitative initiatives in incarceration and opinions surrounding alternatives to incarceration, such as drug treatment courts.

- All interviews will take place over video call, though telephone call is available for participants who lack the means to engage in a video call.

- The initial interview will not last longer than sixty minutes.

- The interviews will be video-recorded (unless the participant required a phone interview, in which case it will be audio-recorded).

\section{Risks and Inconveniences}

The only identified risks for participation in this study is the potential for emotional distress as a result of discussing unpleasant experiences with the criminal justice system. If you do feel distress as a result of answering any of these questions, we invite you to contact Hope for Wellness at https://www.hopeforwellness.ca/ or call the toll-free Help Line at 1-855-242-3310, 24 hours a day, 7 days a week for counselling services.

\section{Possible Benefits}

You may not receive any direct benefit from your participation in this study. However, your participation may allow researchers to better understand how drug court policy established by the provincial and federal governments impacts Indigenous persons in the criminal justice system. In the event that the current policy is found to be harmful, this study could lead to policy reform that better supports the Indigenous peoples of what is known as Canada.

\section{Compensation/Incentives}

You will not be paid or compensated for your participation in this study. However, as a token of thanks for your participation, you will be provided with a $\$ 50$ honorarium to be paid following the interview.

\section{No waiver of your rights}

By signing this form, you are not waiving any rights or releasing the researchers from any liability.

\section{Withdrawing from the study}

If you withdraw your consent during the course of the study, all information collected from you before your withdrawal will be discarded.

After the study, you may request that your data be removed from the study and deleted by notice given to the Principal Investigator (named above) before May 1, 2021.

\section{Confidentiality}

We will remove all identifying information from the study data as soon as possible, which will be after the video-recording (or audio-recording if you lack means to video conference) are transcribed.

We will treat your personal information as confidential, although absolute privacy cannot be guaranteed. No information that discloses your identity will be released or published without your specific consent. 
Research records may be accessed by the Carleton University Research Ethics Board in order to ensure continuing ethics compliance.

All data will be kept confidential, unless release is required by law (e.g. child abuse, harm to self or others).

The results of this study may be published or presented at an academic conference or meeting, but the data will be presented so that it will not be possible to identify any participants unless you give your express consent

You will be assigned a code so that your identity will not be directly associated with the data you have provided. All data, including coded information, will be kept in a password protected network provided at Carleton University.

\section{Data Retention}

After the study is completed, your de-identified data will be retained for future research use.

\section{New information during the study}

In the event that any changes could affect your decision to continue participating in this study, you will be promptly informed.

\section{Ethics review}

This project was reviewed and cleared by the Carleton University Research Ethics Board [A or B]. If you have any ethical concerns with the study, please contact Carleton University Research Ethics Board (by phone at 613-520-2600 ext. 2517 for CUREB A or by email at ethics@carleton.ca).

\section{Statement of consent - print and sign name}

I voluntarily agree to participate in this study.

I agree to be (audio/video recorded)

$$
\begin{array}{cr}
\text { Yes } & \text { No } \\
\text { Yes } &
\end{array}
$$

Note: If you do not consent to be recorded, do you consent to the researcher taking notes through the interview?

Yes No

Do you consent to being contacted for a 15-minute follow-up interview to give you the opportunity to confirm the researcher's interpretation of the information you provided in the initial interview?

Yes

I agree to be contacted for follow up research

Signature of participant
No

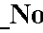

Research team member who interacted with the participant 
I have explained the study to the participant and answered any and all of their questions. The participant appeared to understand and agree. I provided a copy of the consent form to the participant for their reference. 


\section{Informed Consent Form}

Name and Contact Information of Researchers:

Jaclyn Tompalski, Department of Saciology and Anthropology

Tel.:

Email: jaclyntompalski@cmail.carleton.ca

Supervisor and Contact Information: Dr. Aaron Doyle, aaron.doyle@carleton.ca

\section{Project Title}

Under-serving the Over-represented: Indigenous Application, Admissions, and Exclusion from Drug Treatment Courts

\section{Carleton University Project Clearance}

Clearance \#: *** 114449 Date of Clearance: December 01, $2020 * * *$

\section{Invitation}

You are invited to take part in a research project because you are an Indigenous person with previous experience with the criminal justice system, or are a service provider who has worked with Indigenous people involved in the criminal justice system. The information in this form is intended to help you understand what we are asking of you so that you can decide whether you agree to participate in this study. Your participation in this study is voluntary, and a decision not to participate will not be used against you in any way. As you read this form, and decide whether to participate, please ask all the questions you might have, take whatever time you need, and consult with others as you wish.

\section{What is the purpose of the study?}

This study seeks to determine the rate at which Indigenous people are applying to and being admitted into drug treatment courts in what is known as Canada. Further, it seeks to identify any potential barriers or systemic policy challenges that negatively impact Indigenous persons when applying into these programs. Such information will shed light on the Indigenous experience of exploring alternatives to incarceration, and could result in increased knowledge to reform criminal justice policy.

\section{What will I be asked to do?}

If you agree to take part in the study, we will ask you to:

For example:

- Engage in an interview lasting no more than sixty minutes describing your (or your client's) experience with the criminal justice system and rehabilitation efforts provided.

- You will also have the opportunity to engage in a follow-up, narrative meeting lasting no more than fifteen minutes, where the researcher can confirm their interpretations of your information to ensure you feel appropriately represented. 
- The requested information deals with the experiences of Indigenous persons the criminal justice system, specifically rehabilitative initiatives in incarceration and opinions surrounding alternatives to incarceration, such as drug treatment courts.

- All interviews will take place over video call, though telephone call is available for participants who lack the means to engage in a video call.

- The initial interview will not last longer than sixty minutes.

- The interviews will be video-recorded (unless the participant required a phone interview, in which case it will be audio-recorded).

\section{Risks and Inconveniences}

The only identified risks for participation in this study is the potential for emotional distress as a result of discussing unpleasant experiences with the criminal justice system. If you do feel distress as a result of answering any of these questions, we invite you to contact Hope for Wellness at https://www.hopeforwellness.ca/ or call the toll-free Help Line at 1-855-242-3310, 24 hours a day, 7 days a week for counselling services.

\section{Possible Benefits}

You may not receive any direct benefit from your participation in this study. However, your participation may allow researchers to better understand how drug court policy established by the provincial and federal governments impacts Indigenous persons in the criminal justice system. In the event that the current policy is found to be harmful, this study could lead to policy reform that better supports the Indigenous peoples of what is known as Canada.

\section{Compensation/Incentives}

You will not be paid or compensated for your participation in this study.

\section{No waiver of your rights}

By signing this form, you are not waiving any rights or releasing the researchers from any liability.

\section{Withdrawing from the study}

If you withdraw your consent during the course of the study, all information collected from you before your withdrawal will be discarded.

After the study, you may request that your data be removed from the study and deleted by notice given to the Principal Investigator (named above) before May 1, 2021.

\section{Confidentiality}

We will remove all identifying information from the study data as soon as possible, which will be after the video-recording (or audio-recording if you lack means to video conference) are transcribed.

We will treat your personal information as confidential, although absolute privacy cannot be guaranteed. No information that discloses your identity will be released or published without your specific consent. 
Research records may be accessed by the Carleton University Research Ethics Board in order to ensure continuing ethics compliance.

All data will be kept confidential, unless release is required by law (e.g. child abuse, harm to self or others).

The results of this study may be published or presented at an academic conference or meeting, but the data will be presented so that it will not be possible to identify any participants unless you give your express consent

You will be assigned a code so that your identity will not be directly associated with the data you have provided. All data, including coded information, will be kept on a password protected network provided at Carleton University.

\section{Data Retention}

After the study is completed, your de-identified data will be retained for future research use.

\section{New information during the study}

In the event that any changes could affect your decision to continue participating in this study, you will be promptly informed.

\section{Ethics review}

This project was reviewed and cleared by the Carleton University Research Ethics Board [A or B]. If you have any ethical concerns with the study, please contact Carleton University Research Ethics Board (by phone at 613-520-2600 ext. 2517 for CUREB A or by email at ethics@carleton.ca).

\section{Statement of consent - print and sign name}

I voluntarily agree to participate in this study.

I agree to be (audio/video recorded)

$$
\begin{array}{rr}
\text { Yes } & \text { No } \\
\text { Yes } &
\end{array}
$$

Note: If you do not consent to be recorded, do you consent to the researcher taking notes through the interview?

Yes No

Do you consent to being contacted for a 15-minute follow-up interview to give you the opportunity to confirm the researcher's interpretation of the information you provided in the initial interview?

Yes

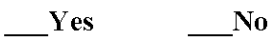

Signature of participant

Date

Research team member who interacted with the participant 
I have explained the study to the participant and answered any and all of their questions. The participant appeared to understand and agree. I provided a copy of the consent form to the participant for their reference. 


\section{Initial Email Contact Script for Organizations}

Edlanet'e,

I am a Northern Slavey Dene Master's student at Carleton University. I am in the process of conducting research for my thesis, which focuses on the representation of Indigenous persons in alternatives to incarceration. I was inspired to conduct this research after several positions in both institutional and community corrections in Edmonton, where I observed the overrepresentation of Indigenous persons incarcerated. My research examines the admissions policy and criteria, specifically the ways (if any) that it supports Indigenous clients. Ultimately, I hope to use this research to shape policy and to redistribute correctional funding to organizations that provide such services in the community.

I will be conducting all interviews over the phone/video calls to avoid unnecessary risks with COVID-19. Specifically, I am looking for Indigenous participants with drug-related (directly or indirectly, e.g. convicted of robbery as the individual required funds to support themselves through addiction) criminal convictions, and the staff/volunteers who work with such clients (the staff members do not need to be Indigenous), as participants for this research. Indigenous clients will be provided with a $\$ 50$ honorarium as a thank you for their participation, which will not go beyond a 60-minute interview. Would you be willing to circulate my research to those within your network? Further, would either of you be willing to participate yourselves?

I am deeply concerned about the research violences that Indigenous peoples have experienced at the hands of colonial researchers. My research exclusively seeks to uplift and support Indigenous persons and communities. Further, I have a committee member who is a member of Ermineskin Cree Nation supervising this research, as well as community Indigenous consultants who work in 
areas of policy, frontline support, or who have relevant lived experience. I completely sympathize that you are likely often approached for research participation by those who have caused harm, but I hope you can tell that I am doing my best to avoid such harms with my research. I also will allow any participant to confirm my interpretation of their interviews following my analysis, so as to assure I am not using their knowledges or experiences in a way that they did not intend.

I thank you for reading this long email - I wanted to ensure you were as informed as possible both about the project and my intentions. If you have any questions or concerns, please do not hesitate to contact me either at this email or by phone at

Mars1,

Jaclyn Tompalski 


\section{INDIGENOUS RESEARCH PARTICIPANTS}

Seeking participants for research on the criminal sentencing of Indigenous persons, specifically their experiences with being educated about, applying to, and admission results into drug treatment courts

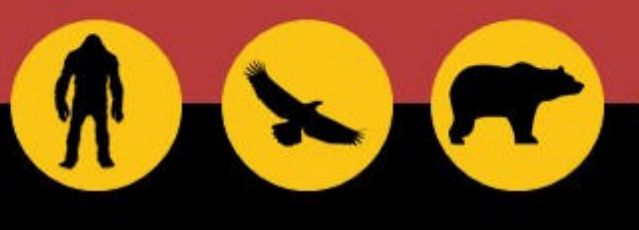

\section{PARTICIPANT REQUIRMENTS}

Are you interested in participating in a study that could shed light on gaps in policy regarding alternatives to incarceration such as drug treatment courts?

Are you an Indigenous person with a drug-related criminal conviction in what is known as Canada?

Do you have access to a device for video calling, or to a phone, for the interview?

Are you able to commit to one 60minute (max) interview session to explain your experiences with the justice system?

You will be provided with a $\$ \mathbf{5 0}$ honorarium as a thank you for your participation.

\section{PLEASE NOTE}

Your confidentiality is assured. Your name will never be used.

This is Indigenous-led research.

You do not need to have attended a drug treatment court to participate.

The research will be conducted separately from the organization who assisted.

\section{CONTACT INFO}

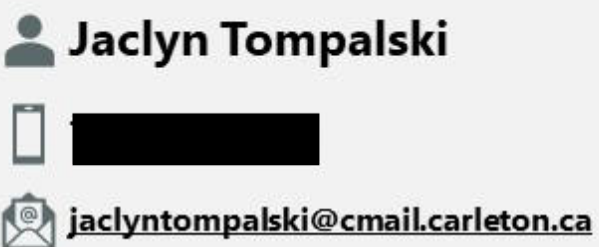

This study has been reviewed by and received ethics clearance through the Carleton University Ethics Committee. Protocol number 114449 


\section{RESEARCH PARTICIPANTS}

Seeking participants for research on the criminal sentencing of Indigenous persons, specifically their experiences with being educated about, applying to, and admission results into drug treatment courts.
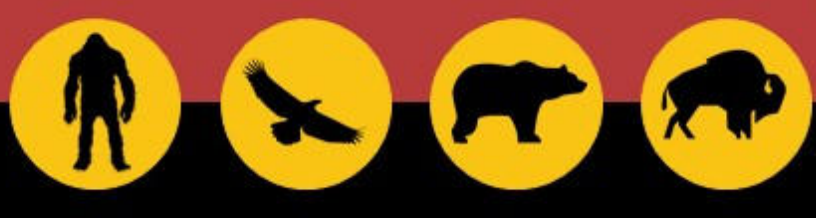

\section{PARTICIPANT REQUIRMENTS}

Are you interested in participating in a study that could shed light on gaps in policy regarding alternatives to incarceration such as drug treatment courts?

Are you a service provider who works with Indigenous clients with drugrelated criminal convictions in what is known as Canada?

Do you have access to a device for video calling, or to a phone, for the interview?

Would you be able to commit to one 60-minute (max) interview session to explain your experiences with the justice system?

\section{PLEASE NOTE}

Your confidentiality is assured. Your name will not be used.

This is Indigenous-led research.

You do not need to be Indigenous to participate.

The research will be conducted separately from the organization assisting in circulating this poster.

\section{CONTACT INFO}

\section{Jaclyn Tompalski

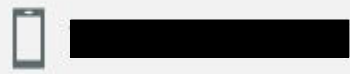 \\ @ jaclyntompalski@cmail.carleton.ca}




\section{Appendix 2 - Admission Eligibility Criteria for Specialized Courts}

\section{Brampton Drug Treatment Court}

- $\quad$ Screening Process

The Brampton Drug Treatment Court receives applications from clients who have been charged with eligible criminal offences.

A. Referral

A standard referral may emerge from the Crown Screening Form in your client's initial disclosure documents, or can equally be negotiated at any time throughout the life of pretrial discussions. Some clients are referred by counsellors, probation officers, police, lawyers, while others may self-identify and inquire what exists to assist them towards recovery from their addiction.

B. Crown Screening

Once a potential client demonstrates an interest, an application is made to the applicable crown's office. If a potential client has both C.D.S.A and Criminal Code offences, applications must be made to both crown's offices. The applicable crown's office will assess the application and make a preliminary decision as to eligibility. The application is assessed based on set criteria that includes seriousness of the offence, whether violence was involved, history of violence offences, etc. If admitted to the program, often one crown's office assumes delegation of all charges.

Once the initial assessment is conducted and the potential client is approved by the applicable crown's office, the potential client's matters are adjourned into the next drug treatment court.

Potential clients in custody at the time of the application will be considered. A determination as to the person's suitability will be made. If in the opinion of the applicable Crown's office, the person is not a candidate for release, the potential client will have to obtain his or her own release before being eligible for the program. If able to obtain their release, the potential participant, upon entry into the program, will enter into a new recognizance which provides for the terms required in the program.

If, based on bail principles, the potential candidate is suitable to be released into the community, he or she will be released on a recognizance with specific terms related to the program.

C. Preliminary drug treatment court assessment

Prior to entry in the program, representatives from PAARC and EFRY, will conduct a brief needs assessment with the applicant. Where possible, clients should attend an out-ofcustody appointment, to highlight their motivations and goals for entry in the program. Where a client is in custody, the initial brief assessment may be done in the jail or may be done after release.

Brampton Drug Treatment Court - Pre-Meeting before Friday Court

Prior to court each Friday, the Drug treatment court team, comprised of representatives from PAARC, Elizabeth Fry, Crowns assigned to the Addictions Court, and the Justice, meet to discuss each case. Clients represented by counsel, or Duty Counsel on behalf of self-represented applicants, are encouraged to send their agent to our weekly Friday meeting, to discuss the client's willingness and capacity to participate.

D. In-Court Interview with the Presiding Justice

The Brampton Drug Treatment Court sits every Friday, beginning at 11:30am, in the designated court. Applicants are required to attend. Prior to entering pleas of guilt, an applicant will be asked by the Justice to discuss why they requested admission to the program.

Judges will gage an applicant's expectations, by affirming the challenge that lies ahead. Participants will be reminded of the rigorous schedule and questioned whether they remain committed to the program.

Participants will then be arraigned on all remaining counts, and pleas of guilt entered, pursuant to s. 606 of the Code.

E. 30-Day Test Period

Pursuant to the waiver agreement, clients who enter a plea of guilt will be closely monitored while in the program. At any time during the first month, if a client feels overwhelmed or for any other reason elects not to continue participating in the program, they are entitled to strike their plea and return to the general court stream.

It is important to note that should the Addictions Team move to terminate a participant from the program, the first 30 days serve as an effective barometer to assess a client's motivations and capacity, to remain in the program. If the Addictions Team determines that the client is not ready for the program, the client may be asked to return to the general court stream, and their pleas will be struck.

Prior to the completion of the 30-day period, a participant will be asked on record, whether they choose to remain in the program. If s/he answers yes, the automatic right to strike his/her plea is then relinquished, and sentencing will proceed before an Addictions Court Justice, at the conclusion of the client's tenure in the program.

In some cases, 30 days will not be an equitable snapshot to assess a client's progress. The Brampton Drug Treatment Court reserves the right to extend a client's 30 -day trial period for a further period of time, giving due consideration to principles of fairness and reasonableness. 
The Brampton Drug Treatment Court program seeks to assist accused persons who are prepared to accept responsibility for their offences, by entering a plea of guilt. Unfortunately, not all offences can come into the program.

The program cannot accept clients facing charges relating to:

- Break \& Enter, into a residence, with the intention of committing an indictable offence;

- Other significant crimes of violence;

- Offences involving an intimate partner

- Offences alleging the Impaired operation of a motor vehicle;

- Trafficking in controlled drugs or substances, for a commercial gain

- Crimes against children

Any other crimes that present a safety risk to the Addictions Team or other participants may be refused entry to the Drug treatment court.

An offender entering a plea of guilt to a crime contrary to the Controlled Drugs and Substances Act (CDSA) or the Criminal Code (Code), should be prepared to admit the essential elements of the offence, and concede their conduct was largely motivated by their substance abuse.

Due to the nature of the program and the length of time required to graduate, all participants are expected to waive their rights to a speedy trial pursuant to section 11(b) of the Charter. Further, pursuant to s. 720(2) of the Criminal Code, the participant consents to a delay in his or her sentencing to enable participation in the program. 


\section{Calgary Drug Treatment Court}

\section{CROWN ELIGIBILITY CRITERIA CALGARY DRUG TREATMENT COURT}

The Crown will consider all relevant information when determining the Applicant's eligibility for participation in the Calgary Drug Treatment Court program.

\section{Mandatory Criteria}

The following pre-conditions must be present for an accused to participate in the Calgary Drug Treatment Court (CDTC).

1. Must be 18 years of age or older;

2. All outstanding charges in Alberta must be waived into Calgary and form part of the CDTC application;

3. A Treatment Assessment completed by the CDTC Treatment team has indicated that the Applicant is suitable for participation in the CDTC program. The Treatment Assessment must also confirm that the Applicant is addicted to a Schedule I controlled substance; and

4. Crown Counsel, after applying the Screening Criteria listed below, has approved the Applicant for participation in CDTC. Upon meeting the above criteria, the CDTC Team as a whole will determine if the Applicant will be accepted in to the CDTC program. The suitability and availability of current CDTC resources and treatment options may impact this decision.

\section{Crown Screening Criteria:}

The Crown will consider all factors including, but not limited to, the following in deciding to approve or disapprove an application for participation in CDTC. The presence of any one of the following factors may result in non-approval for the CDTC program:

1. Whether the Applicant is charged with a serious violent offence;

2. Whether the Applicant has a recent and/or significant history of violence;

3. Whether the Applicant used or threatened to use a weapon during the commission of the offence(s);

4. Whether the Applicant is subject to an enforceable removal order due to "serious criminality" under the Immigration and Refugee Protection Act;

5. Whether the Applicant is a member or associate of a gang or criminal organization;

6. Whether the commission of the offence involves a person $<18$ years of age, or at $/ \mathrm{in} / \mathrm{near}$ a location ordinarily frequented by a person $<18$ years;

7. Whether the commission of the offence(s) was unrelated to an addiction to a Schedule I controlled substance or primarily for commercial gain/profit;

8. Whether the individual is facing a minimum of 6 months' in custody (and prioritizing those facing between 1 and 4.5 years)

9. Whether the Applicant is currently serving a community-based sentence (i.e. CSO, intermittent sentence or probation);

10. Whether the Applicant has been expelled, withdrawn or graduated from CDTC or a similar drug treatment court program within the last 12 months. 


\section{CALGARY DRUG TREATMENT COURT}

Programs \& services

How To Apply

CDTC Participants

FAQ's

Contact Us

Donate

Site Search

a

First Nations / Aboriginal Program

Calgary Drug Treatment Court is cognizant of the unique history that First Nation's people have experienced. With this in mind, CDTC is able to make referrals to Aboriginal Addiction

Treatment programs within the province.

First Nation's and Metis participants are supported in their attendance at healing circles in the community, sweats and in seeking support from Elders. Treatment staff is knowledgeable about various funding sources for programs, education and counseling purposes.

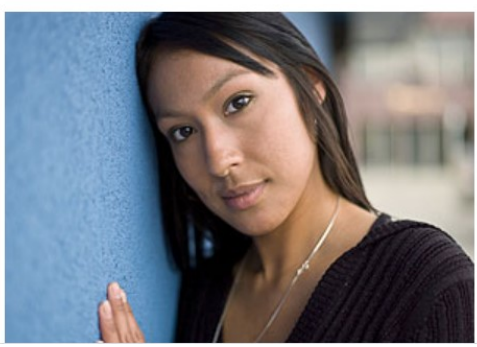




\section{Calgary Indigenous Court}

\section{CALGARY INDIGENOUS COURT}

The Calgary Indigenous Court (CIC) was established in 2019 to provide a culturally relevant, restorative, and holistic system of justice for Indigenous individuals, including offenders, victims and the community harmed by an offender's actions. The CIC is a response to the unique challenges and circumstances of the Indigenous people. It seeks to address the issue of over-representation of Indigenous people in the justice system and is a step forward in implementing recommendations from the Truth and Reconciliation Commission (TRC) as well as the Missing and Murdered Indigenous Woman and Girls National Inquiry (MMIWG) Report.

The CIC focuses on a restorative justice approach to crime through peacemaking and connecting accused people to their cultures and communities. It deals primarily with bail and sentencing hearings, and is open to any offender who is Indigenous and chooses to have matters addressed in the CIC. When an offender is sentenced to probation, a Healing Plan specific to the offender may be included in the probation order. Healing Plans use identified Indigenous community support agencies to assist in re-integrating offenders into the community, and, where appropriate, also encourage offenders to learn about and reconnect with their Indigenous heritage. A ceremony may be held in the $\mathrm{CIC}$ to acknowledge the successful completion of a probation order and the Healing Plan.

The CIC sits every Wednesday beginning at 9 a.m. in Courtroom 1800 of the Calgary Courts Centre. Courtroom 1800 is a specialized courtroom which was specifically designed to support an Indigenous approach to law. It is modelled after a teepee and allows participants to sit in a circle at the same level. Courtroom 1800 has an eagle feather for taking oaths (which is available in all Alberta Courts) as well as special ventilation to allow for smudging during traditional ceremonies.

The CIC utilizes dedicated judges who are either Indigenous or experienced in Indigenous Restorative Justice, a designated Indigenous Crown Prosecutor, designated duty counsel and Indigenous Legal Counsel, Restorative Justice Peacemakers, Traditional Knowledge Keepers, Indigenous Court Workers and community support agencies. Agencies involved with the CIC include the Elizabeth Fry Society of Calgary, Calgary Legal Guidance, the Aboriginal Friendship Centre, the Sunrise Healing Lodge, Indigenous Mental Health, Native Counselling Services of Alberta, Homefront, the John Howard Society, and the Calgary Police Service as well as several other support agencies. 


\section{Edmonton Drug Treatment Court}

\section{Home About - Get Involved - Youth Services - Adult Services - Contact Donate}

What it is: The Edmonton Drug Treatment Court Service (EDTCS) is an intensive one year (minimum) court-supervised drug treatment program that helps participants break the cycle of crime and addiction, learn to live a life free of addiction to drugs, make amends for past crimes and continue on to become productive contributing members of society. Drug Court takes place every Wednesday afternoon at 2 p.m. in court room 267 at the Edmonton Court House. The purpose of the drug treatment court is to restore justice through reduced crime recidivism and victimization in the community and to reduce overall expenditures of the Courts, Legal, Corrections and Human Services systems. The goal of the drug treatment court is to support drug addicts to rebuild their life and learn to live a lifetime in recovery.

Who can apply: The EDTCS accepts adult men and women who are addicted to drugs and are committing crimes to sustain and support their addiction, are at a high risk to continue in their addiction and criminal activity and are facing a substantial jail sentence as a result of their crimes. The drug court operates on a basis of a guilty plea with a delayed sentencing process (s.720 (2) of the criminal code) with entry into the program being dependant on the consent of the Crown, the Court and the Accused. Individuals who are interested in applying to the program should contact their legal counsel or probation officer for a referral.

Who contributes: The operation of the EDTCS is based on a multi-disciplinary team concept that is comprised of the Judge(s), Provincial and Federal Crown Prosecutors, Duty Counsel (Alberta Legal Aid), Social Worker (Community \& Social Services), Edmonton Police Service Liaison, Probation Officer (Alberta Justice \& Solicitor General), and the EDTCS Case Management team. The multi-disciplinary team works collaboratively with the participants by way of intensive judicial supervision through weekly court appearances where participants give an account of their daily progress to the Judge.

How it is funded: The EDTCS is funded by Justice Canada, Alberta Justice \& Solicitor General and also receives private funding from Elvis \& Twyla Iginla (Iginla \& Company). The program works collaboratively with the Ministry of Community and Social Services, Alberta Health Services and a multitude of community agencies, service providers and organizations. Private funding donations are also made by several community businesses and individuals.

The Program: Participants receive intensive supervision through weekly case management and probation involvement, weekly court attendance to speak to the Judge, and random and regular drug urinalysis screens. Participants are required to be actively engaged in daily and ongoing programming while in the drug treatment court.

Like most drug treatment courts, the ultimate goal of the program is to break the cycle of addiction and criminal activity. However, EDTCS places an additional emphasis on the achievement of reintegration of participants into the community and community restoration. EDTCS participants are supported to not only engage in recovery but also improve every dimension of their life including housing, employment, education, physical and mental health, relationships, family, dealing with past trauma, reconnecting to their culture and giving back to the community through volunteer hours and community involvement.

Drug Courts overall have been proven to elicit the most effective and cost-efficient results for the individuals who are drug dependant and at risk of failing in less intensive rehabilitative programs. Over $70 \%$ of program graduates have not had new criminal convictions. The participants of the EDTCS are graduating from drug court as productive contributing members of society.

The program has an ongoing wait list of individuals who are hoping for an opportunity to change their lives. Our goal is to continue to build strong partnerships and increase and create sustainable funding in order to meet the high demand for drug treatment court services in the Edmonton region. 


\section{Edmonton Mental Health Court}

\section{MENTAL HEALTH COURT}

The Edmonton Mental Health Court (MHC) program helps address the over-representation of people with mental illness in the justice system by focusing on underlying mental health problems that often contribute to repeated criminal behaviour.

The MHC is available for adults (aged 18 years or older) who have been charged with a criminal offence and have an ongoing mental health issue that affects or impairs judgment. Individuals with a brain injury or head trauma, including fetal alcohol spectrum disorder (FASD) in some cases, and those with mental illnesses such as schizophrenia, bipolar disorder and major depression will also be considered.

Admission to the MHC is based the following criteria:

- There must be a reasonable basis to believe that an accused has a brain injury, neurological deficit such as FASD, mental illness or mental disorder;

- There must be a reasonable basis to believe that there is a relevant connection between the mental health condition of the accused and the alleged criminal offence;

- The accused must consent and be motivated to participate in MHC; and

- The alleged criminal offence must not be subject to exclusion under the MHC criteria*. (Excluded offences include murder; drug prosecutions, unless a federal prosecutor consents; prosecution handled by Special Prosecutions; breaches of long term offender orders or of certain peace bonds.)

*Cases involving domestic violence usually do not qualify.

Only a Judge can formally refer accused persons to the MHC, but counsel can recommend a referral at any stage, based on their own observations or based on input from others such as police, a Justice of the Peace or family members

The MHC functions like any other court in that the Crown and Defence counsel generally determine what information is placed before the Judge and counsel make recommendations to the Judge as to how a matter should be dealt with. However, this court differs from conventional courts based on an adversarial model. This court takes a more collaborative approach and enjoys extra resources to help the court identify and address the issues underlying the criminal behaviour. In addition to Crown and Defence counsel, there is a mental health worker in the court, a social worker/navigator is available to help accused persons access resources in the community and navigate the system, and a psychiatrist is in regular attendance.

The MHC sits weekly on Mondays, Wednesdays and Fridays, 9:30 a.m. to 4:30 p.m. at the Edmonton Law Courts. 


\section{London Drug Treatment Court}

\section{Is this program for me?}

\section{Primary Eligibility Requirements:}

( Must be 16 years or older

$>$ Currently charged with a non-violent offence related to substance use

$>$ Currently experiencing problematic substance use or require relapse prevention

$>$ History of entries in the criminal justice system

\section{Admission Criteria will include:}

- Express a strong desire to make changes in their problematic substance use with a ultimate goal of abstinence

- Stable housing with an address approved by the Crown Attorney

- Must participate in a comprehensive screening \& assessment process in order to develop an appropriate treatment plan

- Client must be willing to commit to their individualized treatment plan as developed in collaboration with their assigned LDTC Addiction/Mental Health Counsellor which supports an outcome of abstinence

- Must agree to participate in all services and appointments that support the LDTC Program

\section{Referral Procedure}

\section{Who can make a referral?}

- Your lawyer

- Self-referrals or third party referrals are not accepted

\section{How to make a referral and acceptance into the program:}

The program is completely voluntary. Upon completion of the referral, your lawyer will consult with the crown, LDTC judge and members of the treatment team to ensure the referral is appropriate. If the referral is accepted the client will enter a 30 day assessment phase to determine continued eligibility in the program through the utilization of screening and assessment tools. 


\section{Moose Jaw Drug Treatment Court}

\section{WHO IT'S FOR}

The Moose Jaw Drug Treatment Court (DTC) is open to:

- accused adults who are drug dependent and whose criminal behaviour is motivated or caused by their addiction;

- carefully selected youth (if Youth Probations agrees); or

- persons 18 or older on youth orders.

Participants must be Moose Jaw residents

\section{WHO IT'S NOT FOR}

The DTC is not available for persons charged with certain types of offences, including:

- offences with serious violence;

- sexual assaults;

- family violence cases;

- offences involving or relating to children/youth; and

- profit-motivated commercial drug trafficking.

Individuals who have failed in the program are not considered again for 12 months. 


\section{Ottawa Drug Treatment Court}

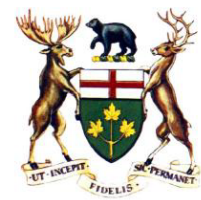

Ottawa Drug Treatment Court Application Process and Information Sheet

1. Who can apply for Ottaw a Drug Treatment Court?

Anyone can apply for admission to Drug Treatment Court. Please note, however that there are basic offence guidelines.

\section{What offences will be accepted for admission to the Ottawa Drug Treatment Court?}

The following is a typical, but not comprehensive list: possession of drugs for personal use or for street level trafficking, theft, possession of stolen property, non-residential break and enter, communication for the purpose, mischief, breaches of Probation and Undertaking.

Those charged with violent offences, including robbery, sexual assault, assault with a weapon etc or who have a Criminal Record including such offences are seen as potentially dangerous to the program and its participants, however are not to be deemed unacceptable for the program prior to intensive research and knowledge of circumstances and situations surrounding those offences.

\section{If I meet the offence criteria, will I automatically be accepted into the Ottawa Drug Treatment Court?}

No. There are a number of considerations which will be addressed. The Crown Attorney will initially screen all information received with regard to the applicant and their charges, which in turn will result in the individual being screened in or out of the program. The next step of the procedure, if screened into the program by the Crown Attorney, is for the treatment provider to be satisfied, through a face-to-face interview, that the applicant does suffer from addiction issues, is committed to his/her desire/want/need to change and is ready for treatment. Subsequently this information will be shared and discussed with the Ottawa Drug Treatment Court Team noting that ultimately the decision for an individual to be accepted into the Ottawa Drug Treatment Court lies with the Court itself. 


\section{How do I apply?}

Simply complete the application form for the Ottawa Drug Treatment Court and submit the document to the Court Support Office on the second floor of the Ottawa Courthouse located at 161 Elgin Street. Once the application has been submitted, all of your matters before the Court should be adjourned to the next available Tuesday afternoon at 2:00 in Courtroom \#8. Please be aware that the goal of the Drug Treatment Court Team is to have a decision on the suitability of the applicant within one week from the date that the completed application form is filed and received by the Team.

\section{What happens if I am accepted into the Ottawa Drug Treatment Court and am unable to complete the program?}

If you choose to leave the Drug Treatment Court Program or are removed by the Court within the first thirty days of your acceptance into the Program, you have the opportunity of striking your plea(s) of guilt and setting a date for trial or sentencing. If you have gone beyond the first thirty days of your acceptance into the Program and you have decided to withdraw from the Program or you are removed from the Program by the Court, then your plea(s) of guilt that were entered are binding and you will be sentenced before the Drug Treatment Court Judge who took your plea(s).

\section{If I am accepted into the Ottawa Drug Treatment Court, what is required of me?}

You will be expected to work hard and demonstrate a commitment toward becoming drug free and to have no future contact/charges within the Criminal Justice System. The Ottawa Drug Treatment Court Program lasts for at least one year. During this time you will be required to attend the treatment facility at various times throughout the week, provide urine screens on a weekly basis as well attend Court every Tuesday afternoon at $2: 00 \mathrm{pm}$ in Courtroom $\# 8$. The ultimate goals are for you to learn to abstain from the use of drugs, find suitable and stable housing and to learn how to make productive use of your time.

\section{Graduation criteria}

The Ottawa Drug Treatment Court Team has established policies with respect to graduation for the participants of the Ottawa Drug Treatment Court and copies of the criteria are attached to this directive.

Please note: this sheet is for information purposes only. For further details with respect to the Ottawa Drug Treatment Court application and rules, reference should be made to the application form and rules accompanied therein. 


\section{OTTAWA DRUG TREATMENT COURT Application}

PART I (To be competed by accused/defence counsel)

This form should be used by drug dependent offenders who wish to apply for the Drug Treatment Court. Eligibility for the Drug Treatment Court will be determined by Crown counsel in accordance with the established eligibility criteria

Name:

$$
\text { (Last) (First) (Middle) }
$$

Gender: $\square$ Male $\quad \square$ Female $\quad \square$ Transgender

DOB:

$$
(\mathrm{dd} / \mathrm{mm} / \mathrm{yyyy})
$$

I prefer to have my treatment in: $\square$ English or $\square$ French

I prefer to have my Court Proceedings in: $\square$ English or $\square$ French

Je désire recevoir mes services de thérapie en: $\square$ Français au $\square$ Anglais

Je désire que mes audiences devant le tribunal se déroulent en:

$\square$ Français au $\square$ Anglais

Race: $\quad \square$ Caucasian $\quad \square$ Aboriginal $\quad \square$ Black

$\square$ Other visible minority $\quad \square$ Don't know

Arrest Date:

Information No.:

$(\mathrm{dd} / \mathrm{mm} / \mathrm{yyyy})$

Is there a

Co-accused? $\square$ Yes $\square$ No Name of Co-accused:

Criminal

Record: $\square$ Yes $\square$ No $\quad$ In custody: $\square$ Yes $\square$ No

Offence Type: $\quad$ CDSA Section(s)

CCC Section(s):

Number of Charges:

Outstanding

Charges: $\quad \square$ Yes $\square$ No *If yes, give details: 
Bench Warrant

Outstanding:

$\square$ Yes $\quad \square$ No *If yes, give details:

Under Probation

Supervision:

$\square$ Yes $\quad \square$ No *If yes, give details:

I have previously been in an alternative measures program or diversion program:

$\square$ Yes $\square$ No

Immigration Order: $\square$ Hold $\square$ Deportation Order $\quad \square$ Other $\square$ None

Lawyer's Name and

Phone Number:

Name Phone Number

Duty Counsel:

Next Court Appearance

\& Courtroom:

(dd/mm/yyyy) Courtroom

I HEREBY APPLY TO BE CONSIDERED FOR THE DRUG TREATMENT

COURT PROGRAM:

Date:

$(\mathrm{dd} / \mathrm{mm} / \mathrm{yyyy})$

Signature of the Accused 


\section{OTTAWA DRUG TREATMENT COURT Questionnaire}

PART II (To be completed by accused with legal counsel)

Please note that if the Drug Treatment Court application is submitted without completion of this form, the application will be considered invalid and cannot be processed. The Ottawa Drug Treatment Court Questionnaire must be completed with the assistance of Counsel. The information provided in this questionnaire is intended to assist the Drug Treatment Court Crown and treatment provider in the initial assessment and will not be used for prosecution purposes if the offender is not approved for the Ottawa Drug Treatment Court Program.

1. Offender's name:

(Last) (First) (Middle)

2. Date of Birth:

$(\mathrm{dd} / \mathrm{mm} /$ yyyy)

3. Charges:

4. What $\operatorname{drug}(\mathrm{s})$ is the offender addicted to:

5. When is the last time the offender used addictive drugs?

6. Has the offender taken any steps in the past to control addictions? $\square$ Yes $\square$ No

If yes, what were these steps?

If no, why not?

7. Is housing available? $\square$ Yes $\square$ No

If yes, what type of housing is available? $\square$ Permanent $\square$ Temporary $\square$ Shelter Details:

8. Does the offender have a Criminal Record? $\square$ Yes $\square$ No 
9. Does the offender's Criminal Record include convictions of violence? $\square$ Yes $\square$ No

10. Can any information be provided with respect to the circumstances surrounding the violent offence(s)?

11. Are there any reasons why you may be ineligible for the Drug Treatment Court Program? $\square$ Yes $\square$ No

If yes, what are they?

12. Are there any additional comments?

Please Note: False or misleading information provided in this questionnaire or during any phase of the Drug Treatment Court screening process may result in this applicant's expulsion from the program.

I have completed this form with the assistance of my counsel or duty counsel. $\square$ Yes $\square$ No

Date:

$(\mathrm{dd} / \mathrm{mm} / \mathrm{yyyy})$

Offender's Signature

Date:

(dd/mm/yyyy)

Lawyer's Signature 


\section{OTTAWA DRUG TREATMENT COURT CONSENT AND WAIVER}

\section{TO BE COMPLETED WITH THE AID OF COUNSEL}

I, , understand that I am charged with

the following criminal offence(s) of:

There are two alternative ways of dealing with my charge(s). They are:

(i) The normal course of a criminal proceeding; or

(ii) The Drug Treatment Court Program.

\section{The Normal Course of a Criminal Charge}

I understand that I am presumed to be innocent of these charges.

I understand that in the normal course of a criminal proceeding, a court may decide to release me on bail until the completion of the process. If I am denied bail at the initial hearing, I have the right to appeal the decision refusing me bail. I also understand that if it is believed that I have disobeyed any conditions of my bail, I may be arrested and a court may cancel my bail. I have a right to be represented by a lawyer at any hearing into whether I should be released on bail.

I understand that in the normal course of a criminal proceeding I have a choice to plead "not guilty" or "guilty" to any offence with which I am charged. If I choose to plead "not guilty", I will have a trial where the Crown must prove that I am guilty of the charge(s) beyond a reasonable doubt or else the charge will be dismissed.

I have a right to know in advance of the trial what evidence the Crown has against me. I understand that I have the right to speak with a lawyer about the case in order to review 
any defences to the charge and whether there are any weaknesses in the Crown's case, which could result in acquittal.

If the Crown proves beyond a reasonable doubt that I committed the offence, I will be found guilty. If, on the other hand, I choose to plead "guilty", and admit the facts without the calling of evidence, I will give up my rights to hear or challenge the witnesses or argue that I should not be found guilty and I will be found guilty.

If I am found guilty, a court will decide what sentence to impose upon me after hearing arguments from both the prosecutor and my lawyer on the law. When deciding on the appropriate sentence, a court may decide, if appropriate, to send me to jail, to grant me a discharge, to sentence me to a conditional sentence of imprisonment in the community, to place me on probation, impose a fine, or impose some combination of dispositions. A court must impose a sentence that in the judge's view is most appropriate, taking into account the circumstances, as well as other aggravating and mitigating factors.

I am entitled to a trial within a reasonable time.

If I am found guilty and sentenced, I have the right to appeal against conviction, the sentence or both the conviction and sentence.

\section{The Ottawa Drug Treatment Court (herein referred to as "ODTC")}

\section{The Program}

Instead of choosing to proceed through the normal course, I may choose to plead guilty and to participate in the Drug Treatment Court program (referred to as "the Program"). No one may force me to participate in the Program. It is entirely up to me whether I choose to do so.

I understand that the Program will take many months, and often more than a year to complete. I understand that the court will delay my acceptance into the Program for a 
period of thirty (30) days, but not exceeding sixty (60) days, while Rideauwood Addiction and Family Services and the ODTC Team assess my suitability for the Program. This period of time is also an opportunity for me to determine if the Program is right for me. If it is determined that I am not appropriate for the Program, I understand that I will be entitled to have my plea(s) struck before the thirty days have passed and to have my matters adjourned to the regular court system.

If I am accepted, there is no fixed time limit for the completion of the Program. It is up to the Court to decide if and when I have successfully completed the Program. However, the Program typically takes approximately one year to complete. By choosing to participate in the Program, I agree to waive my rights pursuant to s. 720 of the Criminal Code to be sentenced as soon as possible.

\section{Application and Assessment}

If I choose to participate in the Program, I understand that I must first qualify for, and be accepted into, the Program. This is a process that entails several steps. After my application has been submitted, the Crown will first make a decision about whether I am eligible to participate in the ODTC Program. This decision is based largely on my outstanding charges and criminal history. I understand that the Crown has the right to exercise a screening out process whereas the Crown's screening decision as to eligibility is final and not reviewable by the ODTC Team.

If I am determined to be eligible to apply and participate in the Program by the Crown, an individual from Rideauwood Addiction and Family Services will conduct a further indepth assessment. I understand that this means I will have to participate in an interview concerning my personal background and history of drug abuse and that I will undergo drug testing. I understand that if I am not accepted into the Program, then everything I have said or done during this application process will be kept confidential and can never be used against me in court. 


\section{$\underline{\text { Pleas }}$}

If I choose to participate in and complete the Program, I understand that I am giving up my right to plead "not guilty" to the charge(s) against me.

By choosing to participate in the Program, I choose to plead "guilty" and accept responsibility for each offence on which the Crown proceeds. Further, any outstanding charges in other jurisdictions must be waived in and plead "guilty" to as well. The process to have the outstanding charges from other jurisdictions transferred should be started within ninety (90) days after admittance into the Program. I admit, in fact, that I did what the Crown states that I did via the evidence or summary of the evidence. In addition, if I am already subject to a probation order, its terms and conditions still remain in full force and effect and are binding on me.

If I decide, within the first thirty (30) days, that the Program is not right for me, I will be able to strike my pleas and return to the normal prosecution stream.

\section{$\underline{\text { Bail }}$}

I understand that my ODTC bail depends upon my being found appropriate for the ODTC Program. I understand that I will be released on an ODTC bail to attend for a thirty (30) day pre-admission assessment at Rideauwood Addiction \& Family Services. I further understand if it is determined that I am not appropriate, or I decide to withdraw from the ODTC, my ODTC bail may be revoked or varied, and I may reapply for bail in the appropriate court if I have not already done so.

I understand that I must abide by the conditions imposed upon me by my bail. If I breach any of my bail conditions, I understand that I may be charged with failing to comply with my bail.

\section{Requirements of the Program}

My participation in the Program will require frequent mandatory court appearances for the purpose of monitoring my progress in the Program. I understand that if I miss any 
court dates, a warrant for my arrest may be issued, I may be charged with "failing to appear" and at my next court appearance my bail may be cancelled and I may be expelled from the Program.

The Program will also require me to attend regularly for counselling and random drug screening (such as urinalysis). The result of any drug screening or any statements made during the counselling sessions will be reported to the Court, which monitors my progress in the Program.

I understand that I have the right to request one re-test of any disputed urine screen. I agree to accept the validity of the urine screen results.

If I dispute any subsequent urine screens, I may be expelled from the Program and sentenced for the offence(s) to which I have pled guilty.

In order to receive the legal benefit of the Program, I must complete the Program to the satisfaction of the Court. The Court will postpone the sentencing decision until I have successfully completed the Program. If I successfully complete the Program to the satisfaction of the Court, the Court's finding of guilt will remain and I will be sentenced, but the Court will not impose a sentence that requires me to go to jail.

If, on the other hand, I fail to successfully complete the Program, the Court will decide the appropriate proceeding in the normal course. The pleas as entered will not be struck. If I fail to complete the Program, I will be sentenced in the normal course.

I waive my right to rely upon the delay created by my participation in this Program to argue that my right to a trial within a reasonable period of time under the Charter has been violated.

I understand that while I am participating in the Program, members of the ODTC team (the judge, duty/defence counsel, crown counsel, treatment providers, evaluators, and 
probation officers) will discuss my case in my absence prior to each attendance in the ODTC. I am satisfied that the duty counsel or my lawyer will represent my interests. I agree to this in order to obtain maximum help/benefit from the ODTC.

I understand that as a condition for being allowed to participate in the Program, I must at all times keep my treatment providers and the Court advised of my current address during my participation in the Program. Home visits and background checks will also be performed to determine suitability of my residence.

I understand that if I am arrested on any new charges while participating in the Program, I must report this to my treatment providers and the Court. The Crown will re-assess my continuation in the program, based on the new charges. It will then be up to the Court to decide whether to cancel my bail and/or expel me from the Program.

I understand that my involvement in the Program may be the subject of study by officials involved in the evaluation of the Program. While any such study must respect my right to privacy, I may be asked to participate in follow-up studies during and after my completion of the Program. By signing this form, I willingly agree to participate in a study seeking to evaluate the Program. I also agree to release to the officials involved in the study, a copy of my criminal record and a list of all pending criminal charges.

\section{Sanctions}

If I fail to fulfill the requirements of the Program, such as missing a urine screen, not attending to counselling sessions as required, missing curfew etc., the Court may:

1. require me to perform community service hours;

2. cancel/vacate my bail for up to a maximum of seven (7) days (Tuesday to Tuesday), pursuant to s. 523 or s. 524 of the Criminal Code;

3. increase the number of times I am obliged to attend for treatment, counselling, or drug testing;

4. extend the treatment period under the Program;

5. expel me from the Program and sentence me; and/or 
impose any other sanction that is deemed to be appropriate in the circumstances.

Before any decision is made regarding a sanction or expulsion, I will have the opportunity, after having consulted with counsel, to make representations to the court. I understand that if I want the Court to postpone making this decision, the Court may still order that, in the meantime, I remain in custody, pursuant to s. 524 of the Criminal Code. If after listening to my explanation, the Court decides to cancel my bail but not to expel me from the Program, I may choose to withdraw from the Program and proceed with my sentencing in the normal course. On the other hand, if I choose to remain in the Program, the Court will consider, within seven (7) days, whether to allow me to remain in the Program and whether to restore my bail. If I ever choose to withdraw from the Program, or if I am ever expelled from the Program, any time, which I spend in custody as a result of the Court cancelling my bail, will not be taken into account when a Court decides on the appropriate sentence.

In making this decision, I have:

[CHECK ONE BOX]

had an opportunity to consult with a lawyer about the Crown's evidence against me,

\section{$[\mathrm{OR}]$}

only been able to consult with a lawyer based on a summary of the Crown's evidence against me,

but nevertheless, am prepared to give up my rights to plead "not guilty" and to have a trial.

I am willing to give up these rights in order to try and benefit from the ODTC Program. 
I have read and understood everything on this form. By signing this form, I am indicating that I have voluntarily chosen to participate in the Program and to comply with all of the terms and conditions.

DATE:

Defence/Duty Counsel Applicant

Counsel/Duty Counsel providing advice:

(Name, address, and phone number)

Translated by me, , a person fluent in

English and languages, before being signed by the

Applicant.

Original to: ODTC

Copies to: Rideauwood Addiction and Family Services

Provincial Crown

Federal Crown

Counse1/Duty Counsel

Applicant 
OTTAWA DRUG TREATMENT COURT

IIIICIAI INTFRIN RFIFASF ORDFR - ONTARIO COIIRT OF .JISTICF - IINIFRTAKING

Name:

Inioffs:

$\checkmark$ 1. Kees the peace and be of good behavioul.

$\nabla_{2}$ To ke released on

CONDITIONS OF RF FASF

$\checkmark$ 3. Appar personally for all subsequent Court appearances as directed and in time.

$\checkmark$ 4. Attend, participate and complete, to he satisfaction of you counsellor, all assessments/treatment and counselling as direcied by Rdeaunood

$\checkmark 5$ Abstain from the consumption of any substances that, a] oontin alsohol,

b] are isted $\mathrm{n}$ the Schecules to the CDSA

c) are non-redically prescribed, $\alpha$,

d) are wurchased jver-he-counter, unless you have Rideaumood's pernission.

$\checkmark$ 6eport ary use of substances outined in paragraph 5 albcve, promply to Fideauwood and any contacts with the police and any highrisk siuations which nay lead you to possess or ase such substances

$V_{7}$. Not io be found in any place where alcohol is sold, except in the company of a Nideaswood staf or designate, $\alpha$ with their written consent and likewise not b be found or associste with anyone tnown by you to possoss of use ilicit substances, excospt for the puppeses of participating in Drag Treatment Court o. Rideauwcod approved programs.

$\bigcup_{8}$ Sign all fcrms requested by Riseauwood br the release ơ personal information to menitor compliance with these terms of release.

$\checkmark 9$ Be konest with the Court and Fideatwood staff and promptly obey al Court orders.

$\square_{10}$. Provide a sanple cf your urine, suibale ior analysis in a manrer, fine and plase as requested by Rideauwood

$\square_{11 .}$ Abstain from commuricating and associating directy and indirectly with anyune nullited by Rideasumed

$\checkmark$ 12. Rieside di the routine and disciplire of such residence.

$\checkmark$ 13. Ful house amest until 8.00 p.n. and $7: 0$ ) a.m, exoept with the approval of Rilieaunood.

14. No to atend,

$\checkmark$ A. The Byward Market Area bourded ky Rideau Street, the Rideau River, the Ottwwa Fiver and Rdeau Canal;

$\square$ 1) Except to attend the Ottawa Withdiawal Manzgement Centre, located at 62 Buyere Street - and wile in transit to and from that Imsatine

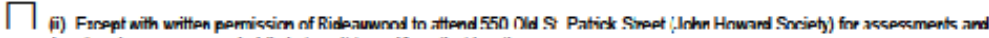
educatonal programs - and while in transit to and from that beation.

$\checkmark$ E. The Vanisr Avea bounded by St. Lavent 3lvd., Montreal Road Vanier Parkway - Beechnood Ave./Hemlkck Road.

$\nabla c$ or any other area named by Fideaunood.

$V_{15 .}$ Abstain rom possessing any weapons or ammunition.

Qntional Trems

$\square$ 16. Report to the Probation Office at rom 3211, 161 Elgin Stree, Ottawa, Ontaro within 2 working days.

$\square$ 17. Nox be in a motor vehicle without the owner present.

$\square$ 18. Not possess any tools while away rom your residence.

$\bigsqcup$ 19. Oher conditions:

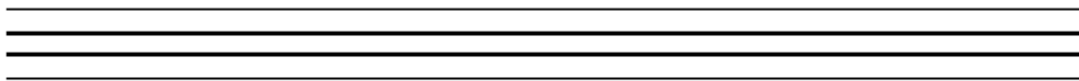

PARTICIPAN

RATF

.IISTIC.F 


\section{Ottawa Drug Treatment Court Request for Re-Admittance}

The following is to be completed by the accused with the assistance of defence counsel/duty counsel:

\begin{tabular}{|l|}
\hline Name: \\
\hline Date of Birth: \\
\hline Date of Bench Warrant: \\
\hline
\end{tabular}

\begin{tabular}{|l|l|}
\hline How did you end up back before the Court? & Details: \\
$\bigcirc \quad$ I turned myself in. & \\
$\bigcirc \quad$ I was arrested. & \\
\hline
\end{tabular}

\begin{tabular}{|l|}
\hline Were you charged with any further offences while at large? \\
Yes. \\
No. \\
\hline If you replied 'Yes' - please list any and all new charges: \\
\hline
\end{tabular}

Are you currently on Methadone?
Yes.
O No

If you replied 'Yes' please complete the following questions:

1. Are you still on methadone?

2. What dose are you currently prescribed?

3. Which methadone clinic do you attend?

4. Are you in good standing with the methadone clinic?

Please Answer the Following Questions in as Much Detail as Possible
(if you require more room for your answers, please attach a separate sheet)

1. Why should the Ottawa Drug Treatment Court Team consider you for re-admittance into the program?

2. What have you learned (if anything) while you were absent from the Ottawa Drug Treatment Court program?

3. What were you doing while absent from the Ottawa Drug Treatment Court program?

I hereby request to remain in the Ottawa Drug Treatment Court program (absences of 30 days or less)

I hereby apply to be re-admitted into the Ottawa Drug Treatment Court program (absences in excess of 30 days)

Lawyer's Name:

Date: Lawyer's Telephone \#: 


\section{Regina Drug Treatment Court}

\section{WHO IT'S FOR}

Participation in the DTC is open to all adults accused of a crime, who are drug dependent and whose criminal behaviour is motivated or caused by their addiction.

Participants must admit responsibility for their actions by entering a guilty plea, and their participation must not pose a risk to public safety. Participants must be Regina residents.

\section{WHO IT'S NOT FOR}

Persons are not eligible to participate in the DTC if they have failed DTC treatment in the past year, or if they are charged with certain types of offences. These include:

- offences with serious violence,

- sexual assaults,

- family violence cases,

- offences involving or relating to children/youth, and

- profit-motivated commercial drug trafficking. 


\section{Regina Mental Health Court}

\section{REOLIA MEITHL HEITHDISPOSTIONGOURT}

The Regina Provincial Court has introduced a collaborative model to coordinate treatment and criminal justice needs for individuals with mental health, Fetal Alcohol Syndrome Disorder (FASD) or cognitive issues who have been charged with a crime. The Regina Mental Health Disposition (RMHD) Court brings together health, social services professionals and criminal justice professionals, and is designed to improve the Court's access to information so that it is better able to support and supervise offenders safely in the community. This may include comprehensive assessments, case management plans and providing services.

The process provides a more effective way of managing offenders who commit crimes because of their mental health, FASD or cognitive issues. It uses a supportive case management model to help participants to reduce or eliminate criminal behaviour and maintain a healthy lifestyle. It uses a "connections approach" to break down barriers and encourage participants to connect with community services. The value added in this approach is an increased capacity for assessment and improved access to mental health services and resources for offenders.

\section{WHO IT'S FOR}

Adults accused of a crime may be referred to the RMHD Court through the Crown Prosecutor if the accused appears to have issues related to mental health, such as cognitive disability, FASD, brain damage or psychiatric disorder. The mental health issue must be related to the criminal behaviour. Defence counsel, social agencies and individuals can contact the Crown Prosecutor and ask that a person be considered for this Court.

\section{WHO IT'S NOT FOR}

Accused facing charges that include Criminal Code driving offences, sexual offences, offences with mandatory minimum penalties in the Criminal Code and offences where the Crown seeks a penitentiary term are not eligible for this approach.

\section{HOW IT WORKS}

- Court is held on the second and fourth Fridays in courtroom 4 at 11:00 a.m.

- First appearance occurs in another court and other appearances may be made before referral to the Crown for RMHD Court eligibility assessment.

- The Crown uses criteria to assess eligibility, including but not limited to the nature of the charges, criminal record of the accused and risk to community safety.

- Legal Aid duty counsel meets with the eligible individual at first appearance in RMHD Court and explains their options.

- If the accused individual agrees to enter the RMHD Court, the judge may, following a case conference meeting prior to the opening of Court, refer the individual to a psychologist or to meet with other professionals to assess needs and strengths and develop a case management plan.

- If the accused agrees to the case management plan, a guilty plea is entered and s/he agrees to follow the case management plan.

- The offender may be sentenced or return to court for progress reports at the discretion of the judge.

- The length of time to conclude the case depends directly on the case management plan and the offender's progress in that plan. 


\section{Saskatoon Mental Health Court}

\section{SHSKHTOON IEITRLLEELLTHSTRAIEQY}

The Saskatoon Provincial Court has introduced a collaborative model to coordinate treatment and criminal justice needs for individuals with mental health, Fetal Alcohol Syndrome Disorder (FASD), or cognitive issues who have been charged with a crime. The Saskatoon Mental Health Strategy (MHS) Court brings together health, social services professionals, and criminal justice professionals, and is designed to improve the Court's access to information so that it is better able to support and supervise offenders safely in the community. This may include comprehensive assessments, case management plans, and providing services.

The process provides a more effective way of managing offenders who commit crimes because of their mental health, FASD, or cognitive issues. It uses a supportive case management model to help participants to reduce or eliminate criminal behaviour and maintain a healthy lifestyle. It uses a "connections approach" to break down barriers and encourage participants to connect with community services. The value added in this approach is an increased capacity for assessment and improved access to mental health services and resources for offenders.

\section{WHO IT'S FOR}

Adults accused of a crime may be referred to the MHS Court through the Crown Prosecutor if the accused appears to have issues related to mental health, such as cognitive disability, FASD, brain damage, or psychiatric disorder. The mental health issue must be related to the criminal behaviour. Legal Aid, defence counsel, social agencies, and individuals can contact the Crown Prosecutor and ask that a person be considered for this Court.

\section{WHO IT'S NOT FOR}

Accused facing charges that include Criminal Code driving offences, sexual offences, offences with mandatory minimum penalties in the Criminal Code, and offences where the Crown seeks a penitentiary term are not eligible for this approach.

\section{HOW IT WORKS}

- Court is held on the first and third Mondays in courtroom 4 at 9:30 a.m.

- First appearance occurs in another court and other appearances may be made before the Crown refers an accused individual to the MHS.

- The Crown uses criteria to assess eligibility, including but not limited to the nature of the charges, potential to benefit from case management, criminal record of the accused, and risk to community safety.

- To participate in the MHS, the accused individual must be out of custody and be prepared to accept responsibility for some or all of their offences.

- If the accused individual agrees to participate in the MHS Court, the judge may refer the individual to a psychologist or to meet with other professionals to assess needs and strengths and develop a case management plan.

- Participants are expected to attend appointments for assessments or other services.

- The offender may be sentenced or return to court for progress reports at the discretion of the judge.

- The length of time to conclude the case depends directly on the case management plan and the offender's progress in that plan. 
Toronto Drug Treatment Court 


\section{TORONTO DRUg TREATMENT COURT Eligibility Criteria and Application Procedure}

The Toronto Drug Treatment Court (TDTC) is a judicially supervised drug treatment and rehabilitation program for offenders whose criminal conduct is motivated by drug addiction. The TDTC program is expected to take between ten and eighteen months to complete.

To enter the program participants must read and sign a Rule and Waiver Form (available from the Duty Counsel Office, Room 251) and plead guilty. Participants who successfully complete the program receive a non-custodial sentence. Participants who do not successfully complete the program ordinarily proceed to sentencing (though in limited circumstances they may be returned to the regular court process).

\section{ELIGIBILITY}

Accused persons charged with offences that were motivated by addiction are encouraged to apply. The TDTC generally accepts adult offenders who are dependant on cocaine, crack cocaine, heroin or other opiates, or methamphetamine.

The TDTC ordinarily screens out applicants who:

- are charged with:

- a significant crime of violence;

- trafficking in drugs for commercial gain;

- committing a drug offence in circumstances that raise concerns about drug-impaired driving or risk to young people; or

- committing a residential break-and-enter;

- have a recent and/or significant history of violence;

- are currently serving a conditional sentence or intermittent sentence; or

- have previously graduated from the TDTC.

There is a presumption that previous TDTC participants who were expelled or withdrew will not be reaccepted. The onus is on them to persuade the TDTC team that they should be given another opportunity.

\section{APPLICATION PROCESS}

The TDTC is a voluntary program. Accused persons whose criminal conduct was motivated by addiction may apply by

- completing the TDTC Application and Crown Questionnaire (available from the TDTC Office (Room 115, Old City Hall, tel. (416) 973-1314, fax (416) 954-5209) or the Duty Counsel Office) with the assistance of their counsel or Duty Counsel; and

- submitting the completed Application and Questionnaire to the TDTC Office or to the Federal Crowns' office (Room 351, Old City Hall).

The information in the TDTC Application and the Crown Questionnaire will not be used by the Crown for prosecution if the applicant's application for entry into the TDTC is unsuccessful.

TDTC applications take approximately 7 days to process. All TDTC applications are returnable at 9:00 a.m. in courtroom 114 on a Tuesday or Thursday. 


\section{SCREENING PROCESS}

There are six phases of TDTC Screening:

1. Crown screening: This is conducted by the Crown based on the Application, the Questionnaire, any additional information that the applicant chooses to submit, the prosecution brief, the applicant's criminal history, and input from the police. The focus at this stage is on public safety, including violent history and indicia of commercial trafficking

2. Preliminary addictions assessment: This is a brief assessment conducted by the TDTC Court Liaison workers from the Centre for Addiction and Mental Health (CAMH). It takes place in the cells (or sometimes in the TDTC courtroom) at Old City Hall on the Tuesday or Thursday when the application is returnable.

3. TDTC team pre-court discussion: This takes place prior to the sitting of the TDTC on a Tuesday or Thursday, and includes input from the Crown, the Court Liaison workers, Probation, Duty Counsel/Defence Counsel, Bail Program and the TDTC Judge

4. In-court interview by the TDTC judge: The TDTC judge ensures that the applicant understands how rigorous the program is and the rights that he/she must waive in order to participate, and questions the applicant about his/her motivation to engage in the program. If the judge is satisfied that the applicant is appropriate for the TDTC, the applicant then pleads guilty to whichever offences he/she and the Crown have agreed to and is released on a stringent TDTC bail including a 7:00 a.m. to 7:00 p.m. curfew. The Crown disclosure obligation stops with the entry of the guilty pleas.

5. In-depth addiction assessment at $\mathrm{CAMH}$ : The day after the applicant's release a therapist at $\mathrm{CAMH}$ conducts a much more lengthy and thorough addictions assessment than the one that was done at court. The applicant then returns to court on the next TDTC sitting day.

6. 30-day assessment period: Once $\mathrm{CAMH}$ is satisfied that the applicant is suitable for the treatment program, the applicant begins participating in the TDTC on a provisional basis for 30 days. Within that period if the applicant decides not to continue with the TDTC, or if the TDTC team feels that the applicant is not appropriate for the TDTC, the applicant may have her/his guilty pleas struck and be returned to the regular criminal justice system. At the end of the 30 days the TDTC team and the applicant decide if the applicant will be formally accepted into the TDTC. Upon formal acceptance into the TDTC the applicant relinquishes the option of having her/his guilty pleas struck.

\section{Processing of Eligible Applicants}

Initial (Crown) screening results are provided on Tuesday and Thursday mornings only, in Courtroom 114. The 114 court crown is provided with the TDTC Instruction List which sets out the screening results for each TDTC applicant returnable that day.

Applicants who are screened eligible by the Crown should expect to spend the entire day in court. They will be assessed by the Court Liaison worker in the morning (in-custody applicants in the cells, and out of custody applicants in Room 115 at 10:30 a.m.) and will appear in the TDTC at 2:00 p.m. in Courtroom 116.

Private counsel for new applicants should obtain a copy of the TDTC Rule and Waiver form from the TDTC duty counsel and review it thoroughly with the applicant. Applicants are expected to sign two copies of the form, one of which is filed with the court and the other of which is given to the Crown.

New TDTC participants are ordinarily dealt with between 2:00 p.m. and 3:00 p.m. each sitting day. Ongoing TDTC participants are dealt with from 3:00 p.m. onward, and ordinarily remain in court until all matters scheduled for that day are completed. 


\section{Vancouver Downtown Community Court}

\section{Downtown Community Court Jurisdiction}

\section{Offences}

The community court receives:

- Provincial offences that are heard by Provincial Court judges (such as driving while prohibited, aggressive panhandling)

- All Criminal Code offences

" In the absolute jurisdiction of the Provincial Court (for example, shoplifting)

- Summary conviction offences (such as causing a disturbance)

- Hybrid offences where the Crown proceeds summarily (examples are assault causing bodily harm, impaired driving)

- Controlled Drugand Substances Act

- Drug possession

Offences relating to non-compliance with community court orders (for example, failing to appear in court or violating the terms of bail or probation) are also heard in the community court.

\section{Geographic Area}

The catchment or geographic area of the court is downtown Vancouver from Clark Drive on the east to Stanley Park on the west, with Great Northern Way as the southern boundary and the Inner Harbour and Coal Harbour of Burrard Inlet as the northern boundary.

Within the geographic area, Vancouver's Downtown Community Court serves a number of distinct neighbourhoods:
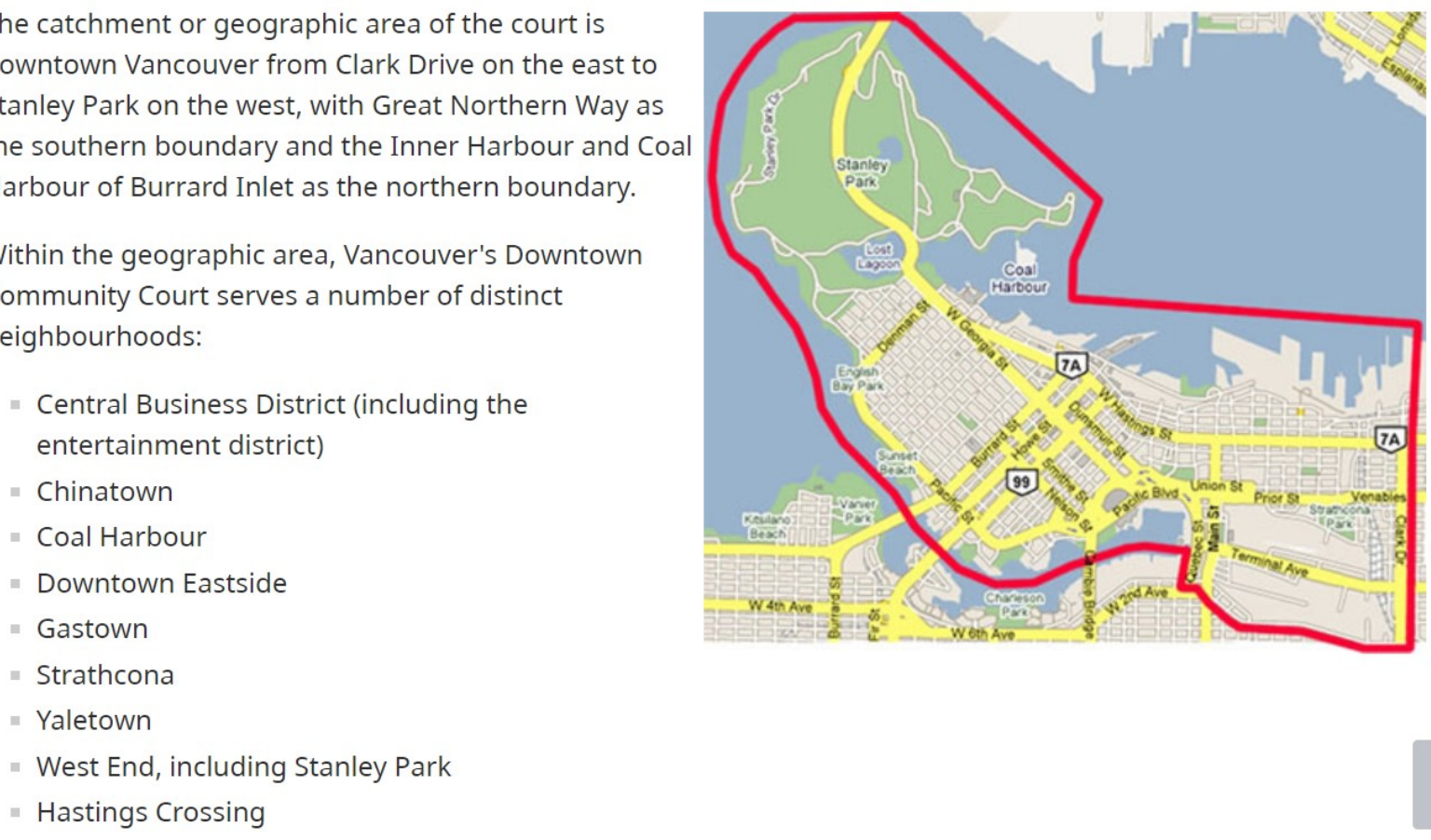
Vancouver Drug Treatment Court 


\section{DRUG TREATMENT COURT OF VANCOUVER \\ Court 303, 222 Main St, Vancouver BC, V6A 2S8}

Updated to May 10, 2016

The Drug Treatment Court of Vancouver (DTCV) provides an alternative to the regular criminal court process for individuals who commit drug offences or minor Criminal Code offences because they have a cocaine, heroin, or methamphetamine addiction. For a minimum of 14 months, DTCV participants undergo drug addiction treatment supervised by a DTCV Judge. At the Vancouver's Drug Court Treatment and Resource Center, DTCV participants receive the services of addiction counselors, case managers, a psychologist, an addictions specialist physician, a nurse and a financial assistance worker.

\section{How the DTCV Works:}

- Participants plead guilty to their offence(s).

- They are released on a DTCV Undertaking, which requires them to attend the Drug Court Treatment and Resource Center daily and undergo random urinanalysis.

- Participants make frequent court appearances before a DTCV Judge. Court sits Tuesdays and Thursdays at 9:30 am 2:00 pm.

- The DTCV Judge reviews each participant's progress in the program and imposes rewards or sanctions, depending on a participant's compliance or non-compliance with directions of the DTCV Judge and the DTCV care team.

- Charges are not typically approved for breaches of DTCV bail. However, failure to comply with program requirements can result in the person being opted out of the program and sentenced or tried for their offences.

\section{What Happens upon Successful Completion of the DTCV Program:}

After participating in the Program for a minimum of 14 months and completing all 4 phases, a participant is eligible to graduate and receive a non-custodial sentence or the charge will be stayed if the participant has:

- abstained from consuming all intoxicants for 3 mos immediately preceding graduation;

- has not been charged with a new offence in the 6 mos immediately preceding graduation;

- has been engaging in secure employment, training or volunteering; and

- has secured stable housing approved by the DTCV Judge.

\section{Eligibility for the DTCV:}

The accused must:

- be addicted to cocaine, heroin or other opioids, or methamphetamine

- be committing crime fundamentally to satisfy a drug addiction (not primarily for profit).

The accused cannot:

- be considered to put public safety at risk (grey area of violence, Crown discretion).

- be serving a sentence or have outstanding charges that include an allegation of domestic violence, a sexual offence, or breaking and entering into residential premises.

- an associate or member of a gang or criminal organization.

- be serving a Conditional Sentence Order.

- be facing a current prosecution which may result in the Canada Border Service Agency initiating deportation proceedings or other removal processes against the accused/offender, pursuant to the Immigration and Refugee Protection Act.

- have criminal prosecutions in other jurisdictions anywhere in Canada which would interfere with the accused's daily participation in the DTCV program.

- have committed a PPT or Trafficking offence near a school yard, playground or other place frequented by children or involved a person under the age of 18 years (see s.10 of the Controlled Drugs and Substances Act: "aggravating factors for sentencing").

- require an interpreter to participate in treatment programming, other than French.

- be a former DTCV graduate.

- Return to the DTCV until a year has passed after their left the program (if they did not graduate).

\section{Canadä̀}


Winnipeg Drug Treatment Court 
The Winnipeg Drug Treatment Court (WDTC) Vision: To break the cycle of drug use, criminal behaviour and incarceration by establishing a partnership between

courts, treatment agencies and social service agencies.

The WDTC works to close revolving doors in the criminal justice system. Offenders are often trapped in a cycle of drug use, arrest, incarceration,

release and re-arrest on new charges. Drug

addiction and criminal behaviour are strongly

linked. People with untreated addictions commit relatively large numbers of crimes and have high rates of re-offending.

WDTC helps break the cycle by providing intensive court-monitored case management with emphasis on treatment and community supports for nonviolent offenders who are addicted and want to quit using illicit drugs.

WDTC increases public safety by addressing root causes of crime:

- It monitors and supports offenders as they work to end their dependence on illicit drugs

- It reduces numbers of crimes committed to support drug dependence

- It reduces the harm people cause themselves and others through their drug use

WDTC helps reduce the economic burden of substance abuse. costs of law enforcement, prosecution and incarceration associated with substance abuse in Canada are estimated at $\$ 9$ billion annually.

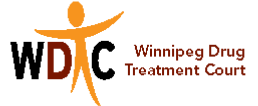

Winnipeg Drug Treatment Court (WDTC) maintains strong partnerships with Manitoba's justice system, community groups, support services and other stakeholders.

For more information about WDTC, please contact:

Winnipeg Drug Treatment Court

204-945-5001

Winnipeg Drug Treatment Court receives support from the Drug Treatment Court Funding Program, part of Canada's National Anti Drug Strategy.

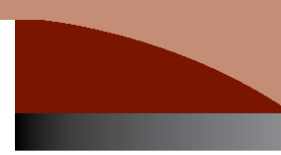

11D $C \begin{array}{r}\text { Winnipeg Drug } \\ \text { Treatment Court }\end{array}$

Promoting public safety by tackling the root causes of crime 


\section{What is a drug treatment court?}

A drug treatment court is a special court that works to redirect drug-addicted offenders into programs of treatment and supervision, instead of keeping them in jail.

The court is supported by a program consisting of addiction recovery services, social service agencies and individual case planning. The Winnipeg Drug Treatment Court (WDTC), launched in 2006, is similar to programs in many other parts of the world.

Why do we need drug treatment courts?

Conventional criminal justice strategies have not been able to bring about a significant reduction in reoffending rates or the demand for and flow of drugs into our communities. Drug treatment courts monitor and support offenders to make changes that will enable them to avoid further criminal activity

Drug treatment courts have proven to be both tough and effective. Offenders who come before the WDTC participate in treatment plans that typically are longer and more rigorous than the sentences they might receive in a conventional court.

Statistics show that DTC participants substantially decrease their drug use and have lower re-offending rates than other offenders.

\section{Does WDTC work like other courts?}

The WDTC judge is in charge of the court, but makes decisions in consultation with a team of experts that includes the Crown, defence counsel, the program manager and the case manager. All WDTC participants must plead guilty to their charges and work with the WDTC team to design an effective rehabilitation plan

\section{Who is eligible for WDTC?}

WDTC is available to offenders charged under the Controlled Drugs and Substances Act (possession, possession for purposes of trafficking, trafficking or with non-violent Criminal Code offences. To be eligible, offenders must be dependent on drugs and their criminal behaviour must have been caused or motivated by their addiction.

Gang members or offenders who used a weapon in committing an offence are not eligible for WDTC

How does someone get their case into the WDTC?

Participation is voluntary. A lawyer may submit a potential case to Crown counsel, who then screens the case to ensure the candidate meets the WDTC criteria. The Crown's screening includes seriousness of offences, other outstanding charges and risk to the community. WDTC staff will also assess each referral from the Crown for program suitability.

\section{What do WDTC programs involve?}

Each participant works with a WDTC case manager and service providers to develop a comprehensive and realistic case managernent plan that includes:

- regular court appearances

- periodic and random drug testing

- client-centred treatment for substance dependence

- counselling

- life skills training

- employment training

- job placement
How can WDTC make sure participants follow their programs?

Participant progress is carefully monitored with regularly scheduled court appearances, frequent drug testing and close supervision from the WDTC team

Incentives and sanctions may be used to ensure program compliance:

- Incentives may include positive feedback, reduced court appearances, progression to next program phase and successful program completion

- Sanctions could include more frequent court appearances, community service work, warrants, bail revocation and expulsion from the program

\section{When does a WDTC program finish?}

To successfully complete the program, participants must:

- Complete all treatment specified

- Establish and maintain a lifestyle that supports recovery and rehabilitation

- Show active engagement in the community through employment, education, volunteering and other structured activities

- Not engage in further criminal activity

- Continue to abstain from illicit drug use

- Receive a recommendation for graduation from the WDTC team

At the end of the WDTC program, the Crown will recommend a non-custodial sentence with probation conditions that take into consideration the nature and severity of the participant's original charges 


\section{Appendix 3 - Program Rules for Participants Once Enrolled in Specialized Court Program}

\section{Brampton Drug Treatment Court}

- $\quad$ Expectations Of The Program

Clients arrive to the Brampton Drug Treatment Court program from diverse backgrounds. For the most part, the path to an individual's recovery can differ based on their subjective experiences. Accordingly, the program tailors its approach to the needs of each individual client.

There are however, specific expectations required of ALL participants. Please speak to your client about their willingness and capacity to undertake the following

Honesty, Honesty and Honesty

- The cornerstone of the program is honesty. The members of the program understand the difficult path faced by the participants. Recovery is a process and as such, it is vital

that participants are honest with the court and the treatment providers to allow them to work with a participant in their recovery.

A. WEEKLY REQUIREMENTS

Court Appearances

- MUST attend court as required, and arrive prior to court being called to order. Until otherwise discussed, clients are expected every Friday, before 11:30 am.

Appointments

- MUST attend all required appointments, on time, and prepared to engage with their counsellor.

This includes appointments with our Case Manager from the Elizabeth Fry Society and with a Counsellor from Peel Addiction Assessment and Referral Centre that are approximately one hour in length.

Being late or missing appointments can lead to consequences which are levied by the court. Consequences can range from being ordered to complete community services hours up to and including a short period of bail revocation to assist the participant get back on track.

Urinalysis

- MUST complete 2 urine screens per week, spaced 3-4 days apart, and share results with the program support staff each week

- As this is covered by OHIP, it is very difficult for persons without access to OHIP to participate in the program. The court will work with potential clients that have access to OHIP but do not have a valid Health Card. Assistance will be provided to obtain a valid Health Card. While the potential client awaits a valid Health Card, the court may pay for urine screens.

- In addition to the two regularly scheduled urine tests, participants will be required to attend for random urine tests at various times during the program.

8. Additional Services

- Clients may also be required to attend additional outpatient programs, sessions with a psychologist and/or psychiatrist, or residential treatment programs. These additional services are offered based on each client's individual needs.

Non-Graduation from the Program

- From time to time, a participant, for various reasons, is unable or unwilling to meet the requirements of the program, that participant, without graduating can choose to be sentenced and will be given credit for what has been accomplished during their time in the program. It is also possible that the Crown may seek the participant's expulsion if they are not meeting the basic requirements of the program.

Graduation

- The criteria to graduate are as follows:

- At least three (3) months of negative urine screens;

- Successful participation and completion in the treatments, counseling and therapies recommended by the treatment providers;

- Stable housing; and,

- Stable employment. 


\section{Calgary Drug Treatment Court}

Page | 12

you are expected to be at Court for 10:30 am. This gives you a short opportunity to meet with Duty Counsel or your Case Manager prior to Court beginning at 11:00 am.

For those participants who are attending a residential substance abuse treatment program you will appear in court following completion of your residential treatment program. The Pre-Court Team will receive regular weekly reports from your residential program and if there are any concerns you may be asked to appear in Court before your program is completed.

Day Treatment Program participants will attend Court on a weekly basis.

CDTC has two dedicated Legal Aid Lawyers who will represent and advise you throughout your participation in the program.

After you have reached stage 3 of the CDTC program you may apply to attend Court on a bi-weekly basis.

\section{PROGRESS REPORTS}

Prior to each Court appearance, the Pre-Court Team, (this includes the presiding Judge), will be given a progress report prepared by your Case Manager regarding your drug test results, employment status, adherence to your individual treatment plan, your engagement within the program, and supervision requirements (Probation). This includes both the struggles and the positive progress you have made during the week.

All requests (i.e., for a cell phone or a weekend outing) will be presented to the Pre-Court Team for review. If you have a non-compliant week requests will NOT be considered and preapproved requests are subject to cancellation.

\section{BASIC PROGRAM EXPECTATIONS}

\section{COMMON RULES AND EXPECTATIONS}

The CDTC Team want you to be successful. With that in mind we have written out some of the common rules/expectations that we have. These are not meant to intimidate you but rather to let you know BEFORE hand what you are agreeing to. Below is a list of some of our expectations:

Calgary Drug Treatment Court Participant Handbook

Revised June 2020 
1. You must call your Probation Officer within 48 hours of your admission into the community.

2. No NEW criminal charges or behaviour. Any new criminal charges or behaviour will result in a presumptive dismissal hearing.

3. You must attend all CDTC treatment-required appointments. These include all individual, group and educational sessions and case management appointments. You need to be on time for all appointments and no appointments should be cancelled by you without approval of your Case Manager.

4. Do not act violently or make threats towards other participants, staff or Court personnel including any members of the Pre-Court Team. Violent or inappropriate behaviour will not be tolerated and will be reported immediately to the Court. Threats or intimidation toward anyone will not be tolerated. Either of these violations may result in your termination from the CDTC program.

5. Possession of weapons could immediately result in your termination from the program and you could acquire new charges.

6. Drug testing is mandatory. Expect to take random and "on demand" drug tests. Tampering with your drug test, or suspicion of tampering, is taken very seriously and can be grounds for dismissal from the program. CDTC staff administering tests are expected to watch each individual while supplying their sample.

7. Be respectful to yourself and others. If you disagree with something, state your position in a calm manner and listen to what is being said. You may also put any issue into writing for the Pre-Court Team to consider. 
Disrespect, excessive arguing or outbursts towards Team members is not acceptable and may result in a sanction.

8. During Court: Dress appropriately for Court and other CDTC appointments. Do not wear clothing to Court that has drug or alcohol related themes, no bare midriff tops, etc. You cannot wear sunglasses and hats in the Court room. No gum chewing is allowed in Court. Please take into consideration that some household items can also be triggering. Court is a time to listen and learn from others. Follow the directions of Team members, Court personnel and Sheriffs. No gum, food, or drinks are allowed in the courtroom

\section{RELATIONSHIPS}

In CDTC we encourage you to focus on your recovery first. Developing new intimate relationships within the first year of the program is strongly discouraged. We support the development of peer relationships but not sexual or romantic ones. Meetings are NOT a place to meet new partners. In fact, we strongly suggest that individuals attend meetings that avoid distractions of this nature.

Developing a new relationship while in the first YEAR of your treatment has been proven over and over again to cause significant difficulties and complications. More often than not, entering into a new sexual/romantic relationship is just another way to medicate your feelings of loneliness, sadness and feeling lost and confused as you try to change your ways.

Through experience we have found that new intimate relationships have a poor chance of success and often lead our participants to get distracted from their goals of recovery. Treatment is a time to develop new skills and to develop a relationship with yourself. You can't have a healthy relationship with another when you don't yet have a healthy relationship with yourself.

While in CDTC you cannot have a sexual or romantic relationship with another person who is in the CDTC program. It is important that the CDTC community is a safe place for all participants; therefore, no sexual/romantic/intimate contact between participants is allowed. Failure to abide by this can result in an 
adjustment to your treatment plan, noncompliance, or dismissal from the program.

If you have been in a committed long-term relationship, we strongly suggest that your partner and any other family members attend any of the various family supports offered throughout the community. Ask your Case Manager.

Addiction is a family disease. It is impossible for loved ones NOT to be impacted by your addiction. We would like to meet the significant people in your life, partners, parents, and children. They are welcome to come and find out about Drug Court. They are also welcome to come to court on Thursdays.

\section{FREQUENTLY ASKED QUESTIONS}

\section{How do I know who my Case Manager will be and how often do we need to meet?}

You will be assigned a Case Manager immediately. Your Case Manager should meet with you on a one-to-one basis within the first week of your acceptance into Drug Court. At that time, you will be given telephone numbers so you can contact your Case Manager and/or the Calgary Drug Treatment Court office.

\section{What do I need to do right away when I am released and/or enter my pleas and bail from the community?}

You are always required to have a copy of your bail order on person. You need to be aware of the conditions outlined in your bail order. Failure to carry your bail order can put you in a difficult situation with the Police or the Courts. Bail orders at this stage are strict but fair.

You need to call your Probation Officer within 48 hours of your release. This is something participants often forget so we are reminding you that it is important to call. You will be given an appointment with your Probation Officer and he/she will go over your bail orders with you. 


\section{When is my first court appearance after being released/entering into the program?}

You will be given an adjournment date at your pleas and bail hearing and your Case Manager will also be aware. Some participants return only after they have completed their residential treatment program. Other participants will be attending weekly even at this stage.

\section{What happens if I am not attending court weekly?}

From time to time, while you are in your Residential Treatment program, your Case Manager will drop by the treatment facility to visit and check how things are going for you. You can call your Case Manager anytime to ask questions, ask for help or just to say hello.

A Case Manager from CDTC will be in regular contact with the treatment program you are attending. Your case manager will be sharing your successes and struggles during this stage of the program with the CDTC pre-court team.

\section{What can happen if I have problems with my addiction treatment program?}

Remember that while you are in treatment you MUST follow all the rules and recommendations of the agency where you are residing. Failure to do so can result in you being asked to leave. If no other suitable housing or treatment program can be found, you might be returned to remand until other arrangements can be made.

If you are experiencing difficulties, we hope you would bring them to your Case Manager and/or the staff at the treatment facility so that we can all problemsolve together. The last thing we want is for you to lose your housing. 


\section{My bail orders are so long. Are there some points I should remember right away?}

You need to stay out of your "no-go zone" unless you have permission from Probation. If you have appointments in this area (other than Court or meetings at CDTC office) you must have written permission.

Just to be clear, you may NOT possess or use a cell phone during Stage One. You cannot use another person's cell phone. If you are found using a cell phone or in possession of a cell phone this is a breach of your bail order and there will be a sanction.

Your Probation Officer will expect to see you face-to-face or by telephone. $\mathrm{He} / \mathrm{She}$ will advise you on frequency and mode of meetings.

\section{How will you know how I am doing in my program?}

Weekly reports from the various addictions treatment programs and Case Managers are shared with the Pre-Court Team. You should be in contact with your case manager so we can hear from you about how you are feeling in your program.

\section{How often am I drug tested and who or where does it get done?}

If you are not in residential treatment, you will be drug tested every week on a random basis by a CDTC staff member. You will receive a message in the morning that will tell you when/where you are expected to present for your test. If you are in treatment, you will be drug tested by your treatment program and the results will be sent to the CDTC office. Remember twice a week is minimum. There may be times when you will be tested more often.

\section{I had a job when I applied to Drug Court, can I go to treatment and work?}

During Stage One you are expected not to work. Most participants are financially supported by AB Works. This financial assistance covers your costs in treatment, a bus pass and some spending money. You are expected to buy a bus pass from the 
money $A B$ Works gives you. NOTE: If you do not qualify for $A B$ Works benefits you will be required to make arrangements for the cost of treatment.

If you are employed at the time of entry into the program you are expected to make arrangements with your employer for time off during Stage One of this program. You may return to your place of employment following the completion of treatment providing your case manager, probation and the CDTC team approve of this employment. If this employment is deemed not conducive to recovery and/or the requirements of this program you will not be permitted to continue the employment. Should we say something about requiring court days off?

\section{I was given a "meeting list" sheet, what is this and why do I need it?}

You will be required to attend various 12-Step/recovery meetings in the community. For those who are not residing in an addiction treatment facility you will attend three meetings a week at minimum. For participants within an addiction treatment program, you will follow the program that they set out regarding meetings.

If you are attending Court on a weekly basis you will be given a sheet of paper called your "meeting list". You record all your meetings here and have the chairperson sign the sheet beside the name of the meeting you attended. These sheets are handed in weekly and failure to hand them in means that you are "non-compliant". Forging a signature is considered being dishonest as is signing for another participant. Forging a meeting sheet or any other document given to the court is grounds for presumptive dismissal from the program

Remember, the goal of the Calgary Drug Treatment Court is to help you achieve total abstinence from alcohol and drugs, address your individual treatment needs and avoid future arrests. 


\section{Calgary Indigenous Court}

\section{CALGARY INDIGENOUS COURT}

The Calgary Indigenous Court (CIC) was established in 2019 to provide a culturally relevant, restorative, and holistic system of justice for Indigenous individuals, including offenders, victims and the community harmed by an offender's actions. The CIC is a response to the unique challenges and circumstances of the Indigenous people. It seeks to address the issue of over-representation of Indigenous people in the justice system and is a step forward in implementing recommendations from the Truth and Reconciliation Commission (TRC) as well as the Missing and Murdered Indigenous Woman and Girls National Inquiry (MMIWG) Report.

The CIC focuses on a restorative justice approach to crime through peacemaking and connecting accused people to their cultures and communities. It deals primarily with bail and sentencing hearings, and is open to any offender who is Indigenous and chooses to have matters addressed in the CIC. When an offender is sentenced to probation, a Healing Plan specific to the offender may be included in the probation order. Healing Plans use identified Indigenous community support agencies to assist in re-integrating offenders into the community, and, where appropriate, also encourage offenders to learn about and reconnect with their Indigenous heritage. A ceremony may be held in the $\mathrm{CIC}$ to acknowledge the successful completion of a probation order and the Healing Plan.

The $\mathrm{ClC}$ sits every Wednesday beginning at 9 a.m. in Courtroom 1800 of the Calgary Courts Centre. Courtroom 1800 is a specialized courtroom which was specifically designed to support an Indigenous approach to law. It is modelled after a teepee and allows participants to sit in a circle at the same level. Courtroom 1800 has an eagle feather for taking oaths (which is available in all Alberta Courts) as well as special ventilation to allow for smudging during traditional ceremonies.

The CIC utilizes dedicated judges who are either Indigenous or experienced in Indigenous Restorative Justice, a designated Indigenous Crown Prosecutor, designated duty counsel and Indigenous Legal Counsel, Restorative Justice Peacemakers, Traditional Knowledge Keepers, Indigenous Court Workers and community support agencies. Agencies involved with the CIC include the Elizabeth Fry Society of Calgary, Calgary Legal Guidance, the Aboriginal Friendship Centre, the Sunrise Healing Lodge, Indigenous Mental Health, Native Counselling Services of Alberta, Homefront, the John Howard Society, and the Calgary Police Service as well as several other support agencies. 


\section{Edmonton Mental Health Court}

\section{MENTAL HEALTH COURT}

The Edmonton Mental Health Court (MHC) program helps address the over-representation of people with mental illness in the justice system by focusing on underlying mental health problems that often contribute to repeated criminal behaviour.

The MHC is available for adults (aged 18 years or older) who have been charged with a criminal offence and have an ongoing mental health issue that affects or impairs judgment. Individuals with a brain injury or head trauma, including fetal alcohol spectrum disorder (FASD) in some cases, and those with mental illnesses such as schizophrenia, bipolar disorder and major depression will also be considered.

Admission to the MHC is based the following criteria:

- There must be a reasonable basis to believe that an accused has a brain injury, neurological deficit such as FASD, mental illness or mental disorder;

- There must be a reasonable basis to believe that there is a relevant connection between the mental health condition of the accused and the alleged criminal offence;

- The accused must consent and be motivated to participate in MHC; and

- The alleged criminal offence must not be subject to exclusion under the MHC criteria*. (Excluded offences include murder; drug prosecutions, unless a federal prosecutor consents; prosecution handled by Special Prosecutions; breaches of long term offender orders or of certain peace bonds.)

*Cases involving domestic violence usually do not qualify.

Only a Judge can formally refer accused persons to the MHC, but counsel can recommend a referral at any stage, based on their own observations or based on input from others such as police, a Justice of the Peace or family members

The MHC functions like any other court in that the Crown and Defence counsel generally determine what information is placed before the Judge and counsel make recommendations to the Judge as to how a matter should be dealt with. However, this court differs from conventional courts based on an adversarial model. This court takes a more collaborative approach and enjoys extra resources to help the court identify and address the issues underlying the criminal behaviour. In addition to Crown and Defence counsel, there is a mental health worker in the court, a social worker/navigator is available to help accused persons access resources in the community and navigate the system, and a psychiatrist is in regular attendance.

The MHC sits weekly on Mondays, Wednesdays and Fridays, 9:30 a.m. to 4:30 p.m. at the Edmonton Law Courts. 


\section{Regina Mental Health Court}




\section{REQLAMEITLL HEMLTHDISPSSIIONEOURT}

The Regina Provincial Court has introduced a collaborative model to coordinate treatment and criminal justice needs for individuals with mental health, Fetal Alcohol Syndrome Disorder (FASD) or cognitive issues who have been charged with a crime. The Regina Mental Health Disposition (RMHD) Court brings together health, social services professionals and criminal justice professionals, and is designed to improve the Court's access to information so that it is better able to support and supervise offenders safely in the community. This may include comprehensive assessments, case management plans and providing services.

The process provides a more effective way of managing offenders who commit crimes because of their mental health, FASD or cognitive issues. It uses a supportive case management model to help participants to reduce or eliminate criminal behaviour and maintain a healthy lifestyle. It uses a "connections approach" to break down barriers and encourage participants to connect with community services. The value added in this approach is an increased capacity for assessment and improved access to mental health services and resources for offenders.

\section{WHO IT'S FOR}

Adults accused of a crime may be referred to the RMHD Court through the Crown Prosecutor if the accused appears to have issues related to mental health, such as cognitive disability, FASD, brain damage or psychiatric disorder. The mental health issue must be related to the criminal behaviour. Defence counsel, social agencies and individuals can contact the Crown Prosecutor and ask that a person be considered for this Court.

\section{WHO IT'S NOT FOR}

Accused facing charges that include Criminal Code driving offences, sexual offences, offences with mandatory minimum penalties in the Criminal Code and offences where the Crown seeks a penitentiary term are not eligible for this approach.

\section{HOW IT WORKS}

- Court is held on the second and fourth Fridays in courtroom 4 at 11:00 a.m.

- First appearance occurs in another court and other appearances may be made before referral to the Crown for RMHD Court eligibility assessment.

- The Crown uses criteria to assess eligibility, including but not limited to the nature of the charges, criminal record of the accused and risk to community safety.

- Legal Aid duty counsel meets with the eligible individual at first appearance in RMHD Court and explains their options.

- If the accused individual agrees to enter the RMHD Court, the judge may, following a case conference meeting prior to the opening of Court, refer the individual to a psychologist or to meet with other professionals to assess needs and strengths and develop a case management plan.

- If the accused agrees to the case management plan, a guilty plea is entered and $s / h e$ agrees to follow the case management plan.

- The offender may be sentenced or return to court for progress reports at the discretion of the judge.

- The length of time to conclude the case depends directly on the case management plan and the offender's progress in that plan. 


\section{Saskatoon Mental Health Court}

\section{SASKATOON WEITHL FESLTHSTRATEOY}

The Saskatoon Provincial Court has introduced a collaborative model to coordinate treatment and criminal justice needs for individuals with mental health, Fetal Alcohol Syndrome Disorder (FASD), or cognitive issues who have been charged with a crime. The Saskatoon Mental Health Strategy (MHS) Court brings together health, social services professionals, and criminal justice professionals, and is designed to improve the Court's access to information so that it is better able to support and supervise offenders safely in the community. This may include comprehensive assessments, case management plans, and providing services.

The process provides a more effective way of managing offenders who commit crimes because of their mental health, FASD, or cognitive issues. It uses a supportive case management model to help participants to reduce or eliminate criminal behaviour and maintain a healthy lifestyle. It uses a "connections approach" to break down barriers and encourage participants to connect with community services. The value added in this approach is an increased capacity for assessment and improved access to mental health services and resources for offenders.

\section{WHO IT'S FOR}

Adults accused of a crime may be referred to the MHS Court through the Crown Prosecutor if the accused appears to have issues related to mental health, such as cognitive disability, FASD, brain damage, or psychiatric disorder. The mental health issue must be related to the criminal behaviour. Legal Aid, defence counsel, social agencies, and individuals can contact the Crown Prosecutor and ask that a person be considered for this Court.

\section{WHO IT'S NOT FOR}

Accused facing charges that include Criminal Code driving offences, sexual offences, offences with mandatory minimum penalties in the Criminal Code, and offences where the Crown seeks a penitentiary term are not eligible for this approach.

\section{HOW IT WORKS}

- Court is held on the first and third Mondays in courtroom 4 at 9:30 a.m.

- First appearance occurs in another court and other appearances may be made before the Crown refers an accused individual to the MHS.

- The Crown uses criteria to assess eligibility, including but not limited to the nature of the charges, potential to benefit from case management, criminal record of the accused, and risk to community safety.

- To participate in the MHS, the accused individual must be out of custody and be prepared to accept responsibility for some or all of their offences.

- If the accused individual agrees to participate in the MHS Court, the judge may refer the individual to a psychologist or to meet with other professionals to assess needs and strengths and develop a case management plan.

- Participants are expected to attend appointments for assessments or other services.

- The offender may be sentenced or return to court for progress reports at the discretion of the judge.

- The length of time to conclude the case depends directly on the case management plan and the offender's progress in that plan. 


\title{
Ottawa Drug Treatment Court
}

\section{Ottawa Drug Treatment Court}

\begin{abstract}
Absconding Policy
Drug Treatment Court Ottawa (DTCO) is conducted once per week and all participants are expected to attend every court session, unless excused by the court for a valid reason. If a participant does not attend court as expected, a bench warrant will be issued for their arrest and a subsequent charge of "Fail to Appear" may be laid. Absconding from DTCO is viewed as a very serious breach of DTC bail conditions which could lead to a separate criminal charge being laid or may result in a DTC sanction and/or removal from the program.
\end{abstract}

If a DTC participant absconds from DTC, the following process will be followed upon their arrest:

1. If the participant returns to DTC within the first thirty (30) days, he/she will be required to fill out a Request for Special Consideration form, which the DTC team will consider in determining their continued participation.

2. If a participant returns to DTC after thirty (30) days or more, he/she will be presumptively removed from the DTCO program and the following process will apply:

a) If the participant wishes to continue in DTCO, there will be a reverse onus for $\mathrm{him} /$ her to convince the DTCO team that they should be re-admitted into the program. Re-admittance into the program will only be granted in exceptional circumstances. The participant will be required to fill out a Request for Readmittance form.

b) The Request for Re-admittance form will be reviewed by the DTCO Team and eligibility to continue in the program will be determined.

c) If it is determined that the participant is eligible to continue in the program, an individual from Rideauwood Addiction and Family Services will conduct an assessment before a final determination for re-admittance into the program is made.

d) If it is determined that the participant is not suitable to be re-admitted into the program, they will proceed to sentencing.

e) At all times, the onus is on the participant to contact Rideauwood Addiction and Family Services to make an application for re-admittance and reinterviewing. 


\section{Ottawa Drug Treatment Court}

\section{Coffee Card Policy}

The Coffee Card is a reward that recognizes and encourages participant's short-term success. Like Early Leave, the Coffee Card provides participants with a short-term goal that is realistically achievable. If a participant fails to meet the criteria one week, he or she can earn it back the following week. Some measure of success and reward is always within reach.

Coffee Cards have a $\$ 5.00$ value and are funded by donations. Coffee Cards are handed out to participants during Tuesday Court appearances.

1. Participants must meet certain criteria to be eligible:

a) no substance use since the prior Tuesday.

b) attended all Treatment appointments since the prior Tuesday (unless excused from attendance.)

c) attended all required UDT's since the prior Tuesday (unless excused from attendance.)

d) been in full compliance with all other Treatment/Court expectations (unless excused.)

e) been out of custody since the previous Tuesday.

2. Participants who are subject to an outstanding sanction are still eligible for a Coffee Card provided the criteria in (1) are met.

3. The Coffee Card may also be withheld for other reasons/concerns at the Judge's discretion. 


\section{Ottawa Drug Treatment Court}

\section{Contested Urine Drug Test Results Policy}

Drug Treatment Court Ottawa (DTCO) conducts Urine Drug Testing (UDT) of all participants. The collected specimens are analyzed by Gamma-Dynacare Medical Laboratories (GD). Participants may attempt to conceal illicit substance use by denying positive $(+)$ UDT test results.

Validity of UDT Results

All DTCO participants have agreed to accept the validity of the UDT results (Ottawa Drug Treatment Court Consent and Waiver.)

Retesting of UDT Specimens

Should an individual contest a UDT result, the original specimen will be retested and the participants name on the specimen container will be verified and checked for corresponding participants initials.

The request for retesting must be made by the participant at the first Court appearance following notification. GD only retains the original specimen for one to two weeks. DTCO reserves the right to limit the number of retests ordered.

Where indicated, Rideauwood Treatment Staff will review with the participant any prescription or over-the-counter medications, vitamins, herbal remedies, and/or supplements recently consumed by the participant to rule out false positives.

Applicable Sanction

A participant denying a verified and retested UDT result is subject to sanction for dishonesty. The nature of the sanction will be at the Court's discretion. The participants "clean date" will be changed based on any verified positive (+) UDT result.

DTC will not accept passive ingestion (i.e. second-hand smoke, adulterated drinks/foods, etc) as an explanation for positive UDT results. Participants are responsible for all substances regardless of how they ingest them. 


\section{Ottawa Drug Treatment Court}

\section{Early Leave Policy}

Early Leave is a reward that recognizes and encourages participant's short-term success. Once the initial criteria are met, early leave must be earned at every Court appearance. Early leave may be withheld. However, participants have the opportunity to earn it back by as early as the next Court appearance. Like the Coffee Card reward, this approach provides participants with a short-term goal that is realistically achievable. If a participant fails to meet the ongoing criteria at one appearance, he/she can always earn it back by the next. Some measure of success and reward is always within reach. Participants who have been granted Early Leave will have their matters dealt with at the beginning of the DTCO docket and they will be permitted to leave immediately after their matter is dealt with.

1. In order for a participant to meet the initial criteria, they must have:

a) been a DTCO participant for at least 60 days.

b) 30 days of continuous abstinence after your first clean UDT result,

c) demonstrated compliance with DTCO bail conditions

2. Ongoing criteria for Early Leave is determined on a per appearance basis and is dependent upon the participant having:

a) attended all required meetings and appointments on time,

b) attended all UDT's as expected,

c) abstained from all substance use,

d) abided by the terms and conditions of their DTCO bail.

3. A participant who fails to meet the above criteria is NOT eligible for Early Leave at that appearance; however, will be eligible at the very next appearance should he/she meet the above criteria and have attended, in person, at least one individual or group Treatment appointment.

4. A participant who is subject to an outstanding sanction is NOT eligible for Early Leave. Such a participant will become eligible for Early Leave again on the Court date upon which the sanction has expired and/or is complete.

5. Early Leave may be withheld for any other reason at the Judge's discretion. 


\section{Ottawa Drug Treatment Court}

\section{Exhausted Patience Policy}

While DTCO does not sanction participants for substance use, it is possible that participants who do not demonstrate sufficient motivation towards a goal of abstinence may be removed from the program primarily on the basis of substance use. This policy is directed at those participants who; a) seem unable to achieve even a short period of abstinence, b) appear to be putting forth little effort to arrest their drug taking behaviour, and c) continue to use despite frequent interventions by Treatment.

1. If, at any time during a participant's involvement in DTC, Treatment assesses that the participant is no longer motivated towards abstinence, or is no longer making sufficient efforts towards achieving abstinence, they will advise the Pre-Court Team.

2. This notification will be discussed at Pre-Court and the Judge may elect to advise the participant that there will now be an expectation that he/she provide a determined number of 'clean' urine samples within a set period of time. Furthermore, if this goal is not achieved, he/she may be removed from the DTCO and proceed to sentencing.

3. Participants who state they no longer have a goal of abstinence may also be removed from the DTCO by the Judge. 


\section{Ottawa Drug Treatment Court}

\section{Graduation Policy}

The DTCO has three primary goals for participants: to extinguish drug and alcohol taking behaviour, eliminate criminal recidivism and improve quality of life. Participants who demonstrate an ability to meet these goals and have a reasonable plan to sustain them are eligible for 'graduation' and release from the requirements of the DTCO.

DTCO recognizes that individual participants may face unique needs and challenges and as such a differential graduation criterion has been established.

1. Application for Program Completion

a. All participants seeking to complete the DTCO are required to submit an application (Graduation Application \& Reintegration Plan.)

b. The application will be submitted at least 30 days prior to the proposed graduation date.

c. The application indicates the Level of Graduation the participant is applying for and a projected graduation date.

d. The application will be reviewed by treatment and forwarded to the DTCO Team with a recommendation for final decision.

\section{Minimum Completion Requirements}

a. The graduate will not have accrued any outstanding new charges or new convictions within the last 6 months prior to the anticipated date of graduation.

b. The graduate will have demonstrated compliance with DTCO expectations during the last 3 months prior to the anticipated date of graduation.

c. The graduate will have obtained stable housing and/or demonstrated an ability to maintain housing during the last 2 months prior to the anticipated date of graduation.

d. The graduate will have demonstrated pro-social community involvement such as: employment, school, volunteer work with a charitable or non-profit organization and/or other activities as approved of by their case manager during the last 2 months prior to the anticipated date of graduation. 


\section{Vancouver Downtown Community Court}

\section{Downtown Community Court Jurisdiction}

\section{Offences}

The community court receives:

- Provincial offences that are heard by Provincial Court judges (such as driving while prohibited, aggressive panhandling)

- All Criminal Code offences

" In the absolute jurisdiction of the Provincial Court (for example, shoplifting)

- Summary conviction offences (such as causing a disturbance)

- Hybrid offences where the Crown proceeds summarily (examples are assault causing bodily harm, impaired driving)

- Controlled Drugand Substances Act

- Drug possession

Offences relating to non-compliance with community court orders (for example, failing to appear in court or violating the terms of bail or probation) are also heard in the community court.

\section{Geographic Area}

The catchment or geographic area of the court is downtown Vancouver from Clark Drive on the east to Stanley Park on the west, with Great Northern Way as the southern boundary and the Inner Harbour and Coal Harbour of Burrard Inlet as the northern boundary.

Within the geographic area, Vancouver's Downtown Community Court serves a number of distinct neighbourhoods:
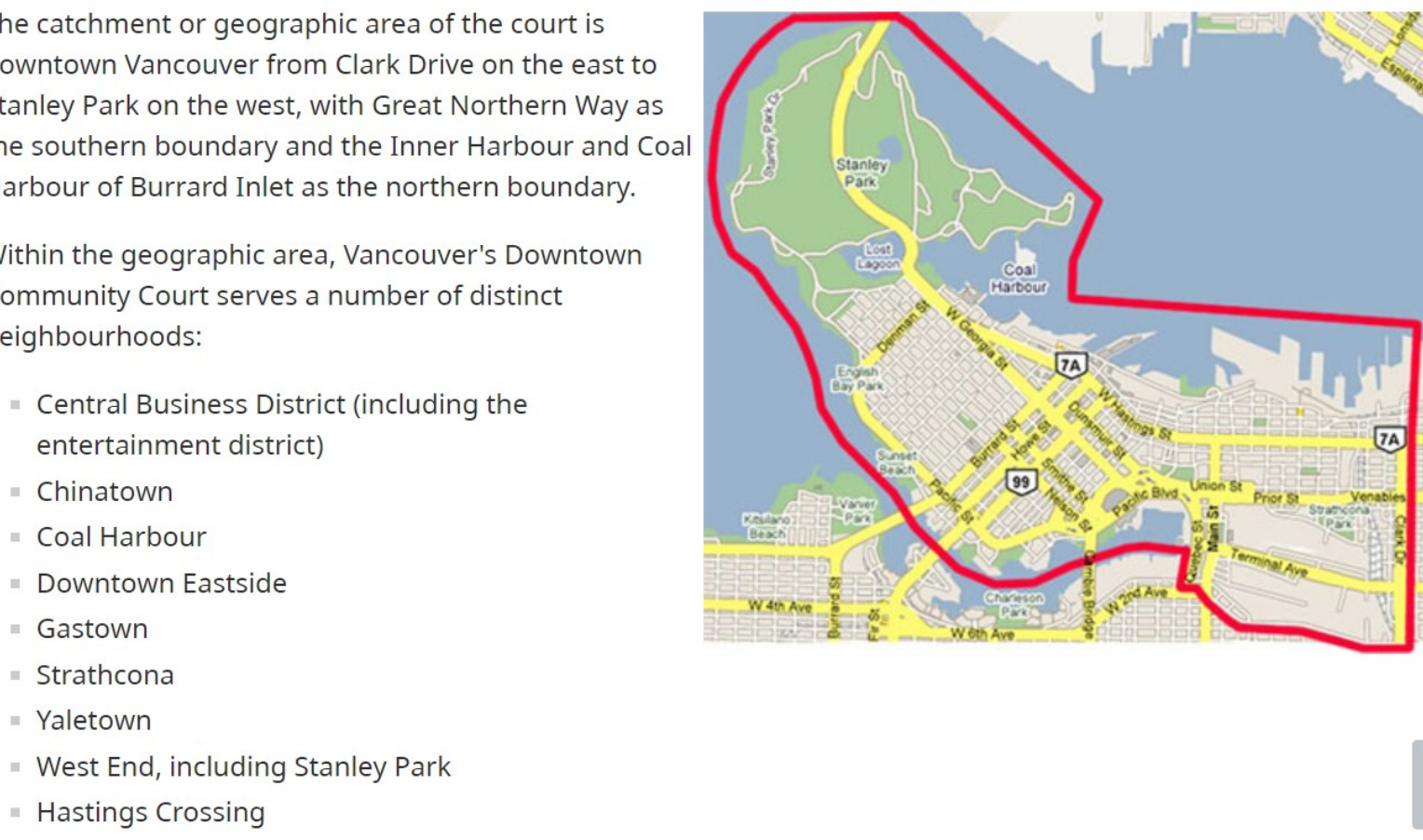


\section{Vancouver Drug Treatment Court}

\section{Getting Through the Program}

There are 4 phases you have to complete to successfully graduate from the DTCV: (1) Assessment /Pre-Treatment Phase; (2) Getting Clean / Relapse Prevention Phase; (3) Stabilization Phase, and; (4) Seniors / Graduation Phase. The group and the phase you are in reflect your progress. Below is an outline of expectations for you in each phase of the program:

\section{Assessment / Pre-Treatment Phase}

- Complete Assessments: See section called "How To Be Formally Accepted Into The Program" for more information

- Attend Groups: Start in the Pre-Treatment Group (5 groups a week)

- Leave Urine Screens as requested

\section{Getting Clean / Relapse Prevention Phase}

- Attend Groups: Start in the Recovery Skills Group (3 groups a week)

- Moving into the Stabilization Group: this requires completing the material in the Recovery Skills Group and having 4 consecutive weeks of clean screens at completion.

- Leave Urine Screens as requested

\section{Stabilization Phase}

- Attend Groups: Start in the Stabilization Group (3 groups a week)

- Moving into the Seniors Group: this requires completing the material for the Stabilization Group and maintaining clean screens, with a minimum of at least 4 consecutive weeks of clean screens at completion.

- Leave Urine Screens as requested

\section{Seniors / Graduation Phase}

- Develop a Plan for Graduation with your care team (counsellor and case manager).

- Start Attending Work / School / Volunteer Placement as outlined in your graduation plan.

- Attend Groups: Seniors Group (2 groups per week).

- Complete Seniors Group material

- Leave Urine Screens every week

9 | Page 


\section{Program Rules}

While attending the Drug Court Treatment and Resource Centre (DCTRC), I hereby agree that:

1. I will keep the peace and be of good behaviour.

2. I will report to the DCTRC at 255 East $12^{\text {th }}$ Avenue, Vancouver, B.C. and obey all the rules and participate in all treatment including attendance at detoxification, residential, or other treatment programs as directed by the DCTRC staff.

3. I will reside as directed, provide my current address and not change my residence without prior permission of a Drug Court Case Manager.

4. I will attend the DCTRC for urinalysis as directed by the DCTRC staff.

5. I will not attend at the DCTRC while under the influence of alcohol.

6. I will provide urine samples as directed by the DCTRC staff and will report to the DCTRC staff member who is taking a urine sample about any drugs that I have used in the last week.

7. I acknowledge that tampering with a urine sample at the DCTRC may lead to me being discharged from the DTCV program.

8. I will sign such releases as are necessary to allow the DCTRC staff to access any information it considers necessary related to my treatment.

9. I will not use any drugs, not prescribed for me, on site at the DCTRC or within one block of the DCTRC.

10. I will not bring any drugs to the DCTRC which are not prescribed for me, and I will not have any drugs delivered to the DCTRC.

11. I acknowledge that engaging in disruptive or aggressive behaviour at the DCTRC, including threatening, disrespectful, or derogatory comments or physical violence may lead to me being discharged from the DTCV program.

12. I acknowledge that I am not to possess any weapons or any item intended to be used as a weapon. Any use and/or possession of a weapon could result in discharge from the DTCV program.

10 | P a ge 
13. If I cannot attend the DCTRC for any reason, I will advise the centre as soon as possible. If directed by the DCTRC staff, I will provide a Doctor's note to confirm absences for medical reasons. I acknowledge that a warrant can be issued for my arrest if I fail to advise the DCTRC staff of my absences from the DCTRC.

14. No pets or bikes are allowed in the centre.

15. If you are late for group by more than 5 minutes you won't be allowed entry until after the break.

16. Any new criminal charges while in the Drug Court program may lead to your discharge from the Drug Court Program.

\section{URINE SCREENS}

Our urine screens test for: Opiates

$$
\begin{aligned}
& \text { Benzodiazepines } \\
& \text { Cocaine/ Crack } \\
& \text { Amphetamines } \\
& \text { Methadone } \\
& \text { THC (marijuana) } \\
& \text { Fentanyl }
\end{aligned}
$$

Clients are required to leave witnessed urine samples when requested. This can occur while you are at the DCTRC or you may be telephoned and directed to come to the DCTRC to provide a sample. If you do not leave a sample when required, you will be deemed to be positive for illegal drugs or substances. "A Missed Screen = a Positive Screen".

- $1^{\text {st }}$ DILUTED SAMPLE:

$>$ Prepare essay that provides information on diluted sample

$>$ Meet with Care Team

$>$ Address diluted screen sample in court

- $2^{\text {nd }}$ DILUTED SAMPLE:

$>$ Bail will be revoked for 3 days (Tuesday to Thursday)

$>$ On $2^{\text {nd }}$ occurrence of diluted test result, participant will be directed to attend court on the following Tuesday regardless of their regular court day

- $3^{\text {rd }}$ DILUTED SAMPLE:

$>$ Bail will be revoked for 8 days

\section{1 | P a g e}




\section{- $4^{\text {th }}$ DILUTED SAMPLE:}

$>$ Expulsion from the program

Tampering with urine screens may lead to your discharge from the DTCV program. "Tampering = Discharge".

When leaving a urine sample you will be asked to sign a form stating any drugs which may be detected in your sample. Please report anything you have used in the past 7 days including prescription drugs. There is no consequence for having used. However, if you leave a positive sample without telling us that you have used, you may be required to attend Court and may receive a consequence for not being honest.

We do accept that relapse is a part of recovery; however, the goal of the DTCV is abstinence. If substance misuse interferes with your ability to participate in the DTCV, we will provide the necessary extra supports. This will often include detox and / or residing in a recovery house.

Remember that medications that you have been prescribed must be disclosed to the DCTRC staff conducting urine screens and will not affect your screen results.

\section{URINE SCREEN POLICY IN EFFECT JULY 2017}

In order to assist with the reporting requirements and facilitate faster drug screen results we are changing the policy regarding the sending of cups to the lab on disputed results.

Clients who request repeated results sent to the lab where those results come back as positive could face sanction. Clients will be given $\underline{2}$ opportunities for unsuccessful challenges without facing sanction. Should a client repeatedly request that samples be sent to the lab where there have already been 2 positive confirmations by the lab the client could face sanctions for a $3^{\text {rd }}$ lab positive.

Clients will not be sanctioned for screens that are deemed negative by the lab, nor will those attempts be counted against the client. 


\section{How to Be Formally AdMITTED}

Within 30 days of starting the DTCV, you will need to complete assessments. The assessments involve attending scheduled appointments with your counsellor, your case manager, the nurse, the physician, and the DCTRC's psychologist. The purpose of the assessments is to help you and the DCTRC's staff, decide whether the DTCV is right for you. If it is, you will attend Court to be formally admitted into the program. If not, you will return to the regular Court system.

Assessments (check boxes when completed)

Counselling Assessment

Case Manager Assessment

Nurse Assessment

Physician Assessment

Psychological Assessment

Psychiatric Assessment (if recommended)

Case Conference

13 | P a g e 


\section{SERVICES AVAILABLe At The DCTRC}

Bus Tickets - You will be provided with bus tickets for transportation to and from the centre for group attendance and to attend Court.

\section{Employment and Assistance Worker}

Once you have been formally admitted to the program, your social assistance file will be transferred to the DCTRC.

Support can be provided to access:

- Persons With Persistent Multiple Barriers (PPMB) and Persons With Disability (PWD) Applications

- Copies of ID from your file

- Replacement ID

- Help opening a bank account and/or setting up direct deposit

- Information about medical and dental coverage

- Program and Training referrals

- Leisure Access passes

- Diet allowances 


\section{GRAduAtion CRITERIA}

In order to graduate, you will need to:

- Complete all treatment phases

- Establish connections in the community to support your ongoing recovery

- Have approved and stable housing

- Have a minimum of 3 months of weekly consecutive negative screens immediately prior to graduation

- Have a minimum of 6 months without a new charge immediately prior to graduation

- Have a minimum of 2 months working and/or attending school $\underline{\mathrm{OR}}$ if you are unable to work or attend school and are on disability: 2 months of regular volunteer work at 4 hours per week*

* It is strongly recommended that you start this process as soon as you move into the Seniors Group

15 | Page 